

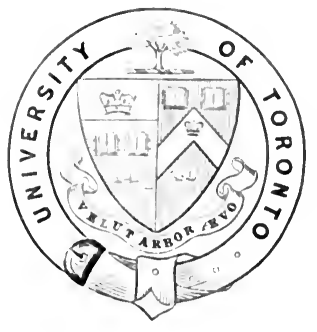

Dresentes to

The Tibraty

of the

University of Toronto

by

P.H. Walks Esq. 


Digitized by the Internet Archive in 2007 with funding from Microsoft Corporation 


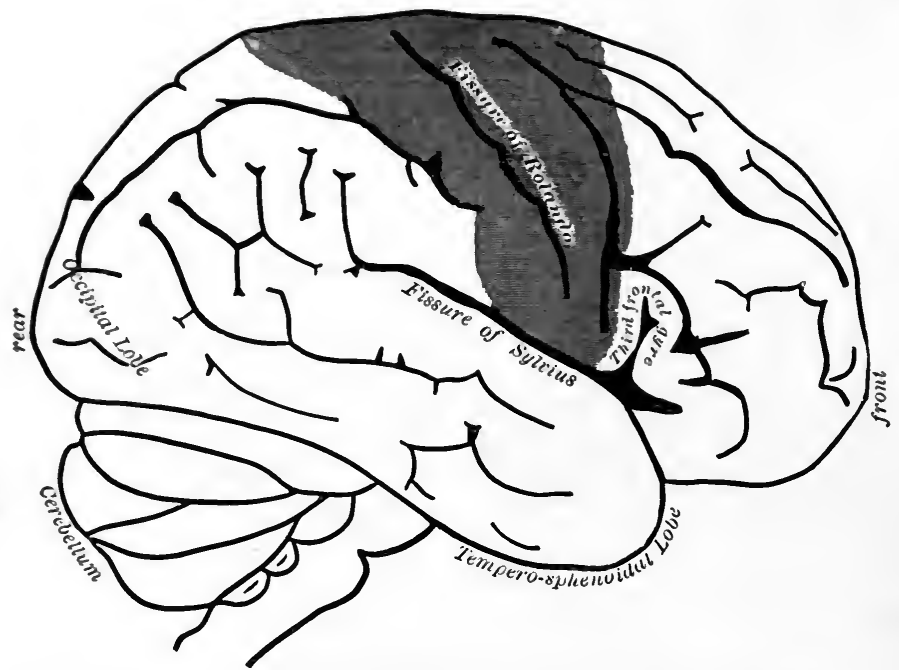

Fig. 1-Outer surface of right hemisphere of the brain (modified from Exner).

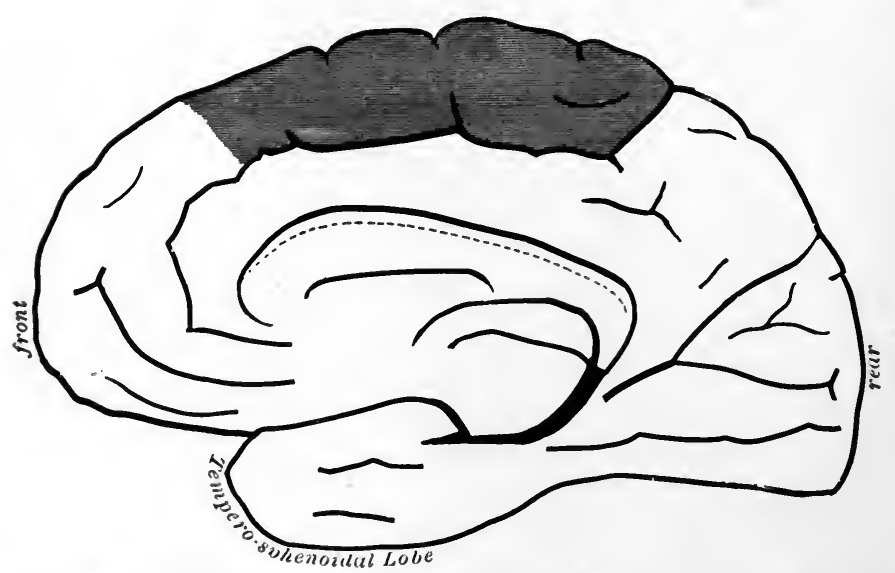

F1a. 2.-Inner (mesial) surface of the right hemisphere of the brain (modified from Schäfer and Horsley).

In both cases the shaded area is the motor zone. See page 114. 


\title{
HANDBOOK OF PSYCHOLOGY
}

\author{
Senses and Intellect
}

Ex

JAMES MARK BALDWIN, M.A., Pн.D.

PROFESSOR OF LOGIC AND METAPHYSICS IN THE UNIVERSITY OF TORONTO:

LATE PROFESSOR OF PHILOSOPHY IN LAKE FOREST UNIVERSITY

SECOND EDITION, REVISED
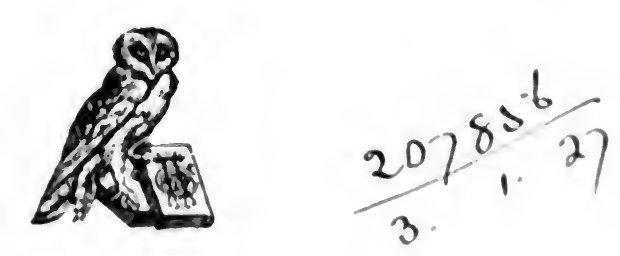

NEW YORK

HENRY HOLT AND COMPANY 1890 


\section{Copyright, 1889,}

iv

HenRy Holt \& Co.

DREMAOND \& NEO, Electrotypers,

1 to 7 Hague Street, New York.

PRINTED BY

D. G. F. CLASS: NEW YORK. 


\section{PREFACE.}

THE justification of another handbook of Psychology is readily found in the present state of the science, a state of such enthusiastic and productive specialism that it is to be hoped no book will hereafter meet the requirements of higher education for more than a generation. Whatever labor this may entail upon mental scientists and educators, whose business it is to systematize and present results as they are established, they should be the first to hail with joy the rapid growth of psychology as of immediate advantage to the philosophy and practice of education.

But apart from the facts of the science itself-the new facts which must be interpreted in a system for educational purposes-I think it is exceedingly necessary that new philosophical conceptions of the sphere and function of psychology should be embodied in special works. This is the more imperative at present, since the conception now prevalent is widely different from that of twenty years ago, when many of the works were written which are yet used as introduction and strong support to the philosophy taught in the universities: the new conception, namely, that psychology is a science of fact, its questions are questions of fact, and that the treatment of hypotheses must be as rigorous and critical as competent scientists are accustomed to demand in other departments of research.

The question of the relation of psychology to metaphysics, over which a fierce warfare has been waged in 
recent years, is now fairly settled by the adjustment of mutual claims. It is in the interests of this adjustment, which I believe to be part of the true philosophy of science in general, that this book is written. We have already in English, treatises which reflect respectively the standpoints of the metaphysical and agnostic schools; books which not only serve their legitimate purpose as a propredeutic to general philosophy, but which contain, en germe, the systems which they are supposed to introduce. The works of Dewey and Bowne on the one hand, of Bain and Ribot on the other, illustrate this subordination of scientific psychology to the supposed demands of a broader philosophic construction.

The terms of the adjustment of which I speak are briefly these: on the one hand, empirical investigation must precede rational interpretation, and this empirical investigation must be absolutely unhampered by fetters of dogmatism and preconception; on the other hand, rational interpretation must be equally free in its own province, since progress from the individual to the general, from the detached fact to its universal meaning, can be secured only by the judicious use of hypotheses, both metaphysical and speculative. Starting from the empirical we run out at every step into the metempirical; and it is as destructive of sound results to omit the theory of the universal as to neglect the observation of the particular. It is in this respect, I think, that Mr. Sully's otherwise most excellent work is defective.

Consequently, while giving more than usual attention to the rich and popularly little known results of the new methods-in psychometry, psychophysics, and neurology -I endeavor, wherever hypotheses of their ground and bearing upon the mental life have been advanced, to suggest and estimate them. Inasmuch, however, as the rational treatment of the data of the science constitutes 
a special department of metaphysics, empirical psychology must be concerned chiefly with the first of these tasks, and with the latter only as far as rational inferences can be confirmed empirically in the stage of development reached. Thus with the establishment of hypotheses, the science of fact will become broader and more profound and the reasoned conclusions of metaphysics will become the conclusions also of a sound and thoroughgoing induction.

By throwing the more difficult and abstract points of discussion into smaller print in the text, I have endeavored to draw a line of demarcation for a more general or a more detailed course of instruction, as the earlier preparation of the student may make advisable. The "Further Problems for Study," at the end of each chapter, are intended to indicate partially unexplored tields in which stụdents may engage themselves in an original way.

Besides the acknowledgments made freely in the text, I wish to express especial thanks to my friend Dr. McCosh for the instruction and personal training I owe to him. My greatest direct indebtedness in this volume is to Prof. Wundt of Leipzig and to Prof. Rabier of Paris.

LAke Fokest, IlL., July, 1889.

J. M. B.

\section{PREFACE TO THE SECOND EDITION.}

Tue unexpected demand for a new edition of the work gives me an opportunity, of which I am glad to avail myself, to express $a$ word of thanks and $n$ word of remonstrance. The word of thanks is gratefully given to the philosophical public for the cordial reception and recognition the book has had both in its philosophical bearings and more particularly with reference to its use in the universities. The word of remonstrance seems 
needed to make it plain-what I thought was plain enough without saying it-that the scope and purpose of the book do not include the treatment of Abnormal Psychology (Mental Pathology, Hypnotism, etc.). The chapter on Illusions is intended merely to give the student an introduction to this important branch of the subject.

I may take this occasion also to correct another misapprehension, which has been so frequent among kindly reviewers as to be of some importance to myself personally ; i.e. the philosophical point of departure from which the book is written. As far as I am aware I have written from a neutral point of view. Indeed the object of the book is largely to demonstrate the independence of psychology as a science. Consequently, while in no sense asserting any other allegiance, I must still strongly disclaim having made a declaration of discipleship in the acknowledgments made to former instructors in my first preface. As far as there are philosophical implications from my discussions themselves, they are my own and I am quite ready to claim them; but they should not be supplied by inference from expressions in a preface written for quite another purpose, as is the case especially with my reviewer in Mind, Jan. 1890. I could not wish a more adequate and sympathetic understanding of the scope and purpose of my work than that which is expressed by Prof. Rodier in the Revue Philosophique, Mar. 1890.

The changes in the present edition are largely supplementary iusertions or verbal substitutions intended to simplify and make more plain. Only one insertion amounting to a page has been made, i.e. on Cerebral Localization, p. 114. With the two figures of the brain opposite the title-page, I have also inserted a diagrammatic representation of the area-phases of consciousness on p. 68. I would like to have expanded the treatment 
of the operations of thought (Chap. XIV), as has been suggested by several reviewers; but I have been obliged to leave it for a future edition, if that should ever be needed. Criticism also from various quarters has been turned to profit. It is my purpose, I may say, in answer to many inquiries, to publish the second volume, on Feeling and Will, as soon as the arduous work of a new field of professional labor will permit its completion.

J. M. B.

Tonosto, July, 1890. 



\section{CONTENTS.}

\section{INTRODUCTION. \\ CHAPTER I. \\ Nature of Psychology.}

\$1. Definition.-Subject-matter of psychology.-Distinction between psychological and physiological facts.True relation of psychology to physiology.-Definition of psychology, . . . . . . . 1-8

§. Difficulties and Errors in Psychology.-Use of reflection.-Means of remedying these difficulties : supplementary psychological sources, . . . . .

§ 3. External Sources and Aids.-Enumeration of external sources.-Advantages derived from external observation, .

§4. Unity of Psychological Sources in Consciousness, . 18-19

\section{CHAPTER II.}

Psychological Method.

51. Principles of Scientific Method.-In general, . . 20-22

8. Application of Scientific Method to Psychology.-Psychological observation, . . . . . .

8 3. Experiment in Psychology. - Limitations of the experimental method, . . . . . . . 25-31

§ 4. Psychological Hypotheses. - General conclusion, . . 31-34

CHAPTER III.

Classification and Division.

81. Three Great Classes, . . . . . . . 35-36

8. Justification of this Classification, . . . . 36-40

8. Unity of the Three Classes in Consciousness, . . 40-41

4. Division of the Subject, . . . . . . 41-42 


\section{PART I.}

GENERAL CHARACTERISTICS OF MIND.

CHAPTER IV.

Conscious Ness.

§1. Nature of Consciousness,

PAGES

§. Consciousness and the Unconscious.-Meaning of the term unconscious.-Arguments for the unconscious. -Conclusion, . . . . . . . .

§ 3. Relative Theory of Consciousness.-Consciousness as a feeling of difference.-Consciousness as a feeling of relation between subject and object,

§4. Area of Consciousness.-Degrees or forms of consciousness.-Apperception, . • . . . . 63-66

§ 5. Development of Conscionsness, . . . . . 66-68

\section{CHAPTER V.}

\section{Attention.}

§1. Definition of Attention.-Attention as mental energy. -Reflex or involuntary attention.-Voluntary attention,

82. Bearings of Attention in the Mental Life.-Relation 69-72 of attention to sensation.-To movement.-To the intellect.-To feeling. - To the bodily functions, .

8 3. Educational Bearings of the Doctrine of Attention.Training of the attention.-Habits of attention, .

\section{PART II.}

\section{INTELLECT.}

\section{CHAPTER VI.}

Division of the Intellectual Functions.

\$1. The Apperceptive Function, . . - . . $\quad 80$

§. The Rational Function, . . . . . . 81 


\title{
THE APPERCEPTIVE FUNCTION.
}

\author{
PRESENTATION.
}

CHAPTER VII.

SENSATION.

§. General Nature of Sensation.-Distinction between PAGRS sensation and impression.-Affective and presentative elements in sensation, . . . . .

§ 2. Characters of Sensation, . . . . . . .

3. Quality of Sensation.-Smell.--Taste-_Organic or systemic sensations. - M uscular sense.-Presentative element in muscular sensations.-Hearing.-Presentative elements in sensations of sound.--Sight.Touch.-Temperature sense, . . . . .

$\S$ 4. Proof of Specific Qualities of Sensation.-Theory of unity of composition of mind,

\$5. Quantity of Sensation: Psychophysics.-Weber's law.-Extensive or massive sensations, . . . . 106-109

8. Duration of Sensation and Thought: Psychometry. -Effect of attention upon the duration and quantity of sensation.-Effect of duration upon the intensity of sensation, . . . . . .

\$ 7. Tone of Sensation, . . . . . . .

§8. Cerebral Localization, . . . . . . . 114-115

\section{CHAPTER VIII.}

Perception.

\$1. Definition of Perception, . . . . . . 116-117.

8. Analysis of Perception, . . . . . . 117-118

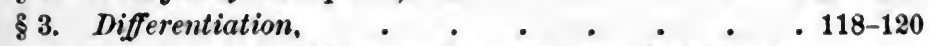

84. Localization.-The perception of space.-Data for the perception of space.--Synthesis of data : tactual space.-Visual perception of space.-Presentation of foreign body.-Visual perception of distance.Localization of sounds in space.-Feeling of equilibrium from the ear.-Ideal product of localization : idea of space, . . . . . . . . 120-133 
§5. Theories of Space-perception.-Nativism of product:

Kant.-Empiricism,

§6. Intuition.-Motor-intuition.-Ideal product of intuition. - Sense-perception and the unconscious. - Deceptions of sense-perception, . . . . . .

§ 7. Reflection or Self-consciousness.-Ideal product of reflection : idea of self, . . . . . . .

\section{REPRESENTATION.}

MEMORY.

CHAPTER IX.

\section{RETENTION AND REPRODUCTION}

§1. General Nature of Memory.-Nature of revived states.-Difference between presentation and representation.-Distinctness of image.-Definition of memory, . . . . . . . . . 145-152

§ 2. Retention.-Theories of retention.-Physiological theory.-Pathological proof of physiological dispositions.-Physical basis of memory.-Mental conditions of retention, . $\quad . \quad . \quad . \quad . \quad . \quad$.

§3. Reproduction.-Its primary condition.-Supplementary condition.-Secondary aids to reproduction.Power of imaging.-Development of the organic in memory.-Retention and reproduction as mental growth, . . . . . . . . . . 164-171

\section{CHAPTER X.}

\section{ReCOGNition and Localization.}

§1. Recognition.-Feeling of familiarity.-Distinction between recognition of an object and of an image.Theories of recognition, . $\quad . \quad$. $\quad . \quad . \quad$ 172-178

§ 2. Ideal Product of Recognition : Personal Identity, . 179

\$3. Localization in Time.-Data for the reconstruction of time.-Intensity as an indication of time.Movements of attention as indicating position in time.-Units of duration.-Perception of time by the ear, 
§4. Ideal Product of Temporal Localization: Idea of

Time, . . . . . . . . . 188

85. Kinds of Memory: Local, Logical, . . . . 189-190

COMBINATION.

CHAPTER XI.

\section{Association.}

§1. General Nature of Association.-Definition.-Ground or reason of association : the preceding idea.-Relation of association to memory.-Physiological basis of association,

82. Laws of Association.-Particular or secondary laws. -Association by contrast.-Universal or primary law.-Law of correlation.-Preference as influencing association, . . . . . . . . . 194-203

83. Forms of Association.-Forms of coexistent or simultaneous association.-Complex associations, . . 203-210

§ 4. Force of Association.-Continuance of the suggesting idea,

\section{CHAPTER XII.}

IMAGINATION.

1. Passive Imagination.-Material of the imagination. -Presuppositions : memory and association. .

5. 2. Modes of Passive Imagination.-Dissociation.-Composition, . . . . . . . . . 218-220

§ 3. Laus of Passive Imagination.-Contiguity and resemblance.-Principle of preference, . . . 220-224

§4. Fancy.-Relation of fancy to reality, . . . 224-226

85. Active or Constructive Imagination.-Definition, . 226-227

8. Analysis of Constructive Imagination. - Natural impulse or appetence.- Law of native talent or preferences.-Intention.-Selective attention.-Feeling of fitness, . . . . . . . . . 22i-234

§ 7. Kinds of Constructive Imagination.-Finished imagination.-Scientific imagination.-Relation of scientific imagination to reality : scientific hypotheses.Asthetic imagination, 
§ 8. Relation of Imagination to Thought.-Law of constructive imagination : correlation,

§ 9. Ideal Product of the Imagination: the Infinite, - 242-243

\section{CHAPTER XIII.}

\section{ILLUSIONS.}

\$1. Nature of Mllusion.-Relation of illusion to mental pathology.-General character of illusion.-Relation of illusion to belief.-Representative nature of illusional states.-Illusion due to interpretation, .

§ 2. Grounds of Illusion.-Similarity of presentations and representations.-Absence of internal stimulus.Intra-organic stimulus: physical change.-Mental predisposition to illusion,

§3. Kinds of Illusion.-Illusion proper.-Physical aspect of illusion proper.-Elements of reality in illusion proper.-Hallucination, . . . . . .

§ 4. Range of Illusion.-Illusions of presentation.-Illu-

sions of representation.-Illusions of thought, . intensity.-Absence of definite locality.-Inappro-

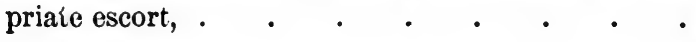

§5. Detection and Rectification of Illusion.-Diminished

ELABORATION.

\section{CHAPTER XIV.}

\section{THOUght.}

$\S 1$. Nature of Thought.-General character of the thinking process.-Stage's in the thinking process, . . 270-272

$\$ 2$ Conception.-Process of conception.-Abstraction.Generalization.-Products of conception.-Conception as discovery of relations.-Language in its relation to conception.-The use of images in conception.-Relation of conception to reality and belief. -Unity of the concept: development of the idea of identity.-Bclief in the reality of the concept, . 272-283

§ 3. Judgment.-Its nature.-Law of identity.-Unity of the judgment.-Parts of the proposition, 283-288 
8. Possible Relations asserted in Judgment: the Predicainents.-Psychological predicaments.-Metaphysical predicaments, . $\quad . \quad$. $\quad$ • $\quad$. $\quad$ 288-291

§ 5. Kinds of Judgment.-According to intension.-According to belief : categorical judgments.-Law of sufficient reason.-Hypothetical judgments.-Relation of these forms to one another,

8. Reasoning.-Its nature and kinds.-Deduction : the syllogism.-Conceptual interpretation of the syllogism.-Neaning of the premises.-Kinds of syllogism.

-Value of the syllogism.--Scientific hypothesis, . 299-307

5 7. Induction.-Relation of induction and deduction, . 307-309

8. Proof, . . . . . . . . . 309-310

9. Ideal Product of Thought, . . . . . $\quad 310$

\section{THE RATIONAL FUNCTION.}

\section{CHAPTER XV.}

REASON.

81. Definition: Reason as Constitutive of Mind, . . 312-813

8. Reason as Regulative of Mind, . . . . 313-314

8. Reason as Knowledge : Intuition.-Intuition as men-

tal act, . . . . . . . . . 314-316

84. Intuition as Mental Product, . . . . . 316-318

85. Sphere and Kinds of Intuition.-Universal intuition :

Being.-Intuitions of sense : percepts or cognitions.

-Intuitions of intelligence : concepts or beliefs.-

Judgments, . . . . . . . . 318-323

8. Final Objects of Intuition.-Intuition of the world.-

Of self.-Of God, . . . . . . . 323-325 



\section{INTRODUCTION.}

\section{CHAPTER I. \\ NATURE OF PSYCHOLOGY.}

\section{§ 1. Definition. ${ }^{2}$}

Subject-matter of Psychology:-Principal Source. The treatment of psychology in general may be either empirical or rational. Approaching it strictly from the empirical or, experiential side, we find it to be, like the physical sciences; a science of fact. The one question upon which the justification of the science depends is this: Is there a separate order of mental facts? Rational psychology goes further in asking:(What is the nature of the principle which affords a rational explanation of these facts? With this empirical psychology has nothing to do, except in so far as its results afford data for rational interpretation. Whether mental facts find their ultimate basis in an independent mental substance or in the brain, the facts and the science of the facts remain the same. Rational psychology alone, in the latter case, would be suppressed.

The question of empirical psychology- "Is there an order of mental facts apart from the phenomena of the physical sciences and especially physiology?"-is sometimes answered negatively. Psychology, we are told by

'On this chapter and Chapter IV, compare the excellent treatment of Rabier in Legone de Philonophie, 1, P'xycholngie, chap. III-v; also Bren. tano, Prychologic com empiriachen Stundpunkie, cap. II-v. 
the materialists, is properly a branch of physiology: since physiology, as the science of the functions of the bodily organs-the lungs in respiration, the heart in circulation-includes the function of the brain, which is thought. Psychology thus becomes a special chapter in physiology.'

This identification of mental facts with organic and vital facts is wrong. There exists between the two orders of facts a radical opposition in several particulars.

Distinction between Psychological and Physiological Facts. The opposition between these two classes of facts takes sereral distinct phases. We may first consider it as an opposition in the nature of the functions of mind and body.

I. Relation to Movement. The organic functions are simply movements of the organs of the body, that is, movements of matter in space. The functions of digestion and circulation are the physical activity of their respective organs, and the science of such functions is nothing more than the complete knowledge of these movements. With thought or feeling the case is very different. Without doubt thought has some of its conditions in the brain,-indeed, to make the argument stronger, we may say all its conditions, - and yet we cannot say that thought is movement. The most that can be said, by the most advanced materialism, is that thought is an effect or result of cerebral movement. Let the movement be what it may and let the mental fact be what it may, there is nothing in common between them. Something must be added to movement to give it feeling. The two classes of facts could not be farther removed from each other. Mr. Huxley says :" "Let us suppose the process of physical analysis pushed so far that one

1 Comte, Maudsley.

"Art. “'Science and Morals," Fortnightly Review, Dec. '86. 
could view the last link of the chain of molecules, watch their morements as if they were billiard-balls, weigh them, measure them, and know all that is physically knowable about them;... we should be as far from being able to include the resulting phenomena of consciousness, the feeling of redness, within the bounds of physical science as we are now. It would remain as unlike the phenomena we know under the names of matter and motion as it is now." The fullest knowledge of the brain would not lead us to suspect the existence of such a thing as thought if we did not know it already in consciousness. If an animal for example, says M. Rabier, experienced sensations quite different from any we know, the most exact knowledge of what takes place in the brain of the animal would throw no light upon their nature; just as full knowledge of the auditory and risual apparatus gives no idea of sound and color to the man born deaf or blind.

Consequently, if we seek for the exact counterpart in the brain of the movements which constitute the functions of the heart and lungs, we shall find it in the molecular movements of the cerebral substance and not in thought. The whole circle of consciousness is an added fact to that of movement.

For this reason, we canuot speak of thought as occupying space or as having exact locality. All such forms of expression will be seen upon examination to refer properly to the physiological accompaniment of thought. For example, we speak of the localization of speech in Broca's convolution; but it is the cerebral modification which accompanies verbal symbolism in thought that is there located. Suppose all our words were impressed upon the brain, making it, as some seem to consider it, a kind of magazine of photographic plates, still the great mental essential, consciousness, would be wanting. 
II. Relation to measurement: mental facts, unlike physical facts, cannot be directly measured. For the measurement of external magnitudes extension affords us at once definite and constant standards; but for internal magnitudes we have no such exact means of procedure. The very fact that such measurements are subjective in their nature makes them liable to all the uncertainties of subjective estimation. This difficulty is further enhanced by the consideration that the mental fact is always associated with a physical fact, and it is impossible to isolate the former. This is seen in both the cases in which physical measurements seem to be most successful : in the measurement of the duration of mental acts and of the quantity or intensity of sensations. In the former case we proceed upon the supposition that time standards can be employed for mind as space standards for body: but the time occupied by the cerebral event is so interwoven with that of the mental that it has proved impossible to separate them. And as regards intensities, the law announced pretends to give only relative measurement, this again being subject to revision when more is known of the relation between peripheral stimuli and their central effects. ${ }^{2}$

Besides this distinction between the two orders of facts in their nature, we find also another striking proof of their separateness.

III. Mental states are distinguished from physical states in the means through which they are known." As modifications of matter, physical facts are known through the senses. Bodily functions are thus laid open to the gaze of the physician and the anatomist. The brain itself may be observed in its activities after the operation of trepanning. But mental states escape all such

3 Weber's Law. See Chap. VII, $\$ 5$ and 6.

${ }^{2}$ Cf. McCosh, Cognitive Powers, I. p. 7 ; also Lotze, Metaphysic, p. 421 . 
observation. They are known, on the contrary, in an immediate way through the consciousuess of the individual. And while we are able to observe and analyze the physical processes of others, our immediate knowledge of mind is limited to ourselves.

Yet we cannot say that all psychological data are presented at once and immediately known in conscionsness; for the field of consciousness is presented in adult life as a mature and developed continuity. Many of our states of consciousness are products, not simple elements, though consciousness does not afford us this information; and even when by analysis the component elements are revealed, they may, in certain circumstances, be beyond the range of conscious presentation. In the absence of attention we are unconscious of states which become distinctly conscious when attended to.'

IV. The most essential characteristic of mental states is their subjective nature; what we may call their inner aspect, in the phraseology of late science. By this is meant that relation to a self or subject that makes them what they are in distinction from outer phenomena, which, as far as we know, have an existence apart from such a reference. This distinction is admitted even by those who reduce the two classes of phenomena ultimately to a single principle, and it is emphasized in the name their theory prominently bears." This fact of a self affected becomes in developed mental states a matter of reflection and differentiation from the not-self; a distinction arising, as will appear, within the inner aspect, and impossible without such an essentially subjective initiation.

V. The method of mental activity is quite distinct from that of the physical forces. As we proceed wo shall find

\footnotetext{
'See discussion of the unconscious, Chap. IV, $\$$, and Volkmann, Lehrbuch der Prychologie, \& 3.

2 "Double Aspect 'Theory," Lewes, Huxley, Wundt.
} 
a constantly recurring fact of mental synthesis whereby, by purely internal activity, the detached and isolated states of consciousness are gathered and unified in new products themselves apparently simple and original. In the physical world we find no such unifying force as that known in psychology as the activity of apperception. $^{1}$

True Relation of Psychology to Physiology. These two orders of facts lead us to two distinct sciencesequally sciences of fact or natural sciences. Psychology cannot be a chapter of physiology because the methots and results of physiology do not reach nor involve subjective data. One is a subjective science and the other is an objective science, and the difference is strictly experiential.

The absolute separation of psychology from physiology, however, in point of matter does not imply their independence of each other in point of fact. They are united in fact by a bond which finds analogy only in that which unites the science of the inorganic, chemistre, with that of life, biology. Life introduces a new series of phenomena into nature, but the morphological changes it produces are accomplished immediately through the processes of inorganic or chemical change. So psychology, while introducing a new order of phenomena, proceeds immediately upon the data of physiological change. The connection of the two is as real as their separation. The physiologist often finds the causes of organic modification (facial expression) in the movements of the mind, and the psychologist likewise finds causes for mental modification (sensation) in states and functions of the body.

Further, this connection between psychology and physiology opens up to us a means of approach to men-

' See Chap. IV, §4. On this contrast, see Lotze, Microcosmus, I. pp. 251-2. 
tal facts by which the reports of consciousness may be confirmed and modified, i.e. experiment. If the bond and method of connection between body and mind be uniform, artificial conditions and states of mind may be produced by the modification of physiological conditions and studied with care and exactness. Sensations of color, for example, may be made the object of research by the actual production of these sensations under artificial circumstances.'

While psychology in its procedure as a natural science may thus be regarded as co-ordinate with the other sciences, yet from the point of view of its subjective principle it takes ureectemer of them all] The external world is known to us only throngh om presentations, yet in natural science the presentation is not itself the object of study, as in psychology : it is but the means of reaching things, and while the laws of psychology are observed, they may yet be quite unknown. It is the external cause and not the subjective effect which the physicist sets before him as the object of pursuit. The knowledge he arrives at of these causes is distinct in kind from that of psychology and constitutes an independent order of science.

The relation of psychology to metaphysics is a question more widely discussed and of more importince in the light of the history of psychology. If it be considered strictly as a naturisl science, it must bear the same relation to metaphysics that the other sciences do. Yet its relative independence is more to be emphasized from the fact that this position is new comparatively, and that there is a large class of thinkers who fail to distinguish the empirical from the rational treatment of mind. Yet the treatment of empirical psychology is often made exclusive and extreme." The absolite divorce of psychology from metaphysics is impossible, as the divorce of physies from metaphysics is impossible. In the former case, as in the latter, there are at least two neeessary presuppositions: first, that there is an actual thing called mind, whether we regard it as substantial being or merely as the ensemile of the inner life. 'The natural scientist assumes a something called matter which is metaphysieal whether he adopt the substantive or the dynamic theory of it. Such a postulate

'For the consideration of the physiological method, see Chay. II.

: Rilot, German Prychology, Introduction. 
seems necessary to give unity to the phenomena under investigation and afford a point of departure. We shall find in

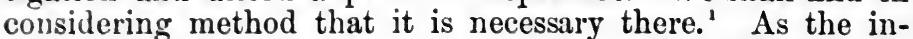
vestigation proceeds, its results give greater definiteness to this assumption and prepare the way for rational psychology. And second, it is necessury to assume that mental phenomena are subject to law. If this were not true there could be no such science. 'There could be no induction in mental states without the law of mental uniformity. Like all the other sciences, also, psychology must hand in its results to higher thinking for the construction of a developed world-theory.

Definition of Psychology. We may, accordingly, define psychology as the science of the phenomena of consciousness, being careful to include consciousness whereever and in whatever stages it be found; or, if we emphasize, not so much the facts with which we deal, as the mode of our knowledge of these facts, and its entire separateness from abstract theory, as the science of mind as we know it.

\section{§2. Difficulties and Errors in Psychology.}

It has already been said that consciousness is the one characteristic of what we denominate mental. The difficulties and errors, therefore, that arise in psyclology must be difficulties and errors either in the reports or in the interpretation of consciousness. There can be no doubt that there are such difficulties and errors, for otherwise the science would long ago have been completed. They cannot arise in the actual reports of consciousness, for by its intimate nature as immediate knowledge of inner states it reveals what actually is and happens. The question of the veracity of consciousness, as discussed by Hamilton, is the question as to whether the real state in consciousness corresponds to a real

1 See Chap. II. Cf. Herbart, Psych. als Wissenschafl, ed. Hartenstein, p. 264, etc.; also Waitz, Lehrbuch, §7.

'See the author's article Postulates of Physiological Psychology, Presbyterian Review, July, '87. 
state without consciousness, otherwise it seems to have no definite meaning. Considered, then, as arising from the interpretation or elaboration of the data of consciousness, several sources of error may be pointed out.

I. Difficulty of distinguishing Consciousness from Association and Inference. The primitive data of consciousness are no longer presented simply in adult life, but carry with them a mass of complex and derived material. "Hardly has consciousuess spoken," says Mill, "when its testimony is buried under a mountain of acquired notions." The fact that there is a higher and lower in the mental life-a development from first things-is sufficient to show the reason of this confusion. For example, we shall find in studying sense-perception that the localization of things in space, which seems to be an immediate act of consciousness, is really due to a very complicated construction from physiological data, and the general process of reproduction carries with it an instinctive belief in the reality of our images, due largely to association, which leads us often into illusion. So marked do these difficulties and confusions become in the higher processes, that some additional safeguard must be resorted to: some method of reducing complex mental states to the simple data of consciousness. This resort is found in Conscious Reflection.

Use of Reflection. Even though the necessity spoken of did not exist, still simple conscionsness, however absolute, would not be sufficient for science. Consciousness is knowledge of present states, presentative and representative, and gives us only a play of observed conditions. The scientific observation of mind demands more than this. It demands the turning back of the powers of thought and reason upon our immediate knowledge for its examination, testing, systematization, and rationalization. Simple observation does not suf- 
fice for the science of physics, nor will it, for the same reason, for the science of psychology.

By reflection, therefore, consciousness itself becomes a matter of consciousness. To observe consciousness I must stand aside, so to speak, apart from myself and report what takes place in myself. If it is attention which I wish to observe, I must attend to the act of attention, in order to describe it. There is in such reflection a species of secondary or subordinate consciousness, from the ground of which we look in upon our primary self. This apparent doubleness, or the effort to place ourselves beyond the range of our own states in reflection, leads to new sources of difficulty.

II. Disturbing Effects of Reflection. Reflection, considered as the turning in of the mental processes upon themselves, necessarily, by a great law of attention,' exerts a disturbing influence. All our mental states are rendered more intense by the attention: consequently as soon as the state observed comes within the range of fruitful observation, it is changed, both in its own integrity and in its relative importance in the mental life. A pain attended to, for the express purpose of estimating its intensity, becomes more intense. Operations, also, which demand close application or successive mental efforts, are completely suspended by reflection. A difficult logical problem or musical performance becomes more difficult or impossible of accomplishment, when, by reflection, we note the stages of the process. Mental effectiveness seems to require a single direction of consciousness. On the other hand, also, certain states of mind make reflection impossible, their temporary importance in consciousness being overpowering: such as strong fear, anger, and the emotions generally. But psychology, as a science, cannot dispense with the 
complete knowledge of such states, since they are sometimes most important and enlightening. Indeed aggravated states, especially when they become manifestations of mental disease, are generally most instructire of the normal processes from which they rise.'

Means of Remedying these Difficulties: Supplementary Psychological Sources. In view of these limitations, the psychologist is thrown back upon any other means he may command to correct, complement, and enlarge the scope of reflection. In general these supplementary sources of information are internal and external.

I. Internal Source: Memory. The errors of internal reflection which arise from the deranging effects of attention may be remedied in large part by memory. Mental states which cannot be made the object of immediate examination in the present, may be recalled from the past and held before the attention as reproduced images. The facility with which the mind does this is quite remarkable. Frequently an experience which is obscure or meaningless, an unknown sound, an unrecognized face, a vision, is thus recalled and given a rational explanation. The psychologist often catches himself just emerging from a state before unconscious, which, being brought back in vivid detail, is of especial value and fruitfulness for his psychological theory.

This fact of memory is farther strengthened by the phenomenon of aiter images or after sensations-traces left in the mental life after the actual stimuli have ceased to act. Of these we shall speak more in detail."

1 On account of this disturbing result of reflection, Brentano protests against the use of the word observation for the process of inuer knowl. edge and insists that it is only inner perception which avalls for the science. Yet when the nature of reflection is considered, it is really observation, and the original act of consciousness, in its immediateness, differs as much from perception as from observation.

'Chap. VII, § 3, Sight. 
There is a vibratory persistence, in the nervous organism, of peripheral shocks, which tends to continue the central process and its accompanying mental state. And the same residuum or after effect is also probably a mental necessity, since time is needed for the shifting movements of attention in its transition to new experiences: during this period there is nothing to drive the former experience from consciousness and it persists a noticeable time.

Yet even when the conditions of mental observation are most favorable, errors are incident to the process from the necessary artificiality which the fact of observation tends to create. The absolute unity between consciousness and its object which we call with great insight, in popular language, unconsciousness-as in the sentence, "he is natural and unconscious," i.e. of himself-is greatly impaired, and the relation between subject and object arises. Memory may be rendered faulty by this consciousness of the effort to remember correctly, or by the desire of discovery. Hence, while at first psychology seems to have in consciousness an extraordinary advantage over other sciences, yet in actual operations this advantage is found to be very small.

II. We are thus led to look without and inquire what external classes of facts or methods of treatment may render service in the construction of psychological science.

\section{§ 3. External Sources and Aids.}

If it is impossible with the positivist to deny the utility of inner observation, it is almost equally dangerous to depend upon it exclusively. Failure to resort unceasingly and repeatedly to external observation at every stage of our study leads to the most chimerical subjective systems and the most one-sided views of life. So evident is this that, even when most strongly emphasizing the inner source of data, psychologists have always laid hold upon whatever pathological or certified records of others' experience they found available, and held them up as valuable. This is true especially 
of the Scottish psychologists, who have availed themselves, when possible, of the data of physiology.

In addition to the points already mentioned at which a resort to external aids is seen to be necessary, several general reasons for it may be urged.

1. External confirms and corrects Internal Observation. As has already been intimated, the development of the inner life in its complex forms gives rise to varied mistakes of observation. As shall appear in detail in the chapter on Iilusions,' the great and often the only means of separating the true and false is by an appeal to external fact. Reality must be made the test of truth. In the minds of others, in the products of human thought, the truest psychological realities are made known, and they often correct the individual movements of the inner life and substitute for them the universal. The true scientist in other departments is never satisfied with the proof of his discovery, but taxes his ingenuity to change the conditions, reverse the stages, improve the instruments of his research: why should the psychologist do less?

2. Internal Observation lacks Generality. The contributions which may be drawn also from observations beyond the circumseribed area of one's own consciousness give generality and breadth to one's interpretations which they would otherwise lack. There are phases of intellectual life which are controlling in one individual and almost wanting in another; differences in temperament, taste, and talent, of wide significance in the inner world-differences which if mucorrected in our theoretical interpretations would make every man his own psychologist. Environment, race culture, education, habit, all are more or less individual, and all of tleeir variations must be included in our finished theory. This necessity

' Chap. XIII. 
for generalizing the principles of psychology is one of its greatest hindrances, and presents one of its profoundest problems to-day, the problem of the psychology of races.

3. Without External Observation Psychology would be entirely Descriptive. This arises from the fact that it is only after a comparatively advanced age has been attained that inner observation is possible. It is only when the higher intellectual powers are mature that reflection can seize and rationalize the facts of experience. But when this is attained, the movements of the inner life have become so fixed and regular that no genetic explanation of them would be practicable. Consciousness could attain no knowledge of the rise, growth, and interaction of the powers in childhood if limited to observation of itself. This necessity for early study is especially noticeable in psychology because of the exceedingly complex and involved conditions of adult life; for the nature of a mental process or fact is best explained by throwing light upon its origin. Science demands explanations, reductions, causes, more than descriptions.

This danger of considering the data of the developed consciousness as the ultimate and original forms of mental activity has an important bearing upon the theory of knowledge and upon general philosophy. It results in the multiplication of first principles and destroys the best means of testing them-an appeal to the beginnings of mental life. It is no gain to an intuitive philosophy to multiply irreducible principles ; on the contrary, it is in the interest of truth, from whatever side we approach it, to take account of the elementary processes of the formation and development of our mental equipment. The idea of space is a good example of such a notion, and Kant's psychological arguments for its subjective interpretation illustrate the danger. 'The very existence of "first principles," the determination of the barest woof and warp of thought itself, is a matter of origins, as the evolutionists claim, and the problem should be approached, as well from the side of infant and comparative psychology, as from the side of the observation of developed reason. 
Enumeration of External Sources. The external means of approach to the human mind apart from experiment upon the body, to which we have already referred, fall into four general classes, giving as many distinct branches of the science.

1. Folk-Psychology.' This is, in the first place, the study of mind in its products in society, the state, religion, customs, and institutions. It accepts all the results of anthropology and views them from the subjective side. It examines ancient philosophies, cults, and civilizations ; literatures, history, laws, mythologies, traditions, the sources from which the human mind has drawn its culture in all ages. It values the reports of travellers, in respect to sarages, heathen, and degenerate races; the conditions of social life everywhere. For in all these manifestations of the life of the human mind, we have direct information respecting its nature and capacities. ${ }^{2}$

2. Animal or Comparative Psychology. As might be expected, the study of animals is of extreme importance for our science; for animals show striking evidences of the phenomena of consciousness both in its lower and many of its higher forms. It is perhaps destined, judging from the contributions it has already made to some departments of research, to throw as much light upon human psychology as comparative anatomy has upon human physiology. As is the case with many physical functions, so certain intellectual states are seen in animals in a less developed and complex state, or in a more sharpened and predominant state, than in man ; and thus the necessity for a genetic study of these states is met to a greater or less degree. Instinct, for example, attaius its most perfect form in animals, memory is often re-

1 The Volkerpychologie of the Germans.

- Consult the table of contents of Zeitschrift für Völkerpsychologie, vols. I-III. 
markably developed, and certain of the senses show a degree of acuteness which we would never expect the corresponding human senses to possess. And the study of animals for psychological purposes is not limited to observation of their habits, productive as such observation is ; but the physiological method is capable of much more extended use than in experiment upon man. Condemned animals may be directly used for purposes of neurological research. The variety of problems which may thus be reached is limited only by our ability to state them and our ingenuity in planning the experiment. ${ }^{1}$

3. Infant Psychology. The importance of the early study of mind has already been insisted upon. By it mental facts are reached, as far as they ever can be, at their origin and in their simplest form. It is more important to know what mind is than what it becomes. The child serves to correct the reports of adult life by opening up object lessons in the growth of mind. At the outset the child mind is lower than the highest animal mind, since, while its human possibilities have not emerged, its instinctive equipment is not as varied as that of animals: but in its rapid development, it exhibits the unfoldings of organic mental growth in correspondence with the growth of the bodily system, an advantage found in none of the other fields of observation.

4. Abnormal Psychology: Psychiatry. As in the former sources of information we deal with mental physiology, here we come to consider its Pathology: that is, we look to all abnormal or diseased conditions of the mental life for light upon its nature and upon its legitimate operations. It includes all cases of variation from the normal and healthy activity of conscious mind:

${ }^{1}$ From both these standpoints, Animal Psychology has made great advances in the last few years: see references at the end of Chap. II. 
somnambulism, dreams, insanity in its multiplied forms, amnesia, aphasia, hypnotism, idiocy, hallucination, disturbances of consciousness. All these variations afford -as such variations in any science afford-instructive views into the working of mind in its most intimate character. And the reason for this is plain. Such cases offer immediate occasion for the application of the logical method of difference, which consists in removing part of a cause or effect and observing the consequent rariation in the corresponding effect or cause. This procedure enables us to attach an effect to its true cause. One most general result of the study of mental disease, for example, is this, that we have learned to seek its cause in diseased conditions of the body, rather than in obscure mental movements or supernatural influences. It has been well said that a man deprived of one of his senses from birth is a subject especially prepared by nature for the application of this canon of induction. The science of mental disease and its cure is called Psychiatry.'

Advantages derived from External Observation. The advantages to be derived from all these external sources of information are well summed up by M. Rabier as follows: "1st. The testimony of consciousness is held in control. Consciousuess, for example, reveals as an essential element of our nature certain religious and moral feelings. Ethnology finds analogous feelings among all peoples in every degree of civilization. Prehistoric anthropology finds in the tombs of races now disappeared, evidence of similar beliefs. What could be stronger or safer than this threefold witness? $2 d$. We reach the psychology, not of an individual or race, black, white, or civilized, but the psychology of the

'Work done in France and Germany has been especially rich in this department : for particular references, see Chap. XIII. 
Human Species. 3d. The observation of children, animals, and peoples more or less barbarous, shows us the mind at its origin and in the different stages of its development: how it arrives, in its progressive advance, at the state of comparative perfection it exhibits in civilized peoples; and in what original principles the diversity and complexity which it finally shows, take their rise. If we consider, for example, the language of the Greeks in the age of Pericles, or that of France under Louis XIV., it.is hard to believe that such an instrument is not a divine gift or a revelation of natural instinct. But when we consider the stammerings of the child, the rude and changing dialects of the savage, the long periods of growth which are necessary to the development of language, we are more readily convinced that it is a creation of man and rests upon the well-known faculties which underlie his other creations in industry, science, and art." And we may add: 4th. By the study of mental pathology, we are able to eliminate the action of causes which are not mental, and arrive at a purified conception of mind.

\section{§4. Unity of Psychological Sources in Consciousness.}

From the external standpoint, psychology stands upon a level with the other sciences of observation : but by the addition of inner experience it attains a unity they do not possess. The medium of all observation of nature, consciousness, which is foreign to the content of other sciences and often acts as a hindering cause, here serves within the circle of the science itself a useful and important rôle. The subjective interpretation of facts, called in science the "personal equation," is in psychology an act of essential value, since data for psychology can be systematized only under the form of inner modification. In short, external observation, which is necessarily of the physical, and of the mental only 
through the physical, must be translated into the forms of our own inner life. The ultimate basis, therefore, of psychological interpretation and ccnstruction is the mental experience of the individual, in so far as it has universal meaning. 


\section{CHAPTER II.}

PSYCHOLOGICAL METHOD.

\section{§ 1. Principles of Scientific Method.}

In General. The question of method is an important preliminary to all scientific construction. It involves the two great necessities of procedure, first the destination, and second the road to the destination. In the preceding chapter, in the consideration of the subject-matter of Psychology, the former has been considered. It remains to inquire into the latter: through what means or by what kind of procedure shall we investigate the matter before us in order to reach the most general and exhaustive results?

- This problem is practically solved for us in the method of the objective sciences. For if, as has been said, psychology is a science of fact, as they are, and is dependent on observation of a given phenomenal content, as they are, then the tried method of procedure which they employ, will be most productive here.

Of the two great historic methods,Deduction and Induction, ${ }^{1}$ recent investigation ${ }^{2}$ has shown that neither alone is exclusively productive of great results in the way of discovery or construction, though in their general characteristics and predominant importance, induction may. be said to be the method of discovery and deduction the method of construction. Considering natural science under both these essential aspects, we may call its true method the Joint Inductive and Deductive or the Synthetic method.

\footnotetext{
${ }^{1}$ See their psychological treatment, Chap. XIV.
}

2 Especially Jevons, in Principles of Science. 
The general characteristics and logical derelopment of this method may be set forth in the three following processes, the first two of which belong more properly to Induction. First, Observation; by which is meant the widest possible appeal to fact, by way of an actual understanding of the cases in hand. It must be extended to include all reliable testimony. The broad defining marks of the scientific content become thus apparent and great classes are reached. This constitutes natural history, rather than natural science; since its results are descriptive and not explicative. Second, Experiment; which consists in the variation of the conditions of phenomenal succession and the discovery of essential reasons or causes. It proceeds by certain subordinate methods or canons of its own, called since Mill "canons of induction." The product of experimental research is the (Hypothesis or Empirical Law ;) a more or less probable conjecture, based upon the results of experimentation, as to the true cause operating in the case in hand. This is, in so far, no longer a description merely, but an explanation. Phenomena are referred to a great mental principle,' and are capable of no further reduction when their causes are pointed out. The hypothesis goes beyond the facts it rests upon, and its accuracy must be tested and confirmed by further application to the data of experience. Third, Deduction; which is the final stage in scientific method. By it, the truth of the general principle set forth in the hypothesis is made applicable to successive individual cases, and by a new appeal to experience, the truth of this application is made sure. Each such successful application tends to establish the hypothesis more firmly until it reaches the rank of a principle or Law of Nature.

Upon this brief summary of scientific method the fol-

'Sufficient Reason, see Chap. XIV. 
lowing remarks may be made, as useful to us in the application of these general principles of method to psychology.

1. In proceeding from a case of real discovered causation to all cases of the same kind, past and future, it is assumed that there is a necessity in the connection between cause and effect in nature; that is, there is a regularity in nature's proceedings. This is called generally the law of the Uniformity of Nature.

2. It is to be noted that no confirmation is possible to an empirical law or hypothesis except by a direct appeal to nature to establish the truth of our deductive inference; that is, the last as well as the first appeal is to observed fact.

§2. Application of Scientific Method to Psychology.

The application of the principles of Method just mentioned to Psychology is, in the main, clear : yet many questions of lively debate arise in consistently carrying them out. The two great spheres of their operation are the two sources of psychological data, internal and external observation.

Psychological Observation. I. Internal. The necessity of internal observation has already been spoken of. It is approached in this connection from the standpoint of psychological method. As a means of access to the phenomena of mind we find it available in three distinct ways. In the first place, the simple fact of Consciousness, that inner aspect which makes mental facts what they are, in its primitive form, is at once awareness of the states of self. However vague and indefinite this primitive presentation is at first, it is still a beginning. No experience in conscious life leaves absolutely no trace of itself in the continuity in which it was mentally present. It is recognized as an experience of one's self, a modifi- 
cation of one's own subjectivity, and so gives ground for the developed act of inner observation. The first fleeting sensations of the child, when there is no subject or object, no store of memory images, no idea of self, exhibit in isolation the kind of primitive consciousness that lies at the basis of all knowledge of self. In adult life these experiences are at once assimilated to the developed forms of intellect and their separate meaning is lost. But in this category are included the vast number of first experiences as they pass steadily on in time, something every moment, and all the information we glean from them before we recall, examine, and reflect upon them. Second, internal observation takes the form of

2 Memory, that is, unconscious and involuntary memory. The immediate past, as has been said, hangs around us as a line of trailing cloud on the horizon of consciousness. So speedy and involuntary is this presence of the shortlypast that it is sometimes held to be the first stage of our inner observation : ${ }^{1}$ yet this cannot be held in the sense of denying the immediate awareness of the primitive consciousness.' For example a loud noise, or a spoken word, is unintelligible until its quick recall enables us to recognize it. We had the "immediate awareness" of the first affection, but the examination of the revived image added much to the scientific value of the experience. This instantaneous act of memory is to be distinguished from the conscious voluntary memory spoken of as a corrective of reflection. Third, we reach

3 Reflection, or rational observation. By reflection is meant the direct exercise of self-conscionsness' in the interpretation of the events of the inner world in

'Sully. Cf. section on Units of Duration, p. 185.

- Brentano's distinction between perception and observation may perhaps apply respectively to these two stages: all that is not strictly in. mediate being observation.

see Chap. VIII. § 7. 
the light of the relation of subject and object. It is the highest form of internal observation. It brings to bear upon the isolated data of the mind, the logical powers of conception, generalization, and judgment, and we pass from a multitude of details in present consciousness or memory, to a class concept, law of succession, or principle of association. That is, Reflection is the rationalizing of inner experience in the forms of hypothesis, which constitutes the second stage of the finished scheme of method.

II. External Observation. Under the method of external observation, it will be at once seen, must be approached the various external sources of psychological data mentioned in the last chapter. The closed nature of the individual consciousness makes it impossible that the consciousness of others should be reached except through the interpreted meaning of external signs. All the products of human genius and culture become thus the objects of observation, with a view to arranging the detached parts of truth thus discovered under the common rubrics of our individual experience. So also, the observation of children and animals brings its rich contribution. In psychology, this external observation is analogous to testimony in physical science.

By simple observation, however, in psychology more than in the material sciences, we do not reach below the surface of mental things. Many claim that this is all that we can do, and that a description of mental facts is the true aim of the science. Yet, as rare as true description is in this field, and as broad a field for analysis as simple observation affords, we find ourselves asking: Is there no means of breaking the complex groups of mental states, of detaching individual mental movements from the enormous mass of interwoven threads which our adult thought presents? In short, is there no field for experiment, either internal or external, in psychology? We 
answer, as recent research is answering, that there is, but with important conditions and qualifications.

\section{§ 3. Experiment iN Psychology.}

The need of experiment in psychology is exceedingly great. When we remember that in the search for causes in the natural world, the difficulties are vastly enhanced, by the concourse of causes, and that it is the function of experiment so to eliminate elements in the causal complex, that isolated agencies may be observed at work; and when we further reflect that no single function of mind is ever found operating alone, but that all accompany and modify each,-- the futility of simple observation in this field becomes apparent. A sense stimulation, for example, may arouse an intellectual train, an emotional outburst, a course of action : are all these the effects of a single cause? A course of action, conversely, may result from an emotion, a thought, a memory, an association, a sensation, an aspiration: can the simple description of the resulting action indicate which is its cause? Antecedents and consequents are thrown into the mental life in inextricable confusion. External or bodily causes, an odor, a spoken word, a pain, an internal organic movement, may start a train. This train may be hindered or advanced by a thousand considerations or emotions; other bodily or mental causes may modify it. And all together make up the cause or complex antecedent state; while vague analogies of thought and feeling, such as temperament, heredity, education, make rariations between individuals, and the present condition of the brain and nerve centres makes variations in the same individual. How can we single out the cause, in this network, by observation? It is as vain as to endeavor to discover the cause of a conflagration from examining the blaze: was it a match, lightning, friction, chemical 
composition? Only one step can determine: the reconstruction, under artificial circumstances, of the conditions, and the exhibition of a single isolated cause. This is experiment. We may look at the case, as before, from the points of view of the internal and external approach to mind.

I. Internal Experiment. The range of internal experiment is very contracted, from the fact that it is hard to induce artificial states of mind entirely from within. Yet we can often suggest things to ourselves that change the course of our thought and give us a plainly isolated effect. We can force ourselves into lines of thought or emotion by holding given images fixedly before the mind-such as a shocking murder or the death of a close friend,-and watch the result in the flow of emotion. On a larger scale one can subject himself to a series of intellectual influences and note the change it works in his habits of thought and feeling. The actor has thus constantly to experiment with his emotional states, cultivating those which adequately portray the character he represents. All such intentional manipulation of consciousness, however, demands a high degree of mental control and concentration, great delicacy of observation, and fidelity of description, to be of use for the general science.

Experiment of this kind, however, is more effective upon others than upon ourselves. The whole possibility of suggestion to others is here open to our touch, and we may play upon their emotions, hopes, ambitions, plans, ideas, as upon the keyboard of an instrument. We are all more or less skilled in such experiment: we suit our advice to the man-offering a money inducement to one, a position of honor to another. So educational methods proceed upon experimental knowledge of others: the awarding of prizes, the use of object lessons, appeals to individual manliness, corporeal pun- 
ishment; indeed all discrimination in the treatment of children proceeds upon such experimental knowledge. In the hypnotic state, an unlimited range of suggestion is open to the investigator, and in sleep the same kind of influence is possible to a much more limited degree.

II. External Experiment. The possibility just spoken of, of finding that a bodily or external cause has been the determining factor in a mental result, opens up to our view the sphere of external experiment. We are at once led to see that a series of experiments upon the body may be devised and the results ascertained which follow in the conscious life: that is, reversing the relation of cause and effect which ordinarily obtains, we may consider bodily modifications cause and their accompanying mental modifications effects, thus isolating mental facts through artificial and single physiological stimuli.

That such a procedure is justified is seen from the fact that our daily lives are full of inferences of this kind. The connection between the physical and the mental is so close and unquestioned that we never fail to take it into account. Many states of mind are treated as arising directly from states of the body. The whole treatment of mental disease proceeds upon this basis; and sensations, the material of knowledge, are known to arise from direct sense stimulation. The effects of alcoholic stimulants upon the mind are plain. The elevation, however, of this rough sense of connection between mind and body into a law of scientific method involves the assumptions' which we have found necessary to the true method in natural science, but which, when stated in their generality, seem more questionable here. The rapid growth of physiological psychology, however, which is simply "psychology approached from a physiological (external experimental) point of view," ' has given them 
full confirmation. They may bo stated in the following propositions :

1. The connection between body and mind must be a constant and uniform one; that is, there is a uniform psychophysical connection. The necessity for this assumption is the same as for that of the uniformity of nature in general induction. If the connection is not uniform, all observation and experiment based upon bodily states are alike vain. If, for example, in one individual or at one time, loss of memory be due to brain lesion and in another individual or at another time, such lesion do not produce loss of memory, our method has given us no generality of result, and is useless, both theoretically and practically.

2. It must further be assumed that, in thus admitting the method of experiment, its results are to be tested only by experience itself. This was remarked above upon general induction in the external sciences, and it must be insisted upon as strenuously here. It will not do to admit experiment only so far as it tends to give experimental confirmation to our earlier theories of the inner life, or so far as the generalizations of experiment can be $\grave{i}$ prior $i$ rendered probable; but its utterances must be treated rigidly as scientific hypotheses and confirmed by the testing of fact in the psychophysical domain. As illustrating both these dangers, the doctrine of free-will has been used, first, to discourage and to disprove the validity of this method altogether, on the supposition that the will is a factor beyond calculation in the psychophysical connection; and second, the same free-will has been used to confirm the experimental hypothesis of nervous inhibition.' The phenomena of free-will are certainly experiential and valid, but our preconceptions as to their

${ }^{1}$ Beaunis; see the author's article, Contemp. Philos. in France (editorial) in New Princeton Review, Jan. '87, p. 141. 
value in the physical world should not be intruded on one side or the other.

Limitations of the Experimental Method.' While thus admitting the validity of experiment in psychology, we find it necessary to set forth its limits in a very unmistakable way. Its value consists in its being, as has been said, the means of separating between physical and mental causes in complex internal effects; and in this very service its limitations are seen.

1. The impossibility of experimental approach to the higher powers. In actual fact the range of experiment has been very contracted. The most definite results have been obtained in dealing with the sense-function of mind, since there the direct physical avenue of connection with the mind's states is known. In general terms, it is only where the mental states can be shown to have an immediate dependence upon the nervous system that experiment can do service. The higher processes, those which constitute the rational, emotional, volitional life, the synthetic activities of apperception even in their direct operation upon the data of sense, have been approached only in a way so conjectural as to carry no scientific weight. This is admitted by the most extreme partisans of the physiological method." Even the repre. sentative operations, which are removed only one step from the sense-function, exhibit the greatest difficulties, for theories of their physical basis, which must precede the application of this method, are still quite hypothetical.

Again, the possibility of approach to the higher operations rests upon the assumption that all mental pro-

'In a briefer course of instruction the remainder of this chapter may well be omitted.

" In all that concerns these phenomena (the higher) experimental research is necessarily useless."-Rnot, llid., Introduction. 
cesses have a definite physiological basis; a proposition which is presumably true, but which cannot be proved, at least until the resources of physiology are much more extended than they now are. In the words of Mill, "To reject the resource of psychological analysis and construct the theory of the mind solely on such data as physiology at present affords, seems to me an error in principle and an even more serious one in practice. Imperfect as is the science of the mind, I do not scruple to affirm that it is in a considerably more advanced state than the portion of physiology that corresponds to it: and to discard the former for the latter appears to me an infringement of the true canons of inductive philosophy, which must produce, and which does produce, erroneous conclusions."

2. Many of the positive results of this method are subject to criticism from the standpoint of exact method. The variations due to individual differences, to lack of delicacy in apparatus, to the abnormal mental condition into which the very fact of experiment usually throws the subject, the repressing and exaggerating effects of self-observation already spoken of,-all these limitations tend to give the results, especially of experiment on the intensity and duration of sensation, ${ }^{2}$ only an average and tentative value.

3. The greatest limitation, however, to the method of external experiment is its necessary subordination to the results of internal observation. The physiological approach to mind is a consequence of the preceding examination of mind from pure observation, and the attempt to usurp the place of consciousness is suicidal and absurd. And this for two reasons. First, observation through consciousness is direct and immediate; external experiment is indirect and mediated through the ner-

${ }^{2}$ Logic, Book VI, chap. IV, $\$ 2$.

2 See Chap. VII. 
vous system. Second, external experiment assumes direct observation in arriving at its results; for if the organic as cause gives the mental as effect, this effect can only be estimated from within, through observation. Consequently any attempt to elevate experiment to the exclusire claim of pyschological method must end in the subrersion of the science altogether; that is, it becomes a chapter of physiology. The question, says Maudsley, "is not a question of psychological or physiological method, but of the existence of the science itself."

It is necessary that the function of experiment. and in general of the physiological method, should be clearly defined since there is a tendency, born of novelty and of the great adrance lately achieved through this positive attitude, to the depreciation of the introspective study which must precede and condition it all. The greater portion incomparably of mental phenomena can only be approached by the methods of the old psychology, and in no case has experiment contradicted its established principles. The relation of physiological psychology to the general study of mind is shown in the following dingram :

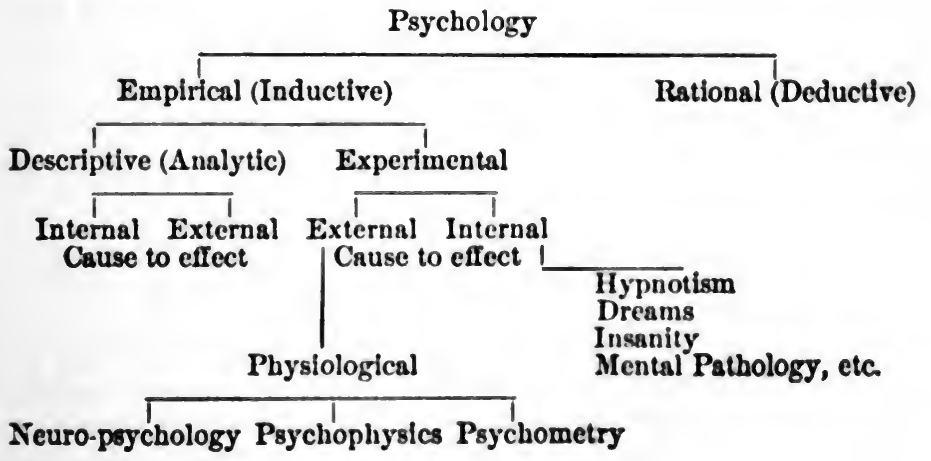

8 4. Psychological Hypotieses.

By the procedure already described, psychological hypotheses are reached which sum up the results gathered from experience. The process of passing from in- 
dividuals and their relations of cause and effect, to their generalized principles, is the rational aspect of induction. These principles are stated in general form and then applied to further experiences for confirmation. This process is very difficult in psychology, indeed we may say that most mental laws are no more than statements of empirical generalization, which owe their probability to wide experience. ${ }^{1}$ This is due to the unheard-of complexity of mental states and the futility of observation and subjective analysis in breaking them up.

Hence it follows that where physiological experiment is able to penetrate and establish a causal ground for mental phenomena, in this explanation of mental facts we reach confirmation of our empirical laws. Here the experimental method renders very great service. For example, what could more perfectly establish the principle that some mental processes require a certain amount of time, than the fact that the physiological processes which they invariably accompany require time? Or what could more perfectly confirm the hypothesis that mental diseases arise from physical causes, than the discovery of certain well-marked disorders of the brain in each case of a peculiar mental disease? For this reason, as Brentano remarks, any treatment of psychology which does not include its physiological bearings is wanting in the most important means of confirming and extending its laws.

The ultimate laws of psychology must, therefore, find their completion in the psychophysical connection, since a complete explanation of a phenomenon must include its cause and essential conditions. This being true, and the law of conservation of energy holding in brain activities, we are led to the high probability that all mental acts have a physical basis. The purely mental in consciousness is therefore psychophysical in fact, and the subjective law of such phenomena must yield in generality to the psychophysical laws which include all mental 
phenomena in fact. With any other supposition, we destroy the unity of mind, since, with the lower operations governed by laws of mind and body in their relation, and the higher by laws of mind without relation to body, how could the two systems of laws be held in harmony? Wundt, for example, forfeits unity in the mental life and finds three problems on his hands instead of one: first, to account for the purely mental ; second, to account for the psychophysical ; and third, to account for this duality. Assuming the universal phrsical basis to all mental acts, we have only the duality of mind and not-mind.

General Conclusion. We are thus led to the following general conclusion as to the nature and method of psychological inquiry: There is, first of all, in consciousness a free intelligent activity which affords at once the necessity aud justification of a higher science, which is inductive, internal, descriptive, and analytic; that its method is that of direct olservation; and that inasmuch as the phenomena of which it is cognizant are purely mental it must precede and embrace those branches of the science which deal with the phenomena of body. Second, these mental phenomena sustain an unirersal and uniform connection with the bodily organism, through which physiological experiment becomes possible, carrying with it a twofold utility: the causal analysis of phenomena and the confirmation of their empirical generalizations. And third, the science can never reach completion or its laws reach their widest generality until all mental facts are interpreted in the light of this connection with body or shown to be independent of it.

On the nature and method of psychology, consult: in general, Volkmann. Ielerbuch aler Psychologie, Einleitung: Waitz. Islorbuch d. Psychologie, 1-3; Drobisch, Empirische IAychologie, Einleitung; Mandsley, Plyssiology of Miml. ch. 1 : Hickok, Mental. Science, pp. 1-61; Lewes, Stuly of Psychology, ch. I, V, and vi ; Hamilton, Metaphysics, Lect. VIII-IX: Thompson, System of Pyycliology. pp. 74-89 ; Fortlage, System der Psychologie, \& 2 ; Porter. Human Intellect, pp. 5-29 and 51-61; Rosmini, Asychologie, pt. 1. ch. I ; Brentano, Psychologie, pp. 1-100: (Observation) Beaussire, Revue Philosophique, xx. p. 580 ; Batiles, Iatters on the Philos. of the 
Human Mind, II-v ; Jouffroy, Nouveaux Mélanges, pp. 223-279 ; Bouillier, Le principe vitale, ch. xxv; Encyc. Britann., 9th ed., arts. Metaphysics, Philosophy.

On the relation of mind and body: Carpenter, Mental Physiology, ch. I-II ; Brentano, Psychologie, pp. 100-130 ; Ladd, Pliysiolog. Psychology, pp. 633-667; Taine, Intelligence, pt. 1, bk. 4; Volkmann, loc. cit. 14-16; Waitz, Grundlegung der Psychologie, p. 100; Maudsley, loc. cit. ch. II ; Croom Robertson, Mind, III. p. 24 ; Lotze, Microcosmus, bk. 3, ch. I-III.

On child psychology: Perez, First Three Years of Childhood, and Child from Three to Seven Years; Preyer, The Mind of the Child; Darwin, Mind, II. 285; Kussmaul, Untersuchungen ïber das Seelenleben des neugebornen Menschen.

On animal psychology: Romanes, Mental Evolution in Animals, and Animal Intelligence ; Espinas, Animal Societies ; Lindsey, Mind in the Lower Animals; Vignoli, Saggio di psicologia comparata ; Waitz, Grundleguny der Psychologie, pp. 139-201; Lewes, Problems, 3d series, p. 118; Lubbock, Ants, Bees, and Wasps; Schneider, Thierische Wille; Perty, Revue Philosophique ; Wundt, Essays, vII ; Rabier, ch. XLVIII ; Perty, Die Seelenlehre der Thiere; Lotze, Microcosmus, I. pp. 556-561.

On race psychology: Zeitschrift für Völkerpsychologie (throughout) ; Ribot, German Psychology, ch. III ; Spencer,-Descriptive Sociology; Waitz, Naturvölker ; Bastian, Mensch in der Geschichte ; Mill, Logic, bk. 4, ch. v; Lazarus, Das Leben der Seele, v. 567; Maine, Village Communities, and Early History of Institutions.

Histories of psychology are : Siebeck, Geschichte der Psychologie (incomplete); Harms, Geschichte der Psychologie; Hamilton, Historical Notes on Reid (in edition of Reid's works); Volkmann, loc. cit., historical notes throughout; Ribot, English Psychology, and German Psychology of To day. 


\section{CHAPTER III.}

\section{CLASSIFICATION AND DIVISION.}

\section{§ 1. Three Great Classes.}

BEsIDEs their common characteristic, consciousness, mental facts have special characteristics which distinguish them from one another and by which they may be divided into great classes. The necessity of this classification is seen in the great multiplicity and variety of these facts. In the beginning of every science, the statement is necessary of the natural knowledge of resemblances and differences, which we may use as a starting point for investigation. In this classification, two great dangers are to be avoided. First, many psychologists, neglecting real resemblances, have made too many divisions or faculties, in a measure dividing the mind into independent principalities and losing sight of the unity of nature which underlies all phenomena of mind.' Again, others go to the other extreme in excessive opposition to the "faculty theory," especially in recent years, and fail to recognize essential differences in mental states."

In the main, however, it is agreed that there are three great classes of facts in the mental life, however strongly

' Reld, Stewart, Jouftroy.

- Herbart, Ribot. The word faculty seems to carry a somewhat metaphysical meaning, as involving the oause mether than the simple class: properly restricted, it is synonymous with function. 
the attempt to reduce them further may be urged. These three classes express the result of three distinct functions of the mind: Intellect, Feeling, and Will. They may be called: 1st, Representative, or intellectual states; $2 \mathrm{~d}$, Affective, or states of feeling; and 3d, Volitional, or states of will. These great departments of mental fact are shown in the very distinct propositions, "I feel somehow," "I know something," "I do something."

\section{§ 2. Justification of this Classification.}

I. In Experience it is complete. The grounds of this classification are found in immediate consciousness, and it can find its justification only in an appeal to direct experience. The representative states have as their common characteristic their reference to a thing or $o b$ ject. Knowledge is a function of mind only as there is some thing to be known, and in the higher forms of its operation its states are taken to represent or signify objects. In its earliest beginnings also, in sensation, the objective bearing of knowledge, as affording us a reference away from ourselves to a something which is presented to consciousness, is its distinguishing feature.

The affective states, on the contrary, as states of feeling, lack this element of objectivity and carry with them only reference to self: that is, they are states in which consciousness is itself affected primarily (pain, fear). They may be entirely lacking in the presentative or knowledge element, or the two may be combined in any degree of connection. They extend from the simplest bodily feelings to the highest emotions, and include impulses, temperaments, and personal tendencies of all kinds.

1 Ward, Encyc. Britannica, art. Psychology. 
In strong contrast to these well-marked divisions the third class, volitional states, stand out in consciousness distinguished by a characteristic foreign to the other two, the sense of effort or exertion. It takes the forms of mental attention, choice, and resolution. The other orders of mental facts may or may not exhibit this willelement. I may be passively affected by pain or emotion, or I may be conscious of a free play of presentations with no effort of my own to control or direct them. This last phase, therefore, may be set apart as a third class, and as representing a third function.

It is held by some that all our conscions states and acts cannot be brought into these classes. Language is sometimes said to require a separate division. But it is difficult to seo how the symbolism of language differs from the symbolism of the notion which it represents. The notion itself represents a generalization from other representative states. And the organic power of speech cannot be considered mental. The activity of conscience also is in dispute. It is held that conscience has both a cognitive (representative) and a motive (emotional and volitional) function. But as its representative activity is admitted to be in the presentation of relations of good and evil, its motire force is only that which attaches to all relations, except that it is the most powerful. Intellectual considerations of all kinds affect the will as motives, and it is as motives that considerations of right and wrong affect the will: these motives are most powerful because they are considerations of conduct, and conduct is the sphere of the will; but they are nevertheless considerations. So we may class conscience as far as its content is concerned in the representative function of mind, and find in itself and its relation to will a reason for its volitional importance. Another point of confusion in regard to conscience arises from the fact that an appetence or primary instinct of our nature, also, is love for good and aversion to evil, this love and aversion being in the iffective class. 'This adds, certainls, new and rery greatly increased force to the motive or volitional value of moral distinctions. If by conscience we understand the entire reason for conduct, then conscience is derived from the threefold netivity of mind taken together; but if by it we mean the power by which we distinguish good and evil, it is represen. tative. 
II. This classification does not admit of further reduction. ${ }^{2}$ Besides the general consideration already spoken of, that the quality of representation is absent from feeling and will considered alone, we find the distinction strongly brought out in the independent variations of which we are conscious in the case of each. The facts of intellect and of feeling, for example, are observable in different degrees of connection with each other. States of consciousness seem sometimes to have no distinct feeling of pleasure or pain. And some states of pleasure and pain convey no knowledge. Our internal and organic sensations, loud abrupt noises, give us no knowledge except the general location of our bodily organs, while the perception of a printed page may convey no positive feeling with it. The demonstration of a geometrical truth may vary in its emotional quality from high pleasurable excitement to complete indifference. All this shows that the two classes of facts can exist together; or that one may vary while the other cloes not, even to limits at which either element seems to disappear.

It should be noted, however, that this mobility and changeableness is greatly in excess in the case of feeling. The rational principles of representation remain fixed in their characteristics, and vary only in the degree of vividness which they present. This fixity makes science possible. In every-day experience our ideas become common property with a fixed meaning to different minds. But affective states are not so. In the same individual, feelings and tastes change constantly. And in different men, these differences are exceedingly great. For example, in the matter of dress, form and color are kept within given limits, but within these limits there is every degree of individual taste. Different persons also have characteristic casts of character, as being intellect- 
ual or emotional; the latter are movable and in constant change; the former fixed in their purposes, methodical and regular in their life. ${ }^{2}$

The opposition between representative and affective states is also shown in the influence they exert upon each other. On one hand, the affective states hinder and interrupt the order of intellectual states. Pleasure and pain when intense, forbid all continuous activity of mind. The habit of indulgence in pleasant states enervates the intellect. On the other hand, intellectual states seem to hinder the emotions. This is seen in the proverbial coldness of highly edncated people. In the same society, the instructed and uninstructed classes are strongly contrasted in this respect. The ignorant classes are impetuous in their emotions: they move in masses carried away by a common feeling, political or social: so much so that it has been said that the "excesses of political revolutions are in inverse ratio to the intellectual development of the people." 3

The connection between these two classes of states and the will is perhaps more intimate, because every act of will involves both an idea of the end in view and a native impulse or appetence to its accomplishment. But it is still true that they can be clearly distinguished. A great number of thoughts and feelings in certain circumstances have no bearing on our volitional life. They are matters of indifference to us. The reading of a historical narrative, for example, may be accompanied with great pleasure, and yet have no apparent effect upon my course of life. The developed forms of will are in consciousness quite distinct from the motives which lead to volition. And as has been said of intellectual and emotional temperaments, so also men differ in their volitional cast. All these differences are traced back to the funda- 
mental one already pointed out, that in strong will there is the massing or concentrating of the mental nature in an effort accompanied with a feeling of the expenditure of force. ${ }^{1}$

\section{\$3. Unity of the Three Classes in Consciousness.}

With the distinction of the three classes of mental fact and the three functions they represent clearly brought out, it must still be remembered that the latter are merely functions. They are not three psychological lives which lie parallel with one another. They are a single life. Their unity in a single principle may be seen under several aspects.

I. They have unity of end. They are functions of a common mental organism and minister to its development. The unity of the body is realized in the unity of the functions of the different organs. The end of all is the conservation and development of the whole. So the intellectual functions are one, in their tendency to preserve the independence of the self and accomplish its destiny. "By intelligence we conceire the end of conduct, by sensibility we are excited to produce it, and by will we govern these impulses in the light of reason and assure the victory of the best. (Without intelligence, man is blind ; without feeling, he is inert; without will, he is a slave." ?

II. They are one in their collective activity. Each seems to depend on the others in an essential way. Attention is necessary to all thought, and feeling is often necessary to direct or is effectual in preventing the direction of the attention. In its reflex activity, attention seems to be a representative or relating function, but it has the fundamental quality of will in its active exer-

1 See Chap. V.

${ }^{2}$ Rabier, loc. cit. Compare throughout this section. 
cise as mental effort. A rolition, as has been said, proceeds upon ideas and appetences to such an extent that one school of psychologists reduce will to the conflict of ideas and another make it a conflict of feelings.' Feeling also involves images or ideas, through memory or imagination, or arises from association, and all of these are representatire. And it seems possible, sometimes, to originate the train from which feeling arises by a powerful act of will.

III. They find their formal unity in consciousness. The completed view of the mind ends, as it began, with consciousness, as the necessary background and formal unity of the whole. Consciousness bespeaks the unit being, the subject of this threefold activity, and in its heathfulness or derangement, under normal stimulation of this threefold order, the proper balance and end of the whole is accomplished.

\section{\$4. Dirisiox of the SubJect.}

In view of the above classification, the subject-matter of psychology falls into convenient parts for treatment. In addition to the three great classes of facts spoken of, the form or mark which is common to them all, consciousness, must be considered. There are accordingly the following four great divisions:

Part I. General Characteristics of Mind.

Part II. Intellect.

Part III. Feeling.

Part IV. Will.

' Herbart aud Bain respectirely. 
On classification and division, consult : Porter, Human Intellect, pp. 40-51; Waitz, Lehrbuch der Psychologie, \& 4; (History) Drobisch, Psychologie, $\$$ 123-138; Herbart, Lehrbuch der Psychologie, pp. 38-90; Brentano, Psychologie, I. pp. 233-306 ; Bailey, Letters on the Philosophy of the Human Mind, vi ; Jouffroy, Mélanges Philosophiques, p. 312 ; Lotze, Microcosmus, II. ch. II ; Patton, Presbyterian Review, 1887, p. 771 ; Ward, Encyc. Britan. nica, art. Psychology; Sully, Outlines of Psychology, ch. II ; Rabier, Psychology, ch. viII ; Spencer, Psychology, II. ch. II and IX.

Further Problems for Study :

History of classification in psychology ;

Principles of logical classification. 


\section{PAR'T I.}

GENERAL CHARACTERISTICS OF MIND.

\section{CHAPTER IV.}

\section{CONSCI OUS NES.}

In the foregoing chapters the term consciousness has been used without explanation. Familiarity with it in the general siguificance it bears in ordinary discourse has been assumed. It is necessary, however, at the outset, to inquire more fully into its nature and position in the science.

\section{§ 1. Nature op Conscroussess.}

Deflnition. Disregarding less important varieties, we may say that two general views of the nature of consciousness prevail among psychologists. On the one haud, it is held that consciousness is itself a capacity, function, or faculty of mind, an inner sense for the perception of the mind and its states, as sight and hearing are outer senses for the perception of body.' This view rests upon the fact of reflection, the developed means of observation of inner states, which has, in common with sense-perception, the relation of subject and object within itself; but not upon the original awareness which we have of our first experiences. This latter bears no analogy whatever to external perception. Locke, who is looked to as the

1 Reid, Stewart, Jouffroy. 
great defender of the inner sense, ${ }^{1}$ makes this distinction, since it is of attentive reflection that he speaks, distinguishing it from simple consciousness. Ideas of reflection are later than those of sensation, he says, "because, though they pass continually, yet like floating visions they make not deep impressions enough to leave in the mind clear, distinct, lasting ideas, till the understanding turns inward upon itself, reflects upon its own operations, and makes them the objects of its own contemplation." This doctrine of consciousness as distinguished from reflection, makes it not essential, but accidental, to mind, an added thing, which may be wanting, as external senses, memory, imagination, may be wanting; and admits the supposition of unconscious mind.

The opposing view is this, that consciousness is the common and necessary form of all mental states: without it mind is not and cannot be conceived. ${ }^{2}$ It is the point of division and differentiation between mind and not-mind.

From the empirical point of view we may make the following observations :

1. Consciousness is not a power or energy of mind. It does not involve the conscious effort of attention. In a state of reminiscence, or revery, the states of mind are uncontrolled and come and go with no let or hindrance from the mind. We are then fully conscious of this play of states, but of no exercise of mental effort accompanying it.

2. Consciousness is not an organ of the mind, to be used by the inner subject in perceiving his states. It is not an inner sense, since it accompanies the exercise of all the senses and is necessary to their function. The senses have specific physical basis also, while consciousness

1 It " might properly enough be called internal sense." Etssay, bk. 2 , chap. I. sect. 4 .

2 Aristotle, Mill, Hamilton, Ward. 
depends upon the healthy and normal activity of the sensorium as a whole.

3. Consciousness is the one condition and abiding characteristic of mental states. The possibility of the separaton of consciousness from mental states is held by many psychologists of the present day, and it is necessary to examine in some detail the grounds for the claim of the existence of unconscious mental phenomena.

\section{§. 2. Consciousness and the Uxconscious.}

Meaning of the Term Unconscious. Unconscious mental phenomena play a great part in contemporary philosophy, and have since Leibnitz. It is necessary carefully to distinguish the strict psychological meaning of the term from its philosophical and metaphysical meanings, since it is only with the former that we have to do. We find attached to the word unconscious no less than three different significations.

1. By unconscions mind is often meant the hidden substratum 'of the soul which underlies all conscions manifestations, yet is never open to our inner gaze in its own essential nature. It is held to be the unifying something beneath intellect, feeling, and will, the substantial spirit. This is a metaphysical doctrine and does not concern us here, being one of the legitimate problems of rational psychology:'

2. The word unconscious may again be applied to facts of least consciousness ; that is, to mental states which lapse from a state of conscious presentation into a region of such obsenrity that they are prectically lost to the conscious life. Such states may also arise from weak or habitual excitatious, which do not ordinarily appeal to the attention.' In this sense the reality of unconscious

I This discussion may well be deferred till after the consideration of the Represeutative Function.

- So Hartmann, Maine de Biran. 'So Kant, Leibuitz. 
states is undoubted, though some other term would better designate them, as distinguished from facts which have no mental reference whatever. However insensibly consciousness may shade away to its extreme limit, there must be a state in which it entirely disappears, and our phraseology should cover this distinction. Yet it is just here that the discussion before us may be said to turn; upon the interpretation of states at one time below the threshold of the conscious life, but yet capable of emerging at any moment into clear conscious value.

3. Closely allied to the last position is the thoroughgoing psychological doctrine of unconscious mental modifications. According to it, states which are at one time conscious may be at another time entirely unconscious, while still remaining mental. They preserve their mental nature, but lose consciousness. This doctrine may be kept strictly within psychological bounds ${ }^{1}$ or it may run into the metaphysical doctrine spoken of above. ${ }^{2}$ Its psychological implications and truth alone concern us here. The arguments upon which it is based will be considered in turn.

Arguments for the Unconscious: I. From the Principle of Causation. The argument oftenest used is based upon the law of causation, and takes a twofold form.

a. It is argued that, if any cause produce a given effect, part of that cause must produce part of the same effect: hence, if certain physical excitations produce a mental effect, a diminished excitation of the same kind must also produce a mental effect. But diminished sense excitations produce no conscious effect, hence their mental effects must be unconscious. "I hear the noise of the sea," says Leibnitz, " but I do not hear the noise of each wave alone; yet the noise of each wave must produce a mental effect, otherwise the whole together would pro- 
duce no mental effect." "Suppose we take a wheel," says Taine, "with a hundred teeth, each tooth coming in contact with a bar as the whole revolves, and remove all the teeth except two, contiguous to each other. We will now have two shocks occupying .001 sec. and giving distinct appreciable sound. But if we take away another tooth the sound is no longer audible. Yet it must still be heard, for the conscious sensation produced by the two shocks was made up of the two elementary sensations." "In the same way an optical sensation which lasts a second is made up of about 451 billions of unconscious sensations $;^{2}$ because at the right of the solar spectrum where the vibrations of ether succeed each other most slowly, there are yet 451 billions per second." "Every minimum visibile," says Hamilton, " is made up of parts still smaller, which do not appear in conscionsness, but have none the less produced a real modification in us." "When we look at a forest from a distance, we do not see the separate leaves or even the single trees; but the green of the forest is made up of the green of the leaves, that is, the total impression of which we are conscious is made up of an infinite number of small impressions of which we are not conscious." "

Particular Answer. In the first place, we may say that, assuming the principle that part of a cause must produce part of the effect of that cause, it is contradicted by the conclusion in this case; for if the whole effect is a fact of consciousness, the partial effect must be a fact of conscionsness also. If a given cause produces a sensation, and by this we mean a conscious sensation, we must understand it to mean conscious sensa-

'De l'Intelligence, 1st ed., vol. 1. p. 208, quoted by Rabier, loc. cit. p. 55 and fol.

- Buid., p. 237.

- Cited by Atill, Philos. of IIamilton. 
tion also when we draw the conclusion that part of the cause will produce part of the sensation. If the effect is not conscious, we can only say that it is not due to part of the same cause. So on this principle we can reach an infinite subsidence of sensation, but not the unconscious.

b. The same principle is used in another way to prove unconscious states : if, we are told, the intensity of consciousness depends upon the intensity ${ }^{1}$ or the degree of change $^{2}$ of the phenomena it accompanies, then we would expect that when either the intensity of these phenomena or their degree of change is very slight, consciousness would be wanting altogether.

Particular Answer. Again, admitting the principle of cause and effect, as stated above, this does not follow; for if a certain intensity of the psychological phenomenon, say pain, produces consciousness and a part of the same cause produces a portion of the same effect, then any degree of pain, however slight, would produce a positive degree of consciousness. If the external excitation as cause produces a given internal fact as effect, then, on the same principle, this internal fact as cause should produce a conscious fact as effect, when it becomes in turn the excitation.

General Answer. But further than this, the principle upon which both these arguments rest is not true; i.e., that part of a cause must have part of the effect of the whole cause. It is true that part of a cause must have some effect, but it cannot be said necessarily to have the same effect in kind as the cause of which it is a part. For the effect may be of such a kind that a certain amount or intensity of the causal energy is necessary to produce it at all. If a certain velocity of wind is necessary to blow down the Tower of Pisa, can we say 
that a wind of slight velocity blows it partly down? Or if a certain force exerted in a blow on a percussion cap causes an explosion, does it follow that a lighter blow produces a slighter explosion? In these cases part of the cause produces no effect uhatever of the specific lind in question. There is a minimum of cause necessary to the beginning of the effect. Now the excitation of the nerrous system is a cause of just this nature, considered with reference to mental effects. A certain strength of central stimulus is necessary to produce such an effect at all, and any action less than this produces no mental modification. The real cause is the central process, and as Hartmann himself says, " a certain energy of cerebral excitation is necessary to provoke a mental reaction." The sound of a single wave, therefore, and the color of a single leaf, in the cases quoted, produce a physical effect, but not a mental. Either they may not suffice to move the sense organ, or if they do, they may not suffice to stimulate the central process.

This explanation holds also of cases in which the partial excitations are successive, as in the case of Savart's wheel, cited by Taine. By a property of the nerves, the successive stimuli overlap and strengthen one another, and so amount to a single inteuse excitation-as the wares of the sea and the leaves of the forest. The sounds of the successive teeth of the wheel do not reach consciousuess in succession but simultaneously ; consequently, we cannot say that each has produced a portion of the effect. Let us suppose, for example, three successive sounds, $a, b$, $c$, following each other at an interval of a thousandth of $a$ second. The stimulus a reaching the auditory centre does not suffice to cause a conscious reaction, but its physiological effect persists more than two thousandths of a second; consequently when the stimulus $b$ reaches the centre it reinforces $a$, doubling the central stimulus; this again persists until reinforced further by the action of $c$, 
and the cerebral activity thus augmented suffices, for the first time, to cause a mental reaction. ${ }^{1}$ The same case of accumulated stimulus is seen in the fact that when Savart's wheel revolves so slowly that the contact of a single tooth is audible, and then so swiftly that two teeth are heard as one, the latter sound is louder than the former. ${ }^{2}$ And it is further supported by experiments in psychometry which show that when excitations follow one another in such quick succession that sufficient time is not given for the central nervous changes, different sensations are not distinguished in consciousness, but a single confused sensation is experienced due to the combined excitations.

II. Argument from the Attention. Another class of arguments for the unconscious in the mental life, is drawn from the activity of attention. Excitations of sense, we are told, which seem to have no mental effect, may be made conscious simply by directing the attention to them. The ticking of the clock is not noticed except when the attention is directed especially to it. The roar of the sea to the sailor, or the noise of his mill to the miller, are never heard under ordinary circumstances. Yet these sounds must have mental counterparts, otherwise how could the attention serve to bring them forward? An experience often cited is that of walking: we are not conscious of our steps until we think upon the muscular and tactual sensations actually involved. And in general, close attention to any part of our bodies brings out innumerable slight sensations of which we were before absolutely unconscious.

Answer. The best interpretation of these and similar facts cited below seems to be gained by the study of attention itself. These facts certainly are true : whether

${ }^{1}$ On such phenomena in sight, see Wundt, Phys. Psychologie, 2d ed., vol. I. p. 435 and fol.

' Exner, in Pflüger's Archiv, vol. XI 
we call them unconscious or conscious is only a matter of words. They are of extreme value for psychology just for this reason, that they cast great light upon consciousness and its active form as attention. ${ }^{2}$ There is certainly a region of such extreme indistinctness in the conscious field, that when the attention is concentrated in another portion of that field, the former region is quite beyond supervision. Whether it becomes merely physical change, as no doubt is the case in retention, or whether it retains some slight degree of consciousness, which is capable, as we see in the more active forms of mental function, of all degrees of intensity, is a question only of area for empirical psychology. We know that the withdrawing of attention does weaken the intensity of consciousness, and that this weakening is proportionate to the intensity of attention elsewhere; so when the attention is fixed, concentrated, we would expect extremely slight degrees of consciousness in other portions of the field. Or the depletion of mind may be so great that the physical process is no longer sufficient to excite a mental reaction at all. In this case it is a physical fact and not a mental fact, and is not of psychological value except as all physical processes are of value as conditioning the rise of mental phenomena.

It is probable, therefore, that in such cases we have a condition of extremely diffused or weak consciousness. That we do hear the ticking of the clock, that the sailor is really conscious of the noise of the waves, and the miller of the sound of his mill, is proved by the fact that the cessation of these sounds is at once known. The child asleep in church wakes when the preacher stops. This shows that the preceding state of consciousness really included the prolonged excitation whose cessation is remarked, unless we hold with Bain that conscious- 
ness itself is change. So also with the sensations of walking. However unconscious they may seem to be, we notice immediately any change in them, as when we step upon different material. The sensations which arise in a limb when it is strongly attended to, are probably excited by the attention itself, and are due to impulses to movement, since the convection between attention and morement is so close that it is often impossible to separate them entirely. Sensations of blushing, for example, arise entirely from an inner feeling. These states do not seem to require, therefore, the doctrine of unconscious mind. The doctrine of "least consciousness" explains them sufficiently.

III. Arguments drawn from Synthetic Sense-perception. ${ }^{3}$ The argument for the unconscious drawn from perception turns upon the co-ordination of sensations in the ideal products, especially space and time. The intuition of percepts affords no basis for the doctrine, since the sensations upon which it proceeds are clearly conscious. We may take the visual perception of space, therefore, as affording the most plausible case. As we shall see in considering the perception of space, ${ }^{1}$ the synthetic activity of mind, in the reconstruction of space, proceeds upon two classes of physiological data. Both are presumed by this argument to have a mental value since the resulting percept space is mental. But we are not conscious of these sensation or their co-ordination; consequently in them we have unconscious mental states. The resulting product is a conclusion or inference made unconsciously. ${ }^{2}$

Answer. In answer to this argument it may be said:

a. That if this explanation of the perception of space be offered from an experiential point of view, i.e., on the ground that these sensations are all that is re-

${ }^{1}$ See discussion of perception, Chap. VIII, especially $\$ 4$.

${ }^{2}$ Helmholtz, Zöllner. 
quired, through associative co-ordination, to account for the perception of space, then from the very fact that the process is unconscious, we may argue that this is not the true theory of the origin of the notion of space. Granted that there are these physical data to any degree, local signs conscious or unconscious, muscular morements of the eye, feelings of central innervation, yet it is difficult to see how these intensive states can by simple co-ordination give extension. "Admitting differences in quality, we are asked to draw differences in position. A qualitative or quantitative difference in reds does not serve to locate one on the left and the other on the right.". The notes of an orchestra, which form an intensive series, are not arranged in space. And it does not help matters to add any number of concomitant sensations, conscious or unconscious, such as Lotze's slight sensations in the neighborhood of the point affected, and Wundt's "feelings of innerration." For if spacial co-ordination can arise from a second intensive series, it could as well arise from the first; and if not, wherein does the hypothesis help us? The adrocates of the unconscious say, this process takes place, therefore there are unconscious mental states; we may say, on the contrary, we are conscious of no such process, therefore it does not take place.

b. Again, if we maintain that, while there are physical stimuli which react mentally under the form of space and these data are the same sensational elements as those held by the empiricists in this connection, there is above this a native mental synthesis or reconstruction of these data ; we are still not shut up to the hypothesis of unconscious mind. For even though we admit that we are not conscious of these empirical elements, the law of accumulated excitation already cited may serve us here. That is, physical data of a certain complexity and strength 
may be necessary to the mental reaction for space, just as the physical stimulus for sight must have a certain complexity and strength. This requirement being unfulfilled, the stimulus remains physical and for that reason unconscions. It does not enter the domain of mind at all. Yet, as a matter of fact, we cannot admit that the empirical elements of space perception are quite unconscious. It is only by means of our conscious sensations that we have been able to determine these elements. Sensations of movement are qualitatively conscious, apart entirely from their local character; and, for all we know, sensations arising from specific points in the skin and retina, called local signs, may have the same conscious value. To say that after the formation of the space notion these sensations do not stand out in consciousness alone, is not at all to deny their essential conscious nature. The generalized concept arises also from individual empirical data, and the characteristics of the individual disappear from consciousness in the product; yet who would say that because the general notion tree does not bring into consciousness all the individual trees of our experience, the original sensations of trees had been unconscious? The difficulty, of course, is to go behind the formation of the spacial percept and see the data, as we can in the case of the general concept; but until this is done, who can assert that these data are unconscious?

IV. Arguments drawn from the Phenomena of Memory. A variety of empirical facts drawn from the varied aspects of the representative function are urged in support of the hypothesis of unconscious mind, facts which find a complete explanation in the proper understanding of the physical process which underlies the revival of presentations. These facts may be classed under sereral heads.

1. Facts of Memory. It is urged that presentations are unconscious between their experience and their rep- 
resentation. "The larger part of our mental riches," says Hamilton, " is hidden away in the obscure recesses of the mind." These facts find complete explanation in the physical theory of retention.' The reproduced image is not the original presentation, but a new production, a re-creation, depending upon the repetition of the physical and mental conditions of the original presentation. Consequently, during the intervening time between the two experiences the mental state has simply not existed.

2. Facts of Association. It is often the case that an association between states of mind is accomplished without conscious links of counection; consequently the links of connection must have been unconscious. Also that ${ }^{2}$ states are revived in consciousness of which we have had no conscious experience. Hence their first mental experience must hare been unconscious. Further, ${ }^{3}$ the brain must be the occasion of unconscious sensations, whenever the activity is reinstated which has already had a conscious accompaniment. Under all these forms of statement, and many others, the error already pointed out is plain. The assumption is made that a physical process of weakened intensity must produce a mental effect, if the same process of heightened intensity produces a mental effect. On the contrary, we hold that the weakened physical process produces no mental effect whatever; though it may serve, through its physical connections, to reinstate mental states. The missing links in broken chains of associations may be supplied from dyumic connections in the cerebral substance. The reproduction of the physical conditions of the last emerging image is sufficient to account for the revival of that image, by whatever means this physical reinstate-

I See Chap. IX.

- Lewes, Problems of Life and Mind, 3d series, p. 55.

Ibid., p. 165. 
ment be brought about: whether by a cerebral process carrying consciousness with it, or not. Indeed, as Mr. Mill conjectured, the successive modifications of the physical series may occur so rapidly that sufficient time is not given for the regular appearance of the subjective series and some links are dropped out. This conjecture is sustained by a law of psychometry, that, in such cases, the physiological process occupies less time than the mental. ${ }^{1}$ The production of new states, also, in old chains of association, is accounted for on the supposition that, in the revival, the physical basis of the new states is sufficient for consciousness, while in the first experience it was not. And there is no necessity whatever for Mr. Lewes' position that every subsequent reinstatement of a physical state once accompanied by consciousness must carry a sensation : it is only true when the reinstatement is strong enough to produce consciousness.

3. Facts of Habit. Further, habit is said to be a constant process of relegating to the unconscious acts which demanded at first conscious consideration and volition; as piano-playing, reading. All such cases are accounted for by a further development of the physical basis of reproduction. The simple fact that repetition of a given physical performance tends to establish physical dispositions which become automatic and mechanical, ${ }^{2}$ gives us at once a physical explanation of such habits. Volition, instead of being unconscious, is entirely wanting. Why bring it in when the physical mechanism is sufficient for the required act?

The inherent contradiction in terms of the expression "unconscious mental activity" is evident on its surface, and another name may be given to the large class of facts which it covers. Dr. Carpenter's " unconscious cerebration " is better,

${ }^{1}$ See p. 110.

${ }^{2}$ Cf. Wundt, loc. cit., 1r. pp. 203-5.

${ }^{3}$ Human Physiology, Phila. 1868, p. 589. 
if we understand cerebration to refer, not to the cerebrum simply, but to the sensorium as a whole. This emphasizes the physical nature of the process-which is really the only aspect under which we know anything about these facts. This whole field in its relation to consciousness has been well called the sub-conscious, from the fact that images formerly in consciousness have now fallen below the threshold, but mav again arise either when the stimulation of the centres is sufficient to draw attention or when the freeing of the attention from the point to which it was directed removes an impeding obstacle to the appearance of the image. Experiments by Fechner show that there is a point of lowest conscionsness for each of the senses: a least perceptible light, sound, etc. This is called the threshold value of the sensation. Let excitations of less strength be considered as unconscious or purely physical, all states which have appeared or may appear in consciousness as $s u b$. conscious, and all states at present before the mind as conscious; and for practical purposes this will serve to classify all the phenomena.

A further bearing of the law already indicated-that the organism tends toward activities already performed-should be remarked. By this law the results of experience, mental as well as physical, are turned aside from the supervision of the mind and passed over to the body, in the shape of refinements of nerrous structure. 'The mind is freed from masses of detailed activities which become organic and reflex. What was once pure intelligence now becomes mechanism. 'This results in permanent nodifications of structure which are handed down by heredity. ${ }^{1}$

It is difficult to see the utility of the hypothesis of unconscious mental states in psychology. It may have metuphysical value in two very distinct ways: 1st, as faroring a material theory of mind: for if the mental can ever be unconscions, why may not the unconscious be ultimately the ground of all the mental? And this is more clearly seen in the open view that such phenomena are distinctly organie although so closely interwoven with the mental. 2d. If all facts which form links in mental processes or produce mental products - us trains of unconscious cerebration ending in a conscions conclusion, or flights of musical or poetical genius-can be called unconscious cases of mental action, why may not the principle be extended to instinct, and design and adaptation in nature, and the conclusion of Hartmann follow?

Mr. Lewes' argument for the unconscious is based upon

'Cf. Spencer, Psychology, 192. 
a different conception of the matter of psychology. The essence of the mental to him is sentience, ${ }^{1}$ the capacity of tissue to react against external stimulus. Wherever, therefore, we find sentient reaction, there is mind, whether it be conscious or not, and whether it be in the human cerebrum or in the leaf of the sensitive plant. All reflex and automatic action is mental. This emphasis laid upon sentience leads him to urge that the general condition of the sensorium or nerrous system is often the determining fictor of our mental states. 'This last inference seems to be true, and needs reiteration. The entire neryous system is a single organ of sensation, and its present state is a history of its life and the life of its progenitors. Generations of unconscious experience are stored up in its present form. And unconsciously to $u s$ it gires tone and cast to our first impulses, directs the reviral of images, and determines the effect of feelings.

Conclusion. From the foregoing we conclude in harmony with our definition of psychology, that consciousness is the "necessary condition and abiding characteristic of mind." " Phenomena called " unconscious mental states" may be accounted for partly from the physical side, as excitations inadequate to a mental effect, and partly from the mental side, as states of least consciousness. Where, in the progressive subsidence of consciousness, these two classes of fact come together we have no means whatever of knowing. The phenomena are given their full psychological value, in the following pages, as we proceed. As Binet says, if there be unconscious mental phenomena "we know absolutely nothing about them." ${ }_{2}$

\section{\$3. Relative Theory of Consciousness.}

In the light of what precedes, a wide-spread but erroneous theory of consciousuess may be examined; the theory of the Relativity of Consciousness.

${ }^{1}$ Lewes, loc. cit., III. chap. viri.

2 Open Court. Jan. 24, '89. In addition to the references given in the course of the discussion and on p. 68 below, consult the articles by Pierre Janet in recent numbers of the Revue Plilosophique. 
Considered in its strict bearing upon consciousness and not in its implications for the general theory of knowledge,' this doctrine takes a twofold form: first, consciousness is considered as a Feeling of Difference or Change, and second, it is considered as a Feeling of Relation between $S$ ubject and Object.

I. Consciousness as a Feeling of Difference. ${ }^{2}$ Bain says" "we are never conscious at all without experiencing transition or change," "we know nothing in itself, we know only the difference that exists between it and something else," and "a change of impression is an indispensable condition of our being conscious, . . . every mental experience is necessarily twofold, . . . in every feeling there are two contrasting states." " "Consciousness," says Spencer, " is the continuous differentiation of its constitutive states."

While resting upon a large class of facts, this theory is not necessary for their explanation. It goes too far. It is undoubtedly true that change is a stimulus to consciousness. Stimuli long prolonged without change become less intense, and gradually so habitual that they are not observed; but as has been already said, we cannot call them unconscious. Change in such conditions tends to revive the state and make it intense. The most that can be said is that change or difference varies the degree of consciousness, not that it constitutes it. If the latter were true we would never be conscious of a prolonged sense stimulus; for however consciousness might be sustained in reference to other changing stimuli, it would not be sustained in reference to the particular stimulus which persists unchanged. But we are con-

'See Mill, Examination of Hamilton.

'Bain, Spencer, George, W. Hagen.

Senses and Intellect, 3d ed., p. 321.

4 Ioid., p. 9. 
scious of such prolonged states: the falling of the rain, the ticking of the clock, a fixed stare upon a motionless scene.

Again, this theory confounds consciousness with its content, or that of which we are conscious. Granted that change is a law of consciousness, we ask : change of what? Of sensations. Then sensation existed before the change and sensations are conscious. ${ }^{1}$ If it be replied that the sensations are unconscious, then we ask: how do you know that they are not physical? And if it be replied again that consciousness is a function of physical, cerebral, change, we ask again : how can consciousness be change when the change is not conscious? As a matter of fact the examples cited in support of this theory are changes in consciousness, that is from one conscious state to another. If this be meant, then consciousness could never have begun except through different simultaneous sensations. For example, we conld not be conscious of the change in color from red to blue unless we already were conscious of red, except when the difference arose from their coexistence, an alternative from which Mr. Bain, at least, is cut off. But even that alternative does not help the case, since granted a difference between two sensations, how do we reach a sensation of their difference?-a question to be urged in speaking of the higher forms of consciousness. A real difference is not the same as a perceived difference. ${ }^{2}$ We can conceive a consciousness in which real differences might not be perceived; the destruction of memory would accomplish this for successive states. Therefore if we are not conscious of the states that differ, how can we arrive at a consciousness of their difference? The

\footnotetext{
${ }^{1}$ Cf. Lotze, Logic, p. 20.

${ }^{2}$ A distinction partially recognized by Mr. Spencer, Psychology, I. pp. 164-5.
} 
feeling of difference is the content of consciousness, not consciousness itself.

The facts on which this theory rests seem to be explained by what has already been said about the unconscious. An excitation long persisting tends to become unconscious both from the withdrawal of attention, and the weakening of the central processes from exhaustion. It is difticult to keep the attention fixed steadily on one subject. It is soon drawn off, and as the mind becomes absorbed elsewhere, the former image falls into the subconscious. The organism, also, experiment readily shows, loses the elasticity of the first reaction, and its functioning is greatly enfeebled from the continued expenditure. A change in the conditions, however slight, draws the attention, at the same time brings new physical elements into play, and so stimulates consciousness. This is seen in the unconsciousness of ordinary sleep. It is produced by exhaustion of the body or by monotonous mental conditions which diffuse the attention. But slight stimulations are sufficient to produce dreams or even to awake the individual, and it is possible that a low state of conscionsness persists during sleep. ' In ordinary forms of hypnotism, the fixed monotony of impression proluces semi-unconsciousness for the same reason. Even in lethargy where consciousness seems completely suspended, it returns at a single physical excitation. If change at all be at the basis of consciousness, it is physical change; but still it is absurd to say that this change is consciousness.

2. Consciousness as the Foeling of a Relation between subject and Object. The second form which the general doctrine of the relativity of conscionsness takes, is as follows: every state of consciousness is a felt relation between the presenting subject and the presented object.

' See observations by Radestock, Schlaf und Traum, pp. 102-108. 
"Consciousness," says Mansel, "is possible only under the form of relation. There is no consciousness without the union of two factors ; and in this union, each is what it is only in virtue of its relation to the other." 1

This form of the relational theory is likewise erroneous. It overlooks the beginning of consciousness in child life and interprets only the contents of the adult mind. We have already seen, in speaking of method, that the early stages of consciousness differ from the later reflective stages in this respect, that there is a lack of the presentative or relational quality: a distinction which we find running through all conscious sensation. These states of pure subjective modification, having no reference to an object, such as simple feelings of pain, hunger, smell, are called affective as distinguished from presentative states." Of these states, this theory offers us no explanation whatever. The earliest child consciousness is probably simply a mass of affective states or a condition of general organic feeling, with no distinction between the me and the not-me. From this state the differentiating process of perception, by means of the presentative element of sensation, leads to the development of the consciousness of self and not-self. ${ }^{3}$

But this theory also confuses the necessity of real relation, with the supposed necessity of a felt relation. In order to sensation at all there is of necessity a subject and an object, and they must be related: but this relation does not enter into consciousness until the subject consciousness looks in upon itself, with its differentiating scrutiny. The distinction between early and late consciousness becomes emphatic in the lower animals. The snail and oyster probably have no consciousness of self as different from not-self. From this simple

${ }^{1}$ See Renouvier, Essais de Critique, I. ch. III ; also Spencer.

${ }^{2}$ See Chap. VII, $\$ 1$.

${ }^{3}$ See Chap. VIII. 
state of feeling in the young child, the human self-consciousness is built up by known laws of mental growth. The two stages of conscionsness may be called therefore respectively simple and reflective consciousuess.

The theory that consciousness is a relation is part and basis of the theory of the relativity of knowledge in general. And the general theory of relativity has its most important psychological application in the doctrine that conscionsness is change in its constitutive parts. The question of external reality, as given or not in perception, is not affected by the theory of relativity, however, since, on our own contention that consciousness is immediate awareness of individual presentations or sensations, we are still unable on purely psychological grounds to pass beyond these to any reality apart from perception. The nature of external reality does not concern us here; yet it is interesting to note that it is not with relativity only that the realist has to contend, but with any critical theory of consciousness. And in this dispute, as will appear later, it is the notion of force which affords greatest support to a doctrine of philosophical realism.

The fact that in the developed or reflective conscionsness the differentiation of subject and object is always present, that is, self-consciousness is distinguished from the consciousness proper of things, leads us to look upon consciousness as an individual possession. My consciousuess is my own and no one's else; and we know of no conscionsuess which includes all individual consciousnesses. "Universal consciousness" does not exist as far as empirical psychology is concerned. If used at all, it means only what is common to individual consciousnesses. So reflective conscionsness is the differentic of self, that which distinguishes me from all other thinking beings. It embraces simply the circumscribed area of my own experience considered in reference to myself.

$$
\text { R \$ 4. Area of Cossciorsness. }
$$

The area of consciousness is the sum of the presentations at any time in consciousness, whether they be distinct or vague. Experiments show that twelve to fifteen strokes of a pendulum can be held in consciousness at once without counting or grouping. If they be grouped by fives, as many as forty may be re- 
tained. The most favorable interval betwen them is .2 to .3 secoud.' Consciousness may be likened to the visual field in which objects are scattered, those being most clearly seen which are in the line of direct vision or centre of the field, and those which lie near the circumference most indistinct. Between these limits there are all degrees of distinctuess. So ideas are distinct or vague in consciousuess according as they are in the line of mental vision, or attention. The idea attended to is most distinct, those connected closely with it in any way less so, and those which are accidentally present and quite unobserved actively, least so. According as they lie in one or other locality of this general distribution, consciousness of them is said to have different degrees or forms.

Degrees or Forms of Consciousness. These may be illustrated by an example. As I write, the noise of my pen is quite unnoticed. By the law of change, already spoken of, it tends to become indistinct. If continued some time, it is no longer heard and is said to be subconscious. If, however, I am suffering with headache and noises irritate me, the scratch of the pen becomes painfully noticeable. The same is the case if the pen is a poor one and scratches more as used. But absorbed in my thought, I continue to write though conscious of the disturbing noise. It is then said to be in a state of passive consciousness. Thus a thousand things around us, the table, chair, books, are present to our minds, but we are passive in regard to them. If now I am led to direct my attention to the noise of my pen and to examine the point in order to remedy it, there is an active putting forth of mental energy - a conscious expenditure of inner force. This is active consciousness or attention, and the process by which the attention is concentrated upon the image is apperception.

' Dietze, Phil. Studien, III. p. 384. Cf. Ladd, loc. cit. p. 494. 
It is well to note the play of ideas through all these forms of transition, from the dark region of subconsciousness, to the brilliant focus of attention. Images pass both ways constantly, acting varyingly upon one another and making up the wonderful kaleidoscope of the inner life. ${ }^{2}$

Apperception. Apperception is the highest and most comprehensive form of active consciousness. By it is meant that activity of synthesis by which mental data of any kind (sensations, percepts, concepts) are constructed into higher forms of relation and the perception of things which are related becomes the perception of the relation of things. "The two presentations $a$ and $b$, , says Lotze," constitute simply occasions whereby the reaction of a spiritual activity is aroused, through which new presentations, such as similarity, identity, contrast, arise, presentations which would not be possible without the exercise of this new spiritual activity." The relation of percepts is not the same as the perception of relation. Apperception is the comprehensive "power of discovering relations;" but is not limited to the operations of thought. It is the essential mental act, as shall appear, in the three great stages of mental generalization, perception, conception, and judgment.'

The use of the word apperception in recent psychological treatises to express the broadest act of mental relation, is of great importance and value. The treatment of the very distinct and familiar act of mind in attention, of grasping details, detached and meaningless, and relating them to one another in a new mental product, has heretofore been confined to its special operations, as perception, conception, judgment, to each of which a different name was given. The phrase apperception singles out that act of mind which is common to them all-the relating activity of attention-and

' See diagram. p. 68.

Outline of Prychology. \$ 23.

${ }^{3}$ Cf. Martineau, Study of Religion, p. 194, nnd Inurie's distinction between attuition and intuition; Metaphysica noov et votusta. 
thus, by its general application, emphasizes the unity of the intellectual function as a whole. In general, we may say, whenever by an act of attention mental data are unified into a related whole, this is an act of apperception. ${ }^{1}$

\section{§5. Develophent of Consciousness.}

The beginnings of consciousness are enveloped in great obscurity. Shortly after birth a child begins to show signs of memory and of the power of connecting impressions. But both the memory and power of association are very weak and depend upon intense degrees of excitation, as a very bright light or a very loud noise. When the child is several months old, a familiar person is forgotten after a week's absence. Gradually attention is discovered, at first vague and discontinuous, and after a few weeks, voluntary. ${ }^{2}$ This is shown earliest for sight and touch, the two senses which discover space relations. It is probable that the earliest consciousness is a mass of touch and muscular sensations experienced in part before birth, and that it is only as the special senses become adapted to their living environment and sensitive to their peculiar forms of excitation, that the general organic condition is broken up and the kinds of sensation differentiated. The power of visualizing or forming permanent images in memory for sight is developed from the fifth to the seventh year. ${ }^{3}$ This process of differentiation of the sensations of touch and the muscular sense gives us very early the form of our own body, and the locality of its parts, and this serves as point of departure for the placing of external objects. The movement of the body contributes largely to the apprehension of the dimensions, forms, and areas of things in space. The movements of the body are at first random and without

${ }^{1}$ On apperception, in general, see Wundt, loc. cit. p. 219.

\& Perez, First Three Years of Childhood, p. 25.

${ }^{3}$ Cf. Jastrow, Princeton Review, Jan. '88, art. Dreams of the Blind. 
control, arising from nerrous discharge under conditions of physical discomfort. They gradually take on a purposive character, but even after two or three years it is difficult for the child to execute any given combination of movements. This fact of control of the body seems to be the first beginning of the exercise of will. It involves a subjective reference more distinct and peculiar to itself than any of the purely affective sensations, and leads to the notion of the $I$ and so to self-consciousness.

The derelopment of conscionsness is largely dependent upon the development of the physical organism. The senses must be awake to their functions before the mind can exhibit its functions. Not till the eves are open and in proper morement can the impressions of that sense begin to play their very great rôle in the forms of external perception." So also must the centres become accustomed to their reactions. If we liken the elective activities of the developed nerrous system to lines of least resistance, we may say that, for the very young child, such organic pathways are entirely wanting and they must be established and maintained by actual exercise. These early physical modifications becoming more and more definite and multiplied, the more complex forms of mental function are made possible. Like other organs of the body, also, the brain grows in size and complexity. It attains its largest size probably much before the maturity of manhood; but its structural development, which consists in the differentiation of parts for special functions and the establishment of various connections throughout its bulk, is then hardly begun. The basal ganglia seem to develop their activities earlier than the cerebral hemispheres. This is to be expected, since they are connected with the organic and essential processes of the body.

The relative value of different images in the early stages of mental growth is illustrated by the following experiment made by the writer upon a girl six and one-half months old. The child's nurse, who had been with her for five months, was absent for three weeks, and on her return was not recognized by her face alone, nor by her voice alone (spoken words), but was fully recognized by sight (face) and sound (nursery rhyme)

\footnotetext{
' See Chap. VIII.
} 
images together. This case illustrates also the theory of recognition advanced below, ${ }^{1}$ i.e. that the degree of complexity of a presentation indicates the degree of recognition it arouses when reproduced.

On consciousness, consult : in general, McCosh. Cognitive Powers, bk. 1, ch. II: Hamilton, Metaphysics, Lect. IX, XI-XIII, and XV; Fortlage, System d. Psychol., ş 6-13 and 93-94, also Beiträge zur Psychologie, \$ 15; Drobisch, Psychologie, §\$ 55-57 and \$ 29; Waitz, Lehrbuch d. Psychol.. \$s 57-58; Volkmann, Lehrbuch d. Psychologie, \$ 105-116; Ladd, Physiolog. Psychol., p. 585: Porter, Human Intellect, pp. 83-119; George, Lehrbuch d. Psychol., pp. 222-234; Brentano, Psychologie, bk. 2, ch. II-Iv; Wundt, Physiolog. Psychol., ch. Xv; Mansel, Metaphysics, pp. 33-66 and 183; Lotze, Microcosmus, bk. 2, ch. I; Rabier, Psychologie, chap. vi and viI ; Bain, Senses and Intellect, pp. 325-339; (area of) Paulhan, in Revue Scientifique, May 28, '87.

On consciousness and the unconscious: Carpenter, Mental Physiol., chap. xiII; Brentano, Psychol., bk. 2, chap. II (of especial value); Lewes, Problems, 3d series, pp. 143-196; Fortlage, Beiträge zur Psychol., p. 164; Porter, Human Intellect, \& 87; Hamilton, Metapliysics, Lect. XVIII; Ardigo, Rivista di filosofia scientifica, Jan. '88; Colsenet, La vie inconscient de l'esprit; Janet, Revue philosophique, xxII. p. 577; Sergi, Psychologie Physiologique, bk. 3, chap. I; Nill, Examination of Hamilton, chap. viII-IX, also chap. xv; Hartmann, Philosophy of the Unconscious, C; Lipps, Grundthatsachen des Seelenlebens, p. 125; Radestock, Schlaf und Traum, pp. 284-287.

Further Problems for Study:

Rise of consciousness;

Animal consciousness;

Theories of consciousness;

Higher forms of consciousness.

1. The Unconscious (physiological).

2. The Subconscious.

3. Passive (or diffused) Consciousness.

4. Active Consciousness or Attention.

5. Apperception.

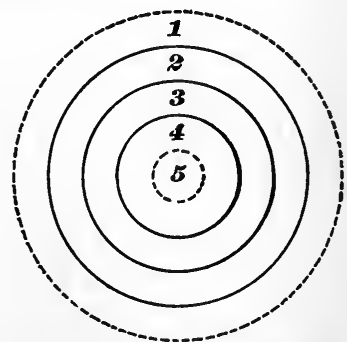

Graphic Representation of Area of Consciousness, after Analogy with Vision (see pp. 63-65).

${ }^{1}$ Pp. 176-8. This case is reported in Science, May 22, 1890, p. 74. 


\section{CHAPTER V.}

\section{ATTENTION.}

\section{\$1. Definition of Atrention.}

Is the consideration of consciousness, a difference was found in its general aspect according as a number of presentations were loosely scattered about its field or as some one held the mind directed to itself. Consciousness is thus passive or active. Active consciousuess is in general attention. It is the act of holding a presentation before the mind. It is in all cases a conscious act. What goes on in the relating of this presentation to others, in their combination, dissolution, arrangement, is due to the activity of apperception, which is, in a large measure, mechanical and subconscious : but the attention which makes the activity of apperception possible is known at once.

Attention as Mental Energy. The most essential peculiarity of attention is the feeling of expenditure which its exercise occasions in the mental life. Mental exhanstion and fatigue invariably follow a more or less prolonged stretch of the attention. Mental states may play for an indefinite period in consciousness withont impairing our mental freshness and vigor, provided the attention is not directed to them. Further, it may be said, indulgence in air-castles, day-dreaming, and rambling meditation, is a means of recovering intellectual freshness after a strong effort of attentive thought. This results from the diffusing of the attention orer a very wide field and relaxing control of the flow of ideas. 
This fact in its bearings upon the mental life, as they shall appear in the course of our exposition, leads us to see in attention the only exhibition of mental energy as distinguished from mental states : and in the consciousness of this abiding energy we find the ground of mental unity and personality.

Reflex or Involuntary Attention. Upon observation of ourselves we find that attention may be stimulated either from some foreign and unexpected source or from the will. A loud noise, a violent contact, a disagreeable odor, at once attract the attention without our volition or even against it. This is reflex or involuntary attention. In the normal state of the consciousness, attention is constantly open to appeals of this kind. Minds with little power of will live under control of such external excitation. The attention is drawn hither and thither in rapid transition with no fixed concentration upon any sensation or idea. In such minds, as we shall see later, the functions of apperception are disturbed, and its products unstable. This state of inability to hold the attention against other solicitations is called distraction: the attention is, as it were, drawn apart in its efforts at adaptation to different conditions.

Another form of involuntary attention is found in cases of insistent ideas. ${ }^{1}$ It very frequently occurs in normal life that a single idea, either by reason of a strong association or of a feeling, or because of previous attention, or even in consequence of the very effort of the will to banish it from consciousness, remains before the mind and holds the attention. This is called an insistent or, in its more intense forms, fixed idea. It is generally removed by a change of scene, companions,

${ }^{1}$ Called in German Zroangvorstellung: from Krafft-Ebing. See art. on Attention by Ribot, Revue Philosophique, Feb. '88. Cf. George, Lehrbuch d. Psychologie, p. 374 and fol. 
and surroundings, the old association being broken or new ideas claiming the attention. As an ilea becomes fixed or imperative, it gathers round it other ideas in growing associations and connections, which soon give a morbid tone to the entire mental life. This is the beginning frequently of monomanias and permanent delusious,' which become chronic in insanity. Frequently also, it is supposed, the primary tendency to some form of nerve disturbance or brain disease, due to heredity, gives occasion and strength to such derangement.

The mechanical uature of involuntary attention and its intimate relation to all physical and mental states is seen in the acts of a patient in a state of hypnotic hallucination. Here it seems that the element of will is entirely eliminated. The patient has absolutely no control over either body or mind, and any suggestion either physical or mental from the hypnotizer is immediately realized in action. It seems only necessary that the attention should be secured, to start the entire train of apperceptive processes with the physical changes which are associated with them: or a physical attitude or movement may be forced upon the patient, only to be followed by all the emotional and intellectual states it suggests. In these states, the intellectual life seems quite normal and the emotions are very excitable and facile in their play ; but all inner control is lost. Action results with complete necessity. The important fact in this form of hypnotism then seems to be the fixing of an idea till it becomes imperative, with the general subjective state unchanged by the substitution of ideas which it brings about.

Voluntary Attention. In strong opposition to this is voluntary attention or attention proper. It may be defined as a state of active consciousness due to voluntary

'See case described by Cowles, Amer. Jour. of Prych., Fob. '88. 
mental exertion or effort. Here a distinctly new element enters into consciousness, mental effort. In voluntary attention we find the first exhibition of will. It is the beginning of all control over the mental life. A thousand things may appeal to me for consideration and I may refuse them my attention. I may give myself to a train of thought and be substantially unconscious of sounds, sights, contacts which would ordinarily excite my attention. It is thus in the familiar condition of $a b$ straction or absent-mindedness. This peculiar outgoing of the self is the something we call consent, in the mental life. From it we first arrive at consciousness of self, by a reference of what we do, to ourselves as doing it. It makes possible, as will appear later, the fixing and connection of ideas in the higher forms of thought.

The frequent or prolonged exercise of attention to the same presentation or idea tends to bring it involuntarily before the mind. Its repetition in varied circumstances establishes various associations by which it may be revived. Insistent and fixed ideas usually become so from voluntary thought upon them-from what we call " brooding" over a subject. Thus the line between reflex and voluntary attention is changed and much that was before a matter of choice becomes automatic and necessary.

\section{§ 2. Bearings of Attention in the Mental Life.}

In its relation to the great classes of mental facts, the attention is of the first importance. In general it may be said that attention intensifies a mental state. It may be considered more particularly and in detail.

$R \quad I$. Relation of Attention to Sensation. There is a twofold or reactive relation between attention and sensation. On the one hand, increased intensity of sensation draws. the attention. The change in intensity of the sensation is 
a direct stimulus to the attention, by forcing its appearance in consciousness : and the attention in this case is reflex. On the other hand, attention directed to a sensution increases its intensity. We have already seen that many sensations may lie in consciousness almost unfelt, while the attention is otherwise occupied. It is only necessary to direct the attention to them to give them their full force. But more than this, the attention may give them increased and rery acute intensity. By fixing the attention upon bruises and burns, we increase the pain they give us. Hence the efforts we make to divert a sick man's attention from the seat of his disease, by fixing his attention on some new artificial sensation, or by interesting him in another topic of conversation. Hot cloths relieve headache, by producing a counterirritation. This effect of the attention is especially great in nervous diseases. Paralysis has been cured or driven from limb to limb in hypnotic patients by a mere suggestion, which so completely occupied the attention as to induce belief in the effect. So insomnia and sometimes dyspepsia and other diseases may be cured.'

Attention has an influence also upon the time occupied by a sensation. Experiments show that a certain time is necessary for the feeling of an excitation from any of the sense organs and the reaction in the movement of the organ. This time is greatly reduced when the excitation is expected. ${ }^{2}$ A certain time seems to be necessary for the adjustment of the attention to the nature and source of the stimulus, and this is reduced when the idea is present beforehand and the attention is already partially adjusted.

II. Rolation of Attention to Movement. The movement of the members of the body is very closely connect-

isee Albert, Beitrag zur therapeutinelien Vericerthung des Hypnotio mus, and Aner. Jour. of Paychol., II. 2, sect. on Hypnotism.

'For details, see section on Paychometry (Chap. VII, \& 6). 
ed with corresponding ideas. No voluntary movement takes place without its idea in the mind: and often the idea produces the morement without any voluntary impulse or even contrary to it. ${ }^{1}$ The imitative faculty of children shows this tendency to carry out all movements thought of. We often find ourselves following the morements of the hands or lips of a speaker with slight movements of our own. It is probable that no word comes into the mind without its partial formation by the vocal chords, as is seen in the movements of the lips by many in reading to themselves and in our thinking aloud. No doubt the physical association involved plays a great rôle in all such cases. The thought of a movement has preceded and led to the movement so often, that there is a positive tendency, at the nervous centres, to the discharge of the energy necessary to the accomplishment of the act, along the proper courses. The act of will, then, seems to be selective and directive of this energy of nervous discharge.

This tendency to movement is greatly increased by the exercise of attention. The attention tends to bring the idea more distinctly before the mind and thus removes all competing ideas which should incite to different movements. This is especially the case when the attention dwells upon the organ or on the thought of movement. There is then a twofold effect due to the attention. It tends to develop latent sensations, as we saw above, in the organ, and these sensations lead to movement for their relief or continuance; or it produces movement by the distinct purpose to perform an act thought of. For example, if the picture is vividly presented of a workman who has his thumb crushed by a hammer, we make instinctive movements to protect the thumbs, by folding them in the hands.

${ }^{1}$ Féré claims that every sensory excitation at first induces an augmentation of motive force which is measurable on the dynamometer. 
The facts of hypnotic suggestion already spoken of show the automatic connection between an idea strongly attended to and its physical performance. The absence of will does not destroy the power to perform the action, but only the power to prevent or direct it. The consciousness is so contracted in this state that each idea in turn is held in the focus of attention.' .

\section{Relation of Attention to the Intellect. Attention,} either voluntary or reflex, is directly involved in the operations of the intellectual functions. It is the merit of the French philosophers of the spiritualistic school to have brought out the fact that volition enters in the most primitive forms of intellectual synthesis." In general, it may be said that attention increases the vividness of representative states and thus renders more definite and lasting the apperceptive activities of syuthesis, aualysis, relation, as seen in memory, association, judgment, and reasoning. It is necessary, first, to the retention of images. The capacity to retain mental pictures depends upon the intensity of the original presentation, and the clearness of its relations; and this intensity and clearness are enhanced by the attention. The supply of materials which we have for use in the higher forms of thought depends at once upon our attentiveness to what passes before us in our every-day life. When we wish to retain any event, we press it upon the attention and note its surroundings. Second, attention increases the intensity of the reproduced image in the same way. If we recall the face of a friend, it is, at first, dim and indistinct, but by holding it closely before us and scrutinizing it, we can bring it clearly out in more detail. The attention shifts rapidly from point to point upon the

1 On the motor accompaniments of altention, and its affective bases, see Ribot, Prychologie de l'Attention.

'Cf. Part IV, on the Will. 
image. Third, the duration or time of all mental states, as of simple sensation, is made shorter by attention, as is seen in experiments on the association of ideas and estimation of differences. ${ }^{1}$

In the view of some, the higher processes of the intellect, depending as they do upon the active principle of attention, are forms of the activity of attention. ${ }^{2}$ So Prof. Wundt in his doctrine of apperception as a relating activity, which is at once a form of will. It cannot be doubted that it is only in and through attention that mental synthesis and elaboration take place, yet it seems truer to the facts to separate voluntary attention from this process. Apperception can then be used for the generic activities of synthesis and relation, which take place through either reflex or voluntary attention. Wundt fails to discriminate sufficiently between reflex and voluntary attention in his doctrine of apperception. ${ }^{\circ}$

IV. Relation of Attention to Feeling. ${ }^{4}$ Attention has the same intensifying influence upon the affective states in general as upon sensation. Emotion is heightened when the attention is directed to it. Hope, joy, fear, anger, grow very greatly in intensity when thought of, and as quickly die down when dismissed from the attention. With the higher emotions it is very difficult to control the attention, so thoroughly do they usurp the field of consciousness. So, also, pleasure and pain, called the tone of feeling, are increased by being attended to and diminished when the attention is withdrawn.

The especial relation existing between the attention and the feeling of interest has often been remarked by psychologists. This feeling of interest is often akin to that of personal advantage or individual preference, which we find playing an important part in the flow of our associated ideas. It gives a spontaneousness and

${ }^{1}$ See Chap. VII, $\$ 6$.

' See Lotze, Metaph., $\$ 273$.

${ }^{3}$ Cf. Volkmann, Psych., pp. 191-2.

Attention as a form of will is treated under Will. 
ease to the attention which renders the latter more effective and less wearisome to the inner life. Attention to that which interests us does not demand the outgo of mental effort.

\section{Relation of Attention to the Bodily Functions.} Attention long directed tends to derange the automatic functions of the body. The automatic functions are those which go on unconsciously to ourselves. The action of the heart is accelerated by being closely attended to. The digestive apparatus may be deranged by being watched, and so also may the breathing process. Attention is also accompanied by certain attitudes of the body, such as turning the ear or eye in a given direction, bending forward, frowning, and other muscular contractions. A feeling of tension also is felt in the end organ. This teuds to show that it is the motor elements of the brain which are involved in attention, while the effect it works upon the sensation shows a sensory modification following upon the other.'

\section{3. Edccational Bearings of the Doctrine of Atrextion. ${ }^{2}$}

Training of the Attention. The considerations already advanced tend to show the importance of the attention in education. The secret of the case rests upon making attention completely voluntary. Strength of thought depends very largely upon the voluntary control or concentration of attention, in such a way as to prevent distraction from accidental and unexpected influences. This training of the attention should begin at the earliest possible period. The child should be taught to observe continuously some thing that interests him,

' Cf. Ladd, Phys. Prychology. Pp. 538 and 542, and Wuvdt, Ibid., 11. p 210.

'C1. Sully, Outlines of Ixychology, p. 103. 
and encouraged to ask questions about objects and their relations. In very early life these things should be left to his own selection, until the law's of apperceptive synthesis are developed, that is, until he learns somewhat to connect things and events and see their bearings. Otherwise the forcing of the will may interfere with the development of the emotions, which are then the controlling factor. But as soon as practicable, the teacher should attract and hold the child's attention, at first to pleasant things and afterward to indifferent things. Great care should be exercised in the general surroundings. All distractions, such as open windows, pet animals, playthings, should be guarded against: they practically call upon the child to attend to several things at once. Care should be taken also not to fatigue the attention. The periods of study had better be too short than too long; for if the child grows tired, the effort becomes painful and the subject distasteful. Frequent recesses should be given and recitations should not be longer than fifteen to twenty minutes, for children under twelve to fourteen years of age. The child's interest should never be allowed to flag.

Habits of Attention. In this way regular habits of attention may be formed very early, which have the same force in life as all other habits. Attention thus becomes application, which is voluntary and agreeable: and with this basis the student has no trouble in devoting himself to subjects of thought for longer periods.

A caution is perhaps in order, as to sameness in the kinds of instruction given in early life. It is well that the same general cast of thought should not engage too much of the early attention of the student. It gives a bent to all his subsequent development. John Stuart Mill is a good example of this. It is especially dangerous when it involves the emotional side of our nature. 
Religious teachers use this fact not only properly to instruct in morality and religion, but also to excite early prejudices and repulsions which can never be shaken off. Nurses often give children associations of fear which persist through life. This is the origin, frequently, of the insistent ideas spoken of, which intrude themselves upon us and make many of us to a degree hobbyists and monomaniacs.

Attention Necessary to Apperception. As will appear later, it is only in and through the attention that the apperceptive function of mind comes into play. In its discriminating, selecting, and relating results, the concentration of attention is called apperception; but the active forceful process which produces these results is the attention. Attention and apperception seem to be the subjective and presentational sides respectively of the same mental fact.

On the attention, consult: Wundt. Physiologische Psychologie, II. p. 205 ; Carpenter, Mental Physiology, ch. III ; George, Psychologie, pp. 84 and 538-542; Waitz, Ielirbuch d. Psychologie, \&55; Hickok, Mental Science, pp. 66-72; Fortlage, System d. Psychologie, p. 100 and $\$ 36-47$; Ribot, Psychologie de l'Attention; Obersteiner, Brain. I. p. 439 ; Cappie, Brain. IX. p. 196 ; Sully. Outlines of Psychology, ch. Iv ; Dewey, Pyychology, ch. Iv. \$ 5 and his references, pp. 154-5 ; Ladd, Phys. Psychology, pp. 538-42 ; Stewart, Philos. ophy of the Human Mind, pt. 1, eh. II : Lewes, Problems of Life and Mind, 3d series, p. 184 ; Bradley, Mind. July, 1886.

On apperception: Waitz, Grundlegung d. Pych., p. 77 ; Wundt, loc. cit. ch. xvı, and Logik, I, pt. 1, ch. II ; Erdmann, Vierteljalirschrift firr urissenschafiliche Philosophie, x. p. 320 ; Lange, Pliilneophische Studien, Iv. 3; Dewey, Rsychology, pp. 85-90; Ribot, German Psychology, p. 220; Lotze, Metaphysic, bk. 3, ch. III ; Stande, Philosophische Studien, i. p. 149 ; Volkmann, Lehrbuch d. Pychologie, ह8 110-114.

Further Problems for Study :

Physical accompaniments of attention ; Affective or emotional basis of attention ;

Accommodation of the attention to its object;

Relation of voluntary attention to will. 


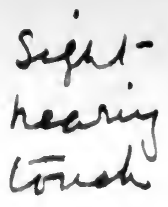

Preaplin

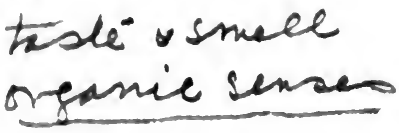
Intrition

PART II.

INTELLECT.

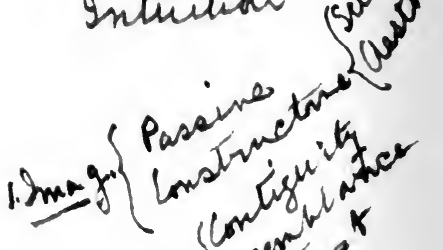

\section{CHAPTER VI.}

DIVISION OF THE INTELLECTUAL FUNCTIONS.

THE Intellect is the faculty of knowledge. It includes the following functions :

I. The Apperceptive Function, which in turn comprises :

1. Presentation or Acquisition, being

a. Sensation; +

3. Perception.

2. Representation, being

a. Conservation or Memory;

b. Combination;

c. Elaboration.

II. The Rational Function.

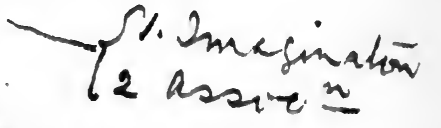

$\S 1$. Demarkation of the Functions.

I. The Apperceptive Function. Under this function are included all those operations which take place under the activity of apperception ; those which owe their product to an active spiritual synthesis. ${ }^{2}$

The function of Presentation or Acquisition is that by which the material of knowledge is gained. It covers

${ }^{1}$ See the definition of apperception, Chap. IV, $\$ 4$. 
the two sources of our knowledge in experience, Senseperception and Self-consciousness.

The function of Representation, as the word implies, is that by which the material acquired in Presentation is retained, reproduced, and intelligently used in the processes of mind. Its operations are considered under three great heads : $a$. Conservation or Memory, which includes the Retention, Reproduction, Recognition, and Loculization in time, of Representations ; b. Combination, which is the disposition of these reproduced states in the new forms of the Imagination, the law of its disposition being Association; c. Elaboration, which is the function of intellect proper, constituting the operations of Thought. Under it we find again three mental stages, Conception, Judgment, Reasoning.

The Elaborative function is further distinguished from the other apperceptive functions as being discursive, rather than sensitive. The sensitive operations are more closely connected with the known conditions of the bodily organism and are common to man and the animals. The Elaborative and Rational functions, on the contrary, show a free development of mind away from the data of sense and thus seem to distinguish man from animals.

II. The Rational Function. All the foregoing operations, both presentative and representative, are subject to a law of universal validity, the law of Identity or Noncontradiction. And the intelligence when exercised upon things in general is governed by the principle of $S$ ufficient Reason. As judgments these principles are also apperceptive, but they are not contingent upon experience, as other judgments are. These with other principles of the same uature, as causation, right and wrong, run through all knowledge and constitute the Reason. 


\title{
THE APPERCEPTIVE FUNCTION.
}

\author{
PRESENTATION.
}

\section{CHAPTER VII.}

SENSATION.

\section{§1. General Nature of Sensation.}

Sensatrons are the primary events of the mental life. They are so called because they arise timrough the senses. We use the word in its usual sense, as meaning the great body of psychological phenomena, both affective and presentative, which result within the mind immediately from impressions upon the senses. The presentations of moisture and resistance which follow from contact with a piece of iron, and the pain felt in case it is hot, are equally sensations.

There are several meanings given to the word sensation, two of which are strongly upheld in opposition to the meaning given above. Sometimes it is applied to phenomena purely physical, that is, phenomena without consciousness. Claude Bernard and Lewes speak of the sensibility of living tissue, meaning to express the fact that living tissue has the property of contracting under excitation. Mr. Lewes" says that "reflex action is a sentient process," and Gerdy ${ }^{2}$ defines sensation as "the change that takes place in the organ affected under the influence of an excitation." But the use of the words sensation and sensibility in this sense is quite unwarranted. Usage requires the limitation of these words to the facts of conscious-

1 Prob. I1, 3d series, chap. virr.

${ }^{2}$ Les Sens et l'Intelligence. 
ness. To apply them to facts of the physical order, to designate by them a property of unconscions matter, is to enlarge the domain of psychology, with Lewes, until it loses all characteristic limits and becomes a department of biology. For such phenomena the words impression, contraction, contractility, may be used, but not the word sensation.

But eren with this limitation, another meaning is often given to sensation; it is used to designate pleasure and pain, as they follow the excitation of the sense-organs. In this case the word perception, which is contrasted with it, is used to signify the qualitative element, as sound, color, which results from the impression. In this sense, sensation is exclusively an affectire and never a presentative phenomenon. The distinction is a true one, in fact, and is alwars to be made; but we cannot use the word sensation to designate pleasure and pain alone. We shall find another term, as used in current discussion, to cover this distinction. ${ }^{1}$

From whatever standpoint we approach the subject, it is universally confessed that experience gives us the first elements of knowledge. Sensations are the beginning of experience, and it is by sensation that we must begin the study of the intelligence.

Distinction between Sensation and Impression. Sensation being thus defined, it must be carefully distinguished from the physical phenomenon which precedes or accompanies it. The impression is the modification of the organ, especially of the nerves and nervous centres, which arises from an external stimulus; as the vibration of ether or air. The nature of the different sense impressions is not well understood; but in each case they are some form of movement. They have all the characteristics of physical phenomena: they can be localized, measured, apprehended by the senses. Sensation, on the other hand, both affective and presentative, cannot be compared with movement of any kind. The difference between them is plainly seen in the fact that an impression may take place without any sensation. The impression may be too feeble, or too prolonged, or too

' For the different meanings of the word sensation, sec Hamilton's Roid, Note D. 
often repeated, as the irritation of our clothing, to which we are habituated: or the attention may be occupied, so that the impression does not produce its usual sensation.

Affective and Presentative Elements in Sensation. In most sensations there is a distinct knowledge element over and above the intensive subjective state, which constitutes the sensation proper. There is an element of knowledge of things without us or of our own bodies. This is the presentative or perception element in sensation. It is often called "original perception" in distinction from the "acquired" or, as we shall say, synthetic perception of objects in their completeness in space. There are great differences in sensations in this respect. And it seems proper to divide the senses into three classes, according as the presentative element is prominent or not. ${ }^{2}$ First the sensations of the inner organs of the body, called organic sensations, and of passive touch and temperature; then sensations of taste and smell; and finally sensations of hearing, sight, and active touch. In the first class the affective element predominates and seems to constitute the whole sensation. In the transition to the second class, and finally to the third, this element disappears by degrees, while the presentative element increases. In the organic sensations, we have no appreciable knowledge, but in sight and hearing we may have much knowledge and very little feeling. Hamilton announced the law, already anticipated by Kant, that the two elements vary in inverse ratio-which is true in a very rough way."

The question as to where perception begins in distinction from sensation is very difficult. It seems to be true that in

1 See McCosh, Psychology, vol. r. p. 28.

? J. Lachelier, Cours inédit.

3 Anthropologie, p. 139.

- Metaphysics, vol. Ir. xxiv. 
most sensations there is a vague awareness of a not-self, to which the sensation is referred, as opposed to self.' Under this aspect we call the phenomenon perception; while considered as a modification or experience of the self alone, it is seusation. It is really the same fact looked at in two ways. M. Rabier's limitation of the affective element to pleasure and pain camnot be upheld; since a sound may be purely affective whether pleasurable or painful or neither, as a loud unlocalized and unrecognized sound. Pleasure and pain are purely affective, but they are not the whole of the affective quality of sensation. The relation of the two elements in the different senses will be spoken of under the various kinds of sensation respectively.

\section{§. 2. Characters of Sensation.}

All sensations have certain general characters, which are subjected to investigation. These characters are four in number.

I. Quality: that property by which sensatious are distinguished as coming from different senses, such as color, sound, taste.

II. Quantity : meaning intensity or mass of sensation. Investigations in intensity constitute Psychophysics.

III. Duration: the time occupied by the sensitive function with its accompanying physical and volitional processes. Investigations in this field constitute Psychometry.

IV. Tone: the pleasure or pain which accompanies all sensation. These characters are considered in order.

\section{3. Quality of Sressation.}

There is much uncertainty as to the proper classification of the sensations. It appears very easy to discover at once what is immediately given as a pure and simple sensation. But it is not so. At the age of maturity, when oue is able to make an analytical study of his sen- 
sitive states, he finds them no longer in that pure and primitive state which he would wish. They have undergone a twofold alteration. In the first place, all our senses act together, and different sensations, by virtue of the laws of association, are integrated as one. And further, by virtue of the same laws, intellectual elements are superposed upon our sensations, making them much more complex. These associations become, after time has made them habitual, almost indissoluble. So that it is very difficult to isolate the different sensations from one another, or the great body of sensitive data from the contributions of reason and experience. Hence observation is not sufficient. As we have already seen, recourse must be had to experiment for the production of artificial conditions; and to abnormal cases, such as when one of the senses is wanting from heredity, disease, or accident.

Smell. The complication of data spoken of may be illustrated in the sense of smell. The pure sensation cannot be isolated : it involves both intellectual data and a multitude of other sensations. Among the acquired notions which a given odor involves, is the representation of the object from which the odor proceeds, an association extremely serviceable to man and animals in finding and testing food; the more or less exact notion of the direction and distance of the object; and finally the idea of the organ of the body which is affected. The localization of smell in the nostrils is very vague and gives us little knowledge. On the other hand the concomitant sensations with which this sense is connected are very numerous and complicated. First, there are organic and vital sensations arising from the digestive and respiratory tracts. We distinguish between appetitive odors and nauseating odors. The odor of meat excites the appetite of carnivorous animals, and that of a full pantry 
mores our own. And in relation to respiration, odors are fresh, as that of Cologne-water, which excites a feeling of freedom in breathing; or suffocating, as that of a long-shut-up house, which seems to hinder respiration. Second, we find sensations of taste always associated with those of smell. The organs of taste and smell seem to act in sympathy. We speak of delicious odors as giving us a taste of the object beforehand. 'Third, sensations of touch are associated with smell in the mucous lining of the nostril, as in impressions which involve a tickling sensation. Fourth, there are also muscular sensations arising from the movement of the nostrils in breathing in odorous vapors. Fifth, to these we add sensations of temperature, heat and cold. The odor of camphor seems cold and that of alcohol warm.

It has been found impossible to isolate pure sensations of smell for classification or description. The most we can do is to throw them into general classes, as aromatic, fragrant, pungent, which are not at all exhaustive. This applies in a measure also to the other sensations, though in a less degree in the higher senses, sight, touch, and sound.

Taste. Taste is involved in the same obscurity. We only know that it has its organ in elements on the surface of the tongue, called gustatory bulbs or flasks, which communicate with the sensorium by the lingual and glossal nerves. The intimate comnection with smell is seen in the fact that the impairment of smell by disease or cold injures the power of taste. Tastes are infinite in their variety and cannot be classified. Certain classes of tastes are well discriminated in experience, such as sweet, bitter, sour; but they are rery few compared with the vast number which remain unlescribed. The presentative element in sensations of taste is very slight. We have an indefinite feeling of the locality of the senen- 
tion, but this arises, in the main, from feelings of touch upon foreign substances in the mouth, and from the muscular movement of the organs involved in eating or drinking. No knowledge of the object affecting us is given immediately in either taste or smell, since the stimulating agent is in gaseous or soluble form.

Organic or Systemic Sensations. There are throughont the body various organic sensations which are quite internal and only indefinitely localized. Such are the risceral sensations, respiratory sensations, feelings of bodily comfort or discomfort in general. Their most marked characteristic is their tone value, the high degree of pleasure or pain which they contain. These sensations, however vague and general, are of great importance to the mental life. They are the background of our emotional condition-since they indicate an elevated or depressed condition of bodily vitality-and give general cast to our state of mind. The dyspeptic soon becomes unreasonable and gloomy, and biliousness interferes with the normal activity of the mind. "The general condition of the sensorium as a whole is often a determining factor in thought and conduct. It is noticeable that changes in climate and weather have a great influence upon these organic feelings, largely through the elevation or depression of the respiratory function.

Muscular Sense. The earliest of the senses in its development is the muscular sense. By it is meant feelings of the activity of the muscles of the body as concerned in movement. As to the existence of such a class of sensations, as seen in lifting, pushing, straining, and in the weariness that follows muscular exertion, there is no doubt. Many psychologists, however, attempt to resolve them into sensations of touch,' or consider them as an "assem-

1 So Rabier, Psychologie, pp. 103-108. 
blage of sensations of different categories."' The former, however, cannot be held, since such sensations remain after complete destruction of the sensibility of the skin in cases of aursthesia of the limbs. Beaunis finds that a singer retains control orer the rocal chords, after their sensitiveness to touch has been destroyed by cocaine. ${ }^{2}$ Clinical cases show the same for the limbs. This indicates that the skin is not the organ of muscular sensations unless ${ }^{3}$ motor habit be so established that the skin is no longer necessary, though at first involved. But, further than this, the muscular sensations have characteristics peculiar to themselves. There are two distinct elements involved in voluntary movements of the muscles: first, a feeling of effort, and second, a feeling of resistance. The feeling of effort arises from the expenditure of nervous energy at the centres, and is called also feeling of innervation. The feeling of resistance, on the other hand, seems to have its seat in the muscle afiected. It is the sense of opposition to muscular morement, and is connected with sensations of pressure spoken of later on. Both of these seem to be involved in muscular sensations, though either may be present without the other. (In cases of paralysis and muscular anæsthesia, there is the feeling of effort with no corresponding muscular movement; and, on the other hand, if the hand or arm be contracted by galvanism, in contact with a solid body, we have the feeling of resistance or pressure without that of effort.") The feeling of effort accompanies the exercise of will in the adult consciousness; but in child life it arises as soon as the limbs are noved and

1 Ferrier and James. For theories of the physical basis and classi. fication of these sensations, see Wundt. Theorie der Sinnexiculirnehmung, p. 3 \%

\footnotetext{
- Mind, July, 1887, p. 430.

3 Lewes.

- So Bernhardt; cf. Iadd, Plyy. Phych., p. 345.
} 
encounter resistance, and the idea of self as actire probably comes through this feeling. Around it the beginnings of attention arise. Feelings of resistance also arise equally early in child experience and are exceedingly important as giving the first knowledge of the external world. ${ }^{1}$ We are conscious of opposing force, and thus arrive at the first condition of matter. It is well to repeat that it is through muscular sensations, with the attention and will which they involve, that we have the idea both of mental and of physical force.

As to the mechanism of the muscular sense, great obscurity envelops the whole subject. Three distinct theories of the nervous accompaniment of these sensations are held, each by eminent authorities in physiology and psychology. It is held by some that the feelings of muscular activity arise from the pulling and crushing which the muscles occasion in the neighboring parts - the skin, joints, ligaments, tendons-and that they are transmitted to the brain by the ordinary sensor courses. This may be true, even in the face of the fact ${ }^{2}$ that muscular movement is unimpaired when the posterior or sensor roots of the spinal cord are cut; since the control of muscular movement can be shown, in frogs, to be independent of muscular feeling. The difficulty with this view is that the ordinary sensor nerve endings, being largely external, do not seem sufficiently distributed to report muscular activity. The feeling of muscular pain and weariness also persists after all activity and seems to issue from the body of the muscle itself. Consequently, it is held by many, ${ }^{3}$ that there are distinct sensor nerve fibrils in the muscles, which are either continuous and parallel with the motor courses, or are branches of the main sensory nerves." This theory is probably true, but it accounts, however, only for the feeling of resistance-actual sensations in the muscles, - not for the feeling of effort. The latter may be entirely absent. Hence a third general view, that

1 On the importance of feelings of resistance, see Spencer, Psychology, II ch. xvrr.

2 Brown-Séquard.

3 E. H. Weber, Sachs.

4 For evidence, see G. S. Hall, Mind, III, The Muscular Perception of Space.

5 Bain, Wundt. 
the muscular sensations are essentially feelings of movement and have their seat entirely in the motor apparatus. The sense of effort is due to the voluntary liberation of motor energy upon the courses: it is entirely central. The degrees of feeling of movement vary with the inner estimate of this expenditure or innerration. This explains the feeling of effort and is the only explanation of it, but it takes no account of the distinctive muscular sensations which result from movement. These Bain admits arise from the "sensitive filaments." "It is therefore probable, on the whole, that the feeling of effort or cause arises from central motor innervation, and the feeling of resistance or effect, from a sensor apparatus, either ordinary or special. 'This is supported by the close automatic connection between sensation and motion in general. The clear distinction between the two classes of sensations is seen in a case reported by Demeaux ${ }^{2}$ of a woman who had lost all muscular sensibility, both deep and superficial, and while the power of voluntary movement remained, was yet ignorant of the actual movement, and the position of the limbs. The sense of effort remained, but the sense of resistance was gone.

It is largely due to Maine de Biran, the eminent French philosopher, that the feelings of effort and resistance, as underlying the ideas of will and force, are prominent in psychology. He held that in the fundamental act of effort accompanied by resistance, there are immediately given self and not-self, the will and the external world. This is seen to be true as a growth in child life. Prof. Bain calls it the most "vital distinction within the sphere of mind." Hence M. Rabier's criticism of Maine de Biran' is mistaken. He analyzes the feeling of effort into will and external resistance, and surs both are presupposed, forgetting that this analysis is made after the feeling is complete, and that neither knowledge of will nor of body is present or possible before the union which gives the feeling of effort.

Presentative Element in Muscular Sensations. Combined with touch, the muscular sense affords us knowledge of extension and force. Sensations of contact, as shall be seen below, repeated on successive portions of the skin or by the same portion on different parts of the object, present data for the projection of a flat surface.

1 Senses and Intelket, p. 77 : also see quotation from Ludwig, p. 79.

- Brain, Mar. 87, p. 11.

Psychologic, pp. 104 and 105. 
It is by pressure added to these sensations that we come to apprehend depth. It is sufficient to remark this here, reserving its further discussion for the section on the perception of space.' Mr. Spencer, speaking of the sensation of resistance as involving feelings of effort, says: "'This sensation is at the bottom of our conception of the material universe, for extension is (as apprehended) only a combination of resistances ; movement is the generalization of a certain order of resistances ; and resistance is also the substance of force." 2

Taken alone the muscular sensations give us little knowledge. We know from them the location and movements of larger or smaller masses of the body: but even this knowledge is very vague, since without touch and sight these movements cannot be coördinated, nor their amounts estimated.

Hearing. Sensations of sound have a specific quality which is known through the ear. ${ }^{3}$ The psychological value of these sensations consists in the fact that they occur purely in time and have no spacial quality. A series of sounds is the type of pure temporal succession.

Presentative Elements in Sensations of Sound. The three most presentative classes of sensations, we have said above, are those of sound, sight, and touch. In the case of sounds, we find peculiar properties upon which exact methods of research may be brought to bear. These properties, however, are presentative only in as far as they sustain relations of time. Like other sensations, sounds may be distinguished in intensity in an exact way. This intensity depends upon the amplitude

$1 \mathrm{Ch}$. VIII, 84 .

2 Loc.cit.

${ }^{3}$ For the mechanism of hearing, see Bernstein, Five Senses of Man.

4 See $\$ 5$. 
of the vibrations of the sonorous body. Further, they are distinguished in their timbre, which depends upon the addition to the vibrations, which produce the fundamental tone, of other vibrations twice, three times, . . . as rapid. This difference in timbre gives its characteristic sound to different materials, as metallic, vegetable, and thus corresponds to the difference in kind of odors and tastes. But the special peculiarity of sounds in this particular is found in what is called tone as distinguished from noise. This quality of the tone or note is tonality or height, depends upon regular periodical vibrations, and raries with their number. There is nothing corresponding to this in smell or taste. We cannot make up a scale or gamut of tastes as we can of notes. Upon this peculiarity of sound, having its basis of sensation probably in the fibres of Corti in the cochlea of the ear, or in the fibres of the basilar membrane to which they are attached, the whole science of music

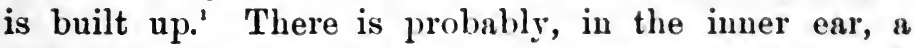
series of vibrating elements which correspond, though more minutely, to the intervals of the musical scale. The perception of distance and direction by the ear is largely acquired by association.?

Sensations of sound are singularly free from the disturbing influence of other sensations, and for this reason they are directly accessible to experimental researches of all kinds. We shall find this the case in speaking of the other characters of sensation.

Sight. ${ }^{3}$ Sight is perhaps the most presentative sense. It gives us direct knowledge of the external

'See Cournot, Du Fondement de nos Conmairances, 1. p. 215.

- On the function of the semicircular cannls as giving balance in space, see Chap. VIII. \&4.

For the mechnnisun und general facts of sight, see Bernstein, loc. cit. and Le Conte, Sight. 
world. Its affective qualities consist in the pure intensity of the light sensation-as the light of one candle or two-and in the distinct order of sensations known as color. The sensations of color arise from the rapidity of vibration of particles of luminous ether. These different rapidities give an ascending scale through the seren colors of the rainbow, from the red to the riolet, similar to the scale in sound sensations, though not as extended or exact. The colors shade off into one another with no regular law of change. Sensations of color have intensity, saturation, and tonality. The intensity, says $\overline{\mathrm{Helm}}$ holtz, depends upon the quantity of light. Saturation is the relative purity of a color. Degrees of saturation are known as shades, as pink in its relation to scarlet. Tonality is the quality of the color as determined by its position in the scale of the spectrum, as blue, green, yellow.

The spacial form of the objects of sight is one of the most interesting of its presentative properties. This will be discussed in the treatment of space form. ${ }^{1}$ The fact that there are two eyes contributes to this result, especially in the perception of the third dimension. It is difficult to isolate pure sensations of sight from the muscular and tactual sensations which are always, in actual life, associated with them, and it is probable, as will appear later, that these-especially the muscular sensations-are also concerned in the formation of the notion of space.

In regard to the process of the perception of color through the eye, two principal theories have been advanced, assuming that the retina is distinctively the locus of this process. We find, in the retina, distinctly differentiated and minute nervous elements called rods and cones which, it is thought, react locally, thus making possible the picture of the object seen. But as to the color sense proper, the case is more uncertain. According to the Young-Helmholtz theory, there are three different

${ }^{1}$ Chap. VIII, § 4 . 
kinds of nerre fibre, each of which reacts to one of the three fundamental colors, red, green, and violet: the other colors are complex and result from their combined action. 'This theory is very generally accepted. Among other objections to it, it is urged that the microscope reveals no such differentiation of fibre, and the smallest sensation which can be perceived by the eye is of white light, which involves all these elements.' The other theory is that of E. Hering, who supposes that there are two kinds of elements each capable of two different reactions, thus giving four fundamental colors, red, green, blue, and yellow. This theory, however, has also grive difficulties to face." Yellow can be produced by the combination of red, green, and violet.

The phenomena of color-blindness support the general view of the differentiation of structure or function in the nerve elements of the retina. 'This is the inability of about one person in twenty to distinguish certain colors. Blindness for red is most common. It is thought that all cases can be reduced to blindness either for red or green; though there are cases in which only different degrees of gray are distinguished. To the latter, all objects seen are like the photographs of the same objects. Different regions of the retina have different degrees of sensibility to color; this sensibility growing less as we go outward from the central part. The outer rim of the retina is normally insensitive for red, but reacts for the other colors. This shows that there are special fibres which react only to red."

A further phenomenon, that of after-images, is especially noticeable and important in sight. Affer-images are the persistence of sensations after their peculiar stimuli have ceased to act. Look at a bright window and then close the eyes, and the after-image is seen. This is called a positive after-image, and is due to the dying out of the nervous process. If the bright object be colored, its after-image plays between that color and its complementary (the color needed to make white in composition with it). 'I'his is due to the exhaustion of the nervous elements involved in the original color, by which white light is broken up and only the complementary elements act. This persistence of sensation in the organism is important hs explaining compound and intensive forms of excitation. As

1 Fick.

- On these theories see Le Conte, Sight, and Wundt. Phys. Prych., $2 d$ ed., 1. p. 460 ; and in criticism of Hering, sce Kries, Arch. Anat. and Phys., 1887, p. 118.

On color-blindness, see Fick, Zur Theorie der Farbenblindieit. 
Fechner has pointed out, the after-image has only two dimensions and thus differs both from the actual percept and its rerived image.

Touch. Sensations of touch constitute the base of a variety of sensations which we distinguish ordinarily as qualitatively different. We have seen that an element of touch enters in sensations of muscular movement, both from external contact and from the rubbing of the inner parts against one another. Besides, we distinguish sensations of the rough, smooth, coarse, polished, damp and sticky; but physiologists have shown that they are unt special sensations, as Reid believed, but acquired judgments based upon modifications of touch, combined with the feeling of resistance already spoken of. The importance of touch, as being capable of so many modifications, as having its end organs over all parts of the body, and as acting in conjunction with other sensations in their peculiar organs, is seen to be very great.

The presentative quality of touch, considered quite alone, is space, as it is built up from the recognition of the locality of the parts of our own body. ${ }^{1}$

The nerve elements of touch or pressure are clearly defined. They are corpuscles situated in the skin, which communicate directly with the great sensor nerves by ramifying fibrils. These corpuscles are distributed in varying number in different parts of the skin. The experiments of $\mathrm{E}$. $\mathrm{H}$. Weber showing this are celebrated. He employed dividers opened at varying degrees, the minimum distance felt between the points being the diameter of the smallest "sensationcircle." The tip of the tongue and the red of the lips have great delicacy of touch; while the back of the neck is very insensible. 'The circles, however, are not the smallest units of tactual sensation and must contain many nerve elements; for it has been shown that there are distinct and very minute pressure spots within these circles. ${ }^{2}$ The same is seen in the marvellous capacity of this sense to become more delicate with

${ }^{1}$ See Chap. VIII, §2, rr.

${ }^{2}$ Goldschneider. 
exercise. In the hypnotic state, also, delicacy of discrimination by touch is greatly exaggerated. ${ }^{2}$

From the universal presence of touch and its immediate reference to the external world, it is of great importance in cases of appeal from the other senses, and in cases of hallucination. When in doubt about the objects of vision or sound, we feel after them with the hand. For this reason, touch is called the "controlling" sense.

Temperature Sense. The last of the senses, in order of mention as in order of discovery, is the temperature sense. Like touch, it is a universal sense and has its end apparatus in the skin. Minute points called "temperature spots" which react, some for heat and others for cold, are scattered over the skin in varying degrees of nearness to one another. They have been plotted on the backs and palms of the hands and on the arms. Of the different nerve terminations in the skin-elements of Krause, Paccini, and Meissner-it is impossible to tell which belong to touch and which to temperature. The varying number of these spots in different localities and the consequent variations in delicacy of perception of heat and cold, make quantitative measurements for this sense very difficult. These sensations have a very slight presentative element in their vague reference to bodily locality. ${ }^{2}$

From this general survey of sensation, in respect to quality, the distinction between affective and presentative elements in sensations is more clear. In each sense, when the affective element is strong the presentative is faint. When a very bright light strikes the eye, it produces a strong affective sensation, but vision is indistinct. On the contrary, when we read printed words, they represent thought, but are only slightly affective. The case is the same with sound and touch.

1 Binet and Féré, Animal Magnetimm. p. $13 \%$.

'On the temperature sense, see Donaldson, in Mind, No. XXXIX. 


\section{$\S 4$. Proof of the Specific Nature of Sensations as RESPECTS QUALITY. ${ }^{1}$}

The specific differences in sensations are denied by a school of psychologists, who hold that the seven orders of facts found here can be reduced to a single principle of sensibility. This tendency to unity is the dominating characteristic of modern science and finds as bold, if not as successful, an application here as in the external sciences.

Theory of "Unity of Composition" or Mind. In the reduction of mental phenomena to unity, three stages of the process may be distinguished. The first step is that of the seusationists, who reduce all mental facts to sensations. Ail the facts of consciousness, intellectual, affective and volitional, are transformed sensations. The second stage consists in the reduction of all sensations of a given class, as color, to a single generic sensation of that class, as, for example, a single color, which serves as basis for the derivation of all the colors. And the third stage is reached when all these generic sensations are reduced to a single form for all classes, a truly primitive form of consciousness. This, while having no determined and definable quality of its own, yet produces by composition with itself, first, the generic sensations, then the different species or kinds under these general qualitative divisions, and then the whole mental life in its higher forms. First, the mental life is reduced to sensation, then to generic sensations, and finally to one elementary sensation. It is the second and third of these steps which concern us here.

The arguments in favor of this hypothesis of unity are of three kinds : first, analogies based upon the mate-

${ }^{1}$ The development of this paragraph follows substantially Rabier, loc. cit. chap. XI. 
rial sciences; second, inductions drawn from the analysis of psychological phenomena themselves; and third, the argument from the fact that this hypothesis succeeds in explaining many perplexities in psychology.

I. Analogies: a. Reduction of the Physical Forces to Unity. Two arguments based upon the physical sciences seem at first sight to render the hypothesis of unity probable.

All the physical forces are being resolved into movement, although in appearance nothing could be more different than sound, light, and heat. In experience we find nothing in common between the sound of a bell and the color of fiowers, between the heat of the sum and the fall of a stone. And in the old physics, each of these was looked upon as a different principle. But the great discovery of the transformation of forces has taught us that these different forces are in reality one and the same, and that all their phenomena represent but a single fact, movement. If this is so, we have by analogy a strong presumption that the corresponding psychological phenomena may be reduced to unity also.'

Reply. The force of this analogy is based upon a misconception of the true meaning of the law of conservation of energy, or transformation of force. It is not true that force is transformed at all, it is only true that there are no distinct forces to be transformed, that our old conception of separate forces was mistaken. So there is no reduction of things which are different to unity. It is only shown that one cause, notion, underlies many specifically different manifestations, or takes on many specifically different forms or degrees. And as far as this is concerned, we may admit the same of the different sensations, referring them to a general principle of sensibility which takes on specifically different forms. This is

' See Mantegazza, Transformation des forces peychiques, Rev. Philoso. phique, Mar. '78. 
what is meant when we say that all sensations are affective states; that in them all, our subjective sensibility is aroused. But this does not in the least degree affect the fact that, as mental states, as data of the inner life, the sensations of the different senses are specifically different.

'This parallel, thus understood, is further emphasized by the fact that recent work in neurology shows all nervous energy to be essentially the same, and further to be a form of motion. The nerve courses are functionally indifferent : any nerve stretch might serve for any sense, and the motor nerves substituted for the sensor and vice versa. It is probable that the end organs impart to the courses distinct forms of motion, which are due to the form of the stimulus in each case, and that these forms are interpreted in their specific sensations through the reaction of the general sensibility. ${ }^{1}$

b. Chemical composition of simple substances in a compound of unique properties, affords a second analogy. It may be stated in the words of Mr. Spencer. "Multitudinous substances," says he, " "that seem to be homogeneous and simple prove to be really leterogeneous and compound, and many that seem to be unrelated are shown by analysis to be near akin. ... Moreover, there is reason to suspect that the so-called simple substances are themselves compound, and that there is but one ultimate form of matter out of which the successively more complex forms of matter are built up. ... (From this) we conceive the possibility that the multitudinous forms of mind known as different feelings may be composed of simpler units of feeling and even of units fundamentally of one kind." s

Reply. This analogy is subject to the same criticism as the foregoing. It does not distinguish actual things in nature from our mental pictures of these things. In

1 This parallel is used to prove that mental force is also a form of motion, but without sufficient ground.

${ }^{2}$ Princ. of Prychology, vol. r. pp. 155 and 156.

${ }^{3}$ See a similar argument in Leibnitz, Nouveaux Essais, vol. Ir. ch. I, $\S 15$. 
order to make the analogy hold, we would have to consider presentations as substantial things with properties of their own, capable of uniting and dividing by their own force. They would have to be entities with different properties, like oxygen and hydrogen. But this is not at all the case. Mental facts are simple states and they are nothing independently of the mind whose states they are. They are the expression of the activity of mind which is one and the same in its different operation. So any conception according to which these states unite by their own inherent force and form a complex is definitively ruled out. If there be a complex of these simple forms, as we shall see there is, it must itself be dne, as they are, to an activity of mind; it must be also a function, not a thing or substance, and must owe its properties to the mind and not to simpler mental states.

Further than this, it may be said that this analogy rests upon a false interpretation of the fact of chemical composition. It is not true in fact that the union of oxygen and hydrogen gives a substance whose properties differ absolutely from those of the constituents. It is an apparent sensible difference, not an absolute one. The difference between the liquid water and the gases which compose it is only a difference in the position of the atoms and in the extent and direction of their movements. In the molecule of sulphuric acid, which is composed of one atom of sulphur' and three of oxygen, there is, to use the figure of Ampère, a small planetiry system, in which these atoms are arranged in a definite order and move with a definite rhythm.' Now in this combination, the atoms have not lost their properties, nor has the whole taken on any new properties. So the difference between the compound and its constituents is not a real difference in the things as things. But the difference between the sensations as sensations is a real difference. As soon as we attempt to re-

1 Wundt says: "There exists in the molecule a certain equilibrium of oscillating movements whose interruption at any point destroys the whole until the equilibrium be agnin established."-Phys. Prychologie, $2 d$ ed., Ir. 462. Cf. Clerk Maxwell, Kev. Scientifique, xIr. p. 867.

'Spencer, ibid. Cf. on Composition of Mind, Taine, loc. cit. 
duce these differences, we go beyond the range of sensation altogether.

II. Arguments Drawn from Psychological Analysis. The attempt is also made to base the theory of the unity of composition of mind upon psychological analysis. Are there any cases of the transformation of psychic force, or of mental synthesis? If so, this seems to afford a solid basis for the hypothesis. It is admitted at the outset that observation gives us no facts of this kind; but it is held that by different physical and physiological experiments sensations have been decomposed. The results of such experiments have been formulated in two great laws, which, if true, are as important for the science of mind as Kepler's laws for the science of the heavens. 1st. A sensation which is simple and undecomposable in consciousness may be in reality decomposed into more elementary sensations which may themselves also be composite. Sometimes the composing elements are conscious : but oftener, although they are real, they escape consciousness absolutely. 2d. Two sensations which appear in consciousness to be quite independent of each other and of absolutely different quality, may differ, really, only in the number, intensity, or order of their composing elements : differences in quantity in the elements may become differences in quality in the conscious sensations.

Spencer and Taine ${ }^{2}$ may be quoted in support of these laws. From the use of the wheel of Mivart revolving once in a second and having a thousand teeth which strike successively upon a metallic tongue and give a continuous sound, while a single tooth is not heard unless immediately followed by a second, Taine argues that the sensation of sound lasting a second is made up of a thousand minute sensations. So the sen-

${ }^{1}$ Spencer, loc. cit.; Taine, Intelligence. 
sation of light which lasts a second is composed of a million sensations of the retina. This confirms the first law. It is true and very important, provided we understand that the unconscious components are not sensations in any mental sense, and that conscious sensation arises only when the accumulated nerve excitation is sufficiently great to occasion the mental reaction. ${ }^{2}$

In support of the second law, it is said again, that sensations of color may be reduced to three principal or fundamental colors, and that the timbre of an instrument has only recently been resolved into added tones of a lower intensity than the fundamental. From the former fact, says Taine, " nothing hinders our concluding that the elementary colors are themselves composite sensations:" "so the innumerable sensations which we refer to the same sense may arise from a single elementary sensation for each sense." And "from the principles stated, we conclude that the elementary seusations of the five senses may be themselves complexes of the same original elements. ... In this case, we would have only one elementary sensation of different rhythms." This primordial sensation Mr. Spencer considers, vaguely enough, a "nervous shock."

Reply. First, as to the analysis of the facts of mind, we may say that no state of consciousness, as such, is composite unless it is perceived to be so. The state of

'See discussion of the unconscions, Chap. IV. $\leqslant 2$.

2 .. The subjective effect produced hy a crack or noise that has no appreciable duration is little else than a nervous shock. Though wo distinguish such a nervous shock ns belonging to what we call sounds, ret it does not differ very much from nervous shocks of other kiuds. An electric discharge sent through the body causes a fecling akin to that which a sudden loud report causes. A strong unexpected im. pression made upon the eyes, us ly a flash of lighining, similarly gives rise to a start or shock. . . It is probable, then, that sonething of the same kind as that which we call a nervous shock is the ultimute unit of consciousness." (Loc. cit., pp. 150, 151.) "The substunce of the so:!! is resolvable into nervous shocks" (156). 
consciousness depends upon the nature of the excitation, at the centre, whether continuous and single, or discontinuous and complex. A musical chord, for example, is composite and is seen to be so. In a sensation of sound from an organ-pipe 32 feet in length, one can distinguish the elementary sounds of which it is composed. But we cannot say that in every sensation of sound lasting a minute there are a thousand minute sensations, since the thousand external excitations of Mivart's wheel lo not reach consciousness as a thousand excitations, but as one. To establish the position, two things would have to be proved: 1 st. That the minimum duration of the impression in the end organs does not exceed the duration of the external stimulus. It is quite possible that an external stimulus which lasts a thousandth of a second, corresponds, in the organ, to a movement which occupies a hundredth or a fiftieth of a second. This possibility is maintained as a fact by many physiologists. $2 d$. It would have to be proved that the minimum duration of the sensation does not exceed that of the organic impression. It is quite possible that in the time which is occupied by a thousand organic impressions there is only time for a hundred or for fifty sensations. Fechner's law ${ }^{1}$ shows a disproportion between the intensity of sensation and its external stimulus; why should there not also be disproportion in their duration? The fact of the persistence of images-in sight, at least an eighth of a second-is overlooked. These persistent images tend to form a single continuous excitation, as is seen in the circle of light made by swinging a torch. So of these two presuppositions, we may say that the second is unproved, and the first is false.

Further, as to the reduction of the different sensations of a given sense to a single type or to simpler forms, few facts are advanced, and these may be explained 
by a reference again to the physical basis of sensation. The fact is cited that the colors of the spectrum united give white, ${ }^{\prime}$ and that when a toothed wheel is turned rapidly the sound of its impacts is ligher than when it turns more slowly: the conclusion being that the sensation white is the synthesis of all the sensations of color, and that of high tones the synthesis of lower. But there is no evidence that in the case of white there is any sensation of color at all. On the theory of different elements in the retina which react for the fundamental colors, it is readily seen that the combined reaction of them all will be a form of motion-or chemical product -different from that of any one of them taken separately. When the colors are seen successively, as in the revolution of a segmented wheel, the persistence of images causes all the elements to be excited simultaneously. The result is the stimulus for white. There is no stimulus present at all for the colors, and so no sensations of color. The same for the sound of the toothed wheel since, as has been seen, the height of the tone depends at once upon the number of vibrations of the sonorous body. In these cases, the fact is a substituiton of sensations and not a synthesis.

Additional arguments in support of the theory of "the unity of composition of mind "are drawn by analogy from the general growth of body and mind together and the reduction of body to atoms. It also serves Mr. Spencer in his general doctrine of evolution, since if mind be developed it must be from a single principle. The evolution of mind is the process by which "the numerous and different forms of feeling arise from a simple and primitive sensibility." But if evolution is to be used to prove "unity of composition," it must first be proved, and this is impossible since mental facts are an important province for the establishing of general evolution. ${ }^{2}$ If unity of composition fails here, it goes so far to dis-

' See J. S. Mill, Logic, bk. 6, ch. IV, and bk. 3, ch. vi ; also Leibnitz, Nouv. Essais. bk. 2, ch. II.

M. Rabier says, Mr. Spencer here attempts to demonstrate obseurum per obscurius. 
prove general evolution. Prof. Wundt's effort also to establish "unity of composition" in the mental life, proceeds upon the hypothesis of "unconscious mental elements," which has already been examined. More recently ${ }^{1}$ he emphasizes the " unity of apperception," as if this were sufficient to account for the specific forms of apperceptive activity, perception, conception, judgment. 'This gives rise to the difficulty already encountered, in accounting for the specific forms of sensation by the general fact of sensibility.

\section{§ 5. Quantity of Sensation: Psychophysics.}

Wober's Law. By quantity is meant intensity or mass. Until quite recently it was considered impossible to measure intensities in sensation, from the fact that they are subjective entirely and we have no abiding internal measure to which to refer them. This difficulty has been overcome by establishing an external unit of measurement, and comparing sensations through it with one another. A relative measurement is in this way attained. This external standard is the quantity of stimulus agreed upon as producing a unit of sensation. The external excitation thus becomes the means of approach to the measurement of the internal fact. For example, if the sensation given by the weight of one gram on the back of the hand be taken as the unit of sensation for pressure, other sensations can be compared with it, in relation to their respective excitations. This procedure has actually been carried out in those of the senses most accessible to experiment and the following law formulated, known as Weber's law: In order that any sensation. may increase by quantities always equal, the excitation must be increased by a constant fraction of the excitation itself; or, the excitation must grow in geometrical progression $(1,2,4$, $8)$, in order that the sensation grow in arithmetical progres-

${ }^{1}$ See Ribot's exposition, German Psychology, p. 214 ; also Wundt, Phys. Prych., 2d ed. 
sion $(1,2,3,4)$; or yet again, the sensation varies as the logarithm of the excitation. ${ }^{1}$

In arriving at this law, it was necessary to show that the smallest perceptible difjerence between two sensations of the same sense, requires a constant fractional increase of the smaller excitation. This has been shown with reasonable exactness for moderate degrees of intensity of sensations of sight $\left(\frac{1}{1} \frac{1}{3}\right)$, touch $\left(\frac{1}{3}\right)$, and sound $\left(\frac{1}{3}\right)$. In dealing with high intensities, the proper working of the organ is deranged and the results vitiated; as with very bright lights. In the case of taste and smell, the difficulties of isolating the sensation and measuring the amount of the stimulus have been almost insurmountable. Three distinct methods of arriving at the smallest perceptible difference of sensation are employed, all of which depend upon the subjective estimate of the person experimented with as to the equality of two stimuli, such as weights or lights. ${ }^{2}$

Thie scale of sensation values has its zero or vanishing point at the smallest perceptible sensution for each of the senses. Hence the necessity of instituting another series of experiments on all the senses to discover this value. The point at which a growing excitation first begins to be felt as a sensation is called the threshold value of the excitation and the sensation is said to be at the threshold." This point raries very greatly according to the conditions of the senses as to exhaustion, and the state of the mind, as preoccupied or attentive."

1 Fcchuer.

2 Sce Ladd, loc cit. p. 364.

This expression was introduced into Psychology by Herbart.

4 Upon these two classes of data, smallest perceptible difference of sensations and smallest perceptible sensation, the logarithmic law of Fechner is based. Assuming that the differences of sensation to be barely perceived are infinitesimal quantities, and that the difference in the excitation is also intinitely small, as compared with the whole stim. ulus, we may, by the calculus, equate difterentials and write (making ds increment of sensation, de increment of excitation, and $k$ the proportional constant)

$$
d s=k \frac{d e}{e} \text {. }
$$

whence, by integration,

$$
s=k \log e \text { : }
$$

or, the sensation varies as the logarithm of the excitation. The thresh. old value then being given, the scale is built up. 
Besides its application to the regular sense perceptions, Weber's law applies, with the same limitations, to the estimation of linear distance ${ }^{2}$ and to the judgment of the flight of small portions of time. ${ }^{2}$ In order that I may judge a line twice as long as another, it must be really more than twice as long; and in estimating five seconds I make the time too short by about one fourth. ${ }^{3}$

The distinction between the affective and presentative elements in sensation is strongly brought out by these researches in respect to quantity. From the nature of this distinction, we would expect that exact research could be applied to sensation only in the degree and aspects in which it is presentative, i.e. capable of appreciation in terms of objective reference. The affective element, on the contrary, is a purely subjective quantity and is beyond all scientific approach. This is borne out in fact. 'The senses which confirm Weber's law are sight, touch, and hearing, and these have been seen to be most presentative. But the law is not proved for taste, smell, organic sensation, which are most affective. And this relation is further confirmed by the fact that in the presentative sensations the law does not hold for high intensities; since then there is a powerful reaction of the affective element, as pain under bright light, or shock when a loud sound is heard. That is, the law holds of the presentative senses only when they are most presentative. So the criticism that quantitative measurement of sensation is impossible, ${ }^{4}$ is true only for sensation proper as distinguished from sense perception. The same is true also as regards the duration of sensation. ${ }^{5}$

The interpretation of Weber's law has occasioned much discussion. How are we to construe the fact that the sensation, which must be considered as effect, does not increase proportionally to the stimulus, which is cause? Three different views are held: first, that this relation is an ultimate law of the relation of body and mind; ${ }^{6}$ second, that the disproportion is due to the activity of apperception and is strictly psy-

1 Cf. Sully, Sensation and Intuition, pp. 50-60.

2 See Glass, Philos. Studien, Iv. p. 423; also James, Jour. of Speculative Philos., Oct. 1886.

3 This can be readily shown by counting seconds with the eyes on the second hand of a watch, and then attempting to repeat it with the eyes closed. Below 1 sec., the time is judged too long.

- Kant, Hering, Delbœuf.

5 Cf. $\$ 6$, below.

6 Fechner. 
chological $;^{1}$ and third, that the disproportion is due to the loss of excitation energy in the physiological processes involved, the processes of transmission by the nerves and central stimulation. This makes the central process the cause of the sensation, instead of the peripheral process, and the law of causation holds. This is on many accounts the best interpretation. ${ }^{2}$

Extensive or Massive Sensations. The quantity of sensation, considered as intensity or intensive mass, is to be distinguished from its quantity considered as extensity or extensive massiveness. If I paste one postage stamp on $m y$ hand and then another beside it, the sensation is increased in the second case in extensive massiveness, but not in intensity. This distinction in quantity is possible for all the senses, but only when there are coexistent sensations of the same sense which do not coalesce to produce a ligher inteusity. It seems to depend upon an extensive organ of stimulation, skin, retina, which is stimulated over a more or less extended area. It is experienced in putting the hand in water, or in hearing, at the same time, a continued musical note and a harsh noise. The difference between the two kinds of increase in sensation is distinct enough to require separate mention.

\section{Dibation of Sessation and Thovgut : Psхchonetur.}

The measurement of the duration of mental acts was begun by Donders about 1861. Before his time, it was generally admitted that psychic processes must be construed in time, and the question of the rnpidity of thought

1 Wundt: defended by Grotenfelt, Das Weberache Geatz.

- See my five ressons in support of this position in Presbyterian Re. ciece. July. "87, pp. 43i-438: supported by work of F. C. Mnller; sce Amer. Jour. of Myels., vol. 1. p. 185 ; cf, also Ward, in Mind, 1. p. 452.

The subsiance of the text of this paragraph was written for Dr. IfcCosh's Prychology (vol. 1. pp. 147-8), and is republished with his consent. 
was discussed from the standpoint of general consciousness. We are conscious of thinking sometimes faster, sometimes more slowly. But this subjective estimation of time was vague, just as that of quantity was vague, for want of a constant measure in the inner life. Since the discoveries of Helmholtz and others, as to the velocity of nerve transmission, it has become possible to arrive at a determinate expression for the time necessary for different sensations and for some of the simpler apperceptive functions.

I. Beginning with simple sensation, the case is briefly this: let the skin of a man in normal conditions be pricked and let him speak as soon as the pain is felt, or let a word be spoken and let the subject press a button as soon as he hears it. The period that elapses between the two events, in any such experiment arranged for two seuses, is called the simple reaction time and varies from $\frac{1}{8}$ to $\frac{1}{5}$ sec., according to the individual and according to the conditions of the experiment.

Upon consideration, it is readily seen that this period may be divided into three parts : first, sensor nerve transmission to the brain centre; second, the mental process of sensation and volition; and third, motor transmission to the organ moved. Now since the velocity in both the motor and sensor nerves is known, we reach by subtraction the time of the mental act. Instruments are used by means of which differences to the ten-thousandth of a second are noted. By this analysis of the simple reaction time, we arrive at two general principles :

a. The simplest mental act occupies an appreciable period of time.

b. The purely physiological or transmission time is less than half of the entire reaction. ${ }^{2}$ Consequently the time

1 The result of four hundred experiments upon myself, after considerable practice, was $.125\left(\frac{1}{8}\right)$ sec.

2 This was conjectured by Darwin from the fact that we wink the 
taken up by the sensation and motor impulse raries slightly either way from $\frac{1}{15}$ sec. This cannot be called purely mental time, however, for the central physical change goes on at the same time.

II. Passing from sensation to the reproduction of ideas as memory pictures, it is concluded from experiments conducted similarly :

a. The time occupied in the reproduction of a state of consciousness is longer than the time of its production.

b. The time of reproduction depends upon the degree of attention given (1) to the original sensation, (2) to the reproduction.'

III. A third operation on which many experiments have been made is that of distinction or discrimination. To experiment upon sight, let two colored lights be shown, the subject understanding that he is to react by speaking or pressing a button only when he sees the color agreed upon beforehand. This involves first a comparison and then a judg'gment, with vơlition. By au easy process, the purely physiological time is eliminated, and the duration of the mental act is found to be $\frac{1}{2} \sigma$ sec. (Kries) to $\frac{1}{1 \sigma}$ sec. (Wundt). The discrimination is easier when the sensation is of high intensity; and since, in all reactions, the signal must be discriminated from other sensations in consciousness, we have the principle that the duration varies inversely as the strength of the stimulus.

IV. Experiment has rendered service, also, in defining and confirming the laws of associntion. The time of a simple association is found to be sec. to sec. Repetition greatly shortens the time by strengthening the association.

V. A fifth class of experiments relates to the logical

eyes without having a change of sensation from light to darkness. Zoinomia, 1. p. 24.

in the general effects of attention, sce below. 
judgment of subordination, i.e. from genus to species. It is found that the time is longest when the subject is abstract and the predicate a more general notion (man is intelligent), shortest when the subject is concrete and the predicate a less general notion (the house is red). The average of a great number of experiments gives the time about 1 sec. This is important as illustrating the growth of the general and abstract notion from the concrete, and indicates that the order of instruction of children should be the same.

It should be said that these results are true only in an arerage sense and under normal conditions; and further, that they represent only a single type of our every-day mental processes, that of more or less concentrated attention. The fact that the subject of the experiment must take part in the arrangements and concert his actions with those of others, makes it impossible to obtain results without the attention. In life, however, most of our actions are not foreseen, and our attention is drawn to sensations by their occurrence, not beforehand. The degree of attention, however, may be somewhat varied and the results noted. The bodily states also greatly influence the duration of mental acts. Fatigne and other unusual physical conditions tend to lengthen the reaction time. The senses with which the most exact results have been obtained are sight, hearing, and touch, the most representative senses : with taste and smell the mechanical difficulties are very great. In dreams, the ascertained durations do not seem to hold, since the flow of presentations then takes on, in many cases, enormous rapidity. ${ }^{1}$

Effect of Attention upon the Duration and Quantity of Sensation. We have already noted the general law that attention increases the intensity of sensations. ${ }^{2}$ It is at once seen that this principle interferes with the application of Weber's law, since a given stimulus is felt more strongly if attended to than otherwise: so that in com-

${ }^{1}$ For attempts to determine the perception, apperception, and will time separately, see references given by Ladd, Phys. Psych., ch. viII. This chapter of Ladd's, with its references, is the latest and finest English summary in this department.

${ }^{2}$ Chap. V, \$2. 
paring sensations by their excitations it is necessary to keep the attention constant in the two cases. The effects of attention upon the duration of sensations is even more marked. In general, attention diminishes the time necessary for ihe reaction. The shortest times are obtained by concentrating the attention. To such an extent may this give rise to expectation of the excitation, that it is sometimes anticipated, the reaction of the hand, for example, being given before the signal is made. In the hypnotic state, where the attention is strongly fixed, the time is shortened. Further, if the attention be fixed upon the reacting seuse rather than upon the receiving sense, the time is shorter.' This concentration is especially necessary at first, before the muscular reaction becomes automatic. The function of attention as a comparing and relating activity, that is, as apperception, is strongly seen in the experiments to determine the distinction time, where very great variations are due to changes in the energy of attention. The shortening of the reaction time by attention has evident pedagogical applications.

Effect of Duration upon the Intensity of Sensation. Within short periods, the intensity of a sensation is diminished if its stimulus be continued. This arises from the accommodation of the organ to the stimulus. It applies especially to slight pleasurable or painful stimuli. Long-continued stimulation, however, from exhaustion

'This I found in my own experiments before secing reference to N. Lange, by Cattell. Mind, Jan. '88, or Wundt's 3d ed. It is probably lue to the fact that when the attention is directed to the receiving sense, the idea of movement becomes dim and the attention must be recalled to it, that the movement may follow: while, in the other case, the iden of the proper movement is kept in apperception. while the signal, if distinct, carries its own discrimination, by what Mr. Sully calls preperception (Outlines, p. 227), without the readjus:ment of attention. This explanntion is supported by Munsterberg, Der Zeil sinn. Lauge's work is published in Mlibos. Shudien. IV. 4. 
of the organ, becomes increasingly intense and painful ; and sensations at first pleasurable become painful under this condition.

\section{§ 7. Tone of Sensation.}

By tone of sensation is meant the feeling of pleasure or pain which accompanies it. It represents somewhat in all sensations, and in the higher senses almost entirely, the affective element. Pleasure and pain are only and wholly affective. Our whole sensational experience is accompanied by pleasure and pain and so has tone. ${ }^{1}$

§ 8. Localization of Functions in the Brain. ${ }^{2}$

The question as to whether there are local areas in the cortex or gray matter of the brain, which are especially active in the exercise of the sense and motor activities, is of great importance for general psychology. Experiments have been very conflicting in their results, but it is now generally admitted that there are a limited number of well-ascertained areas. The motor functions are grouped around the fissure of Rolando, extending roughly from the vertex of the skull downward and forward in a line which passes slightly in front of the orifice of the ear. The centres for the leg, arm, and face are in the order named, proceeding downward. The special muscular groups involved in the finer movements of these organs are distributed on both sides of the Rolandic fissure. Movements of speech have their centre for right-handed persons in the third frontal gyre of the left hemisphere. The sensory area comprehends the region lying back of and beneath the motor zone; the fissure of Sylvius being a rough horizontal boundary between the motor and sensory areas. Of the special senses, sight is located in the occipital lobe, including the so-called angular gyre at the upper end of

1 Pleasure and pain are discussed under feeling.

${ }^{8} \mathrm{Cf}$. figures opposite the title-page. 
the Sylvian fissure. The centres for hearing, taste, and smell lie, less exactly, in the temporo-sphenoidal lobe, the horizontal area below the fissure of Sylvius.

On Sensation, consult: in general. Wundt, Physiologische Psychologie, ch. VII-x; McCosh, Cog. Powers, bk. 1, ch. I ; Carpenter, Mental Physiology, ch. Iv ; George, Psychologie, p. 51 ; Porter, Human Intellect, ch. Iv ; Ladd, Physiolog. Psychol., pp. 303-355; Volkmann, Lehrbuch der Psychol., $32-48$; Waitz, Lehrbuch der Psych., \$ 8-10, and Grundlegung der Psychol., pp.102-111; Drobisch, Psychologie, 4-13; Fortlage, System der Psychol., §§ 78-80; Stumpf, Tonpsychologie; Sergi, Psychologie Physiologique, I. ch. III-VI; Richet. Recherches sur la Sensibilité; (Tempcrature Sense) Donaldson, Mind. x. 399 ; Bernstein. Five Senses of Man ; Morell, Elements, ch. III: Delbouf, Théorie générale de la Sensibilité; Sully, Psychology, ch. v; Pabier, Psychologie, bk. 2, ch. Ix-xı; Bain, Senses and Intellect, p. 117. For references on the individual senses, see Dewey, Psychology, pp. $78-80$.

On Psychometry: Wundt, Plys. Psych., ch. xvi ; Ladd, Phys. Psych., pp. 468-497; Ribot, Germ. Psych., ch. vII ; Sully, Sensation and Intuition. III, A, I ; Sergi, Psych. Phys., bk. 3, ch. Iv ; Cattell, Psychometrische Untersuchungen; Philosophische Studien (numerous articles).

On Psychophysics: Wundt, Phys. Psych., ch. vill : Ladd, Phys. Psych.. pp. 356-381 : Ribot, Germ. Psych., ch. v; Sully, Sens. and Int., III, A, II ; Grotenfeldt, Das Webersche Gesetz: Tannery, Revue Philosophique, xxI. 386 and xvil. 15 ; Delbœuf, Eléments de Psychop. and Ia Loi Psychophysique; Fechner, In Sachen d. Psychop. and Revision d. Hauptpunkte \%. Paychmp. ; G. E. Miller, Grundlegung d. Psychop. ; Fechner. Elemente 1. Psychophysik; F. A. Müller, Das Axiom d. Psychophysil:; Philosophische Studien (numerous articles).

On C'erebral Iocalization: Ladd, Phys. Psych., pp. 239-302 (with references); Calderwood, Mind and Brain, ch. IV; Sergi, Psych. Plys., ch. III-VI ; Charcot, Legons sur les Iocalizations; (A phasia) Huylings-Jackson, Brain, I. 304 and II. 203 and 323; Luciani, Brain, vil. 145; Ferrier, Functions of the Brain, 2d ed.: Franck, Lesons sur les Fonctions Motrices du Cercean; (especially) Horsley and Schäfer, Plitos. Trans. Royal Soc. of Iomulon, 1888, B. For the latest summary, see arts. by Mills, Park (Cerebral Surgery), and Starr (Aphasia), in Trans. of Cong. of Amer. Phys. and Surg., 1888.

Further Problems for Study:

Methods of psycho-physical study;

Experimental approach to the senses of smell and taste;

Application of mathematics to psychology;

Education of the senses. 


\section{CHAPTER VIII.}

PERCEPTION.

\section{§ 1. Definition of Perception.}

THE theory of perception is perhaps the most important as well as the most difficult problem of psychology. The interpretation of the higher processes of mind rests upon it and it underlies the body of our general philosophy. The great philosophies of the world take their rise from initial differences in the method of construing perception. Leaving the general problems of the theory of knowledge to metaphysics, we have to do only with the process of perception, considered as an operation of mind in attaining knowledge of the external world. That is, we have to answer the simple question, "How do we arrive at the knowledge of individual objects localized in space and time?" In view of the terms of this question and of the analysis which follows, we may define perception in a general way.

Perception is the apperceptive or synthetic activity of mind whereby the data of sensation take on the forms of representation in space and time: or it is the process of the construction of our representation of the external world.

Psychologists have generally been accustomed to distinguish between two forms of perception, as simple and acquired: meaning by simple perception, the presentative or knowledge element in sensation, and by acquired perception the derived and synthetic products of the apperceptive faculty. This is only partially true, since the essential fact in both cases is that of presentation. So that while recognizing this truth, it is difficult to separate simple perception from sensation. Indeed, as has been seen, the former is only the form of some sensations, not an independent thing, and it is more satisfactory to 
treat it in that connection. Perception, then, is limited in this chapter to the higher or synthetic process as it takes place in apperception.'

This has also the further advantage of distinguishing more sharply the two forms of knowledge as to their origin. The presentative element in sensation arises from an earlier mental reaction; but, as the basis of further reactions, it seems more akin to primary sensation. And synthetic perception only indicates knowledge in a more adranced stage.

\section{\$2. Axalysis of Perception.}

A little reflection leads to the conclusion that our perception of the external world is a matter of mental construction. All advance into the region of mind must be through mental states. The characteristic of mind is consciousness, and nothing can enter the domain of mind except through the mediation of consciousness. This is seen in the fact that our images play in consciousness in such a way as sometimes to deceive us in regard to the external world. When the eye is deranged, the mind is deceived in regard to colors and distances. When we have a cold, our taste is impaired. When the hand is amputated, irritation of the nerve ends is still localized in the hand. This amounts to saying that the mental picture which in every case is necessary to the perception of the object, is impaired or dissipated. The nervous system also intervenes between the mind and the world, and the proper activity of mind in representation depends upon the normal functioning of this system. This fact, that the mind deals with its images primarily and with external realities only through these images, is best seen when we consider that ail mental states are intensive modifications of a thinking subject, and that the percep-

'Cf. Suliy, Outlines of Prycliology, chrp. vi. There is undoubtedly need for ame worl like Pmf. Laurie's Attuition to designate the original knowiedge element in senantion, in distiuction from the active synthesis of Intuition. Sce Iaurie'g Metaphyrica now ef vetusta, p. 6. 
tion of the external world, however real that world be, with its conditions of space and time, is possible only by some power of mind whereby these conditions can be mentally reconstructed and the intensive lata of experience cast in the forms of this reconstruction.

As a process, perception proceeds upon the presentative element already found in sensation. In connection with each sense this element has been emphasized, and it forms the basis of all our finished perceptions of sense. For example, the representation of extension in the perception of an orange, makes possible the synthesis of affective states, smell, taste, color, which the percept involves.

The construction of the representation of the external world involves three subordinate but synchronous and essential operations, which we may call, respectively, Differentiation, Localization, and Intuition. And each of these, in the perceptive synthesis, has reference, first, to the perception of our own body, that is, of the intraorganic, and second, to the perception of objects foreign to our own body, that is, of the extra-organic.

\section{$\S 3$. Differentiation.}

The beginning of all life experience is probably, as has been already said, a state of general undifferentiated feeling. The affective consciousness, at this earliest stage, may be called an undifferentiated sensory continuum. This has been described briefly in the section on the growth of consciousness. There are, at this beginning of sensation, no distinct forms for the different senses, no feeling of externality, no perception either of one's own body or of things. It is easy to imagine one's self in that condition. All physical feeling is then vague, like the internal sensations which we cannot localize nor trace to their causes. It is probable that the muscular sense, with touch, constitutes almost the whole of this experi- 
ence. The earliest transition from this state of general sensation is also probably due to the muscular sense, through differences of intensity in feelings of resistance, and through the sense of locality in the body. The special organs of the other senses are more complex and must be adapted to their function of reporting impressions from without. Yet no step toward a real differentiation of sensations can take place till an active reaction of mind is possible in the shape of attention. As has been seen, definite sensations are unnoticed and not distinguished without attention. At first this attention takes the form of passive apperception. Apperception is itself the differentiating and defining activity. By it the unordered and chaotic mass of sensation, which is thrown upon the helpless subject, is divided and distinguished and made disposable by the further processes which constitute its completed activity. As this differentiation proceeds, each sense becomes a distinct source of affective experience, somewhat in the following order of development: muscular sense, touch, temperature, light, sound, taste, smell, color. The mere fact of differentiation, however, can give us no feeling of difference between our own body and a foreign body. This distinction can arise only after we begin to localize our states; and even then all these states are located first in the bodily organ through which they arise in consciousness.

It should be borne in mind that these stages in the process of perception are distinguished logically and in kind, and not chronologically. In a general way, we may suppose that the simplest facts of mind are earliest in their derelopment, from the fact that the more complex must proceed upon the simple. Yet we find processes of a higher order present and necessary in these early stages. For example, it is difficult to sce how this differentiation of presentations can be permanent, as a mental classification of experiences, without memory both in its retaining and its reproducing function.' Ihe dirisions neces-

' see Chrp. IX. 
sary to the treatment of the various aspects of mind should. not lead us to carry exclusive divisions into the mind itself.

\section{$\S$ 4. Localization.}

The second stage in the synthesis which is called perception is localization. By this is meant the mental reference of a sensation to a locality in space. In the finished product of the perceiving faculty we apprehend things as in space. Here is a new idea or form, of which, in the purely intensive character that sensation at first presents, we find no intimation. Whence does it arise, and to what factor in the perceiving process is it due? This is the question of the origin of the idea of space: one of the problems most discussed in general philosophy, and one to which contemporary psychology is fully alive.

The origin of the idea of space is more discussed than the origin of the idea of time, because, in the first place, it is the form of outer as opposed to inner phenomena, and according as its solution is idealistic or empirical, our theory of the external world finds its essential character. The idea of time, however, is bound up alike with phenomena of both spheres of experience, and whatever its solution, no advantage is given to one sphere over the other. The former question also presents more richness and complexity of data, and seems to afford more chance for a complete solution, from the very fact that it offers more varied alternatives.

Further, two things should be said in reference to the true manner of approaching this question. First, we should bear in mind that it is the psychological and not the metaphysical problem with which we have to do. It is our business to ask, whence the idea of space; not, what is space. The metaphysical probiem may remain unanswered after our psychological theory of space is complete, except in so far as the origin of the idea may require a doctrine of external reality. In this latter case, we are justified in using any data which a reasoned metaphysic may afford, understanding, however, that these data must conform to the results of our empirical analysis. And second, it must be remembered that the question of origin is a question of genesis, or beginnings, not a question of nature, or quality. The great difficulty with the older dis- 
cussions of this question is, that space in the abstract was brought into court, as a finished world-form of infinite extent: while in reality, psychology has to do merely with concrete perception and the space-form of that perception. Instead of starting with a finished space and asking ourselves how it is that we perceive bodies in it, we must begin with our individual perception of body in all its real complexity of matter and space-form, and ask how we can analyze this complex fact of experience in such a way as to account for its space-form. '

The Perception of Space. It is generally agreed by psychologists that our first experiences of space are connected with the muscular and touch sensations of our own body. As has been said, the sensory continuum, before all differentiation, is largely muscular. The beginnings of differentiation seem at once to implicate the extensive or massive quality of sensation. There is a vague feeling of whereness in this early muscular sensation, and it becomes more definite as the extensive or spread-out sensations from the skin become broken up in localities. But at this beginning of space-experience the question confronts us: How can excitations of the skin and muscles, which are transmitted in the form of molecular action through a homogeneous nerve substance, and which have thereby lost their local coloring, report their locality to the subject: and further, how, if they preserve this local coloring in such a way as to present specific differences of motion at the central bureau, can these differences be reported to the mind, which is an unextended thinking principle capable only of intensive states?

There is only one answer which does not either beg the question at issue or overlook some one of its essential conditions: i.e., The mind has a native and original capacity of reacting upon certain physiological data in such a way that the objects of its activity apperr under the form of space.

' See Croom Robertson, in Mind, 1.1. p. 118. 
In the following paragraph, the relation which this position bears to other theories will be apparent. Recent discussion 'tends clearly to emphasize the fact that no purely empirical explanation is sufficient to account for the extensive form of sensation. Be the data what they may, and be they as important and essential as external data always are in perception, there will yet remain the barrier between intensive feeling and extensive thing. This barrier can only be broken down by an exercise of some form of activity whereby space is mentally reconstructed ${ }^{2}$ upon the basis of the data of sense.

It is objected to this view, that it leaves the problem as obscure as at first. What is this mental reconstruction? This is true, but the same may be said of any other process of mind. What is perception in general? What is sensation? A mental reaction upon a nervous stimulus. What is space perception? The same with the added reaction of space-form. One is as mysterious as the other. But while this is true, this view of the case leaves the question of the data necessary to the perception of space entirely open and thus takes advantage of all the results of the empirical treatment of the senses. The mental reconstruction may proceed upon its own data in each of the senses which give us space-form, and it is our part, as Lotze says, to discover these data and to borrow from physiology all that is attainable and useful in the premises. What these data are for the different extensive sensations, we next inquire.

This is seen to be a form of nativism, but a nativism purely of process, not of product. 'The power to perceive space is as native as the power to perceive anything else; but this does not mean that space is native to the mind any more than trees are or music. Objects are given to us in space, and space is given to us with objects; they are inseparable, and both are, in thought, the product of the synthetic activity of apperception.

Data for the Perception of Space. In the perception of space relations by the muscular sense, touch, and sight, the three senses through which this form is presented, two classes of data seem to be involved. These data are of a physical kind and serve as basis for the mental

${ }^{1}$ Lotze, Wundt, James.

2 "Wiedererzeugung der Rüumlichkeit," Wundt, Theorie der Sinneswahrnehmung, p. 51. 
reaction just spoken of. They are muscular movements and local signs.

I. Muscular Movement. Under the discussion of the muscular sense, the twofold nature of the sensations inrolved was spoken of. Sensations of effort or motor innervation were distinguished from sensations of resistance. The former of these was seen to be central and the latter peripheral. The latter has its anatomical seat in sensor fibres in the muscles or skin, thus assimilating this element of the muscular sense to pure sensations of touch. Both of these seem necessary to the finished feeling of movement, though feelings of resistance play a predominating rôle. We learn from cases already mentioned, that if the feeling of resistance be destroyed, a limb may be moved voluntarily with no knowledge of the actual movement, but, on the other haud, the movement of a limb mechanically is felt as movement when there is no voluntary motor discharge. Hence, though we may hold, with Spencer, that space is a succession of resistances or, with Hall, that space is primitive in the muscular experience, we still find the element of muscular resistance in our first sensations of locality. We see below that movement enters also in the perception of tactual and visual space. Inasmuch as feelings of resistance involve touch as well as pure muscular experience, the second of our data, the local sign, is brought into play.

II. Local Sign. By local sigus are meant specific local differences in the arrangement (Lotze) or structure (Wundt) of the cuticular substance. By these differences, localities partake in perception of the position they occupy in space. I refer an excitation to my hand or foot: why do I give it such a specific reference? Why do I locate a pain in my right hand rather than in $m y$ left? Simultaneous sensations of a purely intensivo nature, as tastes, sounds, are fused together; but simulta- 
neous sensations from neighboring points of the skin and retina preserve their peculiar character and relation to one another. As has been said, the first idea of our own body results from muscular sensations which accompany the feeling of effort, and these sensations are vague and confused; yet even here the feeling of extension is present, also vague and confused. Whence comes it? It can only come from initial differences of some kind which are perpetuated through transmission to the sensorium. These differences, probably in the skin or sensor nerves, and probably a matter largely of association, afford a second datum for the localization of sensations in different portions of the body.

The theory of local signs was first propounded by Lotze, who, however, varied it in its application to the several extensive orders of sensation. For sight, he made the local sign consist in the fixed amount of muscular movement which any retinal point must undergo to be brought into the line of clearest vision. This is a different and definite quantity for every point in the retina. In the skin, the local sign, for Lotze, was the combination of light accessory sensations which are provoked in immediate connection with the point of contact. There would be a varying amount of radiation of stimulus in the skin according to the varying structural consistency of the parts over which the skin is stretched, as bone, muscle, ligament. This hypothesis found development in the more natural position, ${ }^{1}$ that the local sign was an implanted peculiarity in the structure of the skin itself. A further theory, very widely adopted, and suggested by Czermak, makes the local distinctions in the skin due to the rumifications of the spread-out nerve fibrils, each such nerve end reacting for its own position and being thus a local sign. ${ }^{2}$ This position is most probable. It is supported by the fact already cited, that the sensibility of the skin to local differences varies greatly in different parts of the body, and may be increased by the fixing of the attention, by exercise, and in the hypnotic state. These latter conditions tend to bring into play finer elements of the ramifying nerve, and thus to diminish the distance botween the sensitive points. And the same facts tend to refute.

1 Meissner.

${ }^{2}$ See Sully, Outlines, p. 119. 
the theory that the units of tactual feeling are found in Weber's "circles of sensation."

Besides the general consideration that some such hypothesis as that of local signs is necessary to the case, there is direct evidence of the existence of these signs. The fact of rarying local discrimination in the skin has been mentioned; it is also true of the retina. The relative discrimination of localities grows less delicate as we proceed from the centre to the edge of the retina, ${ }^{2}$ and colors lose their intensity as they are projected more and more upon the side of the retinal surface. 'The quality of massiveness or extensity of sensations of touch and sight depends upon the simultaneous independent excitation of units of sensition, and can be accounted for only on the assumption of some characteristic by which these units are kept distinct. If the skin of the forehead be bent down upon the nose and grow there, its irritation is felt still at the forehead. The same is seen in the retina in certain pathological affections, in which the retinal elements are displaced: the irritating points of light falling upon these elements are localized where they would be seen by the healthy eye."

But the fact of local signs is not sufficient to account for the perception of space. Whatever these signs be, the color or local tone they give is a modification in quality alone, an intensive change in the sensation in question, and there still remains the necessity for a mental reaction whereby this intensive sensation, modification or sign is construed in extensive form. How can we infer differences of position from differences of pure feeling? Let a sensation of red be modified in any way whatever as to its redness, and we are still absolutely in the dark as to its location on the right hand or the left. Admitting the concomitant sensations of Lotze, one of two things must be true: either these concomitant sensitions coôrdinate themselves in space in virtue of their own quality or they do not. If they do thus coordinate themselves, why could not the original sensations coürdinate themselves? If they do not thus coördinate themselves, what help are they to us in this coürdination? 'They must be only data by which the coördinating activity of mind proceeds in the matter of space perception."

'On the general theory of Local Sigus, see Ribot, German Prychobogy, chaps. III. and Iv.

"See Sully, Senation and Intuition, p. 54.

Wundt.

4 Wundt, Phys. Prych., 8d ed., it. p. 88.

'It is not necessary, bowever, with M. Rabler (p. 63) to deny the 
Synthesis of Data: I. Tactual space. The two kinds of data mentioned are found in all spacial localization. From the fact that they are thus found, that they enter necessarily into the nature and functions of the sense organs by which space is reported, and that the nonextensive sensations are wanting in the physical conditions which they represent, we are led to conclude that they are at the basis of the reconstruction of space. Upon this basis the mental reconstruction of spacial position proceeds. Locality being thus given, its definition becomes very exact in experience. Feelings at first vaguely localized are given precise spacial position. This is rendered easy by the exploring power of active touch. If left to passive touch from external objects, it is unlikely that we would ever arrive at a clear conception of the extent and form of our own bodies. But by free movement of the hands, with active touch, the relative parts are explored. This is evident from the fact that localization is most exact in the parts of the body most open to active touch and freest in movement, as the hand, arm, tongue, as contrasted with the back and cheeks. This process is also aided by our larger movements and their reversal, and takes place with rapid advance in early childhood.

It should he noted that the idea of our own body is not complete until we already have an idea of foreign body. Such a complete idea involves the action of one part of the body upon another, as the feeling of one hand by the other, to which it is really foreign. It is probable also that sight, as of the hand considered as a foreign body, makes the idea of our own body more distinct. This is seen in the very vague and indistinct ideas of size and distance on the part of those who are born blind.

utility of local signs, as giving us only another series of sensations to explain; for, however obscure their rôle may be, they do enter into our perception of space, as is seen in the fact that sensations for which there are no such signs have no space-form. 
II. Visual Perception of Space. As has been already intimated, the same data enter into the visual perception of space, muscular morement and local sign. The evidence of the presence of local signs in the retina has also been adduced. Ever since the time of Berkeley, it has been generally admitted that the original perception of the eye is of a colored surface only: that is, that the eye has no immediate perception of depth or distance. This is shown most decisively by cases in which sight has been restored to those who were born blind. About a dozen cases of the removal of congenital cataract from the eyes of persons of some age are on record, the oldest and most famous being the Cheselden case. ${ }^{3}$ In each of these cases the evidence is very clear. When sight is restored the patient sees everything in the same plane: there is no distance, no relief, nothing but a colored surface, and this surface seems to be near the globe of the eye. The blind man on whom Cheselden operated said that objects touched his eye. Home's patient said the same of the sun and of the head of the physician. The patients of Nunnely and Franz had the same experience.

The muscular movernents of the eye are of extreme delicacy and variety. There is for every point of the retina a fixed coefficient of movement necessary to bring that point in the centre of clearest vision; and when such a point, right, left, above, below, is excited there is at once a tendency to revolve the ball of the eye in such a way as to bring the line of vision through this point. This represents a given degree of central innerration or muscular strain. Since ocular movement precedes vision, there are no means whereby such movement can

' Berkeley, Theory of Vision.

- See Naville, Revue Scientifique, 1887, p. 943.

'See details of Cheselden and other cases in McCosh's Pyychology, vol. I. p. 45. 
be eliminated from the data of synthetic activity of mind whereby we see things extended; and further, the influence it exerts in localization is seen in the fact that if one of the muscles of the eye be destroyed, so that no movement follows its stimulation, objects are localized as if this movement had taken place.' The necessity for such a synthetic activity is the same as in the case of touch. Sensations from the extended surface of the retina and from its movements over the visual field can be only intensive modifications of consciousness, which are apprehended under space-form by the mind's own reconstruction. The process in this case is the same as in touch and the muscular sense, though we are no longer concerned with the origin of the notion of space. Spacial perception by touch and the muscular sense precedes spacial perception by sight. The idea, as a mental acquisition, is probably gained roughly before we see at all. But this does not impair the fact of spacial perception by sight. Having the idea of space, why do we clothe the data of sight with this form, and why do we not thus clothe the sensations that do not have it in our finished intuition? Evidently because sight offers also the data which we found previously necessary for the mental reconstruction of space.

The fact that tactual precedes visual space renders it exceedingly difficult to determine what is peculiar to vision. We can reach tactual perception alone by observing the blind, but there are no cases of patients having sight but wanting in skin and muscles. For this reason, those who find in sight

'See references given by Wundt, Phys. Psych., 2d ed., Ir. p. 91, and r. p. 375: "For instance, one suffering from paresis of the right external muscle of the eye, where the muscle is able by the utmost. effort to effect a lateral movement of $20^{\circ}$, locates an object, which in reality is only $20^{\circ}$ distant from the median plane, at a point as far outward as corresponds to the utmost outward movement of the normal eye, and when asked to touch the object places his finger far beyond it to the right." 
an immediate perception of the third dimension have no data of a positive kind to prove their point.'

Presentation of Foreign Body. The distinction between our own and a foreign body arises rery early in child life and is not subsequent to the completed idea of our own body. As we have seen, the perception of our own body as extended involves both distance or movement, and resistance. In the primary feeling of resistance, we have the beginning of the perception of foreign body. The amount of movement or distance, measured in feelings of innervation, indicates roughly, at first, but with great precision later, the localities of objects around us in reference to our own body. This is greatly aided by active touch. We feel round a body and give it the third dimension, which we have already found to be an attribute of our own body. The distinction between our own members and other objects is further assisted by the phenomenon of double touch; ${ }^{2}$ that is, the two sensations of touching and being touched, when we come in contact with our own skin. In paralysis our own limbs are to us as foreign bodies, inasmuch as the sensation of active touch alone is present.

The general law which regulates the localization of sensation is this, that sensations localize themselves by association with their cause or condition in the orgunism. Consequently, tactual and visual sensations are at first associated with their respective organs. But, on the other hand, tactual and, as shall appear later, visual sensations often involve movement of the hands to seize or feel, and of the eyes and head to perceive distinctly. This involves distance and adjustment to that distance. So another set of associations comes into play, and the sensations are referred secondarily to objects away from the organism. 'This secondary association becomes the controlling one from the fact that, as our experience extends.

\footnotetext{
' James, Perception of Space, 3 articles, Mind, '87 ; also Hering and Janet.

' So Coudillac.
} 
the reports of the different senses gather around these points of external reference and make them permanent.

Visual Perception of Distance. The visual perception of distance or depth proceeds upon the tactual and muscular perception of distance. It consists in the acquired interpretation of light and color differences in terms of distance already given by the skin and muscles. The original colored surface presented in vision is projected more or less distantly, according as its lights and shades are associated with a greater or less muscular or tactual coefficient. This is seen in the fact that the original errors of sight, in respect to distance, are rectified by touch and muscular movement. In the Trinchinetti case, the patient at first " attempted to grasp an orange with her hand very near the eye, then, perceiving her error, stretched out her forefinger and pushed it in a straight line slowly until she reached her object." Other patients have done the same, when first restored to sight. ' This interpretation in terms of muscular and tactual feeling becomes, in later experience, a matter of the sensitiveness of the eye itself. Its own mechanism of movement and retinal reaction gives data by association for the perception of depth.

A number of factors enter in the mechanical adjustment of the eye to sight at different distances. Among them we may mention: $a$. A muscular strain when the object is near, due to the slight contraction of the pupil and the swelling of the anterior surface of the crystalline lens. This is called the sensation of accommodation. $b$. Difference in an object when seen near or far with both eyes. The difference in the angle of vision of the two eyes, enables us to see parts of the sides and thickness of the object gazed at, and this datum of depth varies with the distance. c. Strain arising from the varying angle made by the lines of vision of the two eyes. When the object is near, the eyes turn toward each other; this is known as the sensation of convergence. d. Dimness of out-

'See McCosh, Cognitive Povers, p. 49. 
line of a distant object, the retinal elements being but feebly excited. e. Diminished size, fewer of the elements being excited. $f$. In addition, there are more general considerations which aid our estimation of distance, such as the number of interrening objects, the known size of the object, and others. But these, with the two preceding, partake more of the nature of a conscious judgment. That the muscular morement of the eye is concerned in the estimation of depth, is proved by the fact that when any one of the muscles is destroyed, the localization of objects away from us is mistaken. This is explained by the consideration that the locality which is associated with a given feeling of morement, is fixed upon whenever that feeling is experienced, even though the actual morement do not take place.

The finer estimation of distance is a matter of cultivation and practice. Indications entirely lost to the ordinary observer are unconsciously taken into account by the sailor and artist: such as the length of shadows, the air perspective, and delicate discrimination of colors. All this is clearly a matter of acquired judgment, which may be improved to an endless degree, almost, by the exercise of trained attention and study. In pictorial art, the process is reversed, the object being to interpret back upon a plane surface those data of the perception of depth which have been before uncon. sciously recognized. So fixed do the associations of distance become that, while our own sense experiences were sufficient to convert our primitive sensations of color into a complex of objects about us, we need a teacher of the elements of perspective to enable us to rerert again to the conditions of our original perception.

Localization of Sounds in Space. The position of sounding objects in space is roughly indicated by the ear, but this rough localization proceeds upon the previous intuition of objects by touch and sight. It is only after the surrounding world is tolerably familiar and its sounds already associated with known objects, that the sensations of hearing are definitely placed. This localization by the ear involves distance and direction. The distance of sounding bodies is judged from the intensity of the sound, especially when its normnl sound is well known. When the hearing is impaired, sounds are located farther awny. The seuse of direction seems to 
arise from several causes, the principal of which is the relative strength of the sound in the two ears. The sounding body is located on the side of the ear which receives more sound waves. If a sound be made on the median vertical line through the heal-say above-it is not localized, but a slight variation on either side the line is at once detected. Consequently, we locate sounds as right and left, before and belind, much better than up and down. Again, there is a tendency to locate loud sounds in front, from the fact that more sound waves from that direction are collected by the external ear. Delicate sensations of touch and muscular movement, also, in the ear, aid us in localizing sounds, though to a much less degree than in the hearing of some animals whose ear muscles are largely developed.

Feeling of Equilibrium from the Ear. ${ }^{1}$ Recent investigations have shown that the feeling of equilibrium of the body in space is due to combined muscular and auricular sensations. ${ }^{2}$ The feeling of erectness arises from muscular strain in the limbs and trunk. The feeling of direction involves also the muscles of the eye. Feelings of the rotation and general position of the head in respect to the body, are given by the semicircular canals of the ear. These canals are projected in the three dimensions of space to which they seem to have, respectively, a determinate relation. ${ }^{3}$

1 See Ferrier's account in Functions of the Brain, 2d ed., ch. IV. 1.

${ }^{2}$ Delage, Archives de Zool. exper., No. 4, '86, pp. 535-624 (see Amer. Jour. of Psych., No. 1, p. 179).

${ }^{3}$ Cf. Elie de Cyon, Comptes Rendus, 1877, and Mind, vol. III, by whom the semicircular canals are considered to be immediate senseorgans for the perception of space. He finds in the eighth pair of cerebral nerves two distinct sensor courses, the auditory nerve and the space nerve. He also shows that there is a connection between the canals and the motor functions of the eye muscles, thus bringing into the problem the phenomena of ocular movement, which Delage thinks suf- 
Ideal Product of Localization: Idea of Space. The apprehension of space as thus treated, is acquired in concrete perception. Space, heretofore, has meant extension, considered as an attribute of objects extended. The finished idea of space, as a void continuum, is derived only by a process of abstraction to be considered later. From the perception of a body extended we pass to the conception of an extension or space which this body fills : we abstract the body and leave the space. The infinite aspect under which both this idea and that of time take form, also comes up for further exposition.

\section{§ 5. Theories of Space Perception.}

Two general theories of space perception are held by psychologists, and under them may be classified the various attempts made to explain the origin of this idea. These are the nativist and the empirical theories. Empiricists hold that presentations of extension (and time) are derived through experience from elements which have not the spacial (and temporal) form. On the other hand, nativists maintain that space and time presentations cannot take their origin in data of consciousness which are simply intensive; consequently that these presentations are primitive data of knowledge, native, innate. In other words, the empiricist asserts the re-

ficient to account for certain rotatory movements of the body without the canals. Cyon advances the theory that the canals have the general function of presiding over the discharge and innervation of the motor centres for all the muscles; and of giving us at once an idea of space in three dimensions. "This central organ of the sense of space presides in the distribution and graduation of the force of innervation communicated to the muscles for all the movements of the globe of the eye, of the head, and of the rest of the body."-Comptes Rendus, 1877, p. 1285. As a phllosophical theory of the origin of the perception of space, this view of a special space sense is open to the objectlons already urged to all strictly empirical theories. See, also, experiments of Brewer, Amer. Jour. of Paych., vol. ir. p. 832. 
ducibility of presentations of space and time, and the nativist asserts their irreducibility.

Further, nativism may be considered as a nativism of process, or a nativism of product. The former is the theory already advocated and has been sufficiently explained: it is held with some differences of detail by Wundt and Lotze.

I. Nativism of Product: Kant. According to the latter, the idea of space and time are the necessary products of the mind's activity in sense perception, and the universal forms which it contributes to the intuition of things. Space, therefore, is an ideal innate construction of the mind imposed upon an unknown external content, rather than a synthetic reconstruction by the mind by which objects which exist, become objects perceived, known. In objection to the theory from a psychological standpoint it may be said: $a$. It does not account for the difference between the extensive and the non-extensive sensations. If space is a form of mind in its sense function, why do not all sensations show this form? $b$. The perception of space cannot be placed on the same footing with that of time, since time is the form of all sensation and higher activity. ${ }^{1}$ c. Again, the idea of space is not. given to us as a finished product, but is built up from tentative experiences of objects. It is a combination of empirically derived localities, which owe their position to signs in the objects themselves. It is only as essential data to the notion of space that differentiating local coloring can be effective. How could objects having no

1 The distinction of Kant, that space is the form of external sense (sight, touch) and time the form of internal sense (consciousness) is not exact. For color, feclings of touch, etc., are just as much internal as any other facts of consciousness. The phrase "external sense" can designate nothing more than the ensemble of the senses by which we perceive the external, and to say that space is the form of the senses by which we perceive space is tautology. 
local significance take place in a homogeneous ideal space? $d$. The different behavior of young animals and young children shows their perception of space to be different. Young chickens stand erect, run in a straiglit line, and thrust their bills skilfully in the direction of their food. Young animals turn at once to the teats of the mother. But the young child goes through a long and painful experience in learuing the first conditions of spacial movement and action.

II Empiricism. The adrocates of the empirical derivation of the idea of space rely upon one of two means of accomplishing it: deduction and association.'

1. Deduction. It is said that the form of space (and time) is deduced consciously or unconsciously from data which have not this form. But this seems, if it be truly deduction, to be impossible on its face. A true deduction of space must necessarily proceed upon data, premises, of space; but to allow it in the premises is not to deduce it.

For example, Herbart deduces space from a series of sensations whose order may be reversed. Let a picture be the extended object perceived, having the points $a, b, c, d$, which are successively taken in by the eye. Now, in the mental construction of the image of this object, those sensations longest in conscionsness are least intense; so in order of intensive reproduction, the points are presented $l, c, b, a$. 'Thus is reached an intensive reversal of an extensive order. All this is true; but the question remains, why is this reversed order projected in space? $\mathbf{\Lambda}$ series of musical notes are reversed in intensity the same way, but they do not assume extensive form. 'There must be some local coloring in $a, b, c, d$, in addition to their time order; but to admit this is to assume the thing deduced. In the same way, Mill overlooks the specific character of the notion of extension in reducing it to a feeling of simple succession. "The ides of space," says he, "is at bottom an idea of time: the notion of extension or distance is that of a series of muscular sensations continued for a longer or shorter time."

'Cf. Rabier, loc. cit. p. 132. 
2. Association. The case is no better with association, as a means of deriving space from unspacial data. Can spacial presentations be constructed from an association of elements foreign to space perception? Not at all; for association has no transforming power, whereby a product is arrived at specifically different from the elements associated. Association can unite what was separated and dissociate what was united; but from the nature of mental states, as states and not things, the laws of their association give no clue to their transformation in terms of extension. Consequently, as says M. Rabier, psychologists who have recourse to association to explain presentations of extension, fall into one of two fallacies: either they introduce extension covertly into the associated data, or, preserving the premises free from extension, they bring forth a product which is not extension at all. Either a petitio principii or an ignoratio elenchi is the result.

Bain's view seems to illustrate the first of these fallacies. He derives the notion of space from the association of muscular sensations among themselves and with tactual sensations. "The prolongation of the muscular contraction," says he, "indicates the course of the organ through space." Now if the idea of space enters through the intensive feeling of muscular contraction, there is more in our conclusion than in our premises and we have an ignoratio; if, on the other hand, the sensation is one of movement proper, extension has already entered and we need no association; this is a petitio. This criticism applies to the theory of Bain in all its details, as to the origin of vague representations of extension, the measure of extension, and direction, all of which he aims to derive from conscious muscular sensations and their differences in point of intensity, succession, and rapidity. In all this there is not, in our view, the first beginning of an explanation of the origin of the notion of space. We are obliged to fall back upon a power of mind whereby the data, given in sensation as affective and intensive, become extended in perception.

The question has often been asked of empiricists, why it is that the muscular sense alone, and not other senses, as hear- 
ing, gives us this idea. In sounds there are differences of intensity, duration, and rapidity. Feelings of continued or successive resistances are feelings just as feelings of continued and successive sounds are, and, before the association claimed, they are equally wanting in the form of extension. Why then are the muscular sensations alone convertible into extension? Bain and Spencer cannot answer, as we do, that it is by reason of certain characteristics of these sensations upon which the mind's peculiar space perception proceeds. They would then be nativists. They are bound to explain why it is that notes do not form lines nor chords surfaces, while muscular sensations, which are equally intensive affections, do form lines and surfaces.

The second of these fallacies is exemplified by the theory of Mr. Mill already spoken of. He starts with succession a matter of time, ends with succession a matter of time, and does not reach space at all.

Under the term "synthesis," some empirical thinkers attempt to hide the weakness of the case for association. They distinguish a simple mixture from a synthetic combination. Space, say they, is the result of such a synthetic combination of elements to which it is in the first place foreign. But if it be a true synthesis, by its very nature it conceals the properties of the elements combined, and it is impossible to say what mental data are involved. How do we know that the states of consciousness indicated as elements of the presentation of extension, are not simple occasions, antecedent conditious, which in themselves do not suffice for its production, howerer they may be necessary to it? Any such empirical synthesis is open to the demand that the account of its elements be exhaustive: to admit any unknown element is to give up the empirical position, for this element may be native. From this point of view, the adrocates of synthesis grant to the "nativists of process" all that they ask. They grant that presentations of extension appear sucldenly in consciousness, they do not know how; and that these presentations cannot be derived logically from any other states of consciousness. This opens the door for the claim of the nativist, that while these elements are truly concerned in the mental synthesis of space, and while the empiricist's appeal to an unknown combination is justified by our ignorance; yet we may go farther and say that no such intensive elements and no such combinations can be, in themselves, sufficient, without a native reaction of mind by which space is reconstructed. 


\section{§ 6. Sense-Intuition.}

The third and last stage in the mental synthesis of the finished perception of the external world may be called Intuition. In the first of the three stages under which we found this process naturally taking place, i.e. Differentiation, we saw the breaking up of the general and vague sensory continuum of the earliest child experience into the differentiated and recognized sensations of the different senses; in the second, i.e. Localization, these sensations have taken position in space; in the third, i.e. Intuition, sensations are gathered together in the permanent units or wholes which we call things in our developed perception.

As illustrating the incompleteness of the perceptive process at the stage to which we have now advanced, we may imagine the subject with a given number of well differentiated and localized sensations; say, a taste, a smell, a touch, and a color. These have no connection among themselves at their first experience, although given the same local and temporal position. There is no reason that they should be thought of together, or that one should suggest the other. That is, there is no reason that the intuition apple should emerge. There is a further process by which this important lack is supplied, and sensations, until now isolated and disconnected, are thrown into permanent complexes or groups. In this further advance, several necessary steps are apparent.

I. Attention. However sensations may be grouped in the passing panorama of diffused consciousness, they have no connection unless their coexistence is attended to. And not only so, but it is doubtful whether simple passive attention would be sufficient for the grouping of sensations in a complex whole. It may at least be safely said, that the arranging and coördinating power of active attention greatly facilitates the earliest intuition of 
things. It is here that the relating or apperceptive function of active attention is most apparent. It will be seen in treating of memory, that the degree and intensity of the power of retaining and reproducing presentations depends upon the degree of attention given to the original experience. This is especially true of the relations in which these origiual presentations stand to one another. The touch, taste, color, smell, or any two or three of the qualities of the apple are experienced, for the first time, in immediate conjunction and, while merely a colligation of sensations, are attended to as such, and their coexistence apprehended. At first the muscular and touch sensations, as localized, precede, and with these the sensations of other senses are observed to be simultaneous. Thus begins the further fact :

II. Association: a principle by which presentations once experienced together, tend to come up in memory in the same order of contiguity. By this principle, the renewed experience of one of the former sensations tends to arouse the others with which it was before experienced. In the further extension of our experience, additional sensations are added to the associated complex, as when we learn that an apple before known as spherical and red, is also sweet and fragrant. Like associations in general, this grouping of sensations becomes fixed only by extensive repetition and movement, ${ }^{2}$ and as this repetition and movement conform to or modify the complex, the intuition is confirmed or new products distinguished. Thus the object in perception becomes clearly defined and distinguished from others, and the external world takes on its permanent form, as a whole of various things existing in space relations.

An additional fact, important to the permanent fixing and discrimination of percepts, is this, that we learn very early

' On the function of movement in defining and differencing things, see Waitz, Lehrbuch d. Prychologie, $\S 48$. 
to name objects as we perceive them. This is the result of a mental power considered later, and need be noticed here only as a great auxiliary to the lasting quality of our sense intuitions. In the ordinary education of children, when their knowledge of language goes ahead of their experience of things, the names are ready beforehand and are applied, under instruction, to objects present, with a number of qualities clearly pointed out. Thus the process of growth in the combination of qualities is greatly abbreviated. Teaching by object lessons is therefore justified psychologically as a method, in that it leads the child to attach the right name to the right object, in the first place, and thus to avoid all tentative and mistaken efforts at discrimination.

Motor Intuition. ${ }^{1}$ The organized data of muscular movement become for the motor consciousness what the organized sensations of the special senses become for the sensory consciousness. Individual motor feelings are integrated in intuitions of external worth. These motor intuitions take the form of ideal coördinations of movement, and become more and more sure and automatic as the muscles are exercised in groups after repeated effort. In as far as they are constituted from simple sensations of movement, they are the earliest data for sense intuition in general. But in as far as feelings of effort are also bound up with feelings of movement, the former constitute a new and active measure of our perceptive construction of the external world. The early random movements of the child are thus worked up into the systematic coördinated muscular groups of the adult life, by adaptation to the environment: for example, walking, piano-playing.

Ideal Product of Intuition. In the process of combining different sensations into a percept whose meaning for the mind is that of a single thing, a new idea or notion takes its rise. This is the idea of synthetic unity. By synthetic unity is meant the unity that stands for itself alone

${ }^{1}$ Bewegungsanschauung. Compare Maudsley's discussion, Physiology and Pathology of the Mind, American edition, chap. virr. 
and cannot be divided; yet the unity that has parts, and results from their synthesis-as the idea of an organism, made up of its various organs. The percept is such a product. The fact of many presentations becomes the fact of the presentation of the many. In the words of Kant: "The conception of combination involves, in addition to the notion of multitudinous elements and their syntheses, the motion of their unity. . . . Combination may be abstractly defined as the idea of the synthetic unity of the manifold."

This is to be distinguished from the idea of general or numerical unity which probably rises in consciousness earlier. It is difficult to see how all feeling of unity and plurality can be absent in the beginning of the differentiation of sensations. It is more difficult as soon as sensations begin to be localized, as are sounds in time and things in space succession. The very discrimination of mental states seems to involve numerical difference. This must precede the idea of synthetic unity, therefore, since the notion of combination includes that of the different units which enter into it.

Sense Perception and the Unconscious. In discussing the unconscious, we have already spoken of the theorists who claim that the fact of a process in perception, of which we are not immediately aware, is evidence of unconscious mental activity. If this threefold process takes place, we are told, and we are not aware of it, it must be unconscious. Yet upon looking closely at the process as we have understood it above, this necessity is removed. We must consider that the growth of perception is coincident with the growth of consciousness itself. However true it is that we know no such process in perception now, it is also true that we did know it, in part, when our consciousness was first taking form. The differentiation of sensations and their recognition as qualitatively distinct, were perfectly conscious. The young

'Quoted by Morris, Kant, pp. 106-7.

2 Chap. IV, \& 2. 
child is conscious of the sounds and sights around it, even before it discriminates them.

In the process of localization in space, the case is different, and upon this great stress is laid.' But here, if we accept the explanation given above, we are not called upon to recognize mental elements at all among the unconscious data of this form. Muscular movement and local signs are physical data, and the synthesis whereby they indicate space position is an immediate act of mind. It might with equal reason be claimed that because the will proceeds upon nervous discharge at the motor centre, a volition to move the arm is a derived and secondary mental fact and rests upon unconscious processes. The fact that the synthesis of these data is mysterious and its exact nature quite unknown, is sufficient to forbid a conclusion that it rests upon unconscious mental elements.

As for localization in time, ${ }^{2}$ the case is clearer still. Here we have no reason to suppose the unconscious. The two classes of data involved are both perfectly conscious, i.e. intensity of sensation and movements of attention. In the final stage, also, intuition, we deal with the earliest forms of child-consciousness, as in differentiation. Consciousness is itself developing. It is probable that the grouping of sensations and their association in permanent form rests upon conscious experience. This process leaves no trace upon adult consciousness, after the analogy of all such early experience. And after the reasoning power is called into activity, the intuitive synthesis is no longer necessary, since by that wonderful capacity of mind to abridge its efforts and conserve its products, old products are held by a name, and the idea of synthetic unity is ready formed for any combination of external qualities we may meet in uature. 
Deceptions of Sense Perception. Errors arise in the process of synthetic perception from the fact that we are no longer conscious of the steps in the process. We fail in our estimate of distance by the eye, of direction by the ear, of time, past and future. We are subject to certain permanent optical illusions. These and all other mistakes of the senses are explained as being fallacious inferences from data at one time conscious and truthful. These errors cannot be shown to extend to sensation itself. A sensation must, by definition, be what it is felt to be. For the same reason, error cannot attach to the presentative element in our first experiences. This will be further treated in the chapter on Illusions.

\section{$\S$ \%. Reflection or Self-conscioussess."}

The highest form of consciousness has been seen to be self-consciousness. In self-consciousuess there is a turning in of the experience upon the self. This involves the establishment of the relation of subject and object which is the fundamental fact in perception, and the return of the mind to itself as its own object. By the result of reflection is meant, therefore, the knowledge which the mind has of its own operations, recognized as its own. It is an advance on the simple awareness of conscionsness, in which there is no reference to self as different from its object. In reflection, this reference has distinct place, and the self is discovered through the act of attentive inspection, as having and exercising the characteristics of mind. The notion of self, like other notions, is a gradual growth. The vague feeling of the ego which the first affective experiences afford, is defined and enriched by added marks, such as efficiency, identity, and permanence. Especially as cause is the self realized early, in connection with muscular feeling and will. 
Ideal Product of Reflection : Idea of Self. Through reflection, therefore, the idea of self is attained and assumes its important place in the mental world. Round the self as a centre the intellectual life plays. To it all possible forms of experience are referred. It brings coherence into the circuit of consciousness, by giving it a centre of reference and a circumference of limitation to the individual.

On perception, consult: in general, McCosh, Cog. Powers, bk. 1, ch. I; Wundt, Phys. Psych., ch. XI-xIv; Carpenter, Ment. Phys., ch. v; George, Psychologie, p. 77 ; Porter, Hum. Intel., pp. 158-221; Ladd, Phys. Psych., pp. 382-467 ; Wundt, Theorie d. Sinneswahrnehmung, pp. 376-445; Waitz, Lehrbuch, §§ 20-27, and Grundlegung der Psychol., pp. 92-100 ; Fortlage, System der Psychologie, \$ 31 ; Laurie, Metaphysica, pt. 1; Spencer, Psychol., II. pp. 131-256 ; Sergi, Teoria fisiologica del percezione; Loewy, Die Vorstellung des Dinges; Binet, La Perception extérieure; Uphues, Wahrnehmung und Empfindung; Ueberweg, Logic, pt. 1; (History of) Bailey, Letters on Philos. of Hum. Mind, 13-20; Sergi, Psychologie Physiologique, bk. 2, ch. IV-vi ;' Ward, Encyc. Britann., art. Psychology; Hamilton, Metaphysics, Lect. XXI-XXVI. Besides, general treatment is to be found in all the works upon psychology, as Sully, Outlines; Rabier, Psychologie; Spencer, in loc.

On space-perception: Fortlage, Beiträge zur Psychologie, pp. 242-281; Volkmann, Lehrbuch d. Psychol., § 18 ; Ribot, German Psychol., ch. Iv; Herbart, Lehrbuch der Psychol., \$\$ 167-178; Stumpf, Psychologischer Ursprung der Raumvorstellung; Spencer, Psychology, II. pp. 178-216; Montgomery, Mind, x. pp. 227, 377, and 512 ; Hall, Mind, III. p. 433 ; Sully, Mind, III. pp. 1 and 167; Sergi, Psychologie Physiologique, bk. 2, ch. VII and $\mathbf{x}$; (History) Porter, Hum. Intellect, ch. Ix ; Binet, Revue Philosophique, xxI. p. 113; Berkeley, Theory of Vision; James, Mind, 1887; Ward, loc. cit.; Lipps, Grundthatsachen des Seelenlebens, ch. xxI-xxv, and Psychologische Studien, I; Lotze, Metaphysic, bk. 2, ch. I, and bk. 3, ch. IV.

Further Problems for Study:

Subject and object in perception;

Validity of the perception of the external world ;

Philosophical bearings of the doctrine of perception;

History of theories of perception. 


\section{REPRESENTATION.}

MEMORY.

\section{CHAPTER IX.}

\section{RETENTION AND REPPODUCTION.}

The data of knowledge, as they are afforded by the acquisitive function of mind, have been thus far enumerated and distinguished. This expression, data of knowledge, implies that these acquisitions remain at the disposal of other mental functions longer than the mere instant of their first experience; otherwise, they would not be the materials of knowledge. Our states of consciousness, as a general fact, may be spontaneously revived. The original states of consciousness are designated Presentations, or primary states; and the corresponding revived states, to which they give rise, Representations, or secondary states.

\section{\$1. Gexeral Nature of Memory.}

The capacity to be revived on suitable conditions extends to all states of conscionsuess. This revival is most vivid and facile for sensations of sight, touch, and sound; from the fact already noticed that these sensations are most presentative, having the forms of space and time. Objects seen are readily pictured when the eyes are closed, and sounds of tunes, and more especially of words, are reproduced with great ease. In reading a page, we recall the sounds of the spoken words involuntarily; and, if it be a page of poetry, the rhythm and rhyme are caught by the quick revival of the words 
and measures in succession. Other sensations, as tastes and odors, are also capable of reproduction. The fact that we distinguish and classify them is sufficient proof of this. Their reproduction is more obscure from the fact that, being more affective, they cannot be pictured under the presentative forms of time and space. But that these forms, and consequently memory pictures in general, are not essential to memory, is seen in the fact that pains and pleasures, and the emotions, which are purely affective states, are remembered with great distinctness; these states afford no data for our picturing faculty. According to Epicurus, the memory of past pleasure and the imagination of future pleasure are the principal source of our happiness. Sympathy depends upon the revival of our own pains and pleasures; for we cannot sympathize strongly in cases which our own experience does not cover. And finally, the acts of will are present in memory, giving, according to their nature, moral satisfaction or regret.

Strictly speaking, a distinction is to bo drawn between states which are revived after having once disappeared from consciousness, and those which persist in consciousness a short period after the external stimulus has ceased to act. The latter is a mental after-image, somewhat like the physical after-image on the retina, already mentioned. Every percept clearly distinguished leaves its outline in consciousness for a very small period, and then fades rapidly away. In the case of a rapid succession of presentations, each percept occupies less time than the unit of duration, ${ }^{1}$ so there is a coexistence of presentations and not a revival. 'This is the case, probably, with written and spoken words, tunes, rapid rhythm.

Nature of Revived States. As to the nature of the states brought up in memory, two general theories are held. On the one hand, it is maintained that there is a specific difference between presentations and their revived images; a difference of nature. Secondary 
states resemble the primary, it is said, as a portrait resembles the original; but there is an absolute distinction in their nature. ${ }^{1}$ In opposition to this view, others hold that between primary and secondary states, there is only a difference of degree. They are truly Presentation and Representation; their nature is the same."

Proof that Presentation and Representation differ only in Degree or Intensity. Several kinds of evidence may be adduced in support of the second of these theories.

I. From Consciousness. We are aware in consciousness of no peculiar marks of revived states by which to distinguish them from percepts, except that they are prevailingly of less intensity. In the conscious reproduction, the conditions of the presentation are vaguely reproduced. The representation of a name, sound, the tic-tac of the pendulum, is referred to the ear. The image of an extended object is formed as extended in the field of vision. If we try to recall the taste of an orange, we seem to have a kind of after-taste on the tongue. In recalling emotions, the general conditions of our first experience of it are found with it in memory by the law of association. In the case of voluntary reproduction, it is true, there is the addition of an exercise of will,' which is of great importance in affording us a means of distinguishing between the percept and its image; but this is not necessary to the reproduction more than to the original perception, since most of our memory pictures arise involuntarily.

II. Presentations and Representations have the same Physical Antecedents and Effects. The physical antecedents of both primary and secondary mental states are

' So Reid and Cardallinc.

'So Hume, most of the English school, and the pliystological psy. chologists. Cf. Rabier, loc. cit. pp. 152-157.

Fichte makes the feeling of freedom essentlal to all reproduction. 
spoken of later under the physical conditions of memory. It is sufficient to say, here, that the immediate physical antecedents, the brain processes, are the same in both cases. The remote antecedents of the percept-presence of an object, and stimulus of the sense-are wanting in the case of the revived image ; but it is the immediate antecedent upon which the representation depends.

The physical consequences or effects are also the same. Müller says, that the simple idea of a nauseous taste is sometimes sufficient to produce sickness, the natural effect of the real sensation. The visual picture of a person who has once provoked our anger serves to produce it again with the same physical expression. Intense mental picturing of a primary color may so exhaust the retinal elements, that the complementary color is seen when the eyes are opened. ${ }^{1}$ It is hard to think upon an energetic action without imitating it, just as in the original attention to the performance of it by others, we had such a bodily tendency; and to have a word in mind is usually to form it with the organs of speech.

Further than this, the psychological antecedents and consequents are almost identical in the two cases. There is this difference between the train of presentations and that of representations, that the latter is accompanied by a feeling of familiarity and anticipation. But it is doubtful whether this feeling is present at the first reproduction, since it involves a measure of previous knowledge which can only be representative. This feeling is present in the perception, also, when by repetition an element of representation is involved in it. The voluntary character of certain reproductions, which seems to make them peculiar as to their antecedents, has its counterpart in certain voluntary efforts of perception; as when we explore an unknown scene with the eye or feel over an unknown surface. Further, as to the consequents-the simple thought of great cold makes one shiver. The thought of the drawing of a sharp knife over glass sets one's teeth on edge, as Darwin says. Any one who has attended a clinical operation knows how acute the sensations of cutting and drawing are at first.

${ }^{1}$ Lewes, Problems, 3d series, p. 448. 
The effects of attention, also, are the same upon the image as upon the first sensation.

III. Frequent Confusion between Presentation and Representation. The strongest, indeed the decisive, proof that psychologically these two classes of states are really one is this: we frequently mistake one for the other. "The proof," said Reid, " that there is an essential difference of nature between these states is that we never confound a sensation, however feeble, with an image, or the contrary." This is simply an error of observation. We do often confound them, and several different cases of this confusion may be pointed out.

1. When the intensity of the image is very great. This is the case in hallucinations and insanity. "Patients continually hear voices speaking to them, or about them, replying to their most secret thoughts, suggesting to them profane and obscene ideas, and advising and threatening them." In these cases, abnormal brain action gives the image the verisimilitude of a sensation and the distinction is completely lost. The same result may arise in normal life from simple force of imagination. Newton could bring before him, when in the dark, an image of the sun, with all the characteristics of reality, and Goethe could evoke an image and cause it to pass through a series of transformations."

Further, there are cases of regular mistake in our perceptions, in which an image passes for the real object. In reading rapidly we do not see all the letters individnally, but pass over them with a supply of appropriate images. It is probable that we see the first letters of the words and the last, slurring over the middle characters and supplying them from our knowledge and from the connection. Yet we think that each letter has been seen in order. The bli:al spot in the field of vision is

1 Maudsley, loc. cil

'Cf. Taine, Intelligence, bk. 2, ch. I. 
filled in by our images, and the field seems to present an unbroken continuity. And our acquired perceptions are often imaged additions to our presentations and interpretations of them. In all these cases the image is of such intensity as to seem homogeneous with the presentational field which it supplements.

2. When the actual sensation is very feeble. The same result is found when the sensation is reduced in intensity to the similitude of the image. For example, when a sound dies out little by little, the time comes when one is uncertain whether he still hears it or only remembers it. If the two experiences were distinct in nature, the line between them would be very plain. Patients often cannot tell whether they feel a pain or only imagine it.

This is especially the case in states of hypnotic hallucination. Here a mere suggestion of the presence of an object suffices to place its image in the conscious field of the patient with a persistence and perceptive consistency which nothing but a counter-suggestion can remove. The image becomes for the patient an actual object for all the senses, the ordinary tests of illusion ${ }^{2}$ fail, and there is absolutely no distinction to the subject between the image and the reality. The psychological nature and value of this state cannot be discussed here; it is sufficient to note its capital bearing upon the point at issue.

In all cases in which there is no actual perceptive experience to correct the force of images, we are liable to illusion, ${ }^{2}$ and hence the mere absence of percepts is often sufficient to canse the errors attributed above to the strengthening or weakening of sensation. 'This is the case in dreaming. The dream world is the only world then in consciousness, and though its intensity is probably feeble, as is seen in the fact that dreams do not linger generally in consciousness, it is taken for real, simply from the absence of anything more real wherewith to contrast it.

1 See Chap. XIII, §5.

Chap. XIII. 
Upon this identity of nature of percepts and their images is based the theory of illusions which is advocated later: and indeed any such theory requires such a basis. For this reason, the ground of the assumption of their identity is entered upon at some length, though among recent thinkers it is with great unanimity maintained.

Distinctness of Image. The difference in intensity between presentation and image, involves both distinctness of outline and vividness, or strength. The former is of greater importance, as uncertainty and vagueness in an image are usually due to breaks in outline and omission of details, rather than to general dimuess.

The differences between presentations and images in respect to their apperceptive surroundings are summed up by Lewes by the word escort. The image is the same mental product as the original experience, differing from it only in intensity; but their trains or escorts differ in a variety of ways, including their relation to the external world.

Definition of Memory. In considering the entire mental function which we call memory, we find that it involves several factors or stages, which are sometimes treated as distinct operations, but may more properly be considered, as we find them, together. Together they constitute a chain of events whereby the mental life of the past is retained and utilized in the present. First, there is the permanent possibility of the revival of a past experience when its first.circumstances are repeated; this is called 1 Retention. Next, there is the actual return of the image

2 to consciousness: Reproduction. Third, this image is known as having already been presented in our past

3 experience: Recognition. And finally, there is, in most cases, an immediate reference to the exact past time of

4 its first experience: Localization. These, taken together, constitute a finished act of memory, and will be considered in the order of their actual rise in conscionsuess. 
Accordingly, memory may be defined as a mental revival of conscious experience; in which the word experience refers to the past and indicates Retention, the term revival answers to Reproduction, and the word mental makes the whole a conscious fact of Recognition. This definition puts the case in the broadest light and admits any interpretation of the subordinate operations which may be consistent with fact.

\section{§ 2. RETENTION.}

It is seen, in the above analysis, that an act of memory touches consciousness at two points; at the beginning, i.e. at the time of the original presentation, and at the end, i. e. in the act of conscious revival. We remember nothing of which we were not conscious at the time of its occurrence, nor do we remember anything when we are in a state of unconsciousness. These two points of contact conceded, the question at once arises: what of the intervening period? I saw, for example, a house yesterday or last year; I was conscious of the presentation. I recall the image of the house to-day, or a year hence; I am conscious of the representation. But where has it been in the mean time, while I was not conscious of it? Several answers have been proposed to this question.

Theories of Retention. I. Images, we are told by the metaphysicians, ${ }^{2}$ are stored away in the mind, in the pigeon-holes of the soul, to be brought out for use when the processes of mind require them. This view, it is needless to say, is not now advocated in this language. The mind has no pigeon-holes; it is not a storehouse of images. But it is maintained in more discriminating form by others who, properly, find it necessary to main-

1 See Hamilton on Latent Images, Metaphysics, Lect. XXX: so Plato and St. Augustine. 
tain a continuity of mind over the chasm of forgetfulness which divides these two points of conscious life. ${ }^{1}$ Yet it seems sufficient answer to this to say that, if the image has left consciousness it has left the mind, as far as we know. It is only by consciousness that we can discorer the image at all. This has greater force, also, in view of what has already been said in reference to the unconscious, and in view of the complete fulfilment of all the requirements of the case which we find in the theory advocated below. If physical processes are sufficient for the case, we violate the law of economy in insisting upon another principle. ${ }^{2}$ And the assumption of a substantial persistent independent soul, which is capable of undergoing permanent modifications, is not allowable from a strictly empirical standpoint at this stage of our progress. If there were no other way, through psychology or physiology, of accounting for retention, we would find here a legitimate argument for such a postulate.

II. Retention is due to a psychological habit." This theory refers retention to habit, and conceives of habit as a permanent disposition of the mind to do again, whenever circumstances permit, what it has once done; to think again what it has once thought. As a description

1 Leibnitz, Ward. “No idea," says Bouillier. Le principe vital ot l'ame pensante, p. 405, " at least of those which memory may recall, ever leaves the mind entirely. No idea leares the mind, but each idea becomes invisible for a time or permanently. To remember is to have new conscionsness of what has not ceased to exist in the soul. Thus there sleep in the depths of our soul and in different beds innumerable ideas which remain unknown till some circumstance, some effort of the attention, brings them to the light."

2 Leibnitz was constrained to admit, in virtue of the principle of prestablished harmony between mind and body, the conservation, in the organ, of physiological dispositions corresponding to these latent memories. So Aristotle held a doctrine of material residues ( $\mu(1)$ cis Kiv $\eta \sigma \varepsilon \imath 5)$ which were correlative with the mental states considered as form. De an., ur. 2, and Anat. post., Ir. 19.

Waitz, Wundt. 
of the actual fact this is true. There is such a tendency, to a very marked degree; but it is merely an observed aspect of memory, and, in noting it, we do not at all explain the activity of memory. When we have called it a habit, a disposition, a permanent tendency of mind, what more can we say? The questions arise : Is it based on psychological grounds, or will physiological facts explain it? Is it an ultimate law, or can it be reduced to simpler principles? Habits are not facts of consciousness, and we have no experience of them except by observation of the states which are supposed to exemplify them; so that they elude our observation. If it is submitted, therefore, as an explanation of retention, that the mind becomes accustomed to acting in certain ways, and so repeats itself, the ground of this mental custom must be again referred to that chasm of the unconscious which affords so ready a repository for the outcasts of our ignorance. As Volkmann remarks, inasmuch as the representations are not essences, but functions, the dispositions or habits of mind must be functional dispositions. Now a functional disposition can only consist in a slight persistence of the function, which, in turn, can only mean a continuation or persistence of the representation in complete unconsciousness. By physical disposition or tendency we may mean combination or arrangement; a readiness of parts for a given result. But in speaking of presentations, as functions, we cannot employ such a meaning. Wundt himself remarks: "If we carry the view (of dispositions of mind) over from the physical to the mental, only conscious presentations can be considered real presentations, while those that are driven out of consciousness may be considered as mental dispositions of an unknown kind toward revival." And he goes on to say: "The essential difference between the spheres of the physical and mental consists in this, that in the former case we may hope to learn more of the changes 
which we call dispositions, while on the mental side this hope is forever forbidden, inasmuch as the limits of consciousness are at the same time the limits of our inner experience."

This is, however, more philosophical than the preceding theory, in that it questions each revived state for itself as a new functional acquisition instead of an old preserved entity. And if we were able at this point to make the assumption of a substance called mind-which was above forbidden-we would be justified in resting in the law of habit in respect to it, as we are in resting in the physiological law of habit to which appeal is made below. Metaphysically this alternative is not excluded; but we are here not concermed with metaphysics, and in refusing this resort we are only following openly in the path followed silently by Descartes, Malebranche and Leibnitz, in turning to the body and seeking in it an explanation more readily confirmable by fact.

III. The image is subconscious. The school of Herbart support the theory, that every image which is capable of being revived in consciousness exists in a state of diminished intensity, having fallen below the threshold of consciousness, to rise again when, for any reason, its intensity is heightened. This may mean that the representation is vaguely or dimly conscious, lying in a state of diffused or contracted attention, but still entering as a factor in the complex whole of our present state; in which case, the theory is true, as is generally admitted. But it then overlooks the great mass of remembered facts; facts which are in no sense eren in subconsciousness, as my memory of a date in history when I am thinking of something to which it is quite foreign. For these entirely unconscious states, the Herbartians ${ }^{3}$ have no alternative but to hold that they still have an in-

'Phys. Prych., 2 d ed., it. p. 205.

'For example, see Volkmann, loc. cit., vol. I, $\S 50$, and $\S 60$, p. 403. 
tensity, below all estimation, in the depths of the psychic life. This is the old metaphysical theory in more modern guise. The phrase " unconscious presentation" may be more scientific and less material than "latent images" or "stored-up ideas," but it is equally obscure and less picturesque.

Another pertinent objection to this theory is that it supposes a degree of separateness or individuality in the unconscious states, which in real mental life is impossible. If representations coexist with slight intensities in unconscious mind, why do not those of the same quality coalesce, as in real presentation? I have a distinct memory of two notes, say $c$ and $c^{\prime}$ : if they are both present in unconsciousness, differing only in intensity from the real sensations, why do they not coalesce in a single sound? So generally with these states: there is no interference or mutual hindrance, as in real experience. ${ }^{1}$

General Criticism. As a general criticism of the preceding theories of retention, the following consideration is of great importance. They agree, especially the first and third, in regarding the representation or image as a thing of itself, a something which exists, and whose presence somewhere else must be supposed, when it is not present in consciousness. We are told, the percept of the house was in consciousness yesterday and the representation will be again to-morrow : where is my image of the house to-day? And these theories attempt to conjecture the whereabouts of this image. Very slight consideration leads us to see that this manner of thought is quite mistaken. The image is not a thing at all, to be stored away or sunk in subconsciousness like a stone in a lake; it is a state, a mental product, dependent upon a process, and in the absence of this process it simply ceases to exist. The true answer to the question, as to where the presentation is in the time between percept and memory, is

${ }^{1}$ Cf. Waitz, Lehrbuch der Psychologie, 1849, p. 84. 
Nowhere. Its reinstatement is simply the reinstitution of the process which at first gave it rise. Its recall is a re-creation, really a new presentation, not the old image. We never have the same representation twice. We are thus led to another theory.

IV. Physiological Theory of Retention. Disregarding the fact of actual reproduction, which is considered below, and looking only to the permanent possibility of such reproduction, that is, to the set of conditions of such permanence as to make the revival of mental states at any time real, we are led to the view that retention is physical, a matter of the modification of brain and nerve structure or function; such modification persisting and giving rise to a physiological habit or tendency. Before proceeding farther to explain and defend this view some general objections may be met.

1. It is objected that physiological modifications could not last as retention does, even admitting the general principle that every organic modification must leave some trace behind it. Here the question is simply as to the length of an admitted process of obliteration. It is not held that these modifications do not fade away and finally disappear, as far as memory is concerned. The fact of forgetfulness, seemingly absolute, establishes the tendency of these traces to disappear. Therefore we only have to ask, how long, relatively, might they last? Admitting this point, we still find it possible to hold that these nervous modifications persist indefinitely, as memory sometimes appears to.' There are analogous cases of long persistence of physical modifica-

I See Ribot, Les Maladies de la Memoire, ch. IV, and Taine, Intelligence, II. ch. II, for remarkable cases of such memory. An iguorant girl, during a severe illness in her twenty -fifth year, recited long pieces of Greek, Latin, and Hebrew, which she had henrd her uncle repent when she was nine years old. 
tion. If a key be laid upon a white paper, and exposed to the sun, and the paper be then preserved in darkness, the image of the key is visible for some years. Even in case of organic modification where the physical elements are undergoing perpetual renewal, the form persists. An insignificant scar on the skin remains through life. The virus of small-pox or the presence once of an infectious disease, leaves marks sometimes, throughout the elements of the body, which are never erased.' Muscular fibre is permanently modified by exercise. We have a further analogy in the permanent disposition which the motor centres assume for the coördination of movements. At first complex movements are performed with great difficulty, the central nervous disposition being wanting; but after some practice these dispositions become established and the coördinated movements become semi-automatic. ${ }^{2}$ Of the superior centres the same, in all probability, may be said.

2. It is further objected that the brain does not afford sufficient substance or accommodation for so many coexisting memories, supposing them to be permanent traces, either in the organism or its functions. But this difficulty, although frequently urged, does not deserve serious thought. According to the most moderate estimate, the large brain contains about 600 million cells and even a larger number of fibres. And we are not at all obliged to think of these elements as having a single function only. They are known, on the contrary, to act together in specific connections, and the varieties of connections of so many elements is simply infinite. Further, we have here, also, analogous cases which settle the

\footnotetext{
1 See Maudsley, Plysiology of Mind.

2 "These movements," says M. Luys, " show the tendency of the sensor-motor cells to preserve traces of discharges which have once taken place, and to persist in the disposition which is earliest given to them. The nerve cells are polarized in the position given them."
} 
question without further consideration : the coexistence of innumerable functional dispositions in the motor arrangement of the nerves and muscles of a single organ of the body ; the marvellous fact of the life development of an organism encased in a single germ, at first microscopic-a germ which possesses, in disposition or tendency, all the organic characteristics of the parents to the most minute detail, as the color of hair, shape of nose, and those indescribable similarities of feature which constitute family resemblance, or the disposition to peculiar motor habits. " If a single germ cell may possess such inexplicable power of preserving differences of form and function, what limit can we set to the similar power of the brain?

The whole question of the possibility of the coexistence of so many tendencies in the brain, seems to be a case of ignoratio elenchi. We cannot doubt the possibility, unless we have some knowledge both of the functional activity of the cerebral elements and of the real nature of the changes which make retention possible. But of both these our ignorance is complete. What is the general character of cellular change in the brain? What is the law of the establishment of fibrous connections in the brain? What changes do sensor stimulus and motor reaction work either in the cells or their connection? 'These questions must all be answered before we can say anything about the possibilities of cerebral disposition.

3. It is again objected that the reduction of retention to a physical tendency and modification, interferes with mental continuity and destroys the unity of mind. This, however, is seen not to be the case, when we remember that we are dealing with the retention of individual states or presentations, whose lapse from consciousness does not affect the unity and continued persistence of consciousness itself. If a presentation be quite out of consciousness, it is lost to the mental life,

I Sce the case of three generations having the habit of striking the nose with the fist while asleep, Paulhan, Physiologic de l'esprit, p. 164. 
whether it be in unconsciousness or in physical disposition. The unity of consciousness, the conscious active unity of apperception, remains present throughout all the come and go of states, some other presentation taking the place of that which is lapsed; or, in other words, another content occupying the active process. The unity of the mental life consists, not in the persistence of single states, but in the conscious oneness of the ego as activity or energy.

Pathological Proof of Physiological Dispositions in the Brain. The actual proof of physiological dispositions in the substance of the brain is derived from cases of disease of memory. If it can be shown that all cases of the impairment of retention are due, other conditions remaining the same, to disease or derangement of the brain or its functions, we have, by the logical "method of difference," proof that the primary condition of retention is cerebral. The argument is not entirely conclusive even for retention, since there remains still the hypothesis of unconscious mental modifications parallel with and depending upon cerebral modifications. If this latter hypothesis be true, we would still possibly find impairment of memory following cerebral degeneration, though it would be exceedingly improbable. For if there be "mental dispositions," as well as "physiological dispositions," why should not the former secure memory when the latter fail in such a way as not to involve the general physical basis of consciousness? The general argument from a pathological standpoint is well made by M. Ribot, though he overlooks the possibility above noted of parallel " mental dispositions," as held by Wundt. He argues through all the details of the growth of memory, its degeneration, destruction, and re-

\footnotetext{
'See the author's article, " Dr. Maudsley on the Double Brain," in Mind, Oct. '89.
} 
covery, with the accidents and variations to which it is subject.

We cannot press the argument further, howerer, with Ribot and make memory entirely "organic," from the fact that it overlooks the most essential mental conditions, which must necessarily be constant, if we would argue from brain pathology at all. These conditions are spoken of below. If, for example, as in the thousand cases of our daily life, memory fails when we have not attended closely to the original percept, we would still, by the "organic" theory, be compelled to look for the failure in the lack of a physiological disposition: while, in fact, this disposition may be entirely intact and very strong, the failure being due to the absence of the purely mental function, attention.

Physical Basis of Memory. As to the nature of the physical basis, which constitutes the primary condition of retention, we may speak in general outline. In the case of any sensation and its reaction in movement, two classes of physical data are inrolved: sensor and motor. The sensation has its seat in the gray matter of the brain, from which, by a fibrous connection, and through certain motor elements in the brain or spinal cord, communication is established with the muscular tissue. Each such system of connected or associated elements is called a sensori-motor connection. Now every sensation, say that arising from a bell, gives two kinds of modifications in the nervous system: first, it works an unknown change in the sensor cells, and second, it tends to establish motor connections. Accepting this as the simplest type of such action, we can conceive of innumerable modifications and complications of it. Numerous motor connections may be possible from a single seat of sensor change. For example, upon feeling a painful contact with the body, we have numerous alternative movements to relieve it. When a limb is fatigued we may move it into various positions of change. When we hear a word we have a tendency both to speak and to write it, involving different motor connections, or we may mako 
a gesture expressive of its meaning. In the same way, different sensory centres become connected with one another by their frequent association together: as the taste and color of an apple. Now every time the sense in question is excited by the same stimulus, the same course of transmission, by the law of least resistance, is liable to be called into play; and there is a tendency, both to confirm the sensor modification and to strengthen the sensori-motor connection. Thus greater facility and rapidity are given to the process, and there arises, in the nervous organism a readiness or disposition to repeat its own acts under similar circumstances.

Now in the case of reproduction, or memory, the same nerve elements are affected, ${ }^{1}$ and in the same manner; except that the sensor centres are excited from within instead of from without: from some other centre instead of from the end organ. For example, if instead of hearing the striking of the bell, I am thinking of architecture, then of the cathedral at Thun, the bells of Thun arise to mind, and I have a memory of the sound of a bell. This, by an established association, excites, entirely from within, the centre of vision, giving a visual image of a bell, this excites the motor-connection with the organs of speech, and I pronounce the word bell. Thus the same elements are brought into play as in the actual presentations by the senses involved-the bell itself being absent. This is the physical basis of a memory. The organism is disposed toward the production of the state of consciousness of the original perception. The execution of movements, at first difficult, becomes easy, then semi-automatic, and often irresistible, and nothing remains to make the physical retention real reproduction, save the mental conditions which inaugurate its movement: the connection is then ideo-motor.

1 See the law given by Bain, Senses and Intellect, p. 333. 
Other physical conditions of memory are only such as are concerned with the maintenance of this nervous function; such as general health of body, active circulation, and rich quality of blood. 'The old doctrine of "animal spirits" as held by Hartley and Locke is an attempt at a physiological explanation of memory. "Custom," says Locke," "settles habits of thinking in the understanding as well as of determining in the will and of motion in the body : all which seem to be but trains of motion in the animal spirits, which, once set agoing, continue in the same steps they have been used to, which, by often treading, are worn into a smooth path and the motion in it becomes easy and, as it were, natural."

Mental Conditions of Retention. The mental conditions of retention are purely conditions and not the retention itself, which we have found to be a matter of the physical organism. First we note the intensity of the sensation. Sensations or perceptions of slight intensity are not remembered; this is because they do not reach the relating and fixing activity of apperception. It is probable that they are retained as bodily modifications and have their influence upon the general cast of our memory. But, not having been given a place and connection in the mental life, they have no associations of sufficient strength to accomplish their recall. Intense sensations, on the other hand, draw the attention to themselves and are remembered. Another condition, or facilitating circumstance, is repetition of the first senseexperience. Repetition tends to bring a presentation before the attention from the very fact that it is the same experience we have before met. A presentation which is at first too slight for notice and so escapes attention, at another time, and under different conditions, is apperceived and fixed in an environment of conscious states. In many cases, also, the very fact of repetition serves to add actual strength to the presentation, proceeding upon the nervous modification or tendency begotten of its earlier occurrence.

'Essay, II, chap. xxxuI, \& 6. 
The most important of these conditions, however, and that to which those mentioned may be subordinated, is the attention. The attention considered in its entire function as the apperceptive agent of our mental life is, as shall be seen later, the one essential mental condition of memory. It carries in it the fact of mental continuity. Here we deal only with its bearing on retention. It is a universal principle, that things attended to are remembered, and things not attended to are forgotten. This arises from a twofold effect of attention : first, as was seen in the chapter on attention, it increases the intensity of presentations, and so gives them a greater strength and nearness in the flow of mental states ; and, second, it gives them a related position, as of contiguity, resemblance, cause, in reference to other states with which or near which they occur. We shall see, in studying association, 'that our mental experiences are never isolated. They are always bound together by relations which the mind discerns in apperception. The more closely and definitely they are bound together the more permanent are our acquisitions; and the more loosely bound, the more easily dropped out and lost. Now apperception is this binding activity. When we say we experience a sight and attend to it, we mean that we bring out its details in relation to one another and in relation to our earlier and later experience, giving them a place in the permanent texture of our memory.

\section{§ 3. REPRODUCTION.}

Its Primary Condition. The first condition of the reproduction of an image is the physiological disposition which appears to constitute retention. Assuming retention, therefore, we inquire into the further elements of reproduction. It is easy to see that this purely physical 
modification does not account for the revival of an image in consciousness. The essential element of memory is lacking. The simple fact that matter modified as you please does not remember, serves to refute the theory of "organic memory." We might, with as much reason, say that the post remembers the nail which was driven into it, because it retains a permanent modification in the arrangement of its elements, or that the seasoned meerschaum pipe remembers by virtue of the molecular changes which its frequent use has wrought; as that the brain remembers because of its molecular dispositions. Of the physical process we may say : $a$. That it is the necessary basis of memory, as far as our experience goes. $b$. That it accounts for retention. c. That it gives direction to the flow of our memories, by the determination of one of many alternative nervous courses. But it is no more an approach to an explanation of the revival in cousciousness of an image, than of the first perception itself. The physical process determines what I shall remember : the mental process, how I shall remember it. ${ }^{1}$

Supplementary Condition. It has already been made more or less clear that a reproduction is a re-creation, a new product, which is due to the same conditions as the original perception, with the lack of the external stimulus. This lack is, however, seeming rather than real, since the central stimulus is as really supplied from within as though the object were present. Admitting, then, the physiological disposition of the organism, due to former experience, we find the further supplementary condition of reproduction to be a new stimulus of the centres, arising generally from an inner or mental source. This new stimulus, however, is not always mental, since there is a vast range of bodily conditions from which the centres may be excited, stimuli which may be called intra-

'Compare the discussion of Ladd, Phys. Psychology, pp. 546-560. 
organic in distinction both from the excitations of the external world and from those of the world of conscious states. Any stimulus which fulfils the one condition of reproducing the physical function, as it operated in perception-the mental conditions of recognition being again present-suffices for the revival of a presentation.

This theory of reproduction explains many mysterious facts which are inexplicable on the theory of mental habit or of unconscious memory. The whole field of unconscious trains of ideas is covered by the consideration of an organic process. We are often surprised at the sudden appearance in consciousness of a representation which has no apparent connection with our irain of thought. ${ }^{1}$ Yet, by close attention, we can often find some dim association with an earlier state. In consciousness we have forgotten the connection, but an organic disposition asserts itself through all the links of our earlier presentation, and the unexpected idea is the consequence. 'This is supported by the fact drawn from psychometry, that in every sensor reaction the physiological process takes less time than the mental. ${ }^{2}$ It is quite conceivable, therefore, that when a series of nervous modifications follow one another very quickly, sufficient time is not afforded between them for the conscious presentation. Often, also, after vain efforts to remember a date or name, we give it up, but when thinking of other things, it suddenly pops up, so to speak, in consciousness. It is possible, that in our casting about for the desired memory, we have started a train of association which has run its course in the organic dispositions, and terminated successfully. These cases will be again referred to in the consideration of the association of ideas. This explanation seems much more natural than the mysterious hypothesis of unconscious mind.

The principle that the same physical process is involved in the reproduction as in the presentation, is confirmed by the distinction above noted, ${ }^{3}$ between a persistent presentation and its revived image. The persistent presentation is seen, at once, to depend upon the same excitation and nerve process which gave the percept; yet it remains when the object is withdrawn.

${ }^{1}$ Cf. Hamilton, Lect. on Metaphysics, IV, and Mill, Exam. of Hamilton, ch. xv.

${ }^{2}$ See p. 110.

${ }^{3}$ See p. 146. 
Hence we have every reason to believe that the revired image is due to the same nerve process, since it differs from the persistent presentation only in its separation from the external stimulus by a very brief period of time. One is a prolongation of the primary state, the other a restoration of it: the former is the continuous effect of a continuous cause, the other the intermittent effect of an intermittent cause. Another proof drawn from physiology that the same nervous elements are called into play in the representation, is the fact that memory fatigues the same centres that the actual perception does. If a bright color be imagined and thought of intensely and the eyes then closed, the complementary color is seen, just as is the case after an actual perception.'

Secondary Aids to Reproduction. There are certain secondary conditions which tend to the most ready reproduction of mental pictures. In their general nature they are almost identical with the auxiliary conditions of actual experience, and so add new evidence of the identity of the two classes of facts. Among them we may notice: $a$. Intensity of the nervous stimulation. All direct excitants of our nerve tissue, as coffee, opium, hashish, stimulate the reproduction of images and thus aid the memory temporarily. So also, any occurrence that excites the nerrous system as a whole, as a blow on the head, great danger, a threat of death. ${ }^{2} \quad b$. The absence or feeble intensity of present states of consciousness. This tends to throw the attention upon the revired image, which is ordinarily feebler than the present presentation. For this reason, we close our eyes when trying to remember something. c. As before, in the case of retention, the attention is the principal aid to reproduction. Representations must be attended to to be apprehended at all, and after this, attention makes them still more distinct. Indirectly also, attention may be used to call

1 Wundt.

'Hence the frequent, but not universal, experience of minute memory of past events when one is in danger, as drowning : geverally it is greatly overestimated. 
up representations. We think of an object or event in some known relation to the one we wish to remember, and set a train of association going which secures to us the desired image. Often, however, the fixing of the attention may hinder the memory seriously, from the fact that it tends to hold an image before the mind to the exclusion of others and so impedes the flow of association. d. By association, finally, as is seen later, the function of reproduction is given consistency and unity, and made available for the higher uses of mind.

Power of Imaging. The power of recalling mental pictures varies greatly with individuals and at different periods of life. Images of sight are most distinct and lasting and become our type of memory pictures in general. It is argued from the fact that persons who become blind before five to seven years of age never have visual pictures in their dreams, that these permanent images are not formed before that age. ${ }^{2}$ Persons who have this power to a marked degree are known as having good imaginations, though simple revival of images is the most rudimentary form of imagination. It may be a bane to the mental life rather than an advantage, as in the case of insistent and fixed ideas. In accordance with the principle of attention already noticed, the images of childhood are strongest in our memory. The attention at that period is not burdened with activities, and trivial things are of great interest and importance: such images are also recalled so often in after years, that repetition gives them great vividness and numberless associations. Many old people are constantly led back in conversation to their childhood, even when memory of middle life is failing. ${ }^{3}$

${ }^{1}$ Chap. XI.

2 Jastrow, in New Princeton Review, Jan. '88.

"On the "visualizing power," see Galton, Inquiries into Human Faculty, chap. on "Mental Imagery." 
Development of the Organic in Memory. It has appeared that the fact of retention is due to a physiological disposition, and that the facility of reproduction depends upon the strength of this disposition. By repetition and habit every act becomes more easy and prompt and less expenditure of force and attention is necessary to its reinstatement. This is, in the first place, physically true: blood flows to the brain in less quantities when the action is an habitual one, "less nervous force is disengaged, ... and the heat resulting from the chemical process is more feeble." ' And, as an immediate consequence, the consciousness accompanying the act becomes less vivid. As Mr. Spencer says : "Memory embraces all that class of facts which are in process of becoming organic. It continues as long as these facts are being organized and disappears when their organization is complete." We find certain acts becoming quasi-unconscious or completely so, as the movement of the pianist and dancer, the motions of our fingers in writing, and of the lips and tongue in speaking. Thus the perfection of the mechanism of memory tends to the suppression of the psychological fact of memory : consciousuess retreats behind the nervous system, and there is a progressive materialization of our thought, a tendency to automatism. As the force of the sun is stored up in coal, so thought finds permanent realization in the structure of the nerrous system.

The limits of this process, however, are seen in the perpetual novelty of our experience and activities. The very acquirement of complex habits leads on to the possibility of performances still more wonderful. The mental life is progressive. As the attention, will, and

On this section, cf. Rabier, loc. cit. pp. 164-16s.

Paullian.

Psychology, vol. I, part 4, ch. vi. 
thought are no longer needed to govern our grosser activities, they are disposable for additional refinements. So our mental life and capabilities are always full and occupied, their function only becoming broader and more elevated from this tendency to organic form. Further, attention tends to keep in conscious operation processes otherwise unthought of. According to Dumont, ${ }^{1}$ the attention occasions a flow of blood to the organic seat of the state which is attended to ; the nervous action is thereby given tone and intensity, and consciousness, by a reaction, is strengthened. A remarkable example of this is given by Egger. " We have no memory or representation of the sensations of touch and muscular movement from the lips and tongue in speaking words, but we have a perfectly clear memory of their sound. Why is there this difference, when the power of speech was learned with great effort and attention? It is because the exercise of the attention has been called into play constantly to word sounds, as the vehicles of thought, while the movements of speech have become automatic and almost unconscious from repetition. Memory has remained psychological in the one case and has given place to the organic in the other.

Retention and Reproduction as Mental Growth. The growth of the mind through accumulated experience is a matter of individual appreciation. There is a constant enlargement of view and strength of purpose due to exercise. Exery mental experience leaves the mind different as every physical change leaves "the body different. There is a progressive development of self-hood; a realization of mental possibility in the form of actual life, which gives individuality to the man and colors his

1 De l'Habitude, Revue Philosophique, vol. I.

${ }^{2}$ Victor Egger, De la Parole intérieure. 
disposition. In this sense, all experience is retained mentally, retained in the altered possibilities which it opens up. Proceeding we shall find that mental habits appear stronger, perhaps, than physical, and such habits, dispositions, vague feelings of intellectual preference and aversion are the sum of all the elements, however minute, of our past. 


\section{CHAPTER X.}

\section{RECOGNITION AND LOCALIZATION.}

\section{§ 1. RECOGNition.}

RECOGNITION is the third stage reached in the development of memory. Granted an image reproduced, a representation, it is then recognized. Representations are " accompanied," says Locke, "with an additional perception (feeling) indicating that they are not new, that they have been before experienced. This is ordinarily called recognition." This additional fact of recognition, however, does not always accompany revived images, and by the study of the cases in which it is absent, we are able to learn what recognition is.

Feeling of Familiarity. In a general view of recognition from the standpoint of common consciousness, it consists in the feeling of familiarity with which an image or object affects us. We say feeling, since the act of recognition, in itself, follows the act of knowledge in which the object or image is again presented: that is, representation or reproduction precedes recognition. This feeling of familiarity is vague and often misplaced, and ordinarily goes unanalyzed.

Distinction between Recognition of an Object and of an Image. The means by which recognition arises, vary as the recognition is of an object or of an image. In the case of the second perception of an object, its recognition is accomplished by means of an image which is already 
recognized. We institute a comparison between the percept and the image, and pronounce them the same or similar. This is seen to be the case in frequent instances in every-day life. If we are asked whether an object is the same as one seen before, we often say we do not know, for we do not remember how the former object looked: which means, that we are unable to call up and recognize any image with which the object present may be compared. In the case of the recognition of an image, such a procedure is impossible. It would presuppose another image still, and so on indefinitely. The question, therefore, is narrowed down to the means by which we recognize a reproduced image.

Theories of Recognition. I. Return to consciousness of an image. A current theory of recognition is based upon the unconscious theory of retention. As seen above, according to this theory, presentations remain in unconsciousness during periods of forgetfulness. They are of diminished intensity, but still the same in nature as before, and of continued existence. Recognition, then, is simply the return of the image to consciousness by an increase of intensity, due either to a second perception or to a train of association. In case the reproduction is a real object, the new percept reinforces the image : and in case it is a new image, brought up by association, it is assimilated to the old image lying in unconsciousness.'

To this theory it may be objected, that it overlooks the distinction between reproduction and recognition. According to it, all reproductions should be recognized; since no image is ever entirely lost, and each reproduction would find an ally necessarily in the depths of the unconscious life of mind. As a matter of fact, however, numbers of our reproduced images are not recognized. Again, it overlooks, as the Herbartian school consistent?

'See Volkmann, loc. cit., 1. p. 414. 
do throughout, the permanent unity of consciousness as a subjective thing. As shall be remarked later, there is a constant reference to self in recognition. The image is the same as when I saw it before; I myself am recognized as being in the same condition as before. If the mind is only a bundle of playing and changing states, whence comes this permanent background to which alone the states are the same, and by which alone they are recognized as the same?

II. Recognition as the feeling of the satisfaction of $a$ physical disposition. This theory again proceeds upon a foregoing doctrine of retention, i.e. that retention is a matter of physiological modification and disposition. It is said that this disposition gives the possibility of reproduction; the reinstatement of the function toward which we were disposed gives reproduction, and recognition is simply the consciousness of this reinstatement of a physical process, with its accompanying mental state. There is no doubt that such a feeling of physical facility - is an indication to us of our former experience of the same act, and that in this way recognition is assisted. The act of volition is assisted by the readiness for motor discharge arising from physical habit. Yet this feeling is, in neither case, the act of recognition or of volition. This is shown by numerous cases of retention and reproduction with their physical basis, in which recognition is wanting, as was said above. If the satisfaction of a physical habit accounted for recognition, all cases of such satisfaction under the same circumstances would be accompanied by recognition. But in fact, the same representation is sometimes recognized and sometimes not. Again, if this theory were true, we would always recognize external objects of whose existence we had be-

${ }^{1}$ So the feeling of novelty in a new experience is due to the establishment of a new physical association ; cf. Drobisch, Empirische P8ychologie, \$32. 
fore been conscious a moderate number of times; since the same physical process is reinstated at each perception. Yet we cannot lay too much stress upon these physiological points. They always admit of exceptions from unknown causes, such as the condition of the body as a whole, and the systemic affections. But it may be objected to this theory, on purely mental grounds, that it does not take account of the mental aspects of recognition which are brought out by the analysis below.

III. Recognition as time perception. By another class of theorists, recognition is considered as the establishment of relations of past and future : that is, the question how is a representation recognized, is answered when we conceive the fact of time perception. Reid defines recognition as "immediate knowledge of the past." Rabier says "to recognize is to refer to the past." Yet a little consideration leads us to see that these two questions are quite distinct in their nature. McCosh hints this distinction in separating the recognition from the "past time" in which it is necessarily construed." The feeling of familiarity is itself quite distinct from the sense of time, and it is only as an interpretation of this feeling that we locate the object or experience in the past. This is seen in many cases of recognition which are quite vague as to time, and which we cannot localize. Illusions of recognition, also-instances in which a strange feeling of familiarity possesses us when we are confident that the experience is new-seem to show that the time element which they indicate is not essential. The contrary is also true; the perception and estimation of time do not always involve recognition. It is probable that the perception of a unit of duration ${ }^{2}$ is a fact of immediate consciousness, and that the beginuing

- Cognitive Powers, p. 153.

See p. 185. 
of localization in time proceeds upon elementary facts of succession.

Yet while this is true, the facts of recognition are necessarily construed in past time. For this reason, the two points come up for discussion together. And there is reason for this general association of recognition and localization in time. Brown says " recognition is the perception of relations of time." This emphasizes the element of relation in connection with recognition. Recognition is grounded on the relations of the image recognized, and to this extent time enters, since every event has time relations. But, as we shall endeavor to show, other relations are also involved, though not as universally. Recognition, therefore, generally presupposes the perception of time relations; but only as one class of the relations-the most important class-which constitute its ground. We are led, therefore, to another theory of recognition.

IV. The recognition of an image is the reinstatement of its apperceptive relations. It has already been seen that the reproduction of an image consists in the reinstatement of the conditions, physical or mental, of the original perception. The reinstatement of the physical conditions suffices to bring an image back into consciousness : but it is not then necessarily recognized. It is only when some of the mental connections-the relations established between the percept and others by apperceptive attention -are again presented, that the sense of familiarity is felt. It is seen to be necessary that there be some accompanying mental state to which the representation is related. Often when an image arises in consciousness, we do not recognize it till we bring back some association with it. Often, also, we see a face and in so far recognize it as to feel vaguely familiar with it; while we strive to bring

${ }^{1}$ Philosophy of the Human Mind, ir. p. 108. 
up more of its apperceptive connections in order fully to identify it. This first vague recognition is probably due to the reapperception of the spacial proportions of the face.

This is further proved by the fact that percepts which are not related in the first presentation, for example single isolated sensations, as the stroke of a bell, are not recognized in the representation. We say of such presentations that there is nothing distinguishing or characteristic about them, whereby they should be recognized. But this is only to say that there were no specific points of connection between this image and others, or between the parts which are separately apperceived. As soon as some sign is made of a peculiar kind in connection with the image, it is recognized. Recent experiments by Lehmann on the recognition of differences of color, strikingly confirm this view.' Different shades of gray, which could not be recognized when seen quite alone, were recognized when they were given names beforehand, or when a number was attached to each in the first perception. Of nine shades without names or numbers, only 46 per cent. gave true recognitions; while the same shades, with numbers, gave 75 per cent. of correct identifications. Here the introduction of a simple local relation in the perception, gare a clue for the reapperception of the representation.

If we trace the case farther back in our mental history, we find additional ground for this conception of recognition. Perception, as has been said, proceeds upon the presentative or knowledge element of sensation : and this presentative element is found to be peculiar to, or at least most prominent in the spacial and temporal senses. In these senses, our sensations take on the form of relations in space and time, and it is this relational character that makes cognition and apperception possible. With this consideration in mind, the hy-

'Alfred Lehmann, Philosophische Studien, vi. This view of recognition was developed before Dr. Lehunanu's work was published. 
pothesis becomes rery reasonable, that recognition is the reinstatement of cognition, i.e. of the apperceptive activity which proceeded upon the relational aspect of sensation.

This view of the case also enables us to take account of the subjective element of recognition, which is overlooked in other theories. There is more in recognition than the sense of familiarity with an image. There is the feeling of ourselves as in familiar circumstances. It is one's self who has been in this state before. That is, there is consciousness of an abiding active self which persists in the twofold experience of presentation and representation. This feeling of self first arises in the active outgo of mental energy in attention, or in the relating process of apperception. Now when by reinstatement of this process, the fact of recognition is experienced, it carries with it essentially the feeling of an emphasized self : the self of the first apperception is again evident in the self of the reapperception, and the sameness of the apperceptive content gives sameness to the subjective agent. The self, then, which we are conscious of as persisting, is the active self ; as the self of attention, which is now reproduced, is an active self. This active phase of the mental life will again appear in localization in time. ${ }^{1}$

By activity here is not meant voluntary activity, but simply the outgo of attentive force. whether roluntary or not. In the case of recognition, indeed, there is lacking the feeling of volition, the conditions of the reinstatement being already fixed in the original apperception. Hence, as Gratacap suggests, ${ }^{2}$ there is lacking that feeling of liberty or freedom which is present in the constructive imagination. This distinction is useful to us in distinguishing between past images and pure creations of the imagination."

1 Below, §3.

2 Théorie de la Mémoire, p. 91.

${ }^{3}$ See p. 249. 


\section{§2. Ideal Prodect of Recognition : Personal Identity.}

In the foregoing discussion, the origin of the idea of identity, in general, and the identity of self, becomes clear. In our feeling of personal identity, it is not self apart from its activities of which we are conscious as persisting, for we know self only through its activities: it is the abiding consciousness of the power of activity which constitutes this feeling. It rests, first, upon reproduction, since a single present experience does not afford the duration or time through which we feel ourselves to be the same. There must be reproduced images with which our present experience is compared. But further, these images must be recognized, and must carry with them that feeling of familiarity which is afforded in the reinstatement of the apperceptive activity of attention. This activity is felt to be $m y$ activity in the second experience as in the first, and the recognition of the $I$ takes place in virtue of this repeated activity.

It should be carefully noted, that as in the original fact of attention, it was activity, potency, that gave reality to our experience and constituted the fact of mind; so here, the ideal product of memory is a conception of personality, which is essentially subjective force or energy.

\section{§ 3. Localization in Time.}

In the foregoing discussion of recognition, relations of time are found to enter necessarily. The discussion as to the nature and origin of the idea of space, has involved to a degree the idea of time also. As has been already said, however, the two cannot be considered under the same mental category. The data to be taken into account in the consideration of the notion of space are more abundant and can be better estimated, from the fact that extensive sensations may be isolated and their 
conditions separately considered. In considering the mental phenomena in which time is involved, no such appeal to the logical method of difference is open to us. All the facts of mind involve time relations. As Kant has said, time is the universal form of inner experience.

The question as to the origin of the idea of time must be approached, as in the similar problem of space, from the standpoint of concrete perception of filled time. Time in the abstract we do not know. We experience time only as we experience events, definite and individual, in time. We sometimes seem to apprehend the flow of pure time, as, in the night we lie awake in silence, conscious of the vacancy of our minds; but even then this flow of time is marked off by distinct events, the beating of the heart, the direction of attention, fragmentary sentences or words which flit over our consciousness and are looked at only to be dismissed.

The inquiry then seems to be as to the localization of events in time, as we have already considered the localization of things in space. There are two general characters of our notion of time under which its relation to our perceiving activity is seen; namely, duration and succession. These correspond in the time continuum, respectively, to length and position in the space continuum.

The question is much discussed, which of these two aspects of time is prior and fundamental to our idea of time. 'The question is not worth its cost, from the simple fact that duration and succession are coincident in the beginnings of the obscure consciousness of childhood. The child consciousness is born of changes in its sensory continuum, which indicate succession, and it is only as these changes persist in relation to others which do not-as the processes of the body, the systemic affections, the broad basis of sensation which makes up the coming individual-that they can be said to have duration. Duration can be perceived only as it is filled with an event, and that event, even though the first in child consciousness, is a change from the vague undifferentiated consciousness which 
preceded it. So, as shall appear below, the answer to the question "What is the form of the mental reaction in the sense of time?"' is probably this : a filled temporal continuum, just as the eye gives us, under the reaction for space, a filled spacial continuum. In one case, length is given, as made up of positions ; in the other, duration, as made up of successions.

The terms of the problem of localization in time are analogous to those of localization in space. Why is it that the experiences or events of our inner life are arranged in time order, as before and after? It is quite possible that it should be otherwise. Suppose a being with no memory whatever; to him each event would be now. There would be no past or future; every mental fact would be worth its face value in the present, with no relation to other mental facts. And again, granting the fact of memory, why is it that each event takes its proper place in the line of time; the place it occupied in the original experience and no other? And further, even though retained and reproduced in consciousness as a present state, why does it not simply remain a factor in the complex make-up of our present experience? In more general terms, how are states of consciousuess of a purely intensive and affective nature projected and localized in time form?

The answer, as before for space perception, is this: By a mental reconstruction of time, whereby intensive data are interpreted in terms of succession.

The difference between the data and their finished time form is simply the difference between the succession of ideas and the idea of succession. 'This difference is very great. As Bradley puts it: "Suppose there is a series of facts outside the mind, the question remains, How can they get in?": In order to the succession of ideas, only one need be present at a time, and they need have no constant connection. But for the idea of succession, there must be at least two ideas before the mind, the preceding and the succeeding. This inrolves the bringing up of past states to the level 
of the present. Now the mind sees all its states in this way-brought up to the plane of the present. I think of four events which happened in four successive days. They are all now present to my consciousness, and it is only my present state of which I am conscious. Of this state, $a, b, c, \bar{d}$ are factors. How is it that these present intensive, qualitative, states are projected in an order of time, the same as their original occurrence? How is it, to use Mr. Ward's figure, that certain states are thrown back in a line at right angles to this plane of the present? "We may, if we represent succession as a line, represent simultaneity as a second line at right angles to the first. Now it is with the former line that we have to do in treating of time as it is, and with the latter in treating of our intuition of time. . . . In a succession of events, say of sense-impressions $a, b, c, d, e, \ldots$ the presence of $b$ means. the absence of $a$ and $c$, but the presentation of this succession involves the simultaneous presence, in some mode or other, of two or more of the presentations $a, b, c, d . "$ This is analogous, as the same writer says, to the projection of the simultaneously perceived points of the visual field in a line of spacial succession, representing distance.

It is seen at once that there must be some qualitative coloring attached to these simultaneous states, which serves as datum for their temporal discrimination. If $a$ is located as before $b$, and $b$ as before $c$, it can only be through the mental interpretation of some accompaniment of $a, b$, and $c$, respectively, by which their temporal position is determined. This interpretation is called the mental reconstruction of time.

Data for the Reconstruction of Time. The data upon which the mental reconstruction of time proceeds, are exceedingly obscure; the more so through the difference already remarked between this process and that in the case of space, to which it is supposed to be analogous. In the case of space, we have non-spacial senses to compare with spacial senses. But with time, there is no such resource, and we are unable to fix upon facts as absolutely necessary to the idea of time, as shown by the absence of that idea in their absence. There are one or two kinds of data, however, so consciously involved in our

${ }^{1}$ Encyc. Britann., 9th ed., art. Psychology. 
localization of objects in time, thatthey may be safely indicated.

I. Intensity as an Indication of Time. Upon consideration, the most evident characteristic of our past experiences is their progressive fading, as they grow more remote. In general, the last hour is more distinct than its predecessor, and yesterday than the day before. It may therefore be stated as a general rule, that the intensity of a representation is a sign of its locality in time, in reference to other representations brought with it into consciousness. This rests upon the principle of memory, that-with certain exceptions, to be instanced later-the power of reproduction and the intensity of the reproduced image vary inversely as the time elapsed since the original perception. Presentations, therefore, experienced in the order $a, b, c, d$, would be reproduced in an order of intensity $d, c, b, a$; and this inverse intensive order serves as a sign for their mental interpretation in the original time order $a, b, c, d$. This is further supported by the fact that mistakes as to the relative time of events are occasioned by simple differences in the intensity of their reproduction. Things which impressed us strongly linger in our memory and seem to be recent, while later events are dim or forgotten.'

The fact of the interpretation of intensities cannot be deemed sufficient in itself for time localization. If uncorrected, the tendency to mistakes spoken of would be a sourco of continual illusion. Of two successive presentations the stronger would always be located last, whatever might be their real order. Hence we cannot stop here with some, "who call these differences of intensive coloring the "temporal sign;" but must seek some further point of reference in the mental life for these, as vet, confused representations.

More intense images also serve as rallying points or dates

'See Herbart's theory of space perception, above, p. 195.

'Lipps. 
in the past, around which other events are grouped. Te date many subsequent events from the death of a friend, the burning of a house, or some other great occurrence.

II. Movements of Attention as indicating Position in Time. Although not as clearly of simple import as the fact of intensity, in its relation to localization in time, the act of attention has an undoubted influence. From one aspect, it assists and reinforces the indication given by intensive coloring. Attention pursues, in the main, a regular rhythmical course and so brings out clearly the intensive relations of successive mental facts. On the other hand, it tends to subvert these indications, since strong attention placed upon one presentation or a series increases its intensity relatively to adjacent states of mind. The former are thus thrown out of their true time order.

As further evidence that the primary movement of the attention is of extreme import in the genesis of the idea of time, the following facts may be spoken of. $a$. The flow of time seems accelerated when the attention is agreeably occupied. This is most true when the occupation is varied in easy stages, and the active efforts of mind are not strongly taxed. $b$. The flow of time is, on the other hand, impeded when the attention is kept in a strained or concentrated condition : this is due to weariness in the mental life, which seems to have an immediate influence upon our time intuition. $c$. Time flows slowly when exciting impressions follow in such rapid succession as to leave the attention in a state of confusion. Here there is not sufficient time for the adjustment of the attention to the successive excitations, and the perception of the lapse of time is, as a consequence, confused. $d$. Time flows slowly when the mind is unoccupied. There are no outstanding ideas upon which the grasping and reacting 
power of attention may seize. $e$. After a given movement of attention, a future movement over the same series is easy, while the rearrangement of the series is difficult; thus the absence of mental effort is a sign of temporal order. $f$. In dreams, where the force of attention is greatly diminished, the sense of time is confused and mistaken. ${ }^{2}$

The least inference which can be drawn from such facts is this: that the intensive states of our attentive mental life are, in some way, signs employed in the mental reconstruction of time. These signs coexist with those derived from our passive sense experiences, and together constitute a general class of intensive data. The intensive phases of reproduced presentatious, on the one hand, seem to bear especially upon the succession of events in the past: we think of succession by the number of things in time. The phases of the attention bear especially upon the feeling of duration in the present. We measure duration in terms of our own attentive adjustment, as having experienced and expecting to experience. Duration is the feeling of the interval between things in time."

Units of Duration. If it be true that the sense of the lapse of time depends intimately upon the rhythmical intensive phases of the attention, we would expect to find units of duration in the flow of time which would correspond with these phases. Experiments in determining the area of consciousness show such units, in the maximal length of filled time which we are able to compass with a single immediate intuition. It was stated, in speaking of the area of consciousness, 'that about twelve distinct impressions of sound, succeeding one another at

'See cases given by Maury, Le Sommeil et les Réres, p. 110.

This distinction is due to Mr. Ward, loc. cit.

3 Above, p. 63. 
intervals of .2 to .3 sec. could be held in consciousness together. Multiplying this interval by the number of impressions, we have 2.4 to 3.6 sec., as approximately the extent of our distinct unit consciousness of filled time. ${ }^{1}$ The maximal extent of our intuition of empty time or pure duration is probably considerably shorter, as is shown by experiments as to the correctness of our estimate of small periods of time. It is found that we estimate correctly an empty period of .7 to .8 sec., shorter periods being overestimated and longer periods made too short. The images given in this "unit" constitute, in contrast with ordinary representations, our so-called "primary memory" (Exner).

It is through this unit consciousness of time that all time distance is estimated. The representations that it includes constitute the plane of the immediate present, which we may consider, in reference to time, as a circle, the earlier impressions in it passing out at one side and the later coming in, as a constant stream. Time, as we know it, is not a single line of succession, but numerous lines giving a certain number of coexistences in the present. It is out of this circle of the present that the past is projected in lines at right angles to its plane, like distance from the field of vision. This is but a figure to aid our conception, but so natural and convenient a figure that we employ it even in unreflective thinking: as when we say, an event is "so far back," or that two events happened "side by side." And there is no reason, in the nature of the case, that intensive data should be spoken of in terms of time, rather than in terms of space.

The various theories propounded to derive the idea of time correspond in the main to those already described under the head of space, i.e. nativistic and empirical. Empiricists do not urge their point with equal force in this case, because data of a physiological and experiential kind are wanting. They generally attempt to bring time in under the cover of the empirical derivation of space, asserting that the same consid-

${ }^{1}$ Prof. James does not seem to be right in taking the number 40 , held in the mind by grouping, as his multiple of impressions; for the groups of 5 to 8 are a device of a symbolic nature to aid the range of mind. Each group represents a unit, and the impressions in it are not distinct in consciousness. Jour. of Spec. Pliioz., Oct. '86. 
erations suffice also for time. On the nativist side, the case takes the form of nativism of product, or "formalism," largely. And it cannot be denied that the grounds for considering time a mental form are not weak. The position we have taken, however, that of a nativism of process precisely analogous to the process of space perception, grants the essential claim of nativism, a mental activity peculiar to time perception, and, at the same time, utilizes the data of experience as they are discovered by investigation. That these data are more obscure than those for the perception of space, does not weaken the philosophic position; while the fact is offset, in a measure, by the force of the analogy between the two. ${ }^{2}$

The older theory of the immediate perception of real time overlooks the distinction between succession as it takes place and succession as it is perceived. Locke derives the idea from "reflection upon the succession of our ideas." This begs the question, since we must have the idea of succession before we can reflect upon it. The question is, how does the successive form of ideas enter the mind at all? Reid's ' refutation of Locke rests upon the same error. He says, if ideas in succession have duration, each idea must have duration, hence we perceive duration without succession. This assumes that the real duration of the single idea is a perceived duration, or, as he puts it, "an immediate knowledge of the past." On the contrary, it is possible that the first stimulus to time perception may arise from a series of impressions each of which has real duration. So with the theory of the Scottish philosophers generally:

As representing the empirical theorists, Mr. Sully may be referred to. He points out somewhat vaguely the passive intensive data cited above for time localization, and hints at the function of attention as giving temporal signs, but fails to account in any way for the transformation of these intensive data into time form ; except so far as calling it an "associa-

\footnotetext{
1 From Kant.

'For recent theories, with references, see James' note, loc. cit. pp. 398-400; also Volkmann, Ielubuch der IAychologie, \$87, Anmerkung 4.

${ }^{3}$ Intellectual Porers, Essuy III, chap.v.

4 So McCosh. Cog. Poicers, p. 156. Stewart divides the problem more properly. He says: "The remembrance of a past event is not a simplo aet of the mind, but the mind first forms a conception of the event, and then judges from circumstances of the period of time to which it is to be referred."-Loc, cit., vol. I. ch. vi.

-Oullines, p. 260.
} 
tion by contiguity" does so. "It implies," he says, "an act of reflection upon the succeeding representations (Locke), and the representation of them together, at the same moment, as successive." But what is the nature of this "reflection," whereby the representation of them together, at the same moment, becomes also the representation of them as "successive"?

Perception of Time by the Ear. Of the special senses, the ear is most acute in the appreciation and measurement of time. Single sound stimuli are discriminated with great delicacy and exactness, both of interval and of duration. For this reason, hearing is called the sense for the perception of time. Its function, in this respect, is similar to that of sight for space. It makes more exact and definite the vague time continuum reported first, probably, by the muscular sense and later by the other senses. This delicacy of time perception underlies the pauses of speech, the quantity of vowel sounds, the metric flow of poetry, and, more than all, the rhythm and technical "time" of music."

\section{§ 4. Ideal Product of Temporal Localization: Idea of TIMe.}

From the conception of coördinated events in the form of past time, we pass by abstraction to the idea of time: that is, we pass from filled to empty time. The point of immediate experience is called the present, in relation to the past, and the whole possibility of additional experience is called the future. The future, therefore, is not time at all : it is simply the anticipation of more experience like that already placed in the past. The finished product, the idea of time, is of late growth in the mental life of the child.

\footnotetext{
1 Sully, Outlines, p. 256.

${ }^{2}$ On the perception of rhythm by the ear, see Sully, Sensation and Intuition, chap. virr.
} 


\section{§ 5. Kinds of Menory: Local, Logical.}

We have found memory, viewed entirely from the subjective side, to be the revival of an image in its network of relations with other images. Things are remembered in groups, as they were at first apperceived. This involves the variety of relations which are possible in apperception. The kinds of relations thus reproduced, serve to aid us in distinguishing between different kinds of memory. For example, an image may carry with it the local connections of its first perception; that is, its locality was the prominent feature of its apperception. Such memory is called local memory. It is in this way that we memorize long sentences by the position on a printed or written page, or the parts and ornaments of a room. These memories are fleeting and temporary, generally, from the fact that local relations are accidental, and do not belong necessarily to the objects remembered. It is only as long as we can reproduce the whole page that we can recall the part desired. The same also is true of temporal memories. Beyond these extrinsic or accidental relations, we find others which are essential. Cause and effect, substance and property, whole and parts, are such relations. Memory by means of these is called logical memory. It is more permanent and valuable than local memory, from the fact that these relations always subsist, and the related image is always suggested, when that to which it is related is capable of being presented. It is seen at once that logical memories should be cultivated rather than local, and that the latter, except when only temporary acquisition is desired, should be avoided.

On memory, consult: Taine, Intelligence, pt. 1, bk. 2, ch. II: Ebbinghaus, Das Gedachtniss; Carpenter, Ment. Physiology, ch. x; Sully, Outlines, ch. vII: George, Psychologie, p. 281: Iadd, Physiol. Psycholngy, pp. 545-559: Volkmann. Jellorluch d. Psychol., \$\$ 69-85 (especially \$ 83); Drobisch, Psychologie, \$\$ 31-39; Ribot, 
Diseases of Memory, ch. I; Fortlage, System der Psychologie, § 14; Fauth, Das Gedachtniss; Hering, Ueber das Gedächtniss; Kay, Memory; Waitz, Lehrbuch der Psychologie, \$ 11, and Grundlegung der Psychol., p. 56; Calderwood, Mind and Brain, ch. Ix; (History) Burnham, Amer. Journal of Psychol., II, Nos. 1-4; Binet, Revue Philosophique, xxIII. 473 and (Richet) xxI. 560; Rabier, Psychologie, ch. xIV-xvI; Gratacap, Théorie de la Mémoire; Beneke, Lehrbuch $d$. Psychol., ch. III. On the educational bearings of the subject, see references given by Sully, Outlines, p. 300, and the treatises on pedagogics, especially Dörpfeld, Beiträge zur paddagogischen Psychologie; (Recognition) Fouillée, Revue de deux Mondes, July, 1885.

On temporal perception and localization: Volkmann, Lehrbuch, §§ 87-89; Waitz, Lehrbuch, § 52; Drobisch, Psychologie, §§ 58-61; Maudsley, Physiol. of Mind, ch. Ix; Calderwood, Mind and Brain, ch. IX; James, Journal of Speculative Philosophy, Oct. 1886; Ward, Encyc. Britann., art. Psychology; Romanes, Mind, III. 277; Spencer, Psychology, 1. p. 207; Sergi, Psychol. Physiologique, bk. 2, ch. II; Glass, Philosophische Studien, Iv. p. 423; Hodgson, Time and Space, pt. 1, ch. III ; Lipps, Grundthatsachen des seelenlebens, ch. XxvI; Exner, Hermann's Handbuch d. Physiologie, Bd. II, Thl. 1, pp. 260-262; also articles by Dietze, Estel, and others in Philosophische Studien.

Further Problems for Study:

Mental continuity in memury;

Memory during sleep;

Cultivation of memory;

Memory systems. 


\section{COMBINATION.}

\section{CHAPTER XI.}

\section{ASSOCIATION.}

\section{§ 1. General Nature of Association.}

Definition of Association. In the foregoing chapters reference has been repeatedly made to the principle of "association of ideas ;" indeed some knowledge of such a principle is so generally implied in the affairs of life that its familiarity has been assumed. The truth that things owe their character to their associations, that men are influenced by their associates, is only a broader application of the law which takes its rise in the psychic life.

The conditions under which the revival of mental images in general is possible have been stated. It proceeds upon a renewal of the nerrous action which accompanied the first perception, and the reinstatement of the original apperceptive act with a sufficient intensity and duration. This, however, does not suffice to inform us what it is that gives specific direction to the flow of reproduced states. Why is it that among an infinite number of possible reproductions, a particular representation rather than others is revived? This question indicates the true function of association, which is the progressive revival of particular mental states. The fact of association may also be defined, as the relation between revived states of consciousness, whercby continuity of successive representation is secured in the form of new integrated states. 
Ground or Reason of Association: the Preceding Idea. If we thus conceive of association, as the law of the connection of representations in consciousness, and picture the series of such representations, the nature of the connection in each case is seen to lie in the character of the antecedent image. For example, I am thinking at this instant of the rain; and why? Because $I$ have seen the heavens corered with clouds. I have an idea of thunder, because I have just seen a flash of lightning. I think of Napoleon because I have already thought of Cresar or Alexander. In each such case, the idea at present before me is determined by the idea which immediately preceded it. If the antecedent idea had been different, so would also the subsequent idea. If, for example, I had thought of Socrates instead of Alexander, it is altogether improbable that Napoleon would have come to mind. There are no states of mind which can be completely isolated from this chain of connected links. Our whole mental life is a progressive series of suggestions, ${ }^{2}$ or of integrations of ideas.

The word idea is used here in its broadest sense, to cover all and every form of mental modification, not alone the purely intellectual, but also the emotional, voluntary, and sensational. We have seen that sensations are associated with movements, and movements with impulses of the will : and later the same universal connection with other states will be seen to hold good of the feelings. The word idea has lost all definite psychological meaning in a more contracted significance-being replaced by exact expressions, such as presentation, representation, notion - and may well bear the general significance which the expression "association of ideas" gives it.

Relation of Association to Memory. The reciprocal relation of association and memory is so close, and the two functions run into each other so intimately, that it is impossible to consider either entirely independently

1 Word used by Brown: it is more appropriate than association. 
of the other. Memory involves both reproduction and recognition, and inasmuch as both of these depend upon the reinstatement of the relation seized upon in apperception, an element of association is involved in the related mental states. That is, the first arrangement of the facts of experience gives ground both for the possibility of reproduction, memory, and for the form of reproduction, association. On the other hand, memory as retention precedes association, properly so called; since images must be retained in order to be associated. But since the association, like the retention, is unconscious, and since memory is conscious only when it is a completed act, we may consider the two together as a completed form of mental activity, memory supplying the content and association the form.

Physiological Basis of Association. In speaking of the physiological habits which lie at the basis of retention, we had occasion to point out the complex nature of the dispositions or tendencies in the mental life to which they give rise. We may suppose both associative connections between localities or elements in the cerebral cortex,' and the multiplication of these connections, in an intricate network of fibrous and cellular tissue. ${ }^{1}$ Considering these connections as constituting the organic counterpart of the associated mental life, we see at once the wide capacity it affords for varied and related representation. The stimulus of a single element in the network arouses many connections, first those best established and oftenest repeated, then others in varying degrees of strength of revival. For example, we may suppose the memories involved in the sight, touch, sound, written signs, and spoken word, of a bell, to be thus connected. The presentation of a bell to view re-

1 Wundt, Phys. Prych., 8d ed., and Charcot. 
vives at once no less than five different memories: the muscular memories involved in spelling the word bell, the word as heard when spoken and seen when written, the sound of the striking of the bell, and its hard smooth touch. These come up in varying degrees of readiness, according as we are accustomed to exercise them respectively in our experience with bells. Other more indistinct memories, such as the church spire, dining-rooms, crowd in upon us, each having its correlative accompaniment in the brain activities. The basis, therefore, of association is the same as that of retention and admits of the same physiological explanation: that is to say, the mere possibility of association in revived states is provided for in the physiological retention of the related molecular changes occasioned at their first experience. The actual revival, however, as remembered states, is mental, as reproduction and recognition are mental. For this reason, the laws of association are unconscious until critical examination of the nature of associated states reveals them. And even then we have no means of penetrating the unconscious to determine their exact nature or scope.

\section{§2. Laws of Association.}

I. Particular or Secondary Laws. "When we seek," says Aristotle, "after an idea which is not immediately before us, we reach it through the mediation of another idea, either by resemblance, or contrast, or contiguity." Modern psychologists generally follow Aristotle in this enumeration of the principles of association, at least as respects resemblance and contiguity. Deferring the discussion of contrast, we may state two great laws of asso-

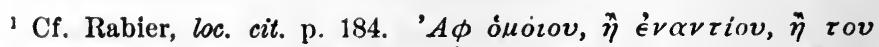

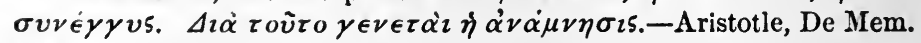
et Rem., c, II-IV, 1. 
ciation; depending upon the two classes into which, in introspection, the facts of the case seem to fall.

In the first place, images are associated. That is, one of two or more states, all of which are reproductions, precedes and brings up the others. The face of a friend, whom I recall, recalls the place and time of our last meeting. On the other hand, a new experience, a presentation, may bring up images of the past. My new acquaintance recalls some one of $\mathrm{my}$ old friends. These two classes of facts exhaust the range of association. In the first of the two cases, the images which come up together have always been together in the mind before: this is contiguity. Whatever their former relation to each other may have been, when we experienced them, whether cause and effect, whole and parts, or any other of the relations the mind discovers, it matters not: it is sufficient that they have been present before in consciousness, as contiguous in time. In the second case, the presentation which tends to recall the image is always seen to be like the latter in some respect: this is resemblance. Resemblance to an image-again disregarding contrast-is the only characteristic of a presentation, which serves as ground for the immediate revival of that image.

The two particular or secondary laws of association may, in accordance with the preceding, be formulated somewhat as follows:

1. Contiguity: Ideas which have been apperceived together are reproduced under the same apperceptive relations.

2. Resemblance: A presentation which in any way resembles an image, tends to cause the reproduction of that image, with its related images.

It should be noted that it is only a new presentation to which the law of resemblance can be said to apply as tending to revive past images. As soon as the presenta- 
tion is repeated its resemblance to the revived image is not emphasized in the reproduction, but the fact that the image which its former perception has left behind has once coexisted with the image suggested at that time, makes it a case of contiguity. For example, I meet a man $B$, and I think of my friend $A$, whom he resembles. After that, the two images are associated together by reason of the contiguity thus established: so that when I see $B$ again, the resemblance is not necessary to the suggestion, though it still strikes me, and is known to be the cause of the first association. In this case the repeated perception adds vividness and strength to the association, since the reality of the object passes over in a measure to the image which it calls up. ${ }^{1}$

This reduction of a large class of cases of seeming resemblance to contiguity, is a step toward the elimination of resemblance altogether, as an ultimate ground of association. While we hold that, from an empirical standpoint, resemblance is an evident and real reason for the comnection between ideas, and must be recognized as such, still on reflection, we find it possible to reduce all cases of resemblance, in their ultimate nature, to contiguity. In every case of resemblance between a presentation and the image it suggests, there may be said to be elements common to the two : elements in the present presentation which affect us in an identical way with elements in the image which it resembles. In a strange portrait, which we say resembles a friend, there are certain points of feature or expression, few or many, which are identical with our friend's : these points coexist with others in the image of our friend, and the whole image is brought up by this coexistence or contiguity. In the presentation there are, say, elements $a, b, c$, etc., and in the image, elements $\mathrm{A}, b, \mathrm{C}$; the common ele-

${ }^{1}$ See the striking examples given by Stewart, Philosophy of the IIuman Mind, chap. v, part 1, sect. 1. 
ment $b$ makes the presence of both necessary. M. Taine, following Brown and Hobbes, formulates a law to express this process of association: When part of an idea appears in consciousness the whole appears.

In illustration of this law, the following quotation from Thomas Brown is apt:" "A ruff like that worn by Queen Elizabeth brings before us the sovereign herself, though the person who wears the ruff may have no other circumstance of resemblance; . . . . it is necessary only that a part of the complexity (the Queen) should be recalled-als the ruff-to bring back all the other parts, by the mere principle of contiguity. ... The eyes of a stranger affecting our vision in precisely the same manner as the eyes of a friend, thus produce one part of the complex whole which we have been accustomed to recognize as our friend, and the one part, by its former proximity, recalls the others. In this manner, we might be able to reduce every case of suggestion from direct resemblance to the influence of mere contiguity."

Brown's position also, that associated emotion often supplies the link of contiguity in cases of resemblance or faint analogy, seems to be just. The events often resemble each other only in the emotion which they excite. This fact of emotion is a part of the experience in each case, and tends to be followed by the reproduction of the secondary image.

The great importance of the law of contiguity in opposition to resemblance is further emphasized by the experiments of Lehmann already spoken of above." The simple addition of a mark, number, or name to the sereral shades of worsted aided the memory by contiguity, when the resemblances of the pieces to one another were too great for distinction. From all the variations in his experiments, he draws the conclusion, that " the law that best explains the facts, is the law of adjacency, in opposition to the law of similarity." "

1 Intelligence, truns., pp. 79-81. Cf. Baiu, Senses and Intellect, chap. II, §2.

Ledtures on the Philosophy of the Mind, Ir. pp. 12-13. Mr. Bradley also finds this theory in Wolfe (1732), Princ. of Logic, 311-312.

Sce p. 177.

4 Sce Science, vol, xir. p. 152. 
Association by Contrast. Since Aristotle, various thinkers have cited contrast as a distinct principle of association. It seems warranted at first sight by a variety of well-marked experiences. The sight of a dwarf brings up a giant, a bright color recalls strongly contrasted colors, sour makes one think of sweet. There can be no doubt, in such cases of contrast, of the reality of the suggestion; but are there not other reasons than that of contrast, to which it may be referred? There are such reasons, it seems, in all cases, and we are led to reduce these associations to resemblance, and ultimately to contiguity.

1. In most cases of contrast there is a standard of reference to which both the presentation and the revived image are referred: this standard constitutes a point common to both ideas, a point of resemblance. For example, the short man suggests the tall, since both are, at once, thought of in comparison with an average man. The one is short only as he is shorter than usual, and the other is tall only as he is taller than usual. Thus in the very conception of the contrasted images, a common element enters. This common element is the $b$ of our earlier illustration, and secures the association by contiguity. This variation from a normal standard accounts also for the association of emotional and volitional states, as great misery with great happiness, great effort with complete inertness.

2. Many instances of contrast arise from the early character of our knowledge acquisitions. The beginnings of knowledge involve, as has been seen, a process of distinguishing or differentiation: ${ }^{1}$ things are fixed and defined in relation to other things. This tends to fix in our minds many instances of contrast. In early education, the child is taught to appreciate qualities in

${ }^{1}$ Chap. VIII, §3. 
some objects by having pointed out to him the conspicuous absence of these qualities in other objects: until it becones a mental habit, and finally a method of logical procedure.' All such primary connecting of contrasted things takes place among contiguous states, and frequent repetition confirms the association. If we had only seen regular oval leaves, they would have no contrasted associations; but having once been led to observe leaves which are very indentate, the contrast at once presents itself afterwards; but the association is due primarily to the contiguity thus established.

3. It is also true, as Brown and Horwicz suggest, that there is an emotional coloring in cases of contrast, as in resemblance, which supplies a connecting point of similarity. Vague analogies which are stronger by reason of inherent contrasts, and contrasts which are brought out by an underlying analogy, occasion a repetition of an affective state, which ties together the members of the relation. For example, a three-handed monstrosity brings to mind a one-handed monstrosity, and all the circus oddities we have ever heard of, come to mind ; simply because they are all monstrosities, they excite in us a common feeling of repulsion. They resemble one another in the fact of variation from normal nature, and in the common emotion this variation excites. The same may be said of states which involve similar rolitional accompaniments. ${ }^{2}$

It seems true, therefore, that all cases of association

'Inductive "method of difference."

2 'The necessity of holding contiguity to be, of the three, the great principle of association was recognized by Berkeley. He says (Theory of Vision, $\S 25)$ : “ That one idea may suggest another to the mind, it will suftice that they have been observed to go together, without any demonstration of the necessity of their coexistence, or so much as knowing what it is that makes them so to coexist." He seems clearly to subordinate relation-" that which makes them so to coexist"-to contiguity. 
by contrast may be accounted for, as either variations from a mental standard, contiguities observed and established in the process of the acquisition of knowledge, or emotional and volitional resemblances.

Yet, as in the case of resemblance, it is proper that contrast should be considered a law of association. Analysis and reduction of a psychological fact does not cast out the fact from our conscious life. 'The means of referring contrast to other classes of suggestion are conscious and apparent on reflection, while the means by which resemblance is seen to be contignity are more hidden; and for that reason, contrast cannot be considered coürdinate with the two secondary laws: but it is still a valid account of a large class of cases, to call them suggestions by contrast.

II. Universal or Primary Law. One great principle of associative reproduction has been found in contiguity by succession, its special forms being simple contiguity, resemblance, and contrast. The tendency to suggestion by this law is greatly strengthened by other factors, whose consideration leads to the underlying principle of all association. If such contiguity were the whole case, only the physical side of memory, that is retention, would be operative in the reproduction : and our memories would present the uniform sequences and regular fadings which physical dispositions undergo. The peculiarities of personal mental life, the characteristics of individuals, which are so striking in the varieties of form and content of memory, would be greatly reduced. But such a supposition is impossible, since memory is mainly mental, as perception is. It is an active synthetic process of constructing relations. Apperception, therefore, is the power which gives definitive cast to our associations, and supplies the lack we have spoken of. The relations discovered in apperception in their variety, and their infinite intensive phases, give character and deeper meaning to contiguous experiences. 
Law of Correlation: every association of mental states is an integration, due to the previous correlation of those states in apperception. The relatious which we discover among the objects of our perception are very varied, and many attempts have been made to classify them.' Besides the relations of time and resemblance which have already found their place in association by contiguity, the principal connections which the intelligence finds among its objects are subordination, causation, and design. The relation of subordination has various applications, as whole and parts, substance and accident, and underlies, as will be seen, the use of the notions of genus and species in the symbolic and discursive operations. The real logical import of this relation is only apprehended after the formation of general notions and the growth of mind on its logical side. In early childhood, it is simply apperceived as contiguity. Causation also, in its completed form, involves the ideas of necessity and potency, which give it the form of a universal relation between given data, while in child life it is simply a perception of succession. Design arises, perhaps, even later in life, since it involves more seldom the simple fact of contiguity, and requires a larger stretch of experience for its generalization in a notion.

The very great value of correlations in our past experience is apparent without amplification. Mere contiguity in time may fade and disappear, when a relation remains intact. For example, all the circumstances surrounding the first perception of a match, the time, persons, manner of striking, material lighted, are long sunce forgotten; but the effect, a blaze of fire, is remembered. The elements of potency and necessity, peculiar to causation and foreign to mere contiguity, are in this case the means of memory. Correlation is, for the mental life, the

' See Chap. XIV, where a provisional list is adranced. 
essential thing. This has already been pointed out in the section on "kinds of memory:" it is, that contiguity, which is merely the mental correlative of the physical process, is supplemented by the attentive force of mind, which gives to our successive states an essential inner connection, corresponding to the relitions of external realities.

Examples readily suggest themselves of memories which show this difference. We remember a string of foreign meaningless words only as long as the actual sounds persist in consciousness. But if we detect, in the sound, similarities to words in our own tongue, they remain longer in memory through this relation. But as before, it is only after the words assume meaning and sense to us that they become permanent acquisitions. McCosh tells the story of a clergyman who asked a sailor boy to box the compass backwards, which he readily did from the correlations of the points of direction with one another-they had the same meaning both ways;but when the boy retorted by asking the clergyman to repeat the Lord's Prayer backwards, the clergyman was defeated. In the latter case, the words had no correlations or meaning, and their simple contiguity was not sufficient for memory. ${ }^{2}$

Preference as Influencing Association. Another factor which influences greatly the direction and character of our association, is found in individual preferences and talents. As a general thing, our preferences take the direction of our talents. Individuals differ notably in the manner in which the same experiences impress them, and in the relations they discover under the same external conditions. An artist sees the red evening sky with feelings only of beauty and pleasure, while the farmer discovers in it probabilities of ruin to his crops. The student of a practical and utilitarian cast of mind cher-

'See p. $189^{\circ}$ For details on the correlative faculty and its products, see Chap. XIV.

${ }^{2}$ On the meaning and value of correlative association, see Lotze, Microcosmus, I. p. 232. 
ishes his books only as a means of increasing his chances of success or usefulness in life, while his more ideal neighbor studies to secure a broader mental range or an acquaintance with deeper truths for their own sake. In this there is an immediate intrusion of the prevailing temperament into the web of daily experience, carrying the attention and effort over upon specific relations of things; which tends in its turn to fix these correlations in mind and thus to heighten the disposition in its peculiarity. Native preference gives direction to associations, and associations becoming fixed give permanence to native preferences. In general, it may be said, that mental work is most successful when done along the line of inclination.

It may be well to point out the danger arising from the free play of this law of association. Free exercise in the line of inclination, to the exclusion of other well-directed mental exertion, tends to develop great disproportion in the growth of mind, especially in childhood. Children should not be allowed to choose their mental pursuits. The disciplinary ralue of compulsory application to things which are distasteful is readily seen, in the increased flexibility of the attention, greater voluntary control of the intellectual impulses, and the broadening of the mental horizon. It is only after these qualities and capabilities have been already attained by a wellbalanced course of compulsory training, that the student should be allowed to devote himself to a more contracted circle of study.

\section{Forms of Association.}

Association by contiguity takes two great forms, when regarded in reference to the objects or erents from which our mental states arise. These events or objects may coexist in time or space, or they may be successive in time. Thus distinguished we have association by $\mathrm{Co}$ existence and by Succession. When we come, however, to 
consider that it is not objects which are associated, but our mental affections, and that, in reproduction, these affections must be projected in a time series whose form is always succession, we find that coexistence of objects gives rise to succession of ideas. That this is true is seen from an eximination of the two possible kinds of coexistence in space and time. Objects which coexist in space, as has been already seen, are apperceived by a rapid shifting of the attention, the maximal unit of immediate apperceptive apprehension, for sounding bodies, being about 12 distinct stimuli, each of which may be itself separately apperceived, and for sight about 5 to 7, which are given as one. For the other senses this range is still more contracted. Each such apperceptive unit constitutes a single presentation, capable of reproduction only as a whole, as one image, and not as a plurality of coexisting images : consequently, the next image brought up is that to which the attention was next shifted, and the representation of all sensation arising from external stimuli must be in the form of succession. For example, after looking at, say, twenty crosses on a blackboard, I reproduce them as four successive representations of five crosses each, or in a longer series of smaller units, the single crosses in each unit being reproduced not as coexistent images, but as components of the unit image of five. If they are reproduced as single crosses, it is in succession, arising either from the apperception of each cross separately, or from the information that the crosses are all alike, which information takes the place of our own apperceptive exploration. So, however reproduced, the representation arises from succession.

Passing to coexistence in time, the same is found to be true. Experiences which happen contemporaneously

${ }^{1}$ Supported by the longer reaction-times of complex presentations. 
are reproduced in a single apperceptive complex, as one image, and not as a plurality of coexisting images. For example, a musical chord is reproduced in its effect, as one thing, the whole giving a single sensitive modification. It is true we may analyze this complex into its elements, but such an analysis proceeds upon a previous analysis of the actual presentation which gave a successive character to the factors comprised. Suppose upon hearing the chord at first, I distinguished in the whole effect four tones; the act of distinguishing or relating these tones depends upon successive acts of apperception, the relating power of attention. And in so doing, the separate tone-stimuli remain no longer coexistent, but are successive.

Thus we hold that the one form of contiguous reproduction is Succession. This we would expect from what has already been found to be the physical basis of memory. Mental reproduction was seen to depend upon the persistence of physical modifications in the form of physiological dispositions; these dispositions being tendencies toward a series of successive molecular changes, which have their mental accompaniment in the succession of conscious states. By the law of cause and effect, these changes are a progressive series in time, the terms being sometimes complex physically, but giving a resultant mental modification, which is a single mental state, and not a coexistent plurality of states. If consciousness be unitary, and have but one centre of apperception, these contemporaneous changes can only constitute for consciousness one modification as a whole, the result being a single presentation. The presentations thus arising, are thrown into successive form by the rhythmic activity of apperception, under the limitation of our perception of units of duration.' If these units of dura- 
tion were shorter or longer, the succession of our ideas would be faster or slower. than now.'

Forms of Coexistent or Simultaneous Association. ${ }^{2}$ Considering the nature and relation of the objects or events which give the later possibility of mental suggestion, they appear often to be coexistent or simultaneous. For purposes of actual reproduction these, as has been said, take the form of succession; but are distinguished from other successive suggestions, in that they depend upon simultaneousness of external stimulus. These associations fall into several classes:

a. Unitary or synthetic associations. This form of expression applies definitively to the associative process involved in synthetic sense perception, the grouping of differentiated and localized sensations in the form of unit objects in space. The function of association in this process has already been pointed out, and it is mentioned here only for purposes of classification. ${ }^{\text {s }}$ The mental process of intuition, whose ideal product is the idea of synthetic unity, proceeds upon the basis of the association of its sense-materials in two forms : (1) $E x$ tensive associations, in which the data of extension are presupposed, as in the association of the sensations which take the form of the percept tree, or of sensations having

1 The prevailing German classification of the principles of association, followed by Herbart, Wundt, Taine, Trautscholdt, is seen in the following table :

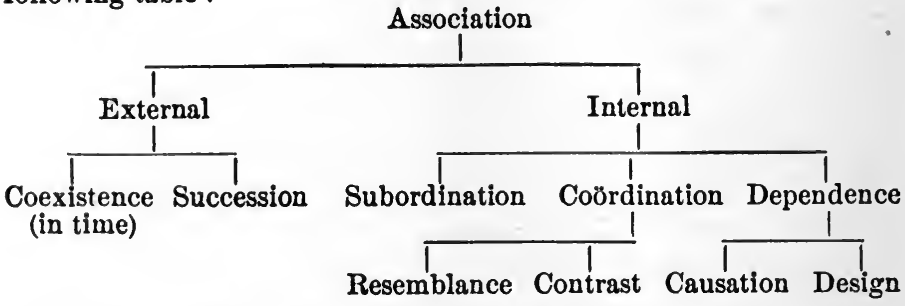

${ }^{2}$ On this section, compare Wundt, loc. cit. ch. xvrr. $\quad{ }^{3}$ See p. 139. 
the property of extensity, that is, made up of component sensations of the same quality whose intensities do not coalesce, and (2) Intensive associations, in which there are no such extended data, as in the associative synthesis of musical tones, where the component sensations of the same quality do coalesce.

b. Assimilative Associations. In many cases, one of two reproduced images is assimilated to the form of the other, and mistaken for it. It is always a case of association by resemblance, and partakes of the nature of an illusion of perception or memory. This process is strongly typified in dreams in which some slight stimulus is assimilated or accommodated to the form of our dream consciousness, and plays an important rôle in its development: a slight noise becomes thunder, and the storm with all its accompanying sights and sounds is present to us. ${ }^{2}$ So in theatrical representations, the scenery is often assimilated to the real actions of the performers, and the whole presents a spectacle of temporary reality.

c. Disparate Associations. These associations arise from the coexistence of disparate presentations, as a sound and a light, a sensation and an emotion, a feeling and a volition. One feels faint at the sight of blood, or sorrow at the sight of black crape. Among these associations, are some very remarkable and important illustrations of the far-reaching application of the general laws of suggestion. The close connection between sensation and muscular movement has already been remarked. It gives rise to our developed motor intuition. In adult life it is so intimate a connection, that we are sometimes unable to sever the sensor and motor elements of our experience from each other. The nervous circuit, which is of great importance in the formation of mental associations, becomes self-acting and reflex. It is quite beyond our power, for example, to prevent flinch-

' See the author's experience in Science, vol. xII. p. 216. 
ing from the seat of expected or real pains, to hide embarrassment by suppressing blushing, to avoid various individual nervous reactions in circumstances of excitement. Among the closest of these motor associations is that between the hearing of words and their speech. The possibility of the use of language depends upon the exactness, variety, and control of these associations: as is illustrated in the great difficulty children have in learning to speak, and by the phenomena of aphasia in its several varieties. The power of articulating certain classes of words, or all speech, may be lost, while the memories of the words, sounds, and written signs, remain intact. Or the motor association involved in writing the sign may be dissolved, ${ }^{1}$ while the word-speaking power remains. These associations, in many other varieties, have become so intimate from repetition, that the organs involved take up their part often unconsciously to the agent."

Another still more remarkable association of disparate sensations is that of colors and sounds; associations which seem to be independent of any individual experience of contiguity, and consequently to rest in the diffusive or sympathetic nature of the sensorial reaction under color and sound stimuli. The case of two brothers named Nussbaumer has become classic. They experienced regular and constant sensations of color in connection with sounds even in their dreams, but only

\footnotetext{
${ }^{1}$ Called agraphia.

${ }^{2}$ The remarkably separate and distinct forms of the motor associations involved in speech are seen in the fact that each language seems to have its consciousness, and the words of one are seldom substituted for those required in using another connectedly. I may cite the case of a little girl five years of age, in Milwaukee, Wis., who uses German and English equally well, and always replies in the language in which she is addressed, with no effort or thought. She has both a German and an English motor intuition for language. A similar case is reported by Carpenter, Mental Physiology, p. 264 .
} 
approximately the same series of colors for the two men. Similar associations of touch and color are reported. The blind are sometimes able to determine sharply contrasted colors by touch, and a hypnotized patient is said to hare sorted colored wools with his eyes blindfolded.'

Complex Associations. The complex character of the physical dispositions which underlie associations has already been remarked. It is impossible to isolate a single track of nervous connection from the general network of elements which constitute the ground of all sensorial reaction: and the difficulty is almost as great in regard to mental phenomena. The idea which we single out as the suggestion of a preceding state is only one, in most cases, of a great plurality of lines of mental direction which are open for our pursuit. And this complexity is enhanced when we remember that the suggesting idea is itself only one of the numerous suggestive progeny of other states antecedent to it. These so-called lines of direction-pursuing the figure of a field of consciousness to which these lines would be perpendicular-all tend outward from a given point, the suggesting idea. For example, the year 1492 suggests the discovery of America, the great events of the Italian Renaissance, the Humanistic movement, and the Exodus of the Children of Israel, together with any or many individual associations which may have been formed with it, such as the dates of other great geographical discoveries. Now in the revival of this network of relations, the richness of its suggestions may serve as a help or as a hindrance to memory, according as the order of the revival be a converging or a diverging association.

' Fontan. See account of the Nussbaumer and other cases, in Lewes, Problems, 3d series, III, chap. Iv, and Amer. Jour. of Prych., vol. I. p. 740 ; also Frutucis Galton, on "Color Associations," in Inquiry into Human Fuculty, p. 145. 
I. Converging Associations. In the converging association, the mind enters upon one of many paths, all of which lead to the same result. This is the great resource of memory in cases of voluntary recollection. We cast about in consciousness for some idea related to the image we wish to call up, and the probability of our finding such a pathway to the goal, depends upon the number of mental relations which have been formed around it. In case I wish to recall the date 1492, I have only to think of any one of the events mentioned which are associated with it, since they all converge in their lines of suggestion to the one result.

II. Diverging Associations. In this case, the process is reversed and the memory is hindered and embarrassed by its possible alternatives. If I wish to remember the date of the invention of gunpowder, and can only do so through its association with the date 1492, I am liable, in the absence of all other means of orientation, to go after it in connection with the Exodus, or any other of the divergent lines of suggestion, and can perhaps only reach the true result, after having exhausted these possibilities, by returning again and again to the central idea.

\section{$\S$ 4. Force of Association.}

From the preceding remarks, the influences which tend to give force and permanence to an association are readily seen. On the one hand, the physiological dispositions which render reproduction possible, are made strong and lasting in the nervous structure, by frequent repetition of the stimulus. Just to the degree of the repetition, as we should expect, is the association strengthened and made facile. This repetition, we may suppose, often takes place in dreams. After seeing an object two or three times, the danger of again failing to recognize it is greatly reduced. Yet the physiological dependence is the least important influence in the 
strengthening of association; since contiguity, though more universal, is less important than correlation, in its establishment. The attention, which establishes the observed relations in association, is the most important means of strengthening them. Strong attention to a single chain of events is often sufficient to fix it permanently in mind; and we are generally able, when troubled with forgetfulness in a particular connection, to relate the desired event to some remembered fact, and thus to hold it in the memory train. This is an exercise of the higher function of apperception. As we have seen in considering the twofold nature of memory, association may be improved both from the physical and from the mental side.

Continuance of the Suggesting Idea. It should be remarked that the suggesting idea, in a case of association, does not give place entirely to the idea suggested, but remains before consciousness, at first in a state of passive attention, but constantly liable to be again brought into the focus of apperception. The mental disposition of both ideas depends upon the interest and value of the association in the mental train. Often among many ideas which follow a given representation, none are fitted to serve the purpose of the intelligence, and they are all dismissed from consciousness, only the original being held in apperception, and further lines of suggestion started. And often the contrary is the case : the image wished once being suggested, the suggesting idea is allowed to fall into subconsciousness and to disappear. It is here, as will appear later, that the voluntary element of our inner life is asserted, not only in the outgo of the energy of attention, but also in the selective and directive act of choice, among possible chains of ideas.

On association, consult : Porter, Human Intellert, pp. 272-300 ; McCosh, Cog. Powers, bk. 2, ch. III ; Taine, Intelligence, pt. 1, bk. 2, ch. II; Wundt, Physiol. Psychol., ch. Xvi; Carpenter, Mental Physiol., pp. 251-259; Volkmann, Lehrbuch d. Psychol., \&s 70-79; 
Taitz, Lehrbuch d. Psychol., § 14; Drobisch, Psychologie, \$§ 33-41; Maudsley, Physiol. of Mind, ch. v; Fortlage, System der Psychologie, §15; Sully, Outlines of Psychol., ch. vII ; Stricker, Studien über die Association; Lehmann, Philosophische Studien, v. 1; (Suggestion) Richet, Revue Philosophique, xxI. 324 and (Brochard) 1x. 257; Morell, Outlines, pt. 3; Hume, Treatise on Human Nature, pt. 1; Gratacap, Théorie de la Mémoire, ch. IV-v; Lipps, Grundthatsachen des Seelenlebens, pt. 3; (especially) Bradley, Principles of Logic. pp. 273-321; (Psychology of association) Ferri, La Psychologie de l'association ; Lotze, Metaphysic, pp. 460-470; Rabier, Psychologie, ch. Xvi. For additional references, see Dewey, Psychology, p. 152, and Volkmann, loc. cit., Anmerkungen.

Further Problems for Study :

The "psychology of association;"

Educational bearings of association;

Ethical bearings of association. 


\section{CHAPTER XII.}

\section{IMAGINATION.}

\section{§1. Passive Imaglitation.}

THE crowning phase of the imaging power of mind is the imagination. It may be understood in two senses. First, imagination is often used to denote the general representative function of mind, the power of representing by images, thus including memory and association, as well as the constructive working up of images. ${ }^{1}$ Second, the word is often more properly restricted to this last process, that whereby the material of representation at the disposal of the thinking subject, is combined in forms of ideal construction, which are independent, in a measure, of external truth. While the latter is more properly the function which now claims explanation, it is not well to disregard the more general phases of the idealizing activity which the broader definition has in view, since they precede its more definitive exercise, and give the best vantage-ground for viewing it.

Material of the Imagination. The material of the imagination, as of the representative function generally, is supplied entirely by the earlier function of acquisition. The imagination never creates. It serves only to give form to ideas revived. The data of sense perception and self-consciousness, understanding by the latter the whole ground of new experience in the threefold aspects of mind, supply all its content. And further, its material is Stoics.

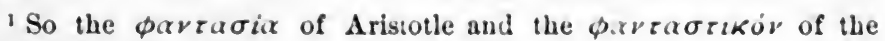


always representable. The products of the higher, or discursive, operations are necessarily excluded; since the abstract or general, in the notion or in thought, cannot be pictured. In brief, imagination uses the percept and not the concept, as these terms are distinguished later.

Proceeding, therefore, to consider the broad characteristics of the imaging power, and disregarding the more particular processes which memory and association comprise, we find that general imagination is $P$ assive and Active.

Passive Imagination. By passive imagination is meant the spontaneous uncontrolled play of images in consciousness, from whatever cause they spring, and in whatever arrangement they take form. It finds its simplest type in the incoherent forms of dream consciousness. Here there is no mental supervision of the flow of ideas, no true appreciation of their relative value for the mental life, no exercise of will in selecting or combining them. The physical and intellectual causes of their production are free to work their own effects, and the result is the storming of consciousness, in its helpless state, with all the missiles of sense-acquisition.

Presuppositions: Memory and Association. It is readily seen that the free play of images proceeds upon the revival and association of images. The method of this revival is both physical and mental, and consists only in the wider range of the dispositions of brain and mind which have been seen to lie at the basis of memory, the how, and association, the what, of reproduction.

1. The physical basis here presents its most complex and intricate activity, as is seen in the boundless combinations presented. Indeed, this infinite complexity and irregularity has led many to deny the dependence of this power upon the laws which ordinarily govern repro- 
duction. But we have only to consider, with Waitz, ${ }^{1}$ the real nature of the inter-connected chains of cerebral association, to see that the truth is what the principle of the unity of mind would lead us to believe. Let us consider the prevailing cast of a subject's consciousness to be determined by an indefinite mass of systemic, emotional, and presentative groups, which cover the entire history of the past, resting now each in subconsciousness, but capable, upon the physical associative reinstatement of the conditions of its first production, of asserting itself, in whole or in part, above the level of the general product. The result will not be the reproduction of long connected series of states. From the nature of the cortical structure, the ramifications of nerve elements which represent unessential or accidental mental modifications, are most readily excited. As mental states, they are outside the chain of ideas, and seem quite detached and irrelevant; but in their physical basis, they are reasonable effects. And this result is indefinitely multiplied by the combinations of different cerebral trains. The entire sensorium vibrates with its single members, and surcharged parts are thus excited by connections perhaps too delicate and fine for any appreciation on the subjective side. Thus images far removed in thought from one another and never consciously connected, are thrown together in imagination.

This state of complete confusion in consciousness rarely extends over its whole area, however; for while we are conscious at all, there is a greater or less degree of mental supervision. Even in dreams, there is a glamour of logical or asthetic consistency thrown over the most inconsistent elements. We think we are making convincing arguments or reciting delicious stanzas, when, awaking, we find it the most meaningless jargon. And in states of light dreaming, when the picture as a whole is coherent, new excitations of the senses are accommodated to it.

'Lehrbuch der Pyychologie, pp. 119 and fol. 
As has been said, dreams are the most evident type of the free play of this physical causation. When we are asleep, the active, distinguishing, correlating, and arranging function of mind is at rest; some of the senses are freely open to excitation from without, and the mechanical element of our personality is predominant. Moreover, the withdrawal of the blood supply from the brain, which is the usual accompaniment of a reduced consciousness, tends to alter the relative potential of its parts. It facilitates the discharge of isolated regions, or exposes elements whose ordinary activity is covered by larger or more recent connections. As would be expected, children dream very little. They have not formed the physical tendencies which give to passive consciousness such a spontaneous complexity.

In our waking states, also, we often indulge in the state of uncontrolled representation, which passive imagination presents. When we relax all mental exertion, and fall into revery or day-dreams, this spontaneous flow of images is realized. Yet the play of representations is never in our waking states as detached and incoherent as in dreams. We can usually detect, even in our states of completest intellectual abandon, the successive connections in trains of ideas, governed by the principles of regular suggestion. In cases of great mental fatigue, when the active exercise of attention is no longer possible, there remains still a form of passive apperception, by which our images are thrown into some degree of logical coherence.

From the consideration of the physical side of passive imagination, we may perhaps explain the fact that the pictures of imagination are often much more vivid than those of memory. In the case of the former the active power of mind, which we have seen to have a great effect in heightening or depressing the intensity of images, is wanting. The attention remains neutral to all the images in consciousness, and the effects of the physical stimulus appear in all their value. In the case 
of active attention, however, the attention is directed only to those images which are of value for the train then before the mind; these are heightened in their effect, and the others fall into dim outline or into entire unconsciousness.

2. The subjective aspect of passive imagination is of more importance and of greater obscurity than its physical basis. And yet its phenomena are in the main consonant with the foregoing presuppositions. We would expect from the intricacy and confusion of the physical network of connections which imagination presupposes, that the mental facts would present the same general appearance; and that, on the other hand, while, in the midst of this intricacy, the laws of dyuamic cerebral association hold invariably, so in the mental phenomena, the laws of association must hold through all the appearance of lawless flow. The first part of this expectation, that the images of imagination will show detached and incoherent form, is certainly realized in fact. The most striking characteristic of imagination is the strange and wanton nature of its combinations. Detached parts of former images are combined in mexpected and ridiculous forms. Monsters before unknown are put together from earlier creatures of thought. Situations are devised which involve persons and places impossible to be reached or associated in real life.

But the second aspect of the case, the reign of the laws of association in the products of imagination, is not at all evident upon the surface, and becomes more questionable in view of the characteristic just mentioned. Yet all that we know of the case leads us to the opiuion that, here as elsewhere, mental facts are subject to mental laws, and that the play of images in imagination is not fortuitous.' 


\section{§ 2. Modes of Passive Imagination.}

The process of imagination, in its passive form, takes on two general modes: it first breaks up the complexes of experience into their elements, small or great, and second, with these elements, builds up new products. These two modes may be called, respectively, Dissociation and Composition.

I. Dissociation. From what has been said, the part played by dissociation is evident. If there were no such breaking up of representations, imagination would be simply memory. The same forms of mental process would be indefinitely repeated. Our mental life would be wearisome in its sameness, except as we widened the range of our actual sense-experience. As a process, dissociation may be more or less prominent, and its thoroughness, or the contrary, indicates the degree of imaginative power possessed by individuals ; since construction or recombination must be limited to the elements at hand. In the process already described, the ground or reason of this dissociation may be seen.

1. It is often due to the breaking up of physical connections in the brain. The fact of forgetfulness or fading of memory is largely to be explained by the separation and dissolution of former dynamic circuits. The command of a language, for example, which has been long neglected, is lost from inability, on the one hand, to recall the verbal elements and, on the other hand, from inability to coördinate the movements of pronunciation. But single words or letters, parts of former groups, remain clearly before us. By the dropping away of certain elements of a complex whole, the others become more vivid and the result is a more or less complete analysis.

2. The same is true of the mental side of our. 
memory : dissociation takes place, also, purely within the range of consciousness. We found that attention, as active apperception, tended to arrange states in groups, and also to heighten their intensity. Now not only are entire groups thus acted upon variously by the attention, giving different degrees of permanence in memory ; but parts or elements of these groups are also affected. Of a long argument, I may remember only a single step, without effort. Of a face, only the nose, perhaps, or the chin, is clear in memory. The whole of a word or sentence is often brought up in memory from the persistence of a single letter or combination, which before attracted the attention. Consequently, in the progressive fading which all representation undergoes, parts of groups, or elements of single images, fall away, while other parts or elements stand out alone. This, as before, constitutes a more or less complete analysis of former complexes. For example, in the complex image we hare of Cresar, we distinguish the orator from the general. If we think of the orator, association brings up Cicero: but if we have the general in mind, Alexander is suggested.'

3. Further than this, we shall find in active imagination a positive separation of the parts of images, by the abstracting and generalizing power of mind. We are conscious of a tendency toward the reduction of complex products to their elements. We note irregularities in outline, protuberances, inconsistencies, and thus isolate portions of our representations. 'This is seen particularly where the association is not a necessary one, and the parts dissociated have a completeness and unity of their own : as the wings, legs, head, of a bird, considered each for itself, or the subject, predicate, and copula of a proposition.

'See Rabier, Prychologie, p. 232. 
There are few, if any, of our mental concepts, which are not subject to this dissociating process. And it seems to rest ultimately upon the basis of the unity of consciousness, of which mention has been made. If our percepts are put together from units by an associative synthesis which becomes permanent only by repetition, it is probable that lack of repetition or a conflicting association would tend to the separation of these units. That is, in brief, the elements which are associated are found in all stages of association, and as long as they do not pass into unconscious reflexes, they are available, as elements, for new combinations.

II. Composition. The analytic data of sense do not remain without form in consciousness, but are built up into new combinations. The forms of these combinations are, as has been said, apparently capricious and without law, especially in passive states, where there is no selective power concerned in their arrangement. But further consideration leads us to a different conclusion.

\section{§ 3. Laws of Passive Imagination.}

Contiguity and Resemblance. The laws of passive imagination are, for the reasons given below, the laws of association $^{1}$ which have already been discovered: Contiguity and Resemblance. The principle of Correlation underlies the constructive imagination.

1. Analogy from the physical basis. We have seen, in speaking of the physical side of imagination, that the same apparent contradiction presented itself there. There are cerebral associations, on the one hand, giving a constant law of molecular change; and, on the other, unusual and detached discharges, which are apparently fortuitous. But it was seen that the latter really arises from the former fact, when viewed in its great complexity. The same elements, being in different connections, are excited sometimes in one and sometimes in another, giving detached or partial reactions, different from the serial

${ }^{1}$ Cf. Kant, on Reproductive Imag., Anthropologie, §§ 27-33. 
changes of their former movement. So the corresponding mental modifications might be expected to present the same phases: detached and broken form, at the same time, and for the reason, that the laws of suggestion are acting together in their complexity. ${ }^{2}$

2. Images combined in imagination are often found to be directly associated, when, at first, they seemed quite disconnected in experience. A little consideration sometimes enables us to detect a coexistence or resemblance which was at first entirely hidden. This simply means that our memory of things may be more distinct than our memory of their relations to one auother: which is perfectly reasouable, since the distinctness of either in memory depends upon the degree of apperceptive energy expended upon it.

3. This position is only an extension of the assumption already made, that the laws of association are generally controlling in revived states. The facts of memory require us to suppose regular suggestions in many cases in which the ground of the association cannot be detected.

4. The law of contiguity affords boundless possibilities of variation in imagination from the combinations of real experience. If we admit the principle that resemblance occasions suggestion by reason of identical points in the ideas connected, which points, by contiguity, bring up the whole of the suggested image, no limit can be set to the unconscious play of this principle. A slight point of resemblance in any part or aspect of mental states, may serve to connect whole combinations in which this point occurs, other parts or points thus being brought together with no link of resemblance. The vaguest suggestious of sameness in a plurality of states may suffice unconsciously to connect them all with one another, and with all their parts respectively. And the same

' Cf. Drobisch, Empirische Prychologie, pp. 101-103. 
holds not only of images proper, but of the volitional and emotional background in which they lie. The same general state of the system, on two occasions, may suffice to connect their whole knowledge content, for future association. Emotions experienced in connection with thought, or events, or actions, may cause them to suggest one another. And of all this, by necessity, we consciously know very little. It is probable that by far the wider realm of imaginative activity lies outside the range of active consciousness. ${ }^{1}$

The extent to which minor and unessential details serve, through vague resemblances, to connect very different ideas, is seen in language. Words often come to our tongues which are entirely out of place in their connection, and the only reason we can discover is a faint likeness in sound or spelling to the words we wish. Mr. Lewes gives the following illustration: "Wishing," he says, "to speak the name of my friend Dr. Bastian, I said Dr. Brinton, and then caught myself about saying Dr. Bridges, but finally succeeded in pronouncing Dr. Bastian. I made no mistake in regard to the persons; but the common element in the three names, the letter B, served to call up all three." Mothers of several children often pronounce the names of three or more of them before properly naming the one addressed. The resemblance, of course, is simply the fact that they stand in a common relation.

5. We may also argue from the fact noticed above, that a state of entire unreasonableness and confusion is never reached by the imagination. There is a slight, or sometimes great, feeling of consistency and logical arrangement, even when the ideas suggested are most heterogeneous; and from this, to complete selective control of the imaging function, many stages are possible. Even in great fatigue and indifference of the attention, we react upon unexpected states and endeavor to reduce them to order. From this involuntary supervision and arranging of images in consciousness, according to the

I Cf. George, Lehrbuch der Psychologie, p. 276. 
laws of association, we may argue the extension of those laws to cases of less evident mental suggestion.

6. Finally, many of these associations-assuming them to be such-may be due entirely to the continuity of the physical process. Cases are at hand of suggestion through the intervention of elements entirely unconscious : elements which, while physically perfectly regular in their serial order, yet present, on the mental side, . breaks or gaps which we cannot fill in. Here the physical links, too feeble perhaps, in their nervous discharge, to be accompanied by consciousuess, suffice to hold together states that are conscious.

From the nature of the case, it is impossible to prove or to disprove the reign of association in imagination. The points given above serve, at the best, to show the possibility of such a supposition, and, by removing all considerations opposed in nature, to render the assumption of a unity of law throughout the apperceptive function, still more probable. The case is further strengthened by the lack of any counter hypothesis. To call the imagination a separate activity, whose function it is to bring confusion into the mental life, is not only to leave it unexplained, but to raise a barrier to our assumption that prychology is a science at all. And the value of the position here taken becomes more apparent as we proceed to active imagination, where we find the process of construction more conseious, and to a degree, under the regulation of will.

Principle of Preference. The facts of passire imagination are probably explainable, therefore, by the two secondary laws of association, Contiguity and Resemblance. But beyond this, the additional principle of association, called above the principle of Preference,' seems to play a wide rôle in determining the what of imagination. This is necessarily true, if the theory of imagination already advocated is true; for the general background of consciousness, from which trains of images emerge, is made up of the whole mental experience: impulses, instincts, volitions, as well as purely representative states. It is

' See p. 228. 
in these elements that personality, character, and preference consist. If preference gives cast and character to association, it must influence imagination, since imagination proceeds upon the data of association.

The same is true of all the auxiliary conditions of association, and the law of preference is emphasized only because its influence is more marked. It becomes very prominent in active imagination, where the fact of native preference or talent becomes the only means of explaining some cases, and the basis of the classification of others. The subject is taken up again under that head below. The preference here spoken of carries with it emotional interest, since interest is only the expression of that readiness of attention, whose motive is preference. Hence interest, instead of indicating, in imagination, the absence of association, as Dewey declares, ' is present as an influencing factor in all association.

\section{$\S 4$. FANCY.}

The combining function of passive imagination, viewed in its product, is called fancy. Fancy is the familiar decking out of commonplace experience with images brought from distant and unexpected regions. Incongruous elements are placed in juxtaposition, grotesque forms grow up from most familiar elements, the most extravagant antitheses, and even contradictions, are allowed indulgence in this delightful license of thought. It brings freshness into the midst of tedious processes and, in its subtle refinements, appeals directly to the emotional and æsthetic nature. The passive automatic play of fancy is to be emphasized in contrast with the more purposive construction of active imagination, which remains to be considered.

The student should notice also the enlarging and diminishing functions of fancy. In addition to the separation and recombination of the elements of our representation, it brings about unexpected and grotesque 
alterations in the size of things. ${ }^{1}$ Pigmies and giants are ordinary acquaintances of our fancy. Things which we fear or dread are apt to be very large, and things which we ridicule or despise, very small. It is probable that this, as many other aspects of the imagination, is due largely to the emotional coloring of the time. The ordinary correctives of reality and thought being wanting, the presentative life is at the mercy of the emotional. The idea which calls the emotion forth accommodates itself to the emotion, by way of justification for it.

Relation of Fancy to Reality. Passive imagination is characterized, throughout, by the absence of all reference to the real world. In it the mind frees itself, as it were, from its accustomed bondage to external things, and makes its universe entirely within. The truthful images of memory are torn asunder, and built up into forms never realized in nature or in sober thought. Animals are given voices, inanimate objects legs, and the world is peopled with beings as strange as rare. Yet this is true only in the nature of imagination, not in its actual results; for in its active forms, as we shall see, it maintains a constant though covert reference to reality : and even in the most automatic play which is ever realized, there is slight supervision and correction from the underlying sense of consistency, beauty, and truth. The vague feeling of satisfaction or dissatisfaction which we experience in connection with our fancies, is due to the habit of comparing our mental states with reality, and even in dreams, where all such reference to the external world is impossible, we believe in our visions as firmly as in the experience of our waking life.

The relation of fancy to active imagination is taken up later. It is a vexed question and has become so because of 
the indefinite meaning given to both terms. Restricting the word fancy to the meaning here given it, and understanding by imagination, as opposed to fancy, active imagination only, the distinction between them is clear. As appears below, their relation to reality is an important point of difference.

\section{§5. Active or Constructive Imagination.}

Definition. The distinction between active and passive imagination has been in part defined. In addition to the processes described in the foregoing, the active imagination involves the exercise of will in some of its forms, whether it be the positive attempt to control the images of fancy, or the merest supervision and direction of their play. By the word active, therefore, is meant energetic. Energy is expended in voluntary attention, in selective choice of imaginative material, and in the impelling desire toward the construction of a given product.

This distinction is already made familiar in the cases of attention and memory. Attention was found to be passive or reflex, and active or voluntary, and memory takes two forms, reminiscence and recollection, according as it is passive or active. The root of the distinction is found in the nature of the exciting cause in each case. In general, mental functions may be called active when they are stimulated from within, from the potential subject itself, being accompanied by a feeling of power and accomplishment : and passive, when they are stimulated from without, that is, from organic or extracrganic causes, being entirely free from the feeling described. ${ }^{2}$

The distinction, however, in this case, is not an absolute one. The beginnings of mental supervision, or at least the feeling of such supervision, is found in the most mechanical play of images. Yet we shall find it valuable for purposes of analysis, as the foregoing sections on passive imagination seem to assure us.

${ }^{1}$ On this distinction, as depending upon desire, see Brown, Philos. of the Hum. Mind, II. p. 125.

${ }^{2}$ See Wundt on this distinction, Phys. Psych., 2d ed., I. 321. 
This phase of the imaging power is further called constructive, from the nature of its product. In it is emphasized, again, the intentional nature of the compound state which is built up. Passive combination or fancy is a kind of construction; but here we deal with the purposive putting together of elements for the attainment of an end of use or beauty. This is the process of artistic and scientific construction.

\section{§6. Axalysis of Constrective Imagisation.}

In analyzing the process of construction by the imagination, we proceed upon the account already given of the passive play of images. That is, the dissociation of the elements of former ideal complexes is assumed, and their readiness to be recombined under the control of the active part of our nature. The analysis, therefore, is now restricted to this active power itself, and its modification of the products of fancy. We may distinguish four factors or moments in the process of construction : 'Natural Impulse or Appetence, Intention, Selective Attention, and Feeling of Fitness. These may be considered in this order.

I. Natural Impulse or Appetence. It is readily seen, that if the automatic flow of images in imagination is to be modified from the side of the inner self, there must be some impulsion, motive, or desire which leads to it. An accidental modification, due to the capricious exercise of will, would be self-defeating, and would secure no systematic construction whatever. There must be some end in view, however vague; and a natural tendency toward it, an attraction or the contrary. In considering the nature of emotion in a later chapter, certain original tendencies of our active self toward or from certain ends or actions will become apparent. Leaving till then all further discussion of their nature, wo simply note here, 
that all exercise of will springs from these appetences, and that the intelligent exercise of will always has in view, as its end, objects which arouse the appetences. Among these "springs of action" may be mentioned, love of pleasure and aversion to pain, the natural affections, love of the beautiful and the right; principles which are common to all men in some degree, but which vary in force within very wide limits in individuals. Any or all of such principles, which are strong enough in the individual to lead to action, or to give cast to the emotional life, may serve as basis for imaginative construction. If we are led to hope for the accomplishment of a desire, we picture ceaselessly the actual attainment of it, ourselves enjoying its benefits, and our enemies discomfited. Nothing is allowed in the scene which does not increase the pleasure, adverse elements, even when known to be real, being discarded. Simply on the ground of strong desire-of praise, money, truth-the images of imagination are constructed, built up into a consistent whole. Principal, however, among the appetences which are predominating in the imagination, are the Love of the beautiful, and the Love of truth, or the desire for knowledge. These lie at the basis of the general kinds of constructive imagination, later designated AEsthetic and Scientific.

Law of Native Talent or Preference. The law of preference which has already been spoken of enters here, and finds in the "springs of action" its adequate explanation. In different individuals, different prevailing temper and taste appear, which are so pronounced, that great classes of men can be separated from one another on this principle of classification. The fundamental differences of temperament-as sanguine, melancholic, etc.-depend upon the sum or general tendency of these motive principles. And the popular distinctions of character, as 
avaricious, selfish, religious, social, point to the prevailing intensity of some one or more of the appetences.

II. Intention. This permanent preference in character leads to desire, as permanent and controlling, to accomplish something in the line of its activity. And the entire life, if circumstances do not prevent its satisfaction, is moulded with this end in view. Professions are chosen, associations formed, pleasures indulged in, all of which both satisfy this permanent desire and strengthen it. This may be called Intention. Intention, as shall be seen in the part devoted to the volitional life, is a form of active readiness or consent, permanent in its kind, and needing only occasion or opportunity to flow forth into action. The scientific man has a constant impulse or intention towards the objects of his science. It has become to him the chosen channel for the expenditure of his intellectual energy. The artist likewise finds his whole life deroted to the pursuit of the forms which gratify his resthetic nature. His consciousness is filled with images of the beautiful, and his intention is so spontaneous, that volition follows, on occasion, automatically.

The factors which have been called Appetence and Intention serve for a preparation on the emotional side, as the laws of reproduction serve, on the intellectual side. The modification of passive imagination, which we are seeking to explain, finds here its necessary basis. The impulse to action presses forward in channels of lasting intention, and has only to be fed by images, as they enter conscionsness by association, to produce forms of construction. The product is yet, however, incomplete; since the controlling elements are hidden in the depths of character, and act without conscious oversight. Such construction can be called active only in the sense that it arises from past action; that is, from fixed tendencies induced by earlier volition. The essential factor, therefore, of true imaginative construction, remains yet to be named.

Though this is true. yet we find that here, as with the carlier intellectual functions, there is a tendency toward the mechanical activity of the process of construction, through 
habit. After much familiarity with the details and means involved in certain classes of constructions, as inventions, works of art, the product comes complete to consciousness with no attention whatever, or expectation. As has been said by Wundt, it comes "like a Hash of lightning." And the result is as great as would have been accomplished by tiresome constructive effort. This is only the case, however, after the mind has grown accustomed to the putting together of its images voluntarily, and is rich in appropriate material. It then dispenses with the will, as the body does when its dynamic counections have become powerful. For this reason, as Volkmann ${ }^{2}$ remarks, educated men narrate events in a reasonable or constructive way, as compared with the illiterate. They leave out unimportant details, construe missing parts, and construct a consistent picture of the whole. Here is a selective and arranging imagination at work unconsciously. The peasant tells things in dry detail, just as they happen.

III. Selective Attention. ${ }^{2}$ We now reach the power which controls the constructions of imagination, the attention. Presupposing the native preferences and tendencies which have been spoken of-summed up, in the phrase of Professor James, as "the idiosyncrasies of interest," - the will, in attention, builds up images, which meet its purpose, into forms of novelty and beauty. The attention is given to reproductions with this construction in view. The scientist or artist views his ideas as so much material, to be directly used for the purpose of his science or art, and each image in turn is scrutinized, alone and with its escort, to discover the possibilities of combination which lie inherent in it. Images which do not present promise of usefulness in the construction are withdrawn from attention and fade away; others which fit into the growing temple of imagination are changed, divided, refined, combined, and cast into complete form, in the relating function of apperception.

The psychological value of this phase of the imagination, consists in the prolonged and concentrated mental

1 Lehrbuch der Psychologie, r. p. 481.

2 Rabier, Psychologie, p. 231. 
reaction which it involves: what Newton has called "patient thought." Surface analogies are seen by the common mind, and need no effort of construction; but the hidden properties, the relations which spread wide out through nature and art-these are discovered only when the veils that conceal them are pierced by the power of constructive thought. Every scientific hypothesis is such a piece of construction. Only the properties of the matter in hand are taken which, by the selective attention, can be arrauged in a logical framework, to be tested by further appeal to fact. Causes are imagined to be working alone, although never so found, and their effects constructed. "So Newton saw the planet falling into the sun, a thing that did not take place, but which would take place if the tangential force were suppressed."

The attention, therefore, in imagination, has a twofold part. First, it is Exclusive, that is, it excludes representations which have no meaning for the task in hand. This is not a positive banishment from cousciousness, since that is impossible. The effort to banish an idea only makes it more vivid, while the attention is held fixed upon it. But it consists in the neglect of this particular idea, as unsuited to the purpose of present pursuit. Thus withdrawn from attention, an image sinks into subconsciousness and is practically banished. Second, it is Selective; apperception and consequent emphasis, of the image made use of, follow upon its selection.

The result, therefore, is a product of apperception: since the construction of imagination is strictly analogous to the construction of the external world in senseperception. In the latter case, objects and relations are forced into consciousness to be arranged, coördinated, reconstructed, by the apperceiving function. Here the

' Rabier, wc. cit. p. 233. 
data are supplied from the dissolution of former apperceptive syntheses, by a selective principle, only to be recombined by a second apperception. In the first construction, reality is the corrective and guide: it is only after repeated experiences, that our synthetic wholes in perception are made correct. Here, in imagination, this corrective is wanting; but its place is supplied by the critical selection of the attention. If a combination passes the scrutiny of the attention, it stands in imagination.

This last distinction is not fully true for all imaginative constructions. In the scientific imagination, appeal is also made to nature for confirmation. In this case, the analugy with synthetic sense-perception is even closer, as is seen later. If, further, the process be in its intimate nature apperception, the result cannot be, in any sense, "fictitious and arbitrary."

IV. Feeling of Fitness. It must have become evident, that this selection of images by the attention, proceeds upon some principle. There must be some criterion of choice, something either in the images themselves or in the end which they are to subserve, which renders some available and others useless. The perception of this fitness requires in general two things.

1. An end or purpose held in conscious thought, which is to be realized by construction. It is readily seen that this must be involved in the active as distinguished from the passive imagination, since the volitional addition in the former case proceeds by motives, and a motive is the consideration of an end. That is, the will is exerted only for the accomplishment of something which is presented as an idea. This end or ideal aim, as shall be seen in considering the æsthetic imagination, may be the vaguest and most general notion, having only the characteristics of the general class to which it belongs. An artist desires to make something beautiful, or some-

1 Abercrombie. 
thing expressive, an inventor, something useful. They begin, with this vague thought, to select their images. And as the construction proceeds, it is as new to them as to others, and satisfies them, if it meet the general requirement of their first thought. Later in the growing process, the end becomes more definite, as the possibilities of the creation become evident. The artist then projects lines of possible combination, to be filled in by actual representations. To use the figure of George, this hypothetical advance of the scientific imagination is like a net, thrown over the objects of consideration at the moment, its lines marking out the path of future discovery. ${ }^{1}$

Not only is this ragueness of the end, in imaginative construction, empirically noticeable, but it is necessarily so, à priori. For, as Brown well maintains, it is "absurd to suppose that we can will the existence of any particular idea; since this would be either to will without knowing what we willed, which is absurd - or to know already what we willed to know, which is not less absurd." " If I willed a particular compound, I must have already conceired that compound, which relieves me of the necessity of willing it. There can be no doubt, however, that the first conception, particularly in a work of art, is brought about by the evident fitness of some present images for further construction; and that they suggest more or less definitelv to consciousness the nature of the product to be realized. The end itself, then, constantly changes, broadening and deepening, as the ideal construction takes form. It is true, also, that the products of passive imagination often suggest combinations and conceptions which serve as ideals or ends in the voluntary selection of images.

2. Feeling of adaptation to this end. It is only necessary at this point to show the presence of such a feeling, not to discuss its nature or origin. It seems to consist in a sense of the adaptation of means to end. Only by it, is the exclusive and selective attention guided in its

1 George, Lehrbuch, pp. 276-277.

- Philosophy, ir. p. 126. 
choice of elements. As a feeling, it extends throughout our entire mental and active life. We pass involuntary judgment on the fitness of an instrument for its use, of the material for a garment, of an officer for his office.

This feeling, in its variations in individuals, is in large part the basis of artistic talent. The general proportions of things, the relative value of details, the harmony of discordant meanings, the reduction of varied elements to a fundamental motive-these and many other problems of the artist, call this feeling prominently into play. He says: "I know not why, but I feel that it must be so." Some men are almost destitute of such a sense. They show its lack in the absence of personal and room adornment, in incongruous and peculiar actions-actions inappropriate to the circumstances. This lack may be summed up concisely as either the want of constructive imagination, or the want of the sense of fitness in selecting its material. ${ }^{1}$

\section{$\S \%$ Kinds of Constructive Imagination.}

Finished Imagination. We are now prepared to gain a view of the entire process of imagination, looked at, not as the union of these separate activities or factors, but as what it appears at first sight to be, a single function of mind. Under the action of the emotional and intellectual elements considered, it gives forth its results as reapperceptions of the data of sense. The final constructive product is a true mental unity or picture, which has its own significance for the mind, apart from its elements. This significance is an ideal meaning, which possesses general interest, and appeals to man universally. Considering the subject-matter of the imagination and the relation which its constructions bear to the world,

1 The further discussion of this sense of fitness, as feeling, is reserved for the treatment of the æsthetic emotions. 
two general forms may be distinguished: the Scientific and the AEsthetic imagination.

I. Scientific Imagination. The scientific or acquisitive imagination is the imagination occupied with the discovery of truth. At first sight, it appears true that the constructions of this facuity have no value for knowledge, and that intellect only suffers from its exercise. But we find that the imagination is the prophetic forerunner of almost all great scientific discoveries. The mental factors seen to underlie all imaginative construction, are here called into play in a highly exaggerated way. The associative material presented covers, generally, the whole area of the data of the scientific brauch in hand : familiarity with the principles and laws already discovered is assumed, and, in general, a condition of mental saturation with the subject. For this reason, we look to scientific specialists for new truths and hypotheses, and have no ear for the vagaries of the dilettante and amateur. Native taste or preference is also here highly significant. There is as distinctly a scientific genius as there is an artistic genius. Great discoverers in science have a facility in discovering deep-seated aualogies and relations, ${ }^{\prime}$ an appetence for positive truth, a tendency to accept only the confirmed deliverances of nature herself. They generally are men of great emotional soberness and intellectual enthusiasm, if the antithesis be allowed. Further than this, their imaginative process is largely under control. This is no doubt the great essential; the preponderating force of the exclusive and selective attention. Not only do great scientists

1 "The discovery of a new law," says Helmboltz, " is the discovery of an analogy in the chain of the phenomena of nature which has remained before unknown. To find new ideas, it does not suffice to gather superficial analogies, but we must penetrate profoundly into the texture of the whole." 
see deeply, but they are able, from an exquisite sense of relative values in nature, and of relative fitness in fact, to dissect, arrange, and classify, until from a few great general resemblances, the construction of a law is possible. And it is only by this force of relating attention, or apperception, that the actual law is finally constructed. A minor scientist may collect data and draw from them generic resemblances, but, with all his study and effort, he does not construct. The trained, refined, and naturegiven constructive force of attention alone does this.

The absence of the strict emotional element is to be noted here, as its presence is remarked in the æsthetic imagination. Emotional excitement of any kind tends to disturb a calm view and deliberate comparison of facts. Even what we have called the intellectual enthusiasm of an investigator-an emotion called intellectual, since it arises from the free play of the discursive faculty - sometimes leads him to immature inferences or false observations.

Relation of Scientific Imagination to Reality: Scientific Hypotheses. This form of imagination has also been called acquisitive, and therein it is plain that it has direct reference to our knowledge of the world and things. It differs in this, both from the passive exercise of the imaging power, which has no guide but interest and preference, and from the rsthetic, whose end is pleasure in an ideal, which is not realized in nature. The end of the scientific imagination is truth and its impelling motive, love of truth. For this reason, the corrective reality which is wanting in the other cases, returns here in its full import. The data of this form of imagination are true images, the elements of knowledge. Its constructions are logical processes, through which further truths may be anticipated by inference; and its anticipations are worthless, unless they stand an exhaustive comparison with nature's phenomena, and by it receive confirmation. The purpose of scientific imagination then is utility, not pleasure. 
The form of all such anticipations of nature is hypothetical. There remains in consciousness, with it all, the feeling that the product is subjective, a creation of mind and an eager desire to test its actual truth. The constructions, therefore, of the scientific imagination are called hypotheses. They carry various degrees of probability, both subjective and objective. By subjective probability is meant the amount of belief which we ourselves attach to our constructions. Often the data are so well understood and the process of construction so conscious, that our belief amounts to psychological certainty. ${ }^{\prime}$

The element of reality, or truth, is further secured to these imaginations, by the exact logical nature of the form into which the data are thrown, another characteristic distinction from the resthetic imagination. Every stage in the growth of the conception must be logically valid. The laws of contradiction, cause, inference, are duly observed in the control by the selective attention : and when this is the case, the mind rests in the product with satisfaction. So, for example, Newton constructed the successive conceptions of his great discovery, building each upon correct inference, and after its direct confirmation, using this inference again, in the construction of a broader generalization. The violation of any logical principle at either stage in the argument would have vitiated the whole. ${ }^{2}$

In most cases, the beginning of discovery is nothing more than a conjecture, a happy supposition. 'The mind at once begins to search for means of testing it, which itself involves the imagination of new material dispositions. These tests are made more and more rigid, if successful, until the crucial test, as it is called, is reached, which either confirms or disproves the hypothesis. As already said, it is, in most cases,

'For the discussion of the general question of our belief in images, see the chapter on Illusions (XIII).

'Cf. Porter, Human Intellect, \& 364. 
the previous qualification of the inquirer which gives his conjecture probability. The means of confirmation or testing are usually experimental, resting upon the logical method of difference. ${ }^{2}$

As far as the construction of hypotheses is a necessary outcome of logical procedure, the result has a universal cast, that is, it is necessarily true. We find, later, that the æsthetic imagination is characterized by a more marked universality of form. It is the outcome of subjective feelings which are general, resting upon common psychological cognitions of the beautiful. The external confirmation of truth, which alone serves to establish the true validity of the scientific construction, is, in this aspect, a point of union between the two forms of imagination. It is the true aim of both to be of unirersal import: æsthetic construction attains it by inward feelings of beauty; scientific construction attains it by reference to fact.

II. \#sthetic Imagination. The æsthetic imagination differs from the scientific, especially, in the end toward which the constructive process tends. Assuming the same factors or stages in its development, the difference is seen in the fact that the end is no longer knowledge, but beauty. The selective attention, therefore, in this case, singles out elements which satisfy the sense of the beautiful, whether or not its construction is realizable in the combinations of fact. What it is that constitutes the beautiful is to be spoken of later. ${ }^{2}$ Among the general relations which are called beautiful, are symmetry, harmony, unity in variety; representative materials which promise these aesthetic combinations are taken up and thrown into forms of construction.

Several empirical features of such mental compositions may be remarked. First, the rsthetic imagination, as James Mill observes,' is accompanied by a lively play

${ }^{1}$ See Mill, System of Logic, p. 280. In sketching this general process of discovery, we do not overlook cases of discovery by happy accident, pure experiment, etc.

2 Treated in connection with the rsthetic feelings.

${ }^{3}$ Analysis, vol. I. p. 181; quoted by Bain. 
of pleasurable excitement, which continues throughout the continuance of the constructive work. It receives great reinforcement or decrease, according as the conception is skilfully or poorly worked out. The emotional life is more intimately concerned than in scientific construction, and instead of disturbing, it greatly assists the operation. The forms of resthetic construction are also more instantaneous and inexplicable, for the reason that they arise from an emotional stimulus, and have no logical and, often, no conscious development. Great artists are usually men of strong emotional temperament, and frequently show a corresponding lack of high practical and theoretical judgment. Their conceptions take shape spontaneously, with little selection of elements, or conscious blending; and when once satisfactorily executed, they are unwilling to admit modification except in unimportant details. Further, the corrective standard of reference is now not reality, but an ideal of universal acceptance-a form not found in nature, but of which nature in her perfect working would be capable. Of course, the conception itself is the artist's ideal, the most perfect copy of a thing, or the most beautiful variation of a thing, which he can conceive: but this imagination is a work of art, only as it embodies what is common to all ideals of the class, and is pronounced beautiful by all cultivated tastes.

The question as to the true province of art, imitation or construction, as the two great theories, realism and idealism respectively, announce it, cannot be long unsolved from a standpoint of the psychology of ideals. If art is the production of the imagination at all, its ideals are imaginative constructions, not natural facts. The act of putting a conception in oil or marble is not the artist's part-a machine might do it better. The art value is entirely the conception. 'The execution is only the more or less adequate means of expression. If imitation, therefore, be the whole of art, execution can be better left to the camera and the death-mask. There is no reason that esthetic ideals should not surpass nature as 
much as the forms of practical invention surpass her rude contrivances for using her own forces. Nature never constructs a phonograph, just as she never puts human thought and aspiration into simple color and form.

\section{§ 8. Relation of Imagination to Thought.}

The old opinion that imagination is opposed to the proper exercise of the severer processes of thought, is giving place to a more discriminating view. It is true that, in so far as imagination proceeds by preferences, and constructs under the leading thread of emotion, the exact processes of logic may be interfered with, as reality is left and fancy indulged. Yet when held in proper restraint, imagination reinforces and assists the operations of thinking; and this in several ways.

1. By the dissociation which the imagination occasions, the elements of knowledge are broken up, and made mobile and disposable for the elaborative function. ${ }^{1}$

2. In the earlier forms of knowledge which are necessary to abstract thinking, the imagination plays an important rôle. In all acquired perception, the imagination goes further than actual cognition: as in the estimation of distance by the eye, the filling in of the blind spot in the retinal field, the reconstruction of images in all cases of illusions of sense. ${ }^{2}$ So also sensations and emotions are more or less under the direct influence of imagination, vague suggestions of pain are constructed into forms of localized disease, and new symptoms are imagined and believed. All sorts of emotions may be aroused by imaginative imitation, until they become actual in consciousness. Likewise, also, general and abstract concepts owe their validity to the imagination; since they sum up resemblances in an entire series of objects or events,

${ }^{1}$ Volkmann, loc. cit., I. 482 and fol.; also see Spencer, Princ. of Psychology, II, p. 534.

${ }^{2}$ George, loc. cit. pp 275 and 278. 
when experience is limited to but few. And universal propositions require the same kind of constructive picturing. Every cleparture from experience, in short, rests in imagination.

3. In the apperceptive act the two functions are essentially one. Passive imagination presents the same ground for imaginative construction that the arena of nature does for synthetic presentation. Hence the breadth of objective knowledge may be and is, as has been seen in scientific imagination, greatly increased through the imaginative function of apperception. This fundamental oneness is insisted on by Wundt, though we cannot go his length in asserting an absolute oneness of process ${ }^{1}$ : since the complete necessity of the logical chain, as it holds in correct thought, is done away with by the personal element involved in construction by imagination.

In contrast with the points of similarity which have been indicated between these two functions, a point of essential difference is noteworthy. It resides in the material which they use respectively. As has been said, the imagination deals with the representable material of the acquisitive function, the percept, that which may be pictured. In thought, on the other hand, we deal with the abstract and general notion; we proceed by words or concepts, which cannot be pictured.

However much the two processes resemble each other in their apperceptive character, we cannot assert their identity while the mental escort in the two cases is so different. We must hold that thought, logical thought, is a conscions operation, however much its more spontaneous forms may have become involuntary through repetition. Wundt himself has given up the principle of unity of thought as he announced it in his first edition. Perhaps as conciso a manuer as may be

1 Pliys. Prych., 2d ed., Ir. p. 321.

'It is this distinction which leads Prof. Wundt in defluo the two functions in terms of each other. "Imagination is thought by means of pictures," and " thought is imagination by means of notions."-Did. 
found, of expressing the real similarity and, at the same time, the ground of difference between the two functions is this : thought is the representative or cognitive apprehension of relations among notions; imagination is the affective or felt apprehension of relations among images.

Law of Constructive Imagination: Correlation. In the apperceptive analogy between the constructive imagination and thought, the law of all active construction becomes evident. Passive imagination has been seen to proceed by the secondary laws of association: active imagination proceeds by the primary law, Correlation. In correlative association, there is a deeper principle, underlying contiguity and resemblance, an essential apperceptive relation; so in constructive imagination, there is a deeper principle, a relation of truth or beauty, which underlies the simple contiguities and resemblances involved in the compositions of fancy. Relations of truth are the objective content of the scientific imagination, and relations of beauty give universal meaning to the æsthetic.

\section{§ 9. Ideal Product of Imagination: the Infinite.}

It is from the imaging power that we attain the idea of the Infinite; since it is only by the enlarging of the limited data of perception, that unlimited extent in time and space can be constructed. Following McCosh, ${ }^{1}$ we may look at the infinite under two aspects : first, defined under its cognitive or representative aspect, it is that to which nothing can be added, the perfect, after its kind. It is called representative, since we find the preparation of this idea in our psychological analysis of imagination. In the scientific imagination, the limit of discovery, or the sum of truth, is the infinite of constructive activity, and, in the ideal of rsthetic construction, we

${ }^{1}$ Cognitive Powers, pp. 181-182. 
have the perfect. The other we may call the emotional aspect of the infinite, since it consists in the feeling of inadequacy which accompanies all our attempts to construct or picture the infinite. All images are felt to be entirely out of place, and we think of the infinite as stretching out beyond our utmost conception. Another emotional ingredient, in tho whole affection which the thought of infinity arouses, is the feeling of awe and selflittleness which passes over us.

The metaphysical and dialectical difficulties to which the conception of the infinite seems to give rise, do not come within our province. We are concerned only with the psychological representations which stand for the infinite, in our mental symbols. In the attempt to picture the general notion, we proceed by an image, as of space stretching in all directions, of objects of huge size, mountains, rivers, etc. But the feeling of inadequacy is rery strong. and the image is dismissed for another, which is, of necessity, just as faulty. The conception of the infinite is an analogous mental movement, the feeling of inadequacy being greatly exaggerated.

On imagination, consult: Wundt, Phys. Psych., Ir. p. 320 ; McCosh, Cog. Powers, bk. 2, ch. v ; Carpenter, Dient. Physiol., ch. xII ; George, Psych., p. 274 ; Porter, Hum. Int., pp. 325-331 ; Volkmann, Lehrbuch, \& 84; Waitz, Lehrbuch, \$15; Maudsley, Phys. of Mind, ch. IX ; Hickok, Ment. Sci., p. 111 ; Joly, L'Imagination : Sergi, Psych. Physiologique, bk. 3, ch. II and III ; Sully, Outlines of Psychol., ch. viI ; Rabier, Psychologie, ch. XvII-xx ; Beneke, Iehrbuch der Psychologie, ch. v ; Hamilton, Metaphysics, Lect. XXXIII.

Further Problems for Study:

Use and abuse of the imagination ;

Growth of imagination in childhood ;

Cultivation of the imagination;

Play-instinct ;

Ethical imagination ;

Imagination and religious faith. 


\section{CHAPTER XIII.}

\section{ILLUSIONS.}

\section{§1. Nature of Illusion.}

Relation of Illusion to Mental Pathology. The imaginative processes described above answer to the normal working of the reproductive function in its broadest aspect. Yet this faculty is subject to various forms of derangement, which greatly widen its sphere of influence in the mental life, and at the same time, afford us unexpected means of gaining insight into its real nature. The study of illusions belongs properly to the pathology of mind, just as the study of the abnormal or diseased condition of any bodily function belongs to the pathology of the body: yet it is more true here, than in the latter sphere, that the normal only needs exaggeration to become abnormal, and that the same principle of explanation serves for both. The most fruitful study of the entire representative function in recent times has been conducted from the side of mental pathology.

There will be occasion, as we proceed, to refer to the new work which recent years have seen in this department : yet a word of general introduction to it is not out of place. The rise of physiological psychology has brought with it a general overhauling of our ideas of all forms of mental alienation. The old conception of insanity, i.e. that the unfortunate victim was no longer the possessor of a mind, in the ordinary sense, but was possessed by an evil spirit, which yielded only to exorcism or violence, ${ }^{1}$ has given place to a conception as much

'See White's art., “Demoniacal Possession and Insanity," in Pop. Sci. Monthly, Feb. '89, and his abundant references. Also the introductory chapters of Krafft-Ebing's Lehrbuch der Psychiatrie. 
more scientific as humane. This conception may be stated somewhat thus : all forms of mental derangement find their rational explanation in the failure or predominance of some bodily function, and in a corresponding unbalance in the mental world. The two sets of functions invariably accompany each other. Consequently modern psychology finds a possible approach to every form of mental aberration, and has as many means of alleviation and cure. Distinction after distinction is made between phases of abnormal intellection, before treated as alike qualifying for a common madhouse, and it is only after the resources of the physiologist, the pathologist, the hygienic specialist, and above all, the intelligent and sympathetic psychologist, have been exhausted, that such a case is pronounced incurable. 'The new psychology, therefore, has many new departments, and many new lines of resource. Neurology, histology, the study of dreams, hallucinations, and monomanias, the mentill processes of the deaf, dumb, and blind, superstitions, spirits, and the numberless vagaries which afflict peoples and influence sound thonght-in short, nothing which springs from mind, whether normal or diseased, can escape the eye of contemporary research. This branch of psychology is laying under tribute all departments of the study of man : and contributions to its matter are found scattered in the journals of physiology, medicine, zoology, as well as those devoted to mind in particular. ${ }^{2}$

In this connection, we have only to deal with those irregular forms of ideation to which the regular processes sometimes give rise: that is, with individual unexpected states, rather than with the general and permanent irregularities which constitute mental disease. Our view includes the beginning of mental tendencies away from the line of average results; tendencies which, like all other mental products, become fixed, through habit, in forms of chronic delusion. It is in the reproductive faculty that mental aberration geverally takes its rise. The imaging power, as a representative power, is true to reality only as its factors unite and functionate in

I On the physiological side, we may mention Chareot, Ferrier, BrownSéquard, Wier Mitchell; and on the nental side, Griesinger. Wundt. Lotze. 
their due relation to one another. We can readily see how a failure in attentive selection of images, gives constructions which are untrue, how mistaken vistas of memory, may lead to fallacious processes of thought, and mistaken forms of action. The imagination stands midway between the acquisition of material and its rational use, and errors in its results, either in the independent working up of the material, or its preparation for higher thought, causes far-reaching deception to the subject.

General Character of Illusion. By illusion, therefore, in its broadest sense, we understand mental deception, or mistaken trust in the validity of a subjective state, be this state what it may. An unconscious logical fallacy is an illusion, a perceptual apparition is an illusion, a mistake in color, due to expectancy, is an illusion, a religious superstition is an illusion. Viewed thus in its breadth as coincident with all the domain of our conscious life, two general points may be found common to all classes of illusions. First, the element of Belief which attaches to all illusional states, and, second, the Representative Nature of all such states.

This general use of the word illusion seems necessary in defect of another word. We shall find in the distinction between illusion proper and hallucination, the meaning to which the word might more properly be restricted, if common usage and this poverty of language did not make it impossible. It is unfortunate that many such terms are first used as generic names, and are subsequently applied to one of the coördinations under the general name. We have found it to be the case both with memory and imagination. For the more restrieted meaning we shall use the phrase illusion proper, except where the context renders the signification plain.

In thus defining illusion, we have presupposed a standard of truth in the normal workings of the mind. We are deceived as to fact when the grounds, upon which we are accustomed to rely, fail. What we are accustomed to in our mental flow is the norm of truth, and variations from it are the false. As to the absolute validity of knowledge and thought - that we have no right to discuss here. To say with M. 
Taine ${ }^{2}$ that all perception is hallucination, even though its report may turn out to be true, is to confuse definitions to no purpose : since if it be true, it is not hallucination. We must keep within the circle of the common consensus of human knowledge, if we would have any standard of reference for psychology at all. For the same reason, we exclude from the class of illusions, all deceptions which are intimately and universally inherent in the bodily organism : that is, deceptions which all men share alike, and which are only discovered by the indirect methols of science. So, for example, is the inverted image of external things upon the retina, the mistakes we all make in contrasting colors, in estimating visual angles and forms. In all such cases, the deception is due to a modified nervous proeess, not to a mental cause. The sensation really sedent upon the central nervous change is what we experience, not the unmerged and separate sensory stimuli. $^{2}$ And by the same principle of exclusion, all states of the universal consciousness which are shown only by extraconscious means to be untrue, are not illusions in a psychological sense; such as the contention that the feeling of continuous personal identity has no real foundation, that the flow of time is not continuous in our experienee, etc.

I. Relation of Illusion to Belief. It has been said that trust in a mental state, or belief in its reality, is a common characteristic of illusional states. We cannot enter here into a discussion of the nature of belief, as a psychological state, since it is not necessary to the case in hand. It is sufficient to note that the mind preserves the same attitude toward those reproductions which constitute illusions in our mental life, as toward those which have a corresponding reality. The reason that the mind is thus disposed to illusion is again reverted to later. We attribute to the products of representation, the correspondences which hold between the presentations of former experience and independent objects or events, external to us. And it is this belief which gives the illusion its

'Intelligence, part 2 , book 1 , ch. 1 .

'For a variety of such so-called deceptions of sense (Sinnestïuschun. gen), see Wundt, Phys. Prych., II. P1. 92-109. But on the other hand, we include mistakes arising after correct perception, from errors in judgment or inference (Wahnilee). 
force. The criteria or grounds of this belief, therefore, are those which justify belief in the external world, as known in sense perception. And on the preceding assumption of the validity of the normal processes of knowledge, we may remain satisfied, except so far as to inquire why, in this latter case, that belief is misplaced."

II. Representative Nature of Illusional States. The second characteristic of all illusions is their representative quality. Deceptions of sense were seen to arise in the synthetic or inferential construction of our sense perceptions. ${ }^{2}$ This synthesis of sense is further based upon the representative, as opposed to the affective, element in sensation. In other words, the formal, space and time, aspect of sensations alone gives ground for representation and consequent elaboration : and only as the product begins to be removed from the immediateness of pure intensive feeling, is there occasion for belief, as opposed to direct knowledge. It is only in a picture, or copy, or representation, that the reality can be simulated; and it is only as the reality is itself a picture, a presentation, that a copy or representation can simulate it. For this reason, we reach a further exclusion of states from the field of illusion, i.e. those sensations, feelings, emotions, volitions, in which the affective force is predominant or unmixed. Consequently, as we should expect, illusions of the eye and ear are most common, and those of touch not unusual, these senses being most representative $;^{3}$ while deceptions in taste and smell are rare, except when they arise purely from mental causes, or from consistency with illusions already established for sight or hearing. Consciousness, in its immediate af-

${ }^{1} \mathrm{Cf}$. treatment of categorical judgments, Chap. XIV, $\S 4$.

${ }^{2}$ See p. 143.

${ }^{3}$ Cf. Sully, Illusions, pp. 33-34.

${ }^{4}$ For example, when we are sure there is fire in the house, it is very easy to smell it. 
fective revelations, cannot deceive, since it is at once aware of its own content, as truth, whatever its external value may be. This doctrine dates back, through Kant ${ }^{\text {' }}$ and Aristotle, ${ }^{2}$ to the Cyrenaic school.

Illusion due to Interpretation. Considering these two characteristics of illusions, we are led to look upon all such states as the result of the mistaken interpretation of representations. In perception, presentations are interpreted in terms of reality, and the interpretation is true: in illusion, representations are, for the same reasons, whatever they are, also interpreted in terms of reality, and the interpretation is not true. We say for the same reasons, meaning that the evidence which leads to belief in the former case, the marks of reality which we recognize, are also present in the second, and induce belief here also. We are now led to ask: What are the grounds of this interpretation?

\section{$\S 2$. Grouxds of Illusiox.}

I. Similarity of Prosentations and Representations. The most misleading feature, without doubt, of representative mental products, is their very close resemblance to the original presentations. This has already been remarked in discussing the nature of mental images.' 'This being the case, there is every reason to expect mistakes in identification, unless there be some marks in the mental accompaniment or escort of reproductions, upon which the mind may seize. That there are such differences is seen in the possibility of detecting and banishing illusions, but the great similarities in the case lead us, in common life, to overlook them.

II. Absence of Internal stimulus. The means by which, in all cases of active imagination, a reproduction 
is known to be such, is found, at least in part, in the feeling of voluntary effort put forth in the revival. This effort is directive, as has been seen in speaking of the selective attention, and is accompanied by the weariness which all attention occasions. We are conscious of having a mental initiative in the reproduction, of being ourselves responsible for the imagrinative product. This we may call an internal stimulus, as contrasted with the sense or organic excitations from which ordinary presentations arise. An entire train or network of ideas may thus be built up, constituting a secondary consciousness, parallel with the first or true series of presentations. The voluntarily pictured scene may arise before me-my distant home, friends, and all the familiar surroundings, with myself among them. But beneath it all, is my matter-of-fact present consciousness, the true state of my mind, in diffused and vague attention. I attach no belief to the former, because I feel myself forcefully responsible for its reproduction.

In the illusional reproduction, on the other hand, there is no such feeling of origination or expenditure. The image is presented in the ordinary course of present experience, as a part of the normal content of consciousness. And the subject is led to the belief, in the absence of internal causation, that the representation is due to an external cause, that is, that it arises from an external object. In this case, we fail to keep distinct the two consciousnesses, the imagined scene being as. real to us as that in which we actually move.

This plainly cannot suffice to explain the greater number of illusions, since a very great part of our imaginative construction is not voluntary. The entire play of passive imagination, which appears to be so varied, is unaccompanied by any feeling of expended energy. The mind is the passive theatre of the play of ideas, under the laws of association. Yet it does not deceive us as to its reality. 'The absence of the internal stimulus is, in cases of active imagination, undoubted- 
ly an additional guarantee and safeguard, but we must look farther for the ground of other and less simple cases of illusion.

\section{Intraorganic Stimulus: Physical Change. In} cases of illusion, if there be any stimulus or cause at all, and it be neither of mental nor of external origin, we are driven to the third and true alternative: the stimulus is intraorganic; it arises from a given condition or modification of the bodily organism itself. We have found that the nervous process which underlies reproduction in general, is the same in its special seat, and in its motor tendency, as the original perception, the stimulus arising either at the nervous centre or in some portion of the nerve courses or endings. The peculiar fact that the stimulus of a nerve course is always located at the extremity, and that the special courses always react in the special forms peculiar to their end organs, has also been remarked. In these facts we have data for the projection of the images which arise from central or general organic causes into the field of real perception. Sensations of light, for example, due to the self-discharge of the centre for sight in the cellular substance-which may be the case when the irritability of the centre reaches a high degree of potential force'-or to the existence of resident light-points in the darkened retinal field, arising from spontaneous excitation by friction or disease, ${ }^{2}$ or again to mechanical violence done to the optic nerve at any point-are alike referred to external luminous objects. There is nothing in the central process to indicate the source of the stimulus. The hearing, also, is often occupied with excitations which have no external sound counterpart. Children hear voices speaking to them, visionaries receive messages from heaven. All of these are cases of spontaneous ex-

'Volkmann, and Wundt, Phys. Prych., p. $35 \%$.

'Wundt, ibid., rr. p. 355. 
citation in the ear or centre, or are due to actual noises in the head or body, conveyed through the tissues to the auditory apparatus. Among the causes of hallucination enumerated by Griesinger, ${ }^{1}$ are the following, which are entirely physical : (1) local disease in the organ of sense; (2) deep physical exhaustion; (3) outward calm and stillness-absence of external stimulus, as in sleep ; (4) action of drugs, hashish, opium, etc., ${ }^{2}$ and many deepseated diseases.

IV. Mental Predisposition to Illusion. The physical processes which underlie reproduction are liable to predispositions to nervous discharge, consisting in a high degree of excitability. The same may be said of predispositions to the reproduction of images, on the mental side. In the first place, the associative law of preference holds, determining the kind of illusion to which one is most liable. Further than this, long indulgence in any train of thought, or frequent repetition of the same mental imagery, tends to give a whole class of images a readiness and facility which often becomes organic and illusional." But by far the most important class of cases arising from mental predisposition, come from a state of high mental expectancy. In this state, the image or idea of the expected object or event is kept so constantly and strongly in mind, that the subject conceives of it as already accomplished. Other events or images take on the form of the expected event or image, by an assimilation to be spoken of later on. A good illustration is found in the anticipation of an expected sound, when it

${ }^{1}$ Mental Pathology and Therapeutics, London, 1867, pp. 94-95.

2 Especially santonine: see remarkable effects given by Mayer, Die Sinnestäuschungen, p. 108. It is well known that optical hallucinations are especially common in cases of heart disease: Hagen, Sinnestäuschungen, p. 127.

3 See cases cited by Carpenter, Mental Physiology, p. 207 and fol. Called by Sully a state of sub-expectation. 
is to be intercalated in a series of other sounds, the expectant attention being strained to receive it. ${ }^{1}$ The illusions of the theatre are due to this mental predisposition. And the success of the spiritualist in bringing up ghosts, lifting tables, and doing other wonders, turns upon the readiness of his audience to fall into illusion. Furthermore, the state of expectancy is greatly enhanced by the aldition of violent emotion, as fear or hope. When under a state of great fear, the most unoffending objects take on the form of our apprehension : ordinary noises become the footfall of burglars, a harmless bush in a graveyard, is a spirit, slight bodily pains are made the symptoms of frightful diseases. The emotion has an immediate influence in quickening and concentrating the attention, and the attention in turn keeps the expected image present, even when the peripheral stimulation is of the most opposed nature. And the illusion is sometimes so powerful that it affects more than one sense.

A further and more philosophical predisposition to illusion, in the normal processes of mind, is found in the assumption already made, that average and ordinary experience is truthful. The growth of mind, from its earliest stages, is based upon this assumption. Indeed, development in mind is the progressive adaptation of the subjective to the objective, the refinement of harmony in a relation of which each term is absolutely dependent on the other. Truth, to us, is what this relation means, and truth, to us, outside of knowledge, is a metaphysical absurdity. We do not stop to question experience, since experience, for psychology, is the final end of all questioning. For this reason, belief in sensations, images, reasoning, is a part of those processes themselves. It is only when, by reason of some inconsistency in our mature life, after mental symbolism becomes 
established, ${ }^{1}$ we find violence done to our belief, that the feeling of illusion enters consciousness at all. The real fact demanding explanation is not the question, why do we believe in some states which are not real in fact, but why do we not believe in all states. Just as the little child confides in all men by nature, and learns from painful experience that all cannot be trusted, so he conficles at first, also, in all his mental states, and learns by an experience just as costly, that some are deceptive. With this new experience, comes also the means of defence against similar illusions, and so the indications are learned by which, under careful weighing, the illusive state may be detected.

M. Rabier's statement of this truth is full and precise: "Thought is in its nature essentially objective or rather $o b$ jectifying. That is to say, whatever is thought, seems to us naturally to be a thing, an object perceived in thought. The operations of sense, of consciousness, of understanding, of memory, even of imagination, appear to us to be acts of vision or perception. We see, or believe we see, sensible objects, abstract truths, the past, the future, etc. . . . From this it becomes evident why belief naturally accompanies evidence. It is because at bottom, evidence and belief are one and the same thing. Both evidence and belief may be defined as the objectification of the object of thought. . . . Naturally, therefore, every representation, in the absence of contradiction, is objectified, and naturally also every representation is accompanied by belief." And Taine is right in saying that under normal conditions the production of the mental state alone, in his words the "intermediary," is sufficient to produce illusion. ${ }^{2}$

The element of truth in James Mill's association theory of belief, is covered by this view of illusion, since the fixing of the escort or normal network of experience, which the illusion contradicts, is brought about by association.

1 Cf. Bradley, Principles of Logic, p. 35.

2 The Intelligence, p. 208 . Rabier, loc. cit p. 272. 


\section{§ 3. Kinds of Illesion.}

The general characteristics of all illusional states have until now been considered. Looking at special cases more closely, we find that they may be divided into two general classes. First, there are many cases in which the state which constitutes the illusion, while itself altogether independent of an external stimulus, is yet brought into consciousness through the perception of some real object different in character from itself: that is, cases in which the image seen is a misinterpretation of some real thing. This is called Illusion Proper. Second, there are cases in which the image is not connected with any external thing whatever, but is a pure projection into the conscious field of presentation. This is called Hallucination.

This distinction is ordinarily accredited to Esquirol, ${ }^{2}$ though Volkmann traces it back to the Stoics' distinction between cataleptic and acataleptic imagination. It is a convenient working classification, but, as will appear below, it cannot be considered in any way a fast line of division. The general grounds of illusion already stated and the consideration of the physical process in the same cases, both tend to show the real identity of the two states. We cannot hold, with the old psychology, that the stimulus in hallucination is purely psychic. It is simply a difference in degree of spontaneity, subjectively considered, or of central potential, organically considered, whether the image appear with no special sense stimulation, or only with it. And whether the stimulus be within the body or without it, is indifferent, as far as the mental product is concerned.

I. mlusion Proper. Proceeding upon this distinction between illusion proper and hallucination, the former may be considered in more detail. At the outset, we find ourselves face to face with the whole class of experiences, in which one mental state is taken for another. There are, really, two images involved, one the rightful

'Des Maladies mentales, I. p. 159. 
image, the presentation, as ordinarily aroused by the stimulus experienced, say the sound of the clock: the other, the image of something different, formed within the domain of the same sense quality, and usually prominent in consciousness before the time of the illusion; as the alarm of fire, into which the striking of the clock is interpreted. The latter is an image in the strict sense of the word, the former, a sensation. This identification proceeds upon similarities which may be very close or very vague. In states of strong emotional tension, simply the quality of the affection-as coming from the same sense-is sufficient to produce illusion, or even further than this, the mere fact of sense stimulation brings the dominant image into apperception, with all the marks of reality. The fact that the sensorium is in a state of reaction, is sufficient, the special sensation experienced being interpreted into that aspect of the illusional image, which would appeal to the same sense, if it were real. The timid traveller in the woods of the West, at night, not only mistakes trees for Indians, but every sound becomes the soft tread of the savage. The dreaded thing is so entrenched in the centre of converging lines of association, that the same image is called up whatever sense is brought into play. ' It is easily seen, also, that this is more readily the case when the sense stimulation is uncertain or vague in its character-as vision at night, - since, in this case, fewer points of opposition are presented to the superposed image.

The actual process, therefore, in cases of illusion proper, is one of Assimilation. It has been seen, in cases of association by contiguity, that images are often assimilated to one another, under conditions of attentive or

1 A good example is given by Dr. Tuke (see Carpenter, Mental Phys., $\S 186)$ : a lady who was occupied with the subject of drinking-fountains, was deceived by a pile of stones on the roadside, and afterwards narrated even the inscription she had read upon this imaginary fountain. 
emotional excitement. ' The result in such cases is the disappearance of the assimilated image and the intensifying of the image that remains. Illusion proper is a case of such assimilation, except that the merging of the two images in this case is entirely unconscious, thus giving ground for the rise of belief. The assimilations of the theatre, on the contrary, rarely rise to illusions, since we are throughout conscious of the duality of our states.

We further find that the intensity of the actual sensation passes over into the imagination, thus bringing it into conditions of harmony with the presentational environment. ${ }^{2}$ This is seen in the fact that the illusion lasts no longer than the actual sensation upon which it rests. The imaginative image passes back into the state of unstable representation which it had at first, when the peripheral stimulus is withdrawn.

Physical Aspect of mlusion Proper. The presence in illusion proper of an actual sensation, gives us access to the physical side of the phenomenon. Remembering that representation involves the same central elements as the corresponding sensation, we may suppose the image which constitutes the illusion, in any case, to have, as its physical basis, a nervous discharge of extreme facility and multiplied connections. Frequent repetition, disease, or drugs, have given its centre a degree of sensibility so delicate, that any activity of the sensorium, as a whole, leads to its discharge; and the discharge is of so wide-reaching a kind, that the regular changes due to moderate sense stimulation are merged in it. The entire movement of the cerebral elements, then, tends to the emphasis of this particular process. And thus emphasized, it passes from the state of unstable tendency,

I See p. 207.

Volkınann; a necessary view from the Herbartian standpoint. 
to that of actual subjective representation. The reinforcement received from the peripheral stimulation, corresponds to the increased intensity already noted in the illusional image.

Elements of Reality in the Illusion Proper. In virtue, also, of the presence of extra-organic stimulation, the illusion proper has elements of reality brought into it necessarily, which are wanting to the hallucination. In an earlier chapter, it was seen that certain subordinate processes were involved in perception, which, by way of synthesis, afford us our knowledge of things, as connected with one another and localized in space. The relation and localization of percepts tend to differentiate them sharply from images, as will appear below, and so far to indicate their reality. The flow of reproductions, even when uncontradicted from the primary consciousness of things around, has no exact and definite local coloring. Even in our dreams, in which the independence and isolation of the imaginations from disturbing reality is as great as is possible, their localization is vague and changing: the relations of space are extremely confused. And their relational connection with one another is of so loose and unimportant a kind, that the most startling and inconsistent transformations do not surprise us.

In the assimilation, however, upon which illusion proper rests, these two characters are supplied by the assimilated sensation. The reproduced image steps into the shoes, so to speak, of the sensation, and appropriates both its local position, and its relational connections in the network of actual fact. The Indian seen in the forest, is no longer a vague placeless image, flitting here and there in consciousness, with no relations to other images, by which he is made permanent and real: but he takes the place of the tree which is assimilated to him, and all its definiteuess of place, time, and environment, becomes 
his. For this reason, as will appear, the detection of illusions is more difficult than that of hallucinations.

II. Hallucination. In hallucination, all extra-organic stimulation is wanting. The illusional image is a pure projection of mind. For this reason, we find that both the mental and the physical process has an enormously exaggerated intensity. On the mental side, it is only when the force of attention has been so long or so violently exerted that an image becomes fixed or imperative, that it attains the appearance of actuality. And on the physical side, not only is the nervous centre highly excitable, but it is in a kinetic state, its discharge is automatic: instead of proceeding from the action of peripheral or central stimuli, it proceeds in spite of all opposing stimuli. This state, either of mind or body, is always near the line of disease: cases of hallucination in normal health are extremely rare, and arise mostly from great weariness in the mental life. The classical case of Nicolai, the Berlin bookseller, need only be referred to. ${ }^{2}$ Thoroughgoing hallucinations are rare, further, from the absence of all means of localizing them, and of connecting them properly with outside states. Even when they are localized outside us, the absence of the connection enables us to detect them, as in the case of Nicolai and numerous others, as Newton and Herschel. Yet in some cases, they carry their associated escort of images with them, giving a consistent presentational continuum; this is the case in hypuotic hallucination.

\section{§ 4. RaNGE OF Illusion.}

The nature of illusional states has been indicated with some exactness : it remains to see just where, in the mental life, such states oftenest appear and how they may be detected. With reference to the intellectual

' Carpenter, loc. cit. p. 167. 
functions affected, illusions, including hallucinations, may be classified as follows: I. 1llusions of Presentation; II. Illusions of Representation; III. Illusions of Reflection or Thought.

I. Illusions of Presentation. Under this heading are included all errors which enter in the complex process of perception, through mistakes in proper identification of sensations, mistakes in their differencing and classification, and, which is very important, mistakes in their localization in space. Under strong expectancy, as has been said, or under violent emotion, sense utterances are very frequently mistaken for one another. A naturalist, under the excitement and hope of an expected discovery, must guard carefully against the danger of reading into his specimens the peculiarities he is searching for. And in classifying and arranging our first sensations, similar mistakes occur; as the confusion of two tastes or odors. Errors of space localization are exceedingly common and varied, since the estimation of distance and direction depends upon complex data of inference. Under this head, therefore, we find all mistakes which enter our consciousness in the perceptive or preparatory processes, before the percept is finished for reproduction, combination, and elaboration. They may be defined as individual errors in the synthetic construction of the percept. ${ }^{1}$

II. Illusions of Representation. Mistakes in the character and connection of representations may proceed from those errors which arise in presentation, simply from the law of the repetition of error. For the most part, however, it is here that illusional states take their rise. Indeed, properly speaking, an element of representation enters necessarily into illusions of presentation, since presentation, in its fullest form in perception, involves the

${ }^{2}$ For detailed accounts of this class of illusions, see Sully, Illusions. 
reproduction of sensational states. This form of illusion may again be riewed differently, according as it arises from mistakes in any one of the integral functions of reproduction. We have, therefore, Musions of Memory, ${ }^{2}$ comprising illusions of Movement, of Recognition, of Localization in Time, and of Self-consciousness.

1. Illusions of Movement, including all mistakes in regard to the movements of the organs of the body; seen in dreams, paralysis, and in cases of the amputation of limbs. Cases are known of patients who feel the articulation of words, while their organs of speech remain motionless. Such states are called motor hallucinations. ${ }^{2}$

2. Illusions of Recognition exhibit, again, the class of external assimilations which are called illusions proper, as opposed to hallucinations. The peripheral stimulation excites the sensation which ordinarily arises from it, but this sensation is not recognized. The process of recognition, which was found to consist in the proper adjustment of a mental state in its apperceptive train or escort, is, in this case, mistaken, not in the direct experience of the sensation, but in the substitution of an ideal escort for the real. The sensation is taken up into the flow of previous states, and identified with one of its connected images.

3. Illusions of Localization in Time. Corresponding to the presentational illusious which involve estimates of space, we find ourselves also subject to illusion in our sense of past time. These states are more popularly known as "illusions of memory." The ground of our localization of events in the past has already been treated of, and we have to deal here, not with the synthetic reconstruction of time, but with the arrangement of experiences in time, that is, with temporal perspective. It presupposes the idea of time, and also certain data of differentiation,

' Cf. Sully, loc. cit. chup. $x$, and Ribot, Les Maludien de he Mimoire.

'Cr. Tamburini in Revista Sperimentale di Treniatria, is59. 
whereby events may be considered as before and after, in relation to one another. The misinterpretation of these data leads to the reversal, confusion, or entire abolishment of order in our memory of the past. Of these states, there are several distinct types.

a. Illusion as to actual time of the occurvence of a past event. This, like mistaken estimates of distance, rests upon empirical data, the most important being the fact of relative intensities of remembered states, as affected by the attention. As the importance of events is distorted, so also is their temporal order.

b. Illusion as to the connections of past events. This is due to the mental exaggeration of particular details, and the imaginary supply of missing links. Ordinary testimony in the law courts, in cases of different versions of the same event, illustrates this class of illusions. Different individuals give contradictory details, according as they have imagined them. Such perversions of truth are entirely unconscious, and are firmly believed in. Further than this, when points are supplied intentionally with purpose to deceive, frequent repetition tends to make them real to the subject. They become constituent parts of the original experience. They are then no longer falsehoods, but illusions. ${ }^{1}$ So, many of our experiences of childhood are not real memories, but have become parts of our consciousness of the past from frequent repetition, by our parents or friends, in our hearing. It will be seen that this unconscious filling in of our past lives with suitable details, takes its color in different individuals from the law of preference.

c. Hallucinations of memory: the projection into the past of experiences which have no foundation of fact. Illusions of this kind, it is seen, shade off imperceptibly into hallucinations and illustrate the real identity of the two states. These hallucinations of memory cannot be

\footnotetext{
'The question of respousibility for such states is not raised here.
} 
explained, as those of perception are, as the projection of a reproduced image into reality, under conditions of emotional or attentive excitement; since it is the fact of reproduction which is in question. In cases of healthful mental activity, such hallucinations arise, probably, from vague likenesses of present or fancied events to real past experience, which leads to their identification. The past experience involved may also be a pure imaginative construction or a dream.' These latter experiences are real, as experiences, and being subject to revival with the images of real presentations, are with great difficulty distinguished from them. The experiences of dreams are, at their occurrence, often pure hallucinations, and though they are rectified after waking, they remain with our creations of fancy, liable to be identified with past events of real occurrence." More often real hallucinations of memory indicate a greater or less degrea of mental alienation. Often insane subjects are overpowered by a single conception, which assimilates to itself the whole mental life, and leads to a new mental personality.

The curions feeling of familiarity which we sometimes experience in the midst of surroundings really quite new, has been much speculated upon. The fact of such a feeling is incontestable. Plato attempts to turn it to account as a feeling of reminiscence, from a former life of the soul. Erolutionists have, in the fact of race experience and its organic modifications, a means of accounting for the phenomenon. Radestock, by tabulating his dreams, was able to refer many such feelings to experiences of his sleep-life. Whatever we may say as to the influence of the experience of our ancestors upon our own per-

' So Radestock, Schluf und Traum.

- See case given by Curpenter, loc. cit. p. 456.

An example of this occurred in the State Lunatic Asylum at Columbia, S. C. - a woman under the permanent illusion that she was Martha Washington. She uarrated detailed incidents from her husband's life, called visitors by the names of his contemporaries, and exhibited a string of gold beads as his last gift to herself. 
sonal life, we certainly find that our dreams become confused with our waking states. And taking these in their infinite variets, in connection with the forgotten details of our waking life, we have ground, certainly, for all shades of indefiniteness in the reference of present states to the past. When we remember, also, that the laws of association in passive imagination entirely elude our conscious observation and are buried, in their activity, in the organic processes, we surmise that the sphere of our temporal localization may also have an enlitrgement from the organic side. Brain modifications too weak for conscions accompaniments, or presenting these accompaniments inopportunely, may be reinstated in actual experience, with so faint a shadow or residue of their i':mer occurrence, as to be absolutely incapable of localization in past time. And the ragueness of their recognition may give its character to the feeling of familiarity they excite. Or there may be a secondary vibration or echo, after a strong stimulation or shock to the sensorium, which is projected into the pist, by reason of the consciousness of a time interval, and of the great difference in intensity of the two shocks. ${ }^{1}$ Again, emotional analogies may often account for this feeling. When a state in which emotion largely predominates is thus referred to the past, it is probably identified with a former emotional state, the representative differences being overlooked. ${ }^{2}$

3. Illusions of Self-consciousness. We come now to speak of the subjective element in memory-the feeling of self which accompanies all representation. By illusions of self-consciousness is meant mistakes either as to the affective state, of self, or as to the personality and identity of self.

Of these subjective illusions we may mention emotional illusions; wrong estimates of our emotional states, as when an angry man declares that he was "never more cool in his life." Desire leads us to misapprehend our own real affective state. Again, we misappreliend ourselves in the past in various ways, such as

1 Cf. Lewes, loc. cit. p. 130.

'Having this feeling on entering a church in Alexandria, Va., for the tirst time, and thinking closely upon it, with a view to an analysis of the experience. I found it to rest largely in the strong religious feeling which the church service called forth. 
exaggerating our importance, our foresight, etc., or, in the present, our sagacity, influence, power. This is due to the intense emotion of self-interest.

Again, the unreflecting mind is under continual illusion as to the continuity of self-consciousness. One thinks of himself as being the abiding watchman beside the come and go of our inner states, whose eye is never withdrawn, and who never falls asleep. Yet so far is this from the truth, that there are constant gaps in the continuity of our conscionsness of self.' Every hour of profound sleep has no memory of events and no memory of self. All lapses from vivid consciousuess, due to drugs, are so many breaks in the thread of our selfconscious life. And when we return to ourselves, we are completely lost, by the failure we experience in our efforts to connect the awaking state with anything before it. As the previous conscious state returns in memory, we simply leave out the interval, and connect the parted ends of life, and continuity is again our illusion. ${ }^{2}$

III. Illusions of Thought. Finally, there is a class of illusional states which arise from the operations of the logical or discursive faculty. These will be better understood when that function has been studied. Considered as exclusive of the other kinds of illusion, they comprise what are termed, in logic, fallacies of inference, material and formal. As far as they are material, they spring from mistaken interpretation of the reality of mental products: and when purely formal, they reside in the method of the logical process itself.'

1 We deal here with the empirical self-consciousness, leaving the metaphysical questions connected with it quite untouched.

'Cf. Sully, Illusions, p. 290 ; also Volkmann, loc. cil., It. p. 220.

See Sidgwick's thorough treatise, Fallacies, and consult the Logics under that heading. 


\section{\$5. Detection and Rectification of Illusions.}

In general, illusional states do not have the charaoteristics which usually distinguish reproductions from presentations. They are intense; they are localized; they are more or less fixed in an escort or ideal environment, which gives them an apperceptive truthfulness and force. For the detection of illusion, it is only necessary that an image return to the normal standard in any one of these respects: that is, that it become very feeble, that it have no definite localization, that it appear in consciousness with an inappropriate apperceptive escort, or with none. Hence from the nature of the illusional state itself, we have three means of detecting it, which, when found existing together, make the case unmistakable.

1. Diminished Intensity. The fact of diminished intensity, as diistinguishing an image from a sense presentation, has already been dwelt upon. The fact applies to all possible reproductions. This test is of little value in cases of very vivid representation, and in cases where localization enters, since, in such cases, this latter fact is the controlling one. But in cases of vague sensation, and of sensations which are not customarily localized, we are driven to the discrimination in intensity, as the only means of detecting illusion.

2. Absence of Definite Locality. On the other hand, in the case of an image whose corresponding sensation is always localized-as images of sight and touch-the. absence of spacial locality is at once a sufficient guarantee of its illusional character. However intense, detailed, and clear, for example, the image of a house may be, if it is not localized in front, behind, somewhere in the visual field, we prouounce it at once an illusion. The 
same is also true of temporal localization in cases of illusion of memory.

A distinction should be made, with Volkmann, between localization, in this connection, and projection. The fact that an image is not definitely localized in space may still be true, though the image may be projected without, as an external thing. Projection seems to imply conditions of space in the mental product, but not conditions of place. When a hallucination is detected and recognized and its position in space filled by real things, it does not then become an image merely, felt to be subjective; but retains its projection without us. This distinction is covered by Taine by saying that with projection a representation is a sensation; without, it is an image. In other words, the sensational data which contribute to the perception of space are present in the projected representation, but without the definite character necessary to localization-a proof, again, that space perception proceeds upon physiological data.

3. Inappropriate Escort. This test gives us a very convenient and practicable method of banishing illusions whenever sense perception, generally, and logical thought are normal. The character which we instiuctively look for is incongruity or contradiction in the presentational continuum. The primary consciousness of the actual world, as it breaks in through the open avenues of sense, presenting a consistent whole reported by all the senses together, suffers immediate violence by the intrusion of a representation which has not external truth. Incongruities and inconsistencies at once arise. These may all be considered as some form of contradiction in consciousness, and lead us to the principle of contradictory representation. This principle may be stated thus: of two contradictory states of consciousness one at least must be false. In the thought function, we find the same principle, called the logical law of non-contradiction. In the sphere of pure representation, this contradiction takes the form of repressive or antagonistic opposition among images; the quality and range of escort being the 
ground of division as to which is true, and which false. In many cases, the escort of the true presentation is already so fixed in consciousness and confirmed by different sense-deliverances, that a hallucination is at once detected. A visual image is seen on the background of a wall or forest, which latter comes strongly out when attended to, and the hallucination disappears. An appeal is often made to another sense to confirm such an image. The other sense, as touch, establishes a different external series, and the hallucination is detected. ${ }^{2}$ This last form of contradiction-that between two different senses-affords the only practicable test, in many cases, of illusion proper in perception, since, as has been seen, the real object in this case gives to the illusional image its locality and escort, as far as a single sense is concerned. There is nothing in the physical surroundings to lead us to believe that the Indian is really a tree, or that the slight noise is not his tread. On approaching and touching the tree, however, our illusion of sight is rectified. Further, we have here the reason for frequent hallucination and illusion when the organ of sense is fatigued. The incapacity of the organ to produce the normal presentation, and its proper escort, removes the means of detecting creatures of the imagination.

This principle of contradiction also enables us to bring to bear upon images the conclusions of a higher nature, which we have before reached : conclusions based upon sufficient reasons. Memory, natural law, testimony, experience, rational truth, any of these may lead us to disbelieve in an image, though it persist in our conscious life. A resident of New York would not believe that a herd of buffalo had been seen in Central Park or a wild Indian in his parlor: a stone unsup-

1 Christ appealed to this test in telling Thomas to touch his body : the vision might well have been a hallucination, duc to exhaustion or grief. 
ported in midair we simply treat as an absurdity. In all such cases the sense report is subordinated to higher rational conviction.

This subordination of lower to higher forms of evidence leads to a conservatism in science which is its only safety from the wildest speculation and delusion. In psychology, the doctrine of telepathy carries with it a proposition in contradiction with the experience and belief of the world in all history : that there may be direct communication between mind and mind. ${ }^{1}$ Not only must the evidence be convincing as to its force and interpretation, but it must also be sufficient to overcome the strong presumption that the alleged facts on which it rests, have a psychological and illusional origin. ${ }^{2}$

On illusions, consult : Taine, Intelligence, pt. 1, bk. 2, ch. I, III, and Iv, and pt. 2, bk. 1; Wundt, Physiolog. Psychol., ch. xIx. 1; Carpenter, Ment. Physiol., p. 165 and pp. 206-209; George. Psychol., p. 362 ; Volkmann, Lehrbuch d. Psychol., \$ 103-104 and 116; Griesinger, Mental Pathology and Therapeutics; Ribot, Maladies de la Mémoire (also Diseases of the Will and Personality, 3 rols.) ; Gurney, Mind, x. p. 161; Esquirol, Maladies mentales; KrafftEbing, Die Sinnesdelirien ; Binet, Mind, IX. p. 206 ; Sully, Illusions ; Krauss, Die Psychologie des Verbrechens, pt. 1, ch. I; (Sleep) Porter, Hum. Int., pp. 331-351 ; Brierre de Boismont, Hallucinations ; Maury, Ie Sommeil et les Rêves; Radestock. Schlaf und Traum; Spitta, Schlaf-und Traumzustände; Mayer, Sinnestäuschungen.

Further Problems for Study:

The problems of mental pathology ;

Hypnotic illusion and suggestion;

Manifold personality ;

Belief and evidence.

'See Gurney. in Phantasms of the Living.

2 For the theory of the detection of logical illusions, or fallacies, see the Logics. 


\section{ELABORATION.}

\section{CHAPTER XIV.}

THOUGHT.

\section{$\S 1$. Nature of Thought.}

General Character of the Thinking Process. As a departure in the mental life, thought seems in its nature to present processes hitherto entirely wanting. .Thought, thinking, reasoning, characterize an operation at first sight distinct from imagination, memory, perception. Yet it is from these subordinate operations in their singular manifestation, that thought is distinct, not from the generic power of apperception which includes and energizes them all. Thought is the crowning act of apperception. In the operations already considered, the relating activity of attention has been presupposed, especially in the synthetic process of perception : but its further pursuit has been neglected in the examination of the representative function of mind. Yet this latter function not only rests upon apperception unconscious, but leads up to and renders possible, apperception conscious. In perception and imagination, the laws of association hold the apperceiving power down to a mechanical reconstruction of the data of presentation : in reasoning, the energy of apperception transcends these bonds, and proceeding upon the data of representation, realizes itself in its own way, according to its own laws. It is conscious and voluntary. Thought, therefore, looked at from the subjective side, is the reapperception 
of the apperceptive product, in an active conscious way : and from the objective side, it is the development of mind in its essential nature as the organ of the realization of truth; a rational and teleological development, which imagination pictures as possible, and synthetic perception, although mechanical, typifies and foreshadows.'

Thought, therefore, is not a power or faculty as held by the old psychology. It is rather the fuller exhibition of the one power or energy which underlies all the faculties. In thought, only, does the attention, which is limited by the senses in perception, and misled by the range and freedom of reproduction, in imagination, get the upper hand, and follow its own rubrics of independent action. As related to perception, therefore, thought can be called the synthesis of percepts, as perception is the synthesis of sensations : and as related to imagination, it may be called the construction of combinations in accordance with laws of its own, and the laws of external truth; just as imagination is the construction of combinations in accordance with the laws of mental reproduction. For example, we can imagine Samson dead and the temple of the Philistines still standing; there is nothing in the mere coexistence of the representations to forbid it. But we cannot think it, for it violates the mental principle of cause and effect. So we can picture the Deity doing wrong, but we cannot think it. The relation to other phases of the mental life will become plainer as we consider the different stages in the thought process.

The relation of psychology to logic should be spoken of here, both to indicate the true sphere of the latter and to justify the following treatment of the reasoning process. Logic as taught in the text-books is a formal science. It deals with the finished products of the apperceptive faculty, as they are seen in their matured forms, independent of their origin, truthfulness, or psychological justification. As a formal skeleton or framework of thought, logic misses the meaning, the motive, which is alone valuable to psychology. There might also be a logic of perception, or of imagination : being the analytic form in which these operations cast their material, whatever this material be. Consequently, we are concerned merely with the nature of the thought process-though a full

'On the apperceptive nature of the thought operations, see Wundt, Logik, I, pt. 1, ch. II. 
treatment would include also its logic,-its value and bearing in the mental life; and reference is made to the books on logic for that side of the case. The distinction is most clearly seen in the treatment of the judgment. ${ }^{1}$

Stages in the Thinking Process. The single apperceptive act in which we have seen thinking to consist, takes forms of more or less complexity in three stages of mental product:

Conception, Judgment, Reasoning. These are both chronologically and essentially dependent upon one another, and will be considered in this order.

\section{§ 2. Conception.}

Process of Conception. Conception is the process by which we reach the general notion; which is, as shall be seen below, a representative state of mind, which holds the attention upon a plurality or class of objects taken together, or upon any individual considered as a member of a class, and not as an individual. Man, tree, government, virtue, are general notions. Considered as products of conception, they are called concepts, and considered as names, in language, terms. The concept is related to the percept as the percept to the sensation. The percept is built up upon the basis of sensations, but can be applied to a single sensation only as it is representative of others, or carries the force of others in itself: so a concept is built up upon percepts, and can be applied to a single percept only as it is taken to represent others. The range of a concept in its application to individuals is called its Extension or breadth: thus man has greater extension than poet. It applies to a greater number of single things. And the meaning of a concept in regard to the qualities, attributes, or characteristics, which it includes, is called its Intension or

'Below, § 3, p. 283. 
depth : thus poet has greater intension than man, since, in addition to the qualities of all men, it includes the quality of being poetical. ${ }^{1}$ The growth of the concept may be observed from the side either of intension or extension: in the former case, it is known as Abstraction; in the latter, as Generalization.

I. Abstraction. 1. Analysis. The finished perception or intuition of a thing, it will be remembered, involves a synthesis of sensations giving an ideal product. The percept, in its first experience, however, is thrown into conscionsness by external causes and has no such distinct unity. The child's first sight of his father is only a mass of visual sensations, and when he begins to use the name supplied from without, he applies it to any man incliscriminately. He has no such thing as a general conception of man; for the reason he calls a stranger papa, is not that the term applies equally to other men, but that he mistakes the individual for the man he is accustomed to call papa. Yet in the psychological state of the child, we recognize a general notion; an image or symbol which answers for any one of many individuals. So it is probably, also, with animals. The peculiar features of different men are undetected, and the intension of the term, while very great, is of the most apparent superficiality. This we believe to be the beginning of all our general notious. In adult thinking when new conceptions enter our mental life, it is from the broadest and raguest mental pictures that they gradually take form. My first experience of a new word, say government, in my reading, gives me only the vague meaning which $I$ gather from the context. I carry this conception, under which all conceivable forms of government might pass, until from some other source my idea is clarified. From tension.

'Mill, Logic, bk. 1, ch. II, $\S 5$; he uses the term connotation for iu- 
this point, increasing experience leads me to limit the meaning of the term, by dropping marks which are not alucys present. That is, the intensive meaning of any notion is analyzed, and only those qualities retained which if dropped would destroy the concept. This form of abstraction may be called Analysis.

The difference between this treatment and that in the formal logies is plain. Abstraction is not, in psychology at least, a voluntary dropping off of certain qualities in order that another, already selected, may be considered alone. 'T'his would involve the conception beforehand ready-made. On the contrary, it is a gradual unforeseen process of elimination, at the discovery of truth necessitates it. Instead of starting with different governments, abstracting the quality of sovereignty from them all, and leaving behind their individual characters: I begin with a vague notion of government, and by analysis through experience, find that sovereignty alone is essential to all its forms. This analysis, as appears later, is the basis of the analytic judgment. ${ }^{1}$ By it the concept is freed from connections with others, and also from confusion and dependence among its own parts.

The growth of our knowledge of an object which thus leads us to drop from the concept all accidental qualities, is a progressive decrease of intension; yet it is a growth toward more exact and comprehensive insight into the real nature of the object defined. For this reason, a distinction should be drawn within the idea of intension, according as intension is great in number of qualities-its usual significance-or in exactness, thoroughness, and adequacy. The former might be expressed by Mr. Mill's term, connotation, and the latter by the word depth. In our example above, the first vague notion has greater intension, as connotation, but, as has been said, it is superficial : it is only as the concept is narrowed down to a few well-marked qualities that our knowledge is adequate and deep. So important is this distinction, that George, though not noting its bearing upon intension, limits the word concept (Begriff) altogether to notions which have this property of liepth: that is, those that carry "complete knowledge of an object and its origin."

'On this view of abstraction, cf. Ward, loc. cit., also Volkmann, loc. cit., II. 246. The distinction between psychological and logical notions is brought out by Sigwart, Logik, pp. 261-272.

'Lehrbuch, pp. 499-500. 
This process of analysis is furthered by the actual play of representations in memory. ${ }^{2}$ By the law of the progressive fading of memories in the past, individual peculiarities are lost, and individuals of the same general nature are identified with one another. The dim shadowy outline thus recalled serves the purposes of the general notion. This accounts for the greater vagueness and indefiniteness of the image, as the notion becomes more general. It gives a representative support to the general concept, though it is not the concept itself : the latter involves something which is felt throughout to be unrepresentable. This reduction of images to a single "composite" or " generic image" is typified in composite photography, as Mr. Galton has shown. ${ }^{2}$

2. Synthesis. Yet another result from experience is necessary to the complete development of the concept: its enlargement in intension. In the testing which we constantly make of the adequacy of our notions, we find that not only must elements be dropped from our first tentatire concepts, but that others must be added. New discoveries constantly increase the intension of familiar concepts. Research in natural science reveals an unexpected property in a substance, or mark in a specimen, which is thereafter a part of the concept. This continual addition to the intension of the concept is synthesis. It lies at the basis of the synthetic judgment.

We thus find two kinds of change constantly going on in our concepts, both of which tend to define and purify them into complete harmony with truth. In the method of Socrates, both these correctives of conception were kept in view, and his appeal to the experience of others was a means to the widening and enlarging of experience. But, further, the same process, especially its synthetic aspect, tends to a modification of the concept in its extension.

II. Generalization. Generalization is the process of

' See the clear exposition of Waitz, Lehrbuch, pp. 518-522.

'Inquiries into Human Faculty. 
making more general the application of the class name to individuals; that is, the bringing of more individuals within the class. Abstraction, as analysis, both hinders and aids this process : it hinders it, inasmuch as by removing the vagueness and superficiality of the concept, it rules out objects at first included; and it aids it, since, in reducing the number of qualities included, it enables more objects to meet the intensive requirement. As synthesis, abstraction increases the generality of a notion, since the discovery of a new quality tends to bring into the class objects before overlooked which possess that quality. Yet we see the contrary result here also, since in adding qualities we increase the requirements of intensive eligibility.

The process of generalization is exceedingly difficult and in actual life seldom absolutely exact. Only in cases of complete induction can we rest safely in it. Mistakes and fallacies in reasoning, failures in nature-discovery, are usually found to rest in hasty or superficial generalization. And further, we may remark at this point, the very great instability and mobility of our concepts. Since they are a development in the mind depending upon experience, and experience is unlimited, our concepts are always subject to correction and revision. A concept which seems clear and exact is given a different place and estimation in our thought, often from an hour's conversation with another; and we say, we "see it in a new light." This is especially true in the higher abstractions. Chapters in moral science are devoted simply to the meaning of the concepts virtue and right. Intercourse labors constantly under the disadvantage which arises from ambiguous meanings.

Products of Conception. From conception, therefore, we obtain two classes of notions: the abstract notion, [which brings before us qualities regarded as more or less distinct from the things in which they inherg; and the general notion, [which brings before us things in more or less disregard of the qualities which inhere in them.] The former is a concept in intension, the latter in extension. To these, as ready classes, the ordinary per- 
ceptions of our adult life are referred by the most rapid and careless reference.

Conception as Discovery of Relations. From the preceding account of conception, its essential apperceptive nature is seen. Relations of identity, likeness, subordination, constitute its ground. Percepts, themselves synthetic products of apperception, are synthesized anew, and their real relations idealized in the concept. The relations thus summed up are conformable to truth, while those of the imagination are not. And it does not suffice, as an account of this process, simply to say that the relations exist, and that is sufficient for their apprehension; for, as has been so often said, we have to pass here, as in synthetic perception, from the relation of perceptions to the perception of relations. It is only as excitations that percepts serve, excitations to a spiritual activity by which presentations of the relations of similarity, equality, contrast, arise: presentations which, as Lotze says, "would not be possible without this new spiritual activity." "

Language in its Relation to Conception. With the general philosophy and development of speech we are not here concerned, having to do simply with its primary function as a means of symbolic representation. Words answer the purpose in conception that images do in perception. They hold in a representable symbol the result of the apperceptive process. The reproduced image passes through all the phases of memory and imaginative construction without recurrent reference to the real objects: so words carry through all the higher operations of thought, the summary of experience which the concept represents. And, further, by means of vocal articulation, they make its communication to others 
possible. Consequently, language has a twofold psychological utility : 1. It fixates and expresses exact stages in mental product, thus enabling the mind, instead of returning constantly to its experiential sources, to take its departure from some advanced position. 2. It, consequently, enormously abbreviates and facilitates thought. A name, once given to a conception, holds it as a conquest ever afterwards, however circuitous and painful were the original route to its acquisition. ${ }^{2}$

Yet language often serves to confuse and hinder thought, in that words tend to give a stability and fixedness to conceptions, and do not admit of the progressive rectification which the process of abstraction affords. A study of word derivations shows the manner in which conceptions grow away from the first meanings of the terms used.

This fact that language simply performs a symbolic function in company with images, sensations, and indeed all representative states, hinder's our elevating it to a distinct place in psychology." Whaterer the "symbolic power" be, it certainly is exercised before the growth of language. It seems to rest in apperception itself, being a relation of substitution or identity.

The Use of Images in Conception. The image which serves to give representative force to the concept, has already been spoken of. ${ }^{3}$ Further, it may be said that the notions which are less general have a distinct mental picture, which presents the barest outline or scheme of the class reality.' This image is seen, if closely exam-

${ }^{1}$ On the physiology of speech, see Ferrier, loc. cit., chap. xI; Maudsley, Pliys. of Mind, chap. virI ; also M. A. Starr in McCosh's Cog. Porkers, p. 201.

${ }^{2}$ Yiclosh, ibid., p. 196.

${ }^{3}$ See p. 275.

${ }^{4}$ So Berkeley, Mill, Hamilton : cf. Drobisch, Psych., pp. 56 and 102, and his quotation from Tiedemann. 
ined, to result from a succession of images of particulars, presented in quick succession, and then discarded as having too great intension. ${ }^{1}$ There is a distinct feeling of the inadequacy of each image in turn, and this feeling persists in the final representation. As Lotze says," "We feel that any other color has an equal right to serve," as that which we picture for the general concept of color. This vague outline takes its particular features from the individuals to which we have given most attention or from the properties which, from experience, we have come to consider essential. The effect of attention, also, is to bring out strongly certain properties in the concept to the neglect of others, as Mill well shows."

In the case of the more abstract notions, however, it is very doubtful whether we proceed by any actual picture of the real meaning; as in the concepts, virtue, and gratitude. Yet the image of the printed word often takes the place of such a picture. In rapid discourse, also, we seem to use the words for what they themselves convey, without further imaging. There is no reason that the mere auditory image of a word should not answer the purposes of the concept as well as the visual image.

Relation of Conception to External Reality. From what has been said, the degree and kind of reference which the concept has to reality, is apparent. 'The concepts are constructed throngh the discernment and mental construction of " intelligible relations" " between percepts ; which percepts, though themselves also mental constructions, correspond to real objective things. Percepts are reconstructions of reality, intuitions. Con-

1 So Hume, Treatise on Hum. Nat., p. 34.

Iogik, p. 31.

\& Extrm. of Hamilton.

- Mansel. 
sequently the concept has an immediate reference to reality in the percepts whose intelligible relations it sums up. Every concept asserts : 1. A plurality of percepts, which assure us of the existence of cne or more objects or events in space or time, and 2. The perception of certain intensive relations between these percepts, which assure us that the same relations are objective. Of any reality further than this, that is of a real objective thing which answers to the conceptual ideal, we have no assurance, either in psychological necessity or objective experience.

In the second of these "assurances," we find the use of the concept as type, in the mind and in nature. Inasmuch as the qualities of the general notion are only those which belong to each member of the class, the concept becomes the type of pure class intension. It is never realized in nature, since the concreting of it makes it subject to the accidental properties of reality. When a single thing is taken as type, it is with the understanding that it is subject to the revision and criticism which we have found all individual images, serving in this capacity, to be subject.

We are here at the heart of the controversy which has given rise to logical Realism, Nominalism, and Conceptualism.' Realists hold that there is an archtypal reality corresponding to the general notion; this doctrine is seen in its purest phase in Plato's idea. Nominalists hold that the general notion has no reality except in individuals, and no mental form other than the individual image : "general notions are only particular ones considered in a certain light." " Conceptualists maintain that the general notion is a mental construction apart from individual percepts, and has reality as such. It is distinct both from the externally real, and from the verbally, or representatively, nominal. Upon

${ }^{1}$ On this great discussion, see Hamilion, Lectures on Metaphy., xxxv; Porter, Hum. Int., part 3, chaps. II and Iv; also references at the end of this chapter.

${ }^{2}$ Hume, Treatise, I, 1, §7. 
this controversy, we may say, in general, that Realism is right in saying: $a$. That there is a real type more or less approached in each individual; and $b$. That the general notion arises from relations of resemblance which are real. On the other hand, Nominalism is right in saying: $a$. That the general notion is a name which has no external reality except that of individual things; $b$. That it proceeds by the use of individual images; and $c$. That words are its peculiar expression. But Conceptualism covers all these partial truths in saying: $a$. That the general notion is a real mental product arising from observation of real relations and itself constituting the type to which individuals more or less closely approach ; $b$. That these relations are thought relations as well as real relations; $c$. That the individual image is itself a thought product; and $\vec{d}$. That words must have a thought significance, otherwise they are a mere afflutus vocis. ${ }^{1}$

Unity of the Concept. Development of Idea of Identity. The unity of the concept is, therefore, an ideal unity, a unity of product rather than of its material or objectire realization. There is no process of conceptual intuition of sense as there is of perceptual intuition of sense; consequently, no external unity, to serve as confirmation and rectification of the concept. But, on the other hand, the fact of internal or logical unity, with the safeguards of reality spoken of above, gives the concept a clear distinction from the constructions of imagination. In the case of the latter, there is a mechanical combination with no necessary or rational unity: here there is a mental growth, guided by the laws of apperceptive synthesis. We, therefore, find an ideal product of conceptual synthesis, which is one with the ideal product of perceptual synthesis: the idea of synthetic unity. 'The idea is tlie same, because the essential apperceptive process is the

I The student should distinguish carefully between logical and phito. sophical Realism : the latter being the doctrine that the external world, as given in perception, is real. It has no necessary connection with this discussion.

See p. 140. 
same; the value of the two mental states varies in their different relations to reality. Perceptual unity is intuitional as well as synthetic, and conceptual unity is only synthetic.

In conception, the idea of identity found in the function of recoguition,' receives further development. By the principle of identity, the synthesis in abstraction is carried forward, new intensive marks being gathered into the unity of the concept: generalization is a process of identifying. And in the analytic abstraction of the conception, the principle later called non-contradiction, is asserted through the impossible conjunction of inconsistent attributes. Through conception, the unapprehended identity of memory, and the unconscious law of contradiction, which leads to the detection of illusions, ${ }^{2}$ find conscious application in the thought process.

Belief in the Reality of the Concept. The reality of the concept, as already explained, is a belief-reality; that is, the concept is asserted to be true in view of the mental tendency to believe in it. But inasmuch as the percepinal data of abstraction are themselves subject to illusion, the concept is even more so. The predisposition to believe all the states of mind here leads us into constant error, since we are apt to take the last stage attained in the development of the concept to be the whole truth. It is only after we have learned the shifting nature of our notions, both as regards intension and extension, through their continued modification, that we exercise more reserve and distrust. For this reason, the intellectual caution of mature age is contrasted with the haste and frequent error of younger life.

The distinction between concepts to which belief is attached and those which do not call it forth, is clearly illustrated in 
the Stoic doctrine of conception. Chrysippus used the phrase

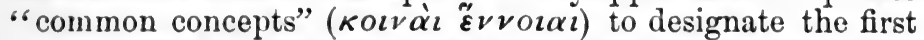
rough draughts of abstraction from the data of perception. As these are subjected to more exact definition and inspection (in science), some of them carry necessarily with them our intellectual assent, or belief in their reality. It is in this assent that conception proper ( $\kappa \alpha \tau \dot{\alpha} \lambda \eta \| l_{5}-Z$ Zno) takes its rise. This " conceptual presentation" ( $\phi \alpha \nu \tau \alpha \sigma i \alpha \kappa \alpha \tau \alpha \lambda \eta \pi \tau \imath \kappa \eta)$ ) carries with it a feeling, or consciousness, of its agreement with its object. ${ }^{\prime}$

\section{§ 3. JUDGMENT.}

Its Nature. The second great stage in the formal development of the thought function is judgment. In the judgment, the discovery and assertion of relations between mental states and, through them, between the things they represent, becomes thoroughly free and conscious. It proceeds fundamentally upon the basis of conception, for its elements are concepts in different stages of growth. In its broadest definition, therefore, Judgment is the mental assertion of the degree of relationship arrived at in some one stage of the process of conception.

This will be illustrated in some detail in the treatment of the kinds of judgment: ${ }^{2}$ it suffices here to give a general example. John is a man, is a judgment. It asserts that the general concept man has reached that stage of development in extension or generalization that it includes the single concept John : or, to express the same relation conversely, this judgment asserts that the single concept John has reached such a stage of development in inteusion that its essential attributes are those of the general concept man. That is, by a psychological assertion, the qualities of the concept man are passed over to the concept John, as a new increment to its in-

'CR. Zeller, Greck Philosophy (Holt, N. Y.), pp. 235-6.

\&5, below. 
tension. The expression of identity between the two, therefore, is merely the sign of this mental movement. Calling the sum of the intensive marks already gathered up in the logical subject, $a$, and the marks now added by the judgmental assertion, $b$, the psychological formula of judgment becomes,

$$
a \text { is }(=) a b .^{1}
$$

Law of Identity. The sign (=), in this formula, is used as equivalent to the copula is; since, in the categorical judgment, the fact of identity already found inherent in the concept, becomes a conscious principle of reasoning, in the form of the Law of Identity or Non-contradiction. The formula exhibits the constant endeavor of the mind to attain truth by the law of identity. In the first member of the equation of identity, $a$ means the reality denoted by the concept, in the second member $a$ denotes the former concept of this reality; $b$ denotes the addition which this former concept must undergo to be true to, or identical with, the new experience of $a$. As Lotze ${ }^{2}$ points out, the act of judging takes place only after this new experience, so the subject is also modified, and the law of identity vindicated. Expressed in language, a judgment is called a Proposition.

The contrast-as in the treatment of conception-between this account of judgment and the definition of the formal logics, i.e., "judgment is the assertion of agreement and disagreement between notions," is sufficiently great. The latter definition answers the purposes of the traditional logic, but gives no insight into the psychological genesis of judgment. And even from a logical point of view, it seems to be insufficient, in that it reduces all the relations to one, resemblance. This will be spoken of later.

1 Cf. Lotze, Logik, $\$ \S 52-55$, and Bradley, Princ. of Logic, pp. 25-27 and 29; also Jevons, Principles of Science, pp. 49-50.

2 Loc. cit., $\$ 58$. 
Unity of the Judgment. We are led by the above to see that the essential content of judgment is not two notions at all, but one, a notion of relation. The relation, as one, is itself a notion and a mental unit, being the product of the judging activity, however true it is that its data, when considered apart from judgment, are themselves mental units. This is readily shown by throwing the judgmental product into the form of the modified notion $a b$ above. For example, the judgment, the dog is fierce, considered psychologically, amounts to the adding of the quality fierce, $b$, to the marks of dog, $a$, and the product, $a b$, is the single concept, fierce dog. Under this aspect, it corresponds to the real object, which is one. As far as the content is concerned, the judgment is not distinguished either from the presentation or the concept: ${ }^{1}$ they are all different stages in the progressive growth of apperception. This unity of the judgment, as a mental product, is further seen ${ }^{2}$ in simple judgments of existence, i.e. giants exist; where the logical predicate is not an attribute or mark, but simply expresses the fundamental assumption of all judgment, belief in reality. This unitary aspect of judgment brings prominently into view its justification as a great example of the synthetic activity of apperception. The essential feature of judgment, in contrast with conception, is therefore this, that it sets forth in a conscious contemplative way the actual stage of the thought movement. It brings out and emphasizes the belief which we found immanent in the concept in its progressive stages. In the generalizing of the concept, this belief was present, as each new percept was brought within its range: and in the judgment each such act of esoteric belief becomes explicit, John is a man, James is a man, etc. Belief is

1 See Brentano, Psychologie, r. p. 272.

Ibid., p. 276. 
therefore necessary to judgment, and constitutes its distinguishing mark. It is here, in its belief force, rather than in its content, that judgment is a distinct mental act. This belief is an immediate reference to reality in all cases, whether it be justified by fact or not; that is, to some reality apart from the law of its own inherent process. It may be reality in the external world (horses are quadrupeds), reality in literature (Dinah Morris is a Christian), reality in legend (mermaids sing), or reality in the mind (sensations are affective states). In all these cases, there is the assertion of a truth, a reality, a relational consistency of concepts, which is believed to be valid universally in the legitimate sphere of its assertion, whether nature, literature, or the mind. We shall revert to this more fully in discussing categorical and hypothetical judgments.

The doctrine that all knowledge is judgment (Wundt) seems to find both its explanation and its answer in the distinction between judgment and presentation, on the ground of belief. If by judgment we mean simple intellectual assent, the recognition of data, as when I discover the resemblance between a new perception and a reproduced image, or the fact of spiritual synthesis wherever found (Laurie), then its distinction from knowledge is done away; but we, then, must find some other term for the case of the conscious assertion of the movement of assent, as when I pronounce the new percept the man I saw yesterday. This latter is true judgment: and the distinction is further supported by the fact already stated, that in ordinary experience in consciousness, belief is so natural and, so to speak, naïve, that it is quite lost in the knowledge aspect, the presentative value of the experience. It is only when there is some logical or useful reason for assertion, that the belief becomes a matter of consciousness at all, and judgment takes place.

In regard to the nature of this primitive belief, it is not our purpose here to inquire, except so far as to indicate the futility of empirical solutions. As to the association theory (James Mill, Spencer), it is sufficiently refuted by a member of the empirical school (J. S. Mill). Mr. Bain's doctrine that belief consists in "motive influence" is thoroughly met by 
Mr. Bradley, ${ }^{1}$ following Brentano. ${ }^{2}$ Psychologically, the position of Stuart Mill seems impregnable, that "the distinction (between a reproduction simple and an assertion of reality) is ultimate and primordial."

Parts of the Proposition. The expressed judgment, or proposition, may be said to be made up of three parts or terms : the subject, that conception of which the relation in question is asserted ; the preciicate, that concept which is asserted to bear this relation to the subject; and the copula, that concept which expresses the kind of relation asserted between subject and predicate. In the judgment, Napoleon conquered Europe, these three parts are seen in the usual order, subject, copula, predicate.

The copula serves, in connecting the subject and predicate, to express any relation which the mind, in its apperceiving function, is capable of discovering between concepts : and in virtue of the possibilities of language, any relation between things which can be a subject of human knowledge. The method of this connection is directly asserted. Hence the reduction of all the possible relations of the judgment to one, resemblance, or identity, is both psychologically vicious and logically arbitrary, and the verbal means of resort to accomplish it, are evidence of its untruth. Napoleon conquered Europe, becomes for logical treatment, Napoleon is one of those who conquered Europe. That is, the relation clearly expressed between Napoleon and Europe is changed into another between Napoleon and other generals (those who conquered Europe): and the entire psychological

Loc. cit. p. 19.

2 Loc. cit. p. 268.

- Note on James Mill's Analysis of the Phenom. of the Human Mind, 1. p. 412. Cf. foregoing positions of the present work. That the distinction is not due to different degrees of vividness or liveliness (Hume) in the meutal state, is too apparent to need contradiction.

- So the formal logicians, from Aristotle down. 
meaning of the copula, as the expression of a given relation, is perverted. Whatever may be the necessities of the Aristotelian logic in this regard, the true psychological bearing of the judgment should not be lost sight of. Its character, as the assertion of the varied products of the conscious manifestation of the most essential process of the inner life, should remain clearly before us. ${ }^{1}$ The content of judgment is the apperceptive construction of relations, in all their variety; its reference to reality is its differentia. Neither the content nor the differentia can be disregarded.

\section{\$4. Possible Relations asserted in Judgment.}

The Predicaments. Assuming thus that the judgment is the sufficient vehicle of all assertion, we are led to ask, what are the general relations or kinds of predication which the mind asserts among the objects of its conception. These relations considered in their widest generality are called Predicaments, ${ }^{2}$ or predicates. $^{3}$ There are two methods by which we may arrive at a classification of the predicaments ; ${ }^{4}$ first, by an actual empirical enumeration of the meanings of sentences, and second, by the use of a classification of namable things-the process of naming having reference to the qualities which may be made the matter of predication.

This problem is an old one, as many suppose that Aristotle had it in mind in enumerating his categories. It is probable,

1 With this position. Sidgwick, Spencer (Psych., sect. 6, ch. viII), and Wundt (Logik, I. pp. 53 and 170) are in full sympathy, even from the standpoint of pure logic. When a piece of interpretation is so wide of its true mental foundation, it is to be strongly suspected, even though, through the flexibility of language, it can be made self-consistent. Sidgwick would properly generalize the copula by employing some such sign as $\longrightarrow$ to express simply the fact of relation.
Mill.
3 Bain.
+ Cf. Bain, Logic, p. 102. 
however, that his purpose was metaphysical, rather than logical: the enumeration of the kinds of reality which can be asserted of things, in opposition to Plato's doctrine that reality dwelt only in the "idea." But these kinds of reality must coincide with the general forms of predication, and his categories may be considered a rough classification of the predicaments. His categories are, substance, quantity, quality,

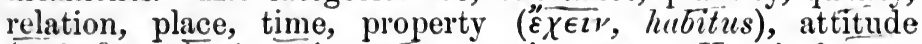
$(\kappa \in \hat{\imath} \sigma \theta \alpha \imath$, situs $)$, active state, passive state. Kant's famous table of categories has an entirely different end in view, although he criticises Aristotle from the standpoint of his own problem: ${ }^{1}$ the enumeration of the à priori forms of the reason. Other classifications are Mill's-existence, coexistence, succession, resemblance, causation ; ${ }^{2}$ Bain's-coexistence, succession, quantity ; McCosh's-identity, comprehension, resemblance, space, time, quantity, active property, causation."

Psychological Predicaments. Proceeding to the classification with reference first to mind and body taken together, and then separately, we have the following classes of relations, which are purely psychological.

I. Universal Predicaments : relations which can be asserted of either mind or body.

1. Coexistence..... $\left\{\begin{array}{l}\text { time } \\ \text { coinherence (Mill, Bain) }\end{array}\right.$

2. Succession..... $\left\{\begin{array}{l}\text { time. } \\ \text { space (as mediated through time) }\end{array}\right.$

3. Subordination..$\left\{\begin{array}{l}\text { genus and species } \\ \text { essence and property } \\ \text { whole and parts } \\ \text { quantity } \\ \text { proportion (beauty) }\end{array}\right.$

4. Resemblance .... \{ $\begin{aligned} & \text { resemblance } \\ & \text { identity } \\ & \text { difference }\end{aligned}$

5. Causation.........cause and effect

6. Design..........utility (Wundt,' Herbart, Ward)

' Kritik d. R. V., Erdmann, p. 99.

2 Logic, p. 823.

8 Logic, p. 6.56.
- Cognitive Poscers, p. 15.

- McCosh's Comprehension.

- Loc. cit., 11. 302. 
Upon this classincation, it may be remarked that Subordination, as including quantity, cannot be reduced to Resemblance, with Mill, nor can Resemblance be reduced to Quantity, with Bain : also that Identity is made a case of complete Resemblance, and that Existence, while truly a predicament,' is still, as Bain claims, a necessary presupposition of all predication-a belief postulateand cannot be included strictly in the psychological predicaments.

II. Object Predicaments: relations asserted of body only.

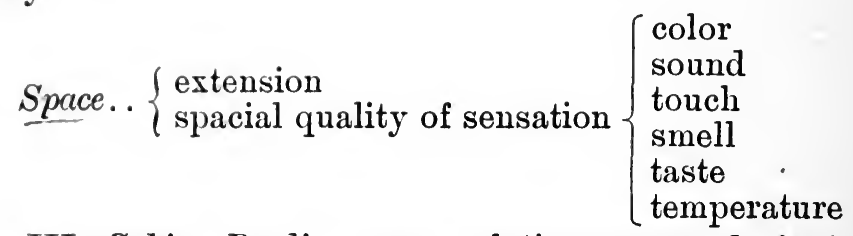

III. Subject Predicaments: relations asserted of mind only.

1. Feeling .. $\left\{\begin{array}{l}\text { sensation (affective) } \\ \text { emotion }\end{array}\right.$

2. Intellect..... strong and weak

3. Will .... \{ $\begin{aligned} & \text { strong and weak } \\ & \text { good and evil }\end{aligned}$

IV. Subject-Object Predicament : relations asserted of mind and body taken together.

Knowledge-the conscious psychological relation of subject-object.

Knowledge is a psychological predicament only to the developed self-consciousness. It assumes the differentiation of self and the object, and the direct consciousness of the relation sustained in the act of knowledge. The assertion of this relation gives us a judgment under this predicament.

${ }^{1}$ Locke, Essay, bk. 4. 
Metaphysical Predicaments. As has been said abore, the common judgments of existence, while truly cases of direct predication, proceed upon the fundamental postulate of belief or trust in the validity of knowledge. They transcend, therefore, the determinations of the psychological processes and rest in the ultimate nature of things. The problem of existence is a metaphysical problem. The same may be said also of the relation of subject-object, when viewed in its absoluteness. The knowledge relation exists before the reflective consciousness apprehends it, and its psychological assertion is accidental to its reality. Hence we have two metaphysical predicaments.

1. Being-transcendental relations of existence.

2. Knouledge-absolute relation of subject and object.

To these two general classes of relations, correspond the two great departments of metaphysics, Ontology and Gnosiology.

On this general scheme, it may be remarked, in addition to what has been said, first, that in making existence a metaphysical predicate, Bain is supported against Mill's insertion of existence in the universal predicaments, and it further disposes properly of existence, as Bain fails to do.' Second, the treatment of knowledge as belonging in both classes aroids the ambiguity it sustains in the usual classifications. The results of our analysis may be stated in the following table:

Predicaments.

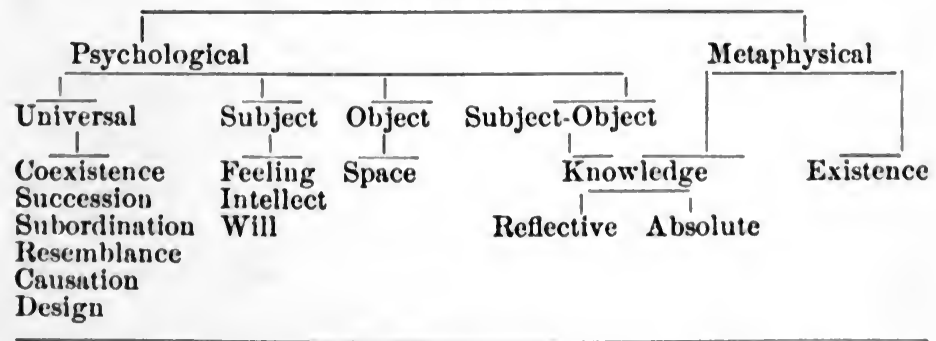

I On the controversy as to whether existence is a real predicate at all, that is, whether the existential judgment has more than one term, see below, §5, pp. 293 and 298. 


\section{§5. Kinds of JudgMent.}

I. According to Intension. Judgments may be considered in their internal intensive structure as being of two kinds: Analytic and Synthetic. Psychologically, these aspects of the judgment indicate different stages in the intensive development of the concept. The analytic judgment consists in an expansion of the subject in an assertion whose predicate has been before included in the intensive marks of the subject. For example, trees have trunks, is an analytic judgment, since the intensive complex represented by the word trunk is a necessary part of concept tree, and its assertion is merely an expansion of that concept. This form of judgment, therefore, represents the development of the concept in the stage of abstraction called above analysis. The vague first-notion tends toward definition and differentiation, by the dropping of accidental inariss, and the confirmation and assertion of those found to be essential. The synthetic judgment, on the other hand, is the product of the building up or synthetic process of abstraction. It asserts predicates before undiscovered, or unincluded in the notion as before made up. For example, cows are ruminating animals, is a synthetic judgment. The quality of rumination is added to the notion cow, as a mark. The addition of marks thus tends to the wider development of concepts, and by it the range of the analytic process is extended : for the fixing of additional marks adds additional predicates. Thus synthetic judgments are constantly passing into analytic. To the naturalist, the ruminating quality is essential to the notion cow, and the judgment which asserts it is analytic.

This distinction may be viewed also from the side of extension, the predicate sustaining the relation of classsubordination to the subject. 
The interpretation of negative judgments further illustrates the psychological ground of the distinction between srnthetic and analytic predications. A negative analytic judgment, in logic, is impossible, simply from the fact that that which is denied of the subject cannot result from an analysis of it: thus the proposition, birds are not parts of trees, cannot be called analytic, for the reason that the finished concept tree excludes the finished concept bird and no analysis of the notion tree takes place. Yet a negative analytic judgment, is possible, looked at from the side of the psychological movement. It is by the analysis of our concepts, that the accidental is discovered and rejected by negation. For example, the child first observes trees with birds, and it is only after he has seen the trees without birds that he can rectify his notion tree, by depriving it of the quality of the growth birds. In this case, the very origin of the negation is found in the necessity of an analysis and rectification of the notion tree.

The negation of a synthesis-which covers all negative judgments in logic-answers to the psychological process, also, in all cases except those mentioned above, in which the negation expresses the result of an analysis.

The continuous growth of concepts, through the formation of successive synthetic judgments, is seen in the process of clucation. 'The pupil's conception of the thing in hand is enriched by all the predicates of his instructor's knowledge.

II. According to Belief': 1. Categorical Judgments. The simplest form of mental assertion, in which an affirmation or negation is made, is the categorical judgment. As has been seen, it is the typical form of the conceptual process, since it is the.result of an instinctive belief in the truth of the processes of mind.

a. Simple Categorical: the ordinary synthetic and analy tic judgments already spoken of.

b. The Existential Judgment rests upon a deeper mental movement than either analysis or synthesis, and represents the assertion of belief, already spoken of as the differentia of judgment, under a more limited form. It goes beyond belief in the consistency and adequacy of concepts and their relations, that is, beyond the real

This principle of classicication, advanced in $m y$ tirst edition, has been since hiuted, by Mr. Venu, Emp. Logic, pp. 243-250. 
reference which all judgment supposes, and attaches itself to belief in the external reality, in nature, of what the concepts represent. We here pass from the assertion of truth for the mind to the assertion of truth for itself; from the assertion of truth, to the assertion of fact; from the judgment, the moon causes lunacy, which is true in tradition, for the mind, to the judgment, the moon exists, which is true in fact, for itself.

Law of Sufficient Reason. Not only is the existential judgment a deeper mental movement, but it is often a more discursive movement. While it brings out only the natural tendency to believe in the facts of mind, it supposes some question aroused, and its refutation, through what we call evidence. There is no psychological meaning in the judgment mermaids exist-whatever the logical necessity for the statement be,-unless I have some reason to doubt their existence. The judgment rests therefore upon the removal of this doubt by evidence. Here we are brought face to face with the conscious working of a great law of the reason, which has already appeared in its unapprehended force, regulating and making consistent the content of representation, i.e. the law of Sufficient Reason. In the judgment of existence, the ground or reason for the first time becomes intelligent, as itself a notion, and a notion of that which gives validity to the unified products of its perceptual and conceptual syntheses. We have found the idea of synthetic unity arising from perceptual synthesis, with a confirming reference to reality as unity; the same idea further brought out and idealized in its content by conceptual synthesis, without this means of confirmation, but with other conceptual safeguards in the general operations of thought.' The reference to reality, in the one case, and the external removal of doubt, in the other, both

${ }^{1}$ See p. 281. 
afford, in the two processes, sufficient reason for the instinctive movements of belief.

c. The Disjunctive Judgment is a form of categorical statement, in which a disjunction, or assertion of alternatives, expresses the belief value of the underlying reason. That is, the ground of the statement is of such a nature, that more than a single relation among the concepts involved may be possible. The assertion, therefore, has reference to all these possible cases. ${ }^{2}$ For example, this man is either a minister or a lawyer, is a disjunctive judgment, the reason of its assertion being adequate to either conclusion, say the dress, manner, conversation, of the person involved. Further search, or clearer definition of the ground of the assertion, eliminates some of these alternatives, and the judgment takes the regular categorical form.

2. Hypothetical Judgments. The hypothetical judgment stands, with reference to belief, midway between the ordinary assertion of the analytic and synthetic judgments, and that of the existential. The two kinds of intensive judgments mentioned express only belief in the truth of the conceptual relations brought out in analysis or synthesis; the existential judgment expresses only belief in a reality corresponding to the conceptual product: but the hypothetical judgment has reference to both these phases of belief. In the hypothetical, the ground or sufficient reason is cited, as the mental condition upon which belief in the stated relation goes out. For example, the statement, If the morals of the people are corrupt, the Republic will not live, is a hypothetical judgment. 'The belief in the proposition (synthetic) the Republic will not live, rests upon the belief (existential) in the proposition the morals of the people are corrupt. The failure of this

'In the words of Venn, the hypothetical simply "widens the reference" (Eimpirical Logic, pp. 246-i). 
belief, in the sufficient reason, or antecedent, removes the ground of belief in the result, or consequent, and the mind is left in a state of uncertainty as to the truth of the cousequent.

Relation of these Forms to One Another. The distinction between judgment and proposition should be carefully observed in weighing the preceding classification. The forms of judgment are by no means correctly expressed in the corresponding propositions. The categorical proposition has a much wider range than the categorical judgment, including a large class of judgments which are distinctly hypothetical. All incomplete inductive propositions, as earthquakes are of volcanic origin, represent hypothetical judgments. The reason of their assertion includes the conditional experience of future cases. Further, all particular synthetic propositions, as some men are poets, carry the hypothesis that the some spoken of be the some of actual fact-a hypothesis which is present in the psychological act. In the last statement, we have a general test of a categorical proposition. Does its assertion include any mental condition or reservation, whose non-fulfilment prevents the judgment? If so, the judgment is hypothetical.

We have not space to discuss the very important question, are all categorical propositions hypothetical ? Herbart ${ }^{1}$ holds that they are, resting the proof on the general hypothesis of existence, which categorical statements involve. This is true; yet this hypothesis, as has been seen, constitutes the differentia of all judgment, categorical and hypothetical alike, and underlies the validity of all knowledge. It is a primary movement of belief, and comes into consciousness neither in the categorical proper nor the hypothetical, and cannot be legitimately used as a point of distinction between them. Drobisch, ${ }^{2}$ who writes from the Herbartian standpoint, admits this. The further limitation ${ }^{3}$ of categorical judgments to singular proposi-

${ }^{1}$ Werke, I. 92.

${ }^{2}$ Logik, \$49.

${ }^{3}$ Bradley, loc. cit., book 1, chap Ir. 
tions overlooks : $a$. Universals which carry their own universality, intuitions which are valid for psychology whatever ontology may do with them; and $b$. Abstract analytic propositions, as yold is yellow, which are true independent of factual existence. 'The further denial of categorical force to the singular analytic proposition, this book is red, from a " higher analysis," is false ; since the psychological growth of this judgment does warrant " the common and most ruinous superstition" that Mr. Bradley ${ }^{2}$ condemns, i.e. that "analysis is no alteration and we have to do with divisible existence in this case." The percept is a synthetic product whose elements exist as differentiated experiences in consciousness, apart from their particular synthesis ; and the analysis is simply the assertion of a given stage in the complexity of perception. And we do not separate the quality apart from the whole in existence, but only in thought. That is to say, the singular analytic judgment is categorical, though not existential; it expresses truth, but not, as far as we know, fact.

The same distinction between proposition and judgment must also be borne in mind in considering the hypothetical judgment. The underlying mental movement, in cases of conditional statement, may be either categorical or hypothetical. Every hypothetical proposition may have a categorical meaning. It may carry the assertion of a background or quality which makes the conditional dependence possible." For example, in the statement, If the morals of the people are corrupt, the Republic will not live, I assert categorically my belief in a certain quality or character as belonging to republics; the simple fact of the fulfilment or non-fulfilment of the condition, in a particular case, being disregarded. On the other hand, in the statement, If you are wet, you will catch cold, the meaning is a simple condition with, ordinarily, no categorical reference. From the standpoint of judgment, simply, this last sentence is hypothetical. The ordinary method of the logies, of reducing hypothetical to

' Cf. Hosunquet, Knonoledge and Reality, p. 84.

- Lac. cil. p. 95.

3 Bradley, loc. cit. p. 87. 
categorical statements, shows the flexibility of language in propositions, but has no meaning whatever for the judgment. To change the statement, if there be a drought, the grass will die, to this, the cases of drought are cases of the grass dying, is not to change the conditional nature of the judgment one whit. It amounts to saying, given cases, or if there be cases. Either the resulting judgment remains conditional in force, or it is not equivalent to the original.

The true relation of the two kinds of judgment is therefore one of coördination. While many categorical statements are psychologically hypothetical, and many conditional statements are psychologically categorical, still there remains a pure type of each, which cannot be resolved into the other. In the words of Drobisch, "it follows as little that the categorical can be derived from the hypothetical as the reverse. The two forms express essentially different meanings." 1

The existential is the purest type of categorical judgment, since the notion existence is here a true predicate. ${ }^{2}$ It is only after reflection and questioning upon the primitive belief in reality, that the mind goes out in its positive assertion. There is here, therefore, an added fact, a becoming conscious of the reality of the concept, which is not taken into account by the theory which denies true predicative force to the existential judgment." 'The is of the existential judgment there is such a thing as virtue, expresses more than the is of the ordinary categorical, virtue is praiseworthy. The former is has a reference to fact which the latter has not. This becomes evident in the attempt to reduce all categoricals to the existential form. The judgment a man is sick is not equiv-

1 Logik, §49.

2 Venn; see also Sigwart, Logik, pp. 73-75.

${ }^{3}$ Herbart, Brentano, Trendelenberg. 
alent to there is a sick man.' The former may be true in fiction, tradition, mythology : the latter is true in fact. ${ }^{3}$

The disjunctive judgment has, in addition to the categorical statement of belief, by which we have classified it, also a hypothetical reference. The categorical assertion extends only, to the entire disjunction, and rests suspended in reference to the single alternatives, the ground of the alternatives not being called in question. There is, however, a direct mental tendency to further assertion, by the erection of one of the alternatives into an hypothesis, when the judgment takes on a distinctly hypothetical form. It is this hypothetical bearing of the disjunction that gives ground for the laws of inference from the disjunctive judgment. Its proper classification as categorical is seen, however, in the disjunctive force of the abstract universal judgment, bodies are colored, which may be written in disjunctive form, by supplying the real disjunction which the predicate leaves in the mind, bodies are either red, or blue, or green, etc.

\section{§ 6. Reasoning.}

Its Nature and Kinds. The consummation of the elaborating activity of mind is reached in Reasoning. Reasoning has already been mentioned as the highest form of the uniting and relating power of apperception, which makes possible perception, conception, and judgment. The function being the same mentally as that already seen in the two preceding stages of the thought process, we look for the differencing peculiarity in the content, the data between which these apperceptive relations are mentally reconstructed. In respect to content or data, we have arisen from the sensation to the synthetic percept, from the percept to the concept and

'The same is true of Brentano's other examples, loc. cit p. 283.

'So Kant, Mill, and the Port Rnyal Logic. 
the judgment: we now deal with judgments, building them into processes which in their logical statement take a twofold form, called Deduction and Induction. The nature and essential function of these two forms of reasoning may be briefly spoken of.

I. Deduction: the Syllogism. Psychologically, the syllogism may be defined as, The apperceptive act whereby a relation is asserted between two concepts in consequence of the previous assertion of the same relation between each of these two concepts and a third.

The parts of the syllogism thus brought out are designated as follows: the two relations first asserted are called premises, major and minor ; the two concepts between which the resulting relation is asserted, terms, major and minor, and the concept to which they sustain respectively the relations of the premises, the middle term : the resulting judgment is further called the conclusion. For example :

Major premise-All men are liable to error.

Minor premise-The president is a man.

Conclusion-The president is liable to error.

Major term-Quality of being liable to error.

Minor term-The president.

Middle term-Man.

From this definition, it appears that the unit of syllogistic construction is the judgment, although in logic the whole process is a matter of the comparison of concepts by means of the middle term. It is by the judgment, as a psychological movement, that both the major and minor terms are related to the middle term in the premises, and it is by the judgment that their relation to each other is made clear in the conclusion.

The fact that the product of the reasoning process is the judgment, shows further that the mental act is the 
same as in conception; that is, that there is not a further mental synthesis, in kind. The function of reasoning is the multiplication and transformation of judgments, not the derivation of new mental forms, nor the building up of new ideal products. Reasoning is, therefore, a process of enrichment of our mental stores, through the going out of belief, over a wider range of fact, and into deeper penetration of its meaning. The implications of former beliefs, which were vague or dimly apprehended, are unfolded, conceptions remote and disconnected are brought into the general harmony of inner truth, in relations before quite unremarked. Truth is widened, knowledge is systematized, details are concatenated, and the most essential self-realization of mind is forwarded and made actual.

Conceptual Interpretation of the Syllogism. We may further define the syllogism in such a way as to show the growth of the concept in it, remembering, what has been said as to the unity of the judgment: Syllogism is the apperceptive act whereby we reach a new stage in the grouth of a concept, in consequence of its twofold modification in the judgment.

As the former definition looks at the syllogism from the side of its expression, this looks at it from the side of its conceptual meaning. Its apparent strangeness ranishes as soon as we refer the syllogism to the doctrine of conception.

We have seen that the product of judgment is only the concept, of which predication is made, modified by the addition of new marks : $a$ becomes $a b$. Thus arises the major premise. In the minor premise the concept $a b$, or middle term, is further modified by the addition of $c$, minor term; that is, $a b$ becomes abc. The conclusion is then simply the statement of the result, that $a$ has tecome abc: 


$$
\begin{aligned}
& a \text { is (=)ab; } \\
& a b \text { is (=) } a b c ; \\
& \text { hence } a \text { is (=) } a b c . \\
& \text { John is (John) man; } \\
& \text { (John) man is (John man) mortal; } \\
& \text { hence John is (John man) mortal. }
\end{aligned}
$$

This simply means that the reality John requires that $I$ add to my notion John, the marks of man, and the marks of man further carry with them the mark mortality. So that my concept John must hereafter carry with it the marks of man including the mark mortality. The process exhibits again the striving of the mind to preserve the identity of conceptions through new experience. ${ }^{1}$

Meaning of the Premises: Kinds of Syllogism. This general view of the syllogism enables us to see at once the meaning of the premises in reference to the resulting judgment. Taken together, they constitute the sufficient reason upon which the movement of belief depends. Stated in the above form, they go to make up a Categorical Syllogism. But the truth of the conclusion depends upon, or is conditioned upon, the truth of the premises ; in other words, we believe the former because we believe the latter. Consequently, the threefold assertion of the syllogism may be put in the shape of a complex conditional proposition, the antecedent (reason) being a double assertion, and the consequent (result) being a single assertion, in respect to two of the foregoing concepts. Thus the above syllogism is the conditional judgment: If all men are liable to error and the president is a man, the president is liable to error. But, beyond this statement of reason in the premises, there is in the syllogism given, also, an implied belief in 
the truth both of the reason and the conclusion. In actual thought, the premises themselves rest upon sufficient ground and so are believed. Consequently we may have a direct statement of belief in the truth of the premises: "All men are liable to error and the president is a man." Now we may combine these two latter expressions of belief in a new form, the Hypothetical Syllogism, as follows :

Major premise-If all men are liable to error and the president is a man, the president is liable to error.

Minor premise-But all men are liable to error and the president is a man.

Conclusion- Hence the president is liable to error.

The hypothetical syllogism, therefore, arises from the supplying of the movement of belief hidden in the categorical syllogism, just as we found the hypothetical judgment to arise from the statement of the ground of belief in the categorical judgment. The categorical syllogism precedes the hypothetical, for the reason that belief precedes its conscious grounding; but, for the reason that belief is present in the categorical as an hypothesis, whose removal invalidates the conclusion, we claim that, in conscious thinking, the hypothetical is the more profound and fundamental form.

As compared with this natural reduction of the categorical to the hypothetical syllogism, the methods to accomplish the reverse found in the logics are strained and arbitrary. The reduction of the hypothetical to the categorical is accomplished by another of those ingenuities of language for which the Aristotelian logic is famous. Instead of the hypothetical if, the categorical the case of, the circumstances of, are used, forms of expression categorical enough in form, but as strictly conditional in meaning. It is only necessary to observe the belief attitude of the mind toward the two forms, if it rain, and the case of its raining, to see that there is no difference whatever, and that the real mental hypothesis remains the same as before the reduction. 
Value of the Syllogism. The general value of the syllogism, as an instrument of inference and discovery of new truth, is disputed from the various standpoints of the theory of knowledge. The questions it involves belong to general philosophy, rather than to psychology. Yet we may say that two great views are held, based respectively upon an experiential and an intuitive theory of knowledge. According to the former, ${ }^{1}$ since all knowledge arises from experience and finds its highest certainty in a wide enumeration of instances, the syllogism constructed in extension is a petitio principii. The conclusion is contained in the major premise, and hence adds nothing to our knowledge. I have no right, for example, to say that all men are liable to error, unless I have actually known all men to err, in which case I must have known the president to err, and my conclusion is given in the major premise. Stated in the intensive form of our definition, this objection runs : in stating a relation between the major and middle terms, which shall be true universally of the middle term, I liave already included, in that statement, all of that relation which the middle term is capable of sustaining, i.e. its relation to the minor term: that is, I have made the said relation of the major extend to the minor term.

If we admit the empirical foundation of this theory, it is true that the syllogism has only a confirmatory and illustrative value, as is seen in cases in which the major premise derives its universality from an exhaustive survey of cases. But if knowledge is not all experiential, if universality can be asserted without exhaustive experience, then the theory breaks down. This we believe to be the case in all synthetic judgments which cannot be shown to have been derived from experience, so-called

. Stuart Mill. 
synthetic judgments à priori. ${ }^{1}$ Such a universal in the major premise, with a fact of experience in the minor, leads to a conclusion which is a particular application of the law of the major. For example:

The whole equals the sum of all its parts;

(1) $x, y$, and $z$ are all the parts ;

hence the whole equals the sum of $x, y$, and $z$.

Here the conclusion is an absolnte gain to knowledge, being in no sense given in the universal à priori principle of the major.

In testing syllogisms in this regard, we have only to inquire whether the minor term is already brought into relation to the middle term in the statement of the major premise. If so, the minor premise can be dispensed with altogether, and the conclusion is self-apparent. This can be shown by throwing the syllogism into the hypothetical form described above. Thus, expressed categorically :

All in this room are students;

(2) I am in this room;

hence I am a student.

Expressed hypothetically:

If all in this room are students and $\mathrm{I}$ am in this room, I am a student;

(a) but all in this room are students and $\mathrm{I}$ am in this room;

hence I am a student.

Omitting the original minor premise, I am in this room, from both premises of the hypothetical, we have:

If all in this room are students, $\mathrm{I}$ am a student;

(b) but all in this room are students;

hence I am a student;

a perfectly valid hypothetical syllogism showing the original was a petitio. The reason is seen to be this, that the universal major in (2) was derived from a com-

The expression is from Kant, the doctrine common to intuitive thinkers from Aristotle down. 
plete enumeration of cases. But applying the same test to the former syllogism (1), we reach a very different result. Expressed categorically :

The whole equals the sum of all its parts;

(1) $x, y$, and $z$ are all the parts ;

hence the whole equals the sum of $x, y$, and $z$. Expressed hypothetically :

If the whole equals the sum of all its parts, and $x, y$, and $z$ are all the parts, then the

(a) whole equals the sum of $x, y$, and $z$;

but the whole does equal the sum of all its parts, and $x, y$, and $z$, are all the parts ;

hence the whole equals the sum of $x, y$, and $z$. Now omitting the minor premise of (1), as before, we have:

If the whole equals the sum of all its parts, then the whole equals the sum of $x, y$, and $z$ (invalid);

but the whole equals the sum of all its parts; hence the whole equals the sum of $x, y$, and $z$ (invalid) ;

that is, we have no information whatever about $x, y$, and z. The reason being that the ground of the original major premise is not an enumeration of cases, as in (2), but rational necessity.

Scientific Hypothesis. The psychological reduction of the categorical to the hypothetical syllogism also illustrates, at the same time that it is confirmed by, the use of the Scientific Hypothesis. An hypothesis, in science, is a formal proposition put forth as an explanation of a whole class of phenomena, from its apparent application to a limited number of cases under that class. It is universal in form, but not in meaning; its successful application to new cases, or under new variations, giving it a wider range and higher probability. The universal ma- 
jor premise of a syllogism is often-indeed always, when experiential and not a perfect induction-such an hypothesis, and hence its only true expression is hypothetical. The object of the syllogism is the application of the hypothesis to a new case: the deduction thus made is then tested by actual observation, and the hypothesis in so far confirmed.

The hypothesis, we have said, rests upon actual experience and is derived from it. Experience is, therefore, gathered up, solidified, and universalized in the hypothesis. We are led to ask by what mental process or function this is accomplished: how is experience held together, its meaning rationalized, and made logically available? This leads up to the second great kind of reasoning.

\section{\& \%. INDUCTION.}

II. Induction. What conception does for judgment, in its gathering, epitomizing, and relating activity, this induction does for higher elaboration, or thought. The function of conception in abstraction and generalization is that of defining experience: concepts are definitions, more or less correct, of what is and must be in experience. Its ideal unity is a unity of individual application, and beyond this its synthetic process cannot go. The function of induction, on the contrary, is that of rationalizing experience. It proceeds upon the basis of conception as affording what is and must be in experience, and goes forward to what might and shall be. It is a higher rational generalization of the judgmental relations of concepts. In its very nature as depicting possible relational truth, it is prophetic of future experience, thus tending to universal statement in the hypothesis.' The instinctive movement of belief, which has

"It is the distinguishing characteristic," says De Gerando, "of a lively and vigorous conception, to push its speculative conclusions 
confronted us already in the form of trust in the truth of representations and in the validity of the concept, here also leads us beyond concepts, as the sum of experiences, and tells us what to expect. Its unity also is a temporary and progressive unity, clanging into higher forms, as new experiences are brought under its rationalizing treatment.

This form of expectation, or mental advance into future experience, arises from the rational principles which we have already found in conception, identity and sufficient reason. The principle of identity applies to relational as well as to conceptual truth. The reëstablishment of an identical form of relational states, is recognized as an identical external experience, and the relational concatenation of the first experience, which offered its sufficient reason, is necessarily held to be, when again presented, sufficient reason for the same external experiences again. Upon this law of sufficient reason, in the form of mental expectancy, and its wide justification in experience, is based the principle of the Uniformity of Nature. This law, which expresses the external fact that the same causes invariably produce the same effects, is the rational basis of induction, as the laws of identity and sufficient reason are of deduction. ${ }^{1}$

Relation of Induction and Deduction. The two processes of induction and deduction do not exclude or invalidate each other, but are the united engine of discovery and proof. The first debt of knowledge is to experience, which is taken up in conception, and cast into the rational form of hypothesis or empirical law, by induction. These first stages in the growth of thought give

somewhat beyond their just limits."-Des Signes et l'Art de Penser, Introd.

1 On the nature of induction and its canons, Mill's great contribution to logic, see his Logic, bk. 3. 
us a point of rational elevation for again exploring the varieties of experience, and bringing new classes oi fact under our conquest by deduction. Thus there is a constant action and reaction between the two processes of reasoning: one leading us from the particular to the general, the other from the general back to the particular. And for each such excursion, we are richer in our mental store.

Further, both the processes of reasoning have their basis and guiding rule in the principles of reason spoken of, called in formal logic, Laws of Thought. It is only as experience is brought into conformity with the principles of identity and sufficient reason that it is rationalized and made thinkable in forms of unity, which are true in their special applications to nature. These principles are spoken of more fully in the consideration of the Rational Function.

\section{§ 8. Proof.}

Proof is the inverse process of inference. In the syllogism and in induction, we are given premises, the sufficient reason, to find the conclusion, the result : in proof, on the contrary, we are given a conclusion, or thesis, to find its sufficient reason, or ground. For example, given the thesis the president is liable to error, it is proved by finding the sufficient reason, all men are liable to error and the president is a man. The essential nature of proof, therefore, consists in establishing belief, or giving reality to a thesis.

The adequacy of the ground thus reached is tested by throwing it into the regular forms of reasoning: either deductively, as in a syllogism, concluding to the thesis; or inductively, by raising the thesis to the rank of an hypothesis and concluding to the particular cases under it. Thus the thesis, poets are liable to error, may be proved by this deduction : 
All men are liable to error;

poets are men ;

hence poets are iiable to error;

or inductively, by stating the thesis as hypothesis:

Poets are liable to error ;

Tennyson, Wordsworth, etc., are poets ;

hence Tennyson, etc., are liable to error;

the conclusion being then tested in experience to verify the hypothesis.

Deductive proof alone gives complete certainty, since the ground is some rational or thoroughly established principle. Its province is the proof of singulars, or of subordinate laws. Inductive proof, on the other hand, never reaches absolute conclusiveness, except in perfect inductions, and is of use in establishing general and higher laws. It covers proof by analogy, testimony, circumstantial proof, and other forms. ${ }^{1}$

\section{§ 9. Ideal Product of Thought.}

As a process of relational synthesis, thought brings into clearer light and greater definiteness the ideal products of perception and representation ; since these operations here become self-conscious and rational. We come through thought, also, to the apprehension and statement of the principles of Reason which underlie and regulate all mental movement. The fundamental forms of Reason, as far as they belong to intellect, have already been noted in the foregoing discussion. These are Identity and Sufficient Reason. Their more particular treatment is reserved for the account, in the next chapter, of the Rational Function.

On conception, consult: Porter, Hum. Int., pp. 388-430; McCosh, Logic ; Taine, Intelligence, pt. 1, bk. 1, ch. II-III, and pt. 2, bk. 4, ch. I; George, Psych., p. 499; Waitz, Lehrbuch, § 48; Drobisch,

${ }^{1}$ On proof in general, see Sidgwick's excellent chapter in his Fillacies. 
Iogik, \$ 13-38; Herbart, Lehrbuch, $\$ 179-193$; Fortlage, System d. Psych., § 23; Sigwart, Logik, \$\$ 40-44, 75-78, and 6-8; Lotze, Logic, I, ch. I; Trendelenberg, Logische Untersuchungen, §15; Wundt, Logik, I, pt. 2; Ueberweg, System d. Logic, pt. 2; Strümpel, Grundriss d. Logik, ch. Iv; Mill, Exam. of Hamilton, ch. XviI.

On the relation of conception to language: Muller, Science of Lang.; Whitney, Lang. and Study of Lang.; Porter, Hum. Int., pt. 3, eh. IV: Locke, Essay, bk. 3; Calderwood, Mind and Brain, ch. x; Lotze, Microkosmus, bk. 5, ch. III; and the Logics generally. On the general psychology of language, consult also Perez, First Three Years of Childhool, pp. 236-264; Kussmaul, Störungen der Sprache; Lazarus, IDas Leben der Seele, II. pp. 87-345; Preyer, The Mind of the Child, in loc.

On realism and nominalism; Rabier, Psych., p. 307; Bowen, Mod. Philosophy, ch. vilI; Sully, Psych., p. 347; Mill, Exam. of Hamilton, ch. xviI; Taine, in loc.; Volkmann, Lehrbuch, II. p. 259.

On judgment: Porter, Hum. Int., p. 430; Drobisch, Psych., \$\$ 62-64, and Logik, 39-53; Venn, Empirical Logic, in loc.; Lotze, Iogik, I, ch. III; Bradley, Principles of Logic, bk. 1; George, Logik, ch. I. 4; Trendelenberg, Log. Untersuch., II, \$14-16; Wundt, Logik, I, pt. 3; Laurie, Metaph., pt. 3; Sigwart, Logik, \$\$ 9-38; Ueberweg, Iogic, pt. 4; Spencer, Psych., pt. 6, ch. I-IX; Strümpel, Grund. d. Logik, ch. vil-xII; Hodgson, Time and Space, ch. vil.

On proof: Drobisch. Iogik, \$ 31-48; Sidgwick, Fallacies, pt. 1; Lotze, Logic, bk. 4-5; (Belief) George, Logik, p. 400; Encyc. Britann., art. Belief; (Hypothesis) Lotze, Logic, II, ch. vili; Naville, Ia Logique de l'Hypothèse; Venn, Mind, III. 43; Ueberweg, Logic, pt. 5; (Belief) Sully, Sensation and Intuition, IV.

On reasoning: George, Logik, p. 463; Porter, Hum. Int., pp. 439-469; Mill, Ingic, pp. 117-126; Waitz, \$\$ 48-50: Venn, Empirical Logic, in loc.; Bosanquet, Knowledge and Reality: Iotze, Logic, I, ch. III; Bradley, Princ. of Iogic, bk. 2-3; Trendelenberg, Ing. Untersuch., $\$$ 14-18; Wundt, Logik, I, pt. 4; Sigwart, Logik, \$ 49-59; Binet, La Psychologie du Raisannement; (Hist. of Logic) Ueberweg, Iogic, Introd.; Prantl, Geschichte der Logik; (Induction) Sigwart, Logik, \$§ 93-102; Wundt, Logik, II, ch. I; Bowen, Inductive Logic; Strümpel, Grundriss d. Iogik, ch. xIv-xvII; Duhring, Iogik, II, ch. II.

Further Problems for Study:

Nominalism and conceptualism;

Theories of judgment;

Theories of syllogism;

Scientific method;

Formal logic;

Nature of proof;

Burden of proof. 


\section{THE RATIONAL FUNCTION.}

\section{CHAP'TER XV.}

REASON.

Definition. The second great function of the mind . in its knowledge activity is reason. The rational function is contrasted with the apperceptive function in the absence of the element of process, which constitutes the essential nature of the latter. Apperception is a process, through which the material of acquisition passes in preparation for the higher uses of mind. Reason, on the contrary, is not a process, as the more special ter'm, intuition, given to it, implies. It conditions and underlies all mental processes. It is the nature of mind itself as it reveals itself in consciousness. Accordingly, by reason, in its broadest sense, is meant: The constitutive, regulative principle of mind, so far as it is apprehended in consciousness through the presentative and discursive operations.

\section{$\S 1$. Reason as Constitutive of Mind.}

By the constitution of a thing is meant its intimate nature, that which makes it what it is, and without which it would not persist as itself. The ultimate question of philosophy relates to the constitution of things. This question can be answered from experience, only so far as experience appears to reach and reveal the whole accessible area of the manifestation of the thing in question. As has been before contended, experience in consciousness is the only approach we have to the phenom- 
enal manifestations of mind; consequently, as far as knowledge can go with the question as to the constitution of mind, the emergence in consciousness of the mentally essential is our ouly hope of solution.

Further, considering the normal exhibition and development of mind in general to be that which we tind universal and internally truthful in man: we have the right to conclude, that whatever in consciousness can be shown to be absolutely necessary to this manifestation and development, is constitutive of mind. The question of the reason, therefore, becomes : what in our mental life is absolutely essential? What, if remored, would wreck the mental life?

To illustrate, without anticipating the results of later analysis, the principle of identity, above recognized, may be cited. This principle is a law of reason, inasmuch as it underlies all development of mind from the general sensibility up to the logical operations. Perception, memory, imagination, thought, all would be impossible if there were not, in the original constitution of mind, an inflexible law that the same is always the same and never different, and this is this and not that.

\section{§ 2. Reason as Regulative of Mind.}

In its regulative aspect, the reason comes more clearly inio consciousness as setting limits, prescribing channeis, and differentiating elements in the developed mental life. The regulative aspect, however, is only an aspect; for such principles are as truly constitutive as anything in the nature of mind which does not rise, as they do, in consciousness to control and direct our activities. Both aspects are unified in the original basis of mind itself. Yet, in the regulative aspect, the reason passes through its transition to the form of knowledge. The modes of reason become the form into which the 
material of acquisition is cast. That which constitutes mind what it is, thus passes into function upon a content, and it is in function alone that the mind becomes aware of its own nature.

The regulative aspect of the reason is exemplified in the intuition of power, as it arises in the exercise of attention. The necessary exercise of power in attention renders possible the conception of cause, in connection with all the apperceptive products of our perception.

\section{§ 3. Reason as Knowledge : Intuition.}

The knowledge aspect of reason is, however, that with which we have more strictly to do. Reason considered simply as truth, or as the essence of mind, does not enter into the range of empirical science. But its value as knowledge is, if what has been said is true, inestimable. The presence of necessary rational principles in the mind, taken with the immediate awareness of self which consciousness presents, gives to all knowledge thus presented, characteristics singular and unique. Inasmuch as, taken in its constitutive aspect, it reveals the necessary nature of mind, and taken in its regulative aspect, it controls all the special activities of mind, reason has a universal and categorical function, as the foundation of the structure of thought. We come, therefore, to look at reason as Intuition: and intuition may be considered first as a mental act, condition, or source, and second, as a mental product.

I. Intuition as a Mental Act. The distinction between intuition as an act, and as a product or acquisition, is as important as that between any mental act and its product. Yet by the term act we are not to understand process. As has been said, reason is never a process. It is an act only inasmuch as, like consciousness, 
it has an immediate revelation to make, and this revelation is at one time of one principle, at another time, of another.

The parallel between intuition as an act, or mental condition, and consciousness, in its higher forms, may be further remarked.

1. Intuition is immediate. Like consciousness, intuition is a matter of immediate cognizance or awareness. It is necessarily so in its nature, as knowledge, since the content of its revelation is not derived from a sphere exterual to itself; its content is of the nature of mind itself. Knowledge attained from the world is mediated through an organ or process. For the perception of things in space, we need senses, apperception, memory, as processes; and for the perception of intellectual truth, historical, æsthetic, we need the apperceptive and discursive faculty. But for the apprehension of rational truth, no such mediation is necessary or possible. It is true that it is only in such processes that rational truth reaches consciousness : but, on the other hand, it is only as the reason is operative, that these processes are possible. The processes of mind are not means to intuitive apprehension, they are the sphere of the manifestation of reason as truth, and of its apprehension as knowledge.

The immediateness of intuition is seen in the word itself, the Latin in and tuor, meaning to look upon at once or immediately. The rise of such a principle and its apprehension through a process, yet not because of the process, is seen in the rise of the notion of space, of which we have already treated at length.

The immediateness of intuition tends at once to obscure rational truth, at the same time that it makes it the most secure and certain of all knowledge. Knowledge, as has been seen, proceeds by differencing, subordinating, and classifying. Attention, as a relating activity, brings truth to a logical interdependent whole. All 
this is impossible with the early revelations of reason. Being a matter of immediate awareness, rational truth cannot be related, subsumed, or classified with reference to any mediating or corroborating principle apart from itself. Intuition cannot be defined for the same reason that consciousness cannot be defined.

2. Intuition is a necessary postulate of knowledge. While itself knowledge, intuition, like consciousness, underlies and makes possible all knowledge. Consciousness, as universal form, arises in the act of sentience and presentation; so reason takes on incipient manifestation in the same early facts of the dawning mental life. The origin of both is wrapped in the inscrutable mystery which envelops all origins-the veil of modesty beneath which nature hides the throes of her productive travail. But that reason is, even here, latent, implicit, in knowledge, is revealed in the early activities of child life, as they are at first adjusted to the conditions of the living environment. And this presupposition continues throughout subsequent development, becoming more consciously integral to intelligence, as the laws of its mental morphology are realized in the higher life.

The postulates of reason are well exemplified in the law of right and wrong which attaches, as an additional fact, to the intellectual character of a consideration or motive. The most developed analysis of the judgment of moral quality fails to resolve it into elements less original, and it must be recognized as an implicit principle of reason, coincident in its rise with the growth of consciousness itself.

\section{§ 4. Intuition as Mental Product.}

II. Considered as acquirements of knowledge, the intuitions are late mental products. They arise from the reflective consciousness in its scrutiny and criticism of 
itself. By its own relating and dividing apperceptive activity, it distinguishes between form and content, between itself and its acquired material, and holds up to view the principles of its activity. The form of knowledge thus becomes content, while yet remaining form, by self-knowledge, that marvellous property of mind. It is only as they are products that a science of the intuitions is possible. All original principles, however constitutive and regulative in their nature, and however operatire in the mental life, must first be seized upon as content, bent in upon themselves, as the objects of their own operation, before their isolation can be reached and their characteristics discovered. When this act of isolation is performed, we find rational principles characterized by two great peculiarities.

1. Intuition is of the universal : that is, its product has reference to an accompanying universal element of content. The intuition arises, as has been sail, in connection with a process, and is the law of this process, apart from the particular objects upon which the process is exercised. It is only the universal aspect of the process, not its particular application, which the reason reveals. But this universal aspect must find parallel justification in the universal nature of the object which the process bespeaks. However seemingly individual, therefore, the ribject of experience, whether thing, event, relation, it becomes to us rationally productive only as it has universal significance or meaning: a meaning which attaches to all things, events, relations, that may enter into the same mental process. All strictly particular incilents of experience are accidental and meaningless for the reason.

For example, all purely affective states of sensation, as sweet, odorous, pleasurable, have no rational meaning, except as they are synthesized in some perceptual unit, an orange, an apple. It is in the synthetic process, 
not in the particular content, that the rational laws of apperception are revealed. And the particular product, orange, apple, is again unproductive of a higher reach of rational truth, unless it be given general or universal meaning in the concept.

2. Intuition is categorical. Further, rational truth is, in its nature, categorical. As a revelation of what is in mind and of what must be in knowledge, it is unconditional in its communication of itself. The primitive form of belief, which was found ${ }^{1}$ to accompany the earliest advances of mind in childhood, here finds its rational explanation. Sense-perception is believed in, memory is trusted, the reports of the constructive imagination are given full credence, by this principle of the mental life. Conditions and hypotheses grow up and are justified, only as the mind departs from the area of its primitive certitude, and weighs the conflicting testimony of other voices than its own. Here we are confined to the single voice; and whatever we may discover as to its truthfulness to external fact, we find no uncertainty attaching to its reports of our own internal life.

The categorical nature of rational truth is clearly seen in the axioms of number and space, as employed in mathematics, and the law of duty, the "categorical imperative," which admits no questioning or excuse.

\section{§5. Sphere and Kinds of Intuition.}

The constitutive and regulative aspects of reason extend necessarily throughout the mental life and do not terminate with the intellectual function. Accordingly, the sphere of intuition embraces also feeling and will. In the present connection, however, we are concerned only with the reason as it reaches formulation through the activities of intellect, except so far as its principles

${ }^{1}$ See pp. 246 and 248. 
are of identical nature in the three great divisions of the mental life. Leaving for future discussion the question of the value of the intellectual intuitions for feeling and will, we find underlying the entire mental life a single Universal Intuition. Considering, further, the principles of reason in relation to the varied activities of the intellectual function, and naming such intuitions after the analogy of these activities, we find the intellectual intuitions to be, first, Intuitions of Sense, and, second, Intuitions of Intelligence. ${ }^{2}$

I. Universal Intuition: Being. The categorical significance of the reason attains complete conscious realization in the universal intuition of being. It is the primitive postulate of consciousness in all its forms, affective, presentative, volitional. ' It is fundamental to all knowledge, yet inexplicable in terms of knowledge. It is equally present in the ready and unconscious acceptance of sense-perception, in the conscious consent to the reality of the concept, in the existential assertion of the judgment. It is a rational principle of the empirical consciousness, whatever its place be in metaphysical theory.

II. Intuition of Sense: Percepts or Cognitions. The fact, of seuse-intuition, arising as the finished result of sense-perception, has already been spoken of. It was viewed, in the former connection, merely as an empirical fact, and given its due place in the development of thought. We are here concerued with its value and meaning for the reason.

Unity. In sense-intuition, the manifold of sensation is found unified and universalized. The process of its

The rational accompaniments of feeling and will are treated in the consideration of those aspects of the mental life. 
accomplishment is perception. Its unity is first an ideal unity, through which the unity of the external thing of perception is interpreted and reconstructed: but this ideal unity is in so far concealed in the potential unfolding of the process of perception, that it seems to arise consciously by abstraction from the unity of the thing. Such a derivation of the principle of unity is impossible. The unity of a thing could never be known, as such, unless the multiplicity of its affective manifestations were seized upon and unified by the rational principle of the perceptive process, and thrown into the form of a unitary percept. The intuition of a thing, in nature, is universal, therefore, since it is the typical application of a rational principle to a definite sense content. This rational principle is that of unity.

Power. The act of attention by which the construction of a thing in perception is possible, involves, as has been said, an essential feeling of effort, found nowhere else in the mental.life. Yet it is only as this attentive activity accompanies all the operations that they are possible. The principle of successful effort, or of power, therefore, arises in the mental life, regulative of the energy of the whole. The principle of power, like that of unity, it is readily seen, takes its rise in the subjective side of the perceptive process ; but it is only as it is realized in an objective law as an effect, or movement, that the regulative principle becomes apparent as knowledge. The subsequent intuition of external power or force may be construed as a transition from the subjective to the objective aspect of this experience. A second principle of sense intuition is therefore power.

Extension and Duration. In the processes of localization in space and time, we have found ' forms of construction into which the entire material of the sense 
function is cast. The necessary presence of these forms has already been spoken of. They are regulative of our perception of the external world of things and events. They take, in concrete perception, the form of extension and duration, and are additional intuitions of sense.

The principles of reason thus found to be regulative in the sensitive function may be designated as intuitive percepts or cognitions,' having reference both to the perceptive process through which they reach consciousness, and to their own nature as in turn material for higher forms of rational truth. The derivation of these higher forms appears in connection with the higher processes of mind.

III. Intuitions of Intelligence. 1. Concepts or Beliefs. The analogy between perception, as typical of the apperceptive processes in general, and conception, has already been pointed out. Conception departs from the correctives of reality, and establishes a unitary product of its own through the universal element in reproduction. The passage from the singular percept to the general concept is, however, not accidental: it is mediated through the constructive imagination, which reveals a principle of universal construction, while still busy only with particular elements of content.

End, the Unlimited. The constructive imagination, we have seen, is ungoverned either by the tests of external truth or by the regulative laws of conceptual composition. Yet in its principle of movement it cannot escape its own rational form. The universal element it reveals is end, or purpose. It is inherent in the selective attention, the feeling of fitness, which culminates in the

McCosh gives the following threefold division of the intuitions under the terms, Cognitions, Betings, and Judgments. See his First and Fundamental Truth. 
perfect, and in progressive construction, which culminates in the unlimited.

Identity. The products of the constructive imagination are further universalized in conception. The rational laws of conception appear in certain characteristics of the product, which are intuitive truths wider in generality than the rational percepts of sense. The percept of unity, released from the individual conditions of the perception of things, reveals its universal character by the intensive modifications it undergoes in reproduction. Unity thus becomes broadened and deepened, and in its successive applications to a content, is apprehended as identity. Identity is a rational principle expressing the recurrence of the same mental factor in consciousness.

Cause, Self, Substance. The intuition of power, likewise, suffers the same universalizing modification. Passing from the attentive exercise of mental power, by recurring instances, we reach the concept, cause. Further, the identical experiences of inner causation lead us to apprehend the sameness of the self, a rational concept appearing early in the mental life, and the basis of the developed exercises of knowledge. Generalization from self and the permanent cause in the world without, which recurs, like self, in our experience, leads to the rational concept, substance.

Space and Time. Extension and duration also are freed from their reference to a concrete perceptual content, and become, in the development of thought toward the universal, space and time.

2. Judgments. By the thought operations, which follow in the progressive development of apperception, products of the highest universality are reached. The simple fact of identity upon which conception proceeds, gives place to the broader establishment of the relations given in judgment. The relational activity in its fullest 
form now brings into our self-reflection the assertive forms of reasoning. The rational grounds of this procedure are again wider reaches of the principles already discovered. Intuition takes on the form of the operation it accompanies, and the reason announces itself in Judgment.

Axioms of Mathematics. Judgments of reason take their root in the perceptual or conceptual forms of reason. Here we formulate the axioms of space and number, utilized in geometry and general mathematics.

Judgments of Time, Quantity, and Causation, have a similar rational origin, from the concepts time, space, cause.

Axioms of Logic. Thus arise, also, the developed forms of the discursive or thought operations, which have already been seen in their psychological genesis.' They are, first, the Law of Identity, and, second, the Law of Sufficient Reason. The law of identity is the absolute generalization of the concept of identity. As a rational principle it has complete universality. In like manner, the law of sufficient reason announces the principle, of which the concept of cause is a more partial and particular intimation. The concept of cause, upon which the law of effect is based, becomes the logical law of ground, upon which inference is based.

Judgments of Design, the Infinite. The laws of the constructive imagination lead on to rational formulation in judgment. The concept of end is universalized for thought in the rational principle of design. The concepts, also, of the unlimited and the perfect find their generalization and expression in the postulate of the infinite.

\section{6. Final Objects of Inturtion.}

The rational principles thus briefly pointed out may be considered with reference to three great objects of

' See p. 810. 
knowledge, in the final apprehension of which they are organized in a dependence among themselves. These great centres of rational convergence are the World, Self, and God. The ultimate end of knowledge is the comprehension of self in relation to the world and God: the comprehension of the universe as a system, of the self as realization of reason in its energetic reconstruction of the world, and of God as the final rational demand alike of reason in itself, and of the world of its completed reconstruction.

I. Intuition of the World. As the data of sensation, in its presentative aspect, are gathered up and universalized in perception, by the laws of its rational procedure ; so the entire area of rational intuition, in its external realization, is swept, for the organized intuition of the world. The world as a whole, a system, is the integration of reason in its application to an external content. The isolation of principles finds here its reverse law. And the external world, in its unity of many parts and laws, becomes one in thought, as it is in fact.

II. Intuition of Self. The laws of the inner world undergo a corresponding unification, with reference to self, the centre of all knowledge and of all being, as far as it is construed as knowledge. Self is the point of departure in the first instance, and the point of approach in the last instance, by the reflex movement of self-conscious reason.

III. Intuition of God. The final conceptive product or ultimate generalization of reason, proceeds out from the world and self, and seeks a further unifying postulate. This final unity is adumbrated in the unity of the apperceptive process, the identity of the reasoning powers, and the instability of all the complexes constructed in experience. Unity, identity, constructive infinity, end, 
cause, perfection, categorical being-all lead on by the necessary progression of intellect, through the conditions and limitations of finite mind, to the intuition of the absolute and unconditioned subject, God.

We thus reach a return of reason to self-consciousness : a return which is also mediated through feeling and will. The universal intuition being, is given its deepest meaning in the universal postulate of reason, God. Through the strife and incompleteness of our entire inner life, the goal of all emerges: the infinite Self, to which knowledge is intuition, and existence is reason.

On reason, consult : McCosh, Intuitions of the Mind, inductively investigated, and First and Fundamental Truth; Waitz, Lehrbuch der Psychologie, 46, 53, 54 ; Drobisch, Psychologie, \$112, 113, and Logik, \$8 54-60 ; Porter, Hum. Intellect, pt. 4; Hickok, loc. cit. p. 117 ; Sigwart, Logik, $\$ \$ 23-25$ and 32 ; Mansel, Metaphysics, p. 248; Wundt, Logik, I, pt. 6 ; Laurie, Metaphysica nova et vetusta, pt. 5 ; Morell, Outlines of Psychology, pt. 5; Lotze, Microcosmus, bk. 2, ch. Iv, and Logic, II, ch. v; Hodgson, Time and Space, eh. vII, 3, and vilı ; Bradley, Principles of Logic, bk. 1, ch. v.

Further Problems for Study:

Tests of intuitive truth :

Experiential theory of intuition ;

Hegelian doctrine of absolute reason ;

Intuition and evolution;

Validity of intuition. 



\section{INDEX.}

Abstraction-as a mental state, 72; as a coudition of the imagivation, 273.

Activity-mental contrasted with physical. 5; unity of a. of the mental functions, 40.

Adamson-on belief, 260 .

Advantages-of external observation, 17.

Affective-self-reference of the a. states, 36; as opposed to presentative states, 62 .

After-image-nature of, 95-96; in memory, 11, 146.

Agraphia-207.

Aids-to reproduction, 167-8.

Abert-on hypnotism, 73.

American Journal of Prychology article on hypnotism, 73 ; on Maller, 109; on Lange, 113; on Brewer, 133; on association of sounds and colors, 209.

Ampire-on chemical composition, 101.

Analogy-between physical and mental force, 99-100; between association and chemical com. position, 100-102.

Analysis-mental a., 102; of perception, 117; of seuse-intuition, 138 ; as stage in conception, 273275; analytic judgment, 292.

Animal-a. psychology, 15; references on a. psychology, 34.
Answer-to arguments on the unconscious, 47-55.

Apperception - as distinguishing the mental, 4; as active consciousness, 64; definition of, 65 ; references on, 79; division of the a. function, 80 ; a. function, 82; reinstatement of $a$. in recog. nition, 176-17\%; association as a., 201 ; a. in imagination, 241 ; a. in thought, $2 \pi 1$.

Appetence-in imagination, 228230.

Application-as a mental state, 78 . Archiv für Anat. und Plys.-article by Fich, 95.

Archive de Zool, exper.-article by Delage, 132.

Area-of consciousness, 65.

Arguments-for the unconscious, 46-58; for identity of presenta. tive and representative states, 147-151; on associative laws of imagination, 220-223.

Aristotle-on consciousness, 44 ; on material residues, 153: on laws of association, 194; on imagination, 213; on identity as relntion of judgment, 287; on the categories, 289.

Assimilation (tive) - in illusion, 256; a. association, 207.

Association-argument from a. for the unconscious, 55; as aid to 
Associution-(Continued).

reproduction, 168; definition of, 192; relation to memory, 192 ; physical basis of, 193-194; secon. dary laws of, 194-197; by contiguity, 195-200; by resemblance, 195-197; reduction of resemblance to contiguity, 196-197; by contrust, 198-199; universal law of: correlation, 200-202; as integration of states, 191-192; law of preference in, 202-203; danger of free association, 203; forms of, 204-210; unitary, 206; assimilative and disparate, 207; motor a., 208-209 ; complex, converging, diverging, 209-11; references on, 211-212; a. in sense-intuition, 139 ; a. as condition of imagination, 214.

Attention - (69-80); argument from a. for the unconscious, 50 ; effect of a. on consciousness, 51; a. as active consciousness, 64; definition of, 69 ; as mental energy, 69; reflex a., 70; a. in the hypnotic state, 71 ; voluntary a., 71 ; bearing of, in the mental life, 72-77; relation of, to sensation, 72, 112; effect of a. on duration of sensation, 73, 112; relation to movement, 73-75; relation to intellect. 75; to feeling, 76; to the bodily functions, 77,170 ; references on, 79 ; training of, 77; habits of, 77; a. as condition of retention, 163 ; of reproduction, 167 ; a. in senseintuition, 138; a. as indicating position in time, 184-18.5; a. in dreams, 185; a. in imagination, 230-232.

BAIN-on empirical laws, 32 ; on consciousness as change, 48,51 ;
Bain-(Continued).

relative theory of consciousness, 59; on muscular seuse, 90-91; on space perception, 136; on the physical basis of memory, 162; on association by resemblance, 197; on the theory of belief, 286 ; on the predicaments, 288292.

Buldwin-on relation of psychology to metaphysics, 8; exposition of Beaunis, 28; on Weber's law, 109; experiments in psychometry, 109-117; experience in a dream, 207.

Basis-physical b. of mind, 29-30; physical b. of memory, 161.

Beaunis-on nervous inhibition, 28; on the muscular sense, 89.

Belief-b. and conception, 279, 280,281 ; b. and illusion, 247; b. and judgment, 293-299; association theory of, 296; b as intuitive, 321.

Beneke-on intensity of consciousness, 48.

Berkeley-on perception of distance by the eye, 127; on association, 199; on class images, 278. Bernard (Cl.)-on sensibility, 82.

Bernhardt-on the muscular sense, 89.

Bernstein-on the five senses, 9293.

Binet-on the unconscious, 58; $\mathrm{B}$. (and Féré) on touch in the hypnotic state, 97.

Body-functions of $\mathrm{b}$. and the attention, 77; perception of, 126.

Bosanquet-on categorical judgments, 297.

Bouillier-on retention, 153.

Bradley-on idea of time, 181; on association by resemblance, 197; on trust in mental states, 254; 
Bradley-(Continued).

on the law of identity in judgment, 284; on the theory of belief, 287.

Brain-as condition of mind, 2; operation of trepan, 4; localization in the b., 114; capacity of, 158-159; associative connections in, 193.

- (Magazine)-article by Demeaux, 91.

Brentano-on nature and method of psychology, 1; on observation, 11, 23; on the physiological method, 32; on judgments, 285, 298.

Brescer - on the semicircular canals, 133.

Broca-speech centre, 4.

Bronon-on recognition, 176 ; on suggestion, 192 : on association by resemblance, 19i; on emotion in association, 199 ; on mental energy, 226 ; on constructive imagination, 233.

Brown-Séquard-on the muscular sense, 90.

Casals-function of semicircular c., 132-133.

Cardailluc-on distinction of presentation from representation, 147.

Carpenter-on unconscious cere. bration, 56; on illusions, 252, 259; illusion due to dreams, 261. Categorical-c. syllogism, 302; c. judgment, 202.

Cattll-on attention in psychometry, 113.

Causation-principle of c. applied to the unconscious, 46-50; as law of association, 201.

Change - as basis of consciousness, 59-61.
Characteristics-general c. of mind, 43-79.

Charcol-on associative connections in the brain, 193; on pathology (mental), 244.

Cheselden-case reported by, 127.

Christ-appeals to test of incongruity, 268.

Classification-of mental states, 35-42; completeness of, 36-3i; unity of $c$. in consciousness, $40-41$; references on, 42 ; of sensations, 85; of intuitions, 323.

Coexistence-association by, 20t210.

Color-sensations of, 94-96; c. blindness, 95.

Composition-by imagination, 218220.

Comptes Rendus-article by Cyon, 132-133.

Comte-on identity of psychology and physiology, 2.

Conception (272-283)-process of, 272-276; products of, 276; c. as discovery of relations, 277 ; relation of, to language, 277; use of images in, 278; relation to reality and belief, 279-281, 282; unity of, 282; references on, 310-311; intuitive c., 321.

Conceptualism (280-281).

Condilions-meutal c. of retention, 163.

Conduct-element in conscience, 37.

Confusion-of presentation and representation. 149 .

Conscience-not a separate func. tion, 3 .

Consciousness-contrusted with movement, 3; complex states of, 5; as defining psychology, 8; ns association, 8 ; as reflection, 10 , 
Consciousness-(Continued). 143; unity of sources in c., 18; as method, 22; as mental characteristic, 43-68; nature of, 43; c. and the unconscious, 45-58; not a power, 44, not an organ, 44; least c., 45, 52; relative theory of, 58-63; c. of self. 143; simple and reflective, 63 ; as differentia of self, 63; area of, 63; forms of, 64; passive c., 64, 69 ; active c., 64, 69, 71; development of, 66; self c., dawn of, 67; references on, 67-68.

Constructive-c. imagination, 226243.

Content-of consciousness, 60 .

Contiguity -as secondary law of association, 194-198.

Continuity-mental c., 159-160; c. of representation in association, 191.

Contradection-law of $c$. in representation, 267.

Contrast-in association, 198-200.

Convergent-c. association, 209.

Correlation-law of, 201-202.

Corti-fibres of, 93.

Cournot-on sensations of sound, 93.

Conoles-on insistent ideas, 71.

Criticism - of the experimental method, 29-31; of theories of retention, 156.

Cyon (Élie de)-on semicircular canals, 132-133.

Czermak-on local signs, 134.

DARwin-on duration of sensation, 110; on the effects of representation, 148.

Data-physical d. for the perception of space, 122; synthesis of space data, 126; $d$. for the perception of time, 182-185.
Deceptions-of perception, 143.

Deduction-as psychological meth. od, 20; as a kind of reasoning, 300-307; as proof, 310.

Definition-of perception, 116; of judgment, 283; of association, 200 ; of syllogism, 300 ; of reuson, 302.

De Gerando-on the hypothesis, 307.

Delage-on the semicircular canals, 132.

Delbœuf-on impossibility of measuring sensation, 108.

Demeaux-case reported, on the muscular sense, 91 .

Descartes-on the physical basis of memory, 155.

Design-in association, 201 ; as predicament, 290; as intuition, 323.

Detection -of illusions, 266-269.

Development - of consciousness, 66 ; of the physical organism, 67 ; of the organic in memory, 169 ; of the idea of identity, 281.

Dewey-on feeling of interest in association, 224.

Difference-consciousness as feeling of $d ., 59-61$.

Differentia-consciousness as d. of self, 63.

Differentiation --as stage in the process of perception, 118-120.

Difficulties-in psychology, 8-10.

Discursive-d. function distinguished, 81.

Disparate-d. associations, 207209.

Dissociation-d.by imagination, 18. Distinction-d. time in psychometry, 111; between the recognition of object and image, 172173.

Distraction-as a mental state, 70 .

Divergent-d. association, 209. 
Division-of psychological system according to method (table), 31 ; of matter of psychology, 41; references on, 42.

Domaldson-on the temperature sense, 97.

Drobisch-on recognition, 174; on detached images, 221; on class images, 278; on cutegorical judg. ments, 296, 298.

Dumond - on the physical basis of attention, 170.

Duration-of mental states, 4; of sensation, 85, 109, 117; effect of d. upon the intensity of sensation, 113; as empty time, 180; units of d., 185-186.

EAR-feeling of equilibrium arising from e., 132 .

Effect-law of partial e., 46-50; identical e. of presentation and representation, 147.

Effort-sensations of, 89.

Egger-on the organic in memory, 170.

Emotion-in imagination, 239; illusion due to c., 264.

Empirical (cism)-e. psychology, 1; of space,135; of time,18ij-187.

Encyclopadia Brilannica-article by Ward, 36, 182; by Adamson, 260.

End-unity of e. of mental functions, 40.

Energy - mental e. in attention, 69, 70 ; in recognition, 178.

Epicurus - on memory, 146.

Equilitrium-from the ear, 132.

Errors-in psychology, 8-10; of observation, 12, 25; of observing only the mature mind, 14.

Escort-mental e. as a test of illusion, 267.
Esquirol-on distinction between illusion and hallucination, 255.

Evolution-of mind, 105.

Existential-e. judgment, 293-294, 298.

Exner-on sound intensities, 50 .

Expectation-as leading to illusion, 252 ; in induction, 308.

Experience-relation of, to experiment, 28; e. as ground of classification, 36 ; revival of experiences in memory, 152; truthfulness of ordinary, 253.

Experiment-in psychology, 7 ; as method, 21, 25-31; internal e., 26-27; external e., 27-29; as dependent on experience, 28 ; impossible in higher powers, 29; subordination of, to observation, 30; in psychometry, 110-113.

Extension-in conception, 22-24.

Extensive-e. association, 206.

FAct8-contrast between mental and physical f., 2-6; mental f., 1 ; division of mental f., 41; classification of mental f., 3542; three great classes of f., 36 ; f. of memory as argument for the unconscious, 54; $\mathrm{f}$. of association and the unconscious, 55; f. of habit and the unconscious, 56.

Faculty-defined, 35.

Familiarity-feeling of, 172.

Fancy (224-226)-relation of $\mathrm{f}$. to reality, 225.

Fatigue-due to attention, 69.

Fechner-on after-images, 96 ; on the logarithmic lnw of sensation, $10 \%$.

Fecling-as class of mental facts 36; effect of attention on f., 76, f. of familiarity, 172; $f$, of atness in the imagination, 232-234. 
Féré-on sensori-motor excitation, 74.

Ferrier-on the muscular sense, 89 ; on cerebral localization, 114 ; on the semicircular canals, 132.

Fichte-on the feeling of freedom in reproduction, 147 .

Fick-on color-blindness, 95.

Fitness-feeling of $\mathrm{f}$. in the imagination, 232-234.

Folk-f. psychology, 15; references on $f$. psychology, 34 .

Force-reduction of the physical $f$. to unity, 99-100; mental f. reduced to unity, 99 ; $f$. of association, 210-211.

Fortnightly Review - article by Huxley, 2.

Franz-case reported by, 127.

Function-three great f., 36; unity of $f$. in consciousness, 40; in. tellectual f. distinguished, 8081 ; f. of combination, 191 ; enlarging and diminishing $f$. of fancy, 224-225.

GaLToN - on mental imagery, 168 ; on color associations, 209 ; on generic images, 275 .

Generalization-in conception, 275. George-on relative theory of consciousness, 59; on tixed ideas, 70; on unconscious imagination, 222 ; on scientific imagination, 233; on imagination and thought, 240 ; on intension of concepts, 274.

Gerdy-on nature of sensation, 82. Glass-on estimation of time, 108.

God-intuition of, 324.

Goethe-imaging power of, 149.

Goldschneider - on pressure-spots, 96.

Gratacap-on feeling of freedom in reproduction, 165 .
Griesinger-on mental pathology, 244; on causes of illusion, 252. Grotenfelt-on Weber's law, 109. Ground-of association, 142.

Gurney-on telepathy, 269.

HABIT-argument from $h$. for the unconscious, 56 ; law of physiological h., 57 ; h. of attention, 78; retention as a psychological h., 153; retention as physiological habit, and proof of same, 156-160; physiological h. as a condition of reproduction, 164 ; same as basis of recognition, 174.

Hagen-on relative theory of consciousness, 59 ; on illusions, 252 .

Hall-on muscular sense, 90; on space perception, 123.

Hallucination $(255,259)$ - of memory, 262.

Hamilton-on the veracity of consciousness, 8 ; on consciousness (nature of), 44; on the unconscious, 47 , 55; on sensation, $83,84-85$; on latent images, 152,166 ; on area of consciousness, 204; on class images, 278; on logical realism, 280.

Hartley-on animal spirits, 163.

Hartmann - on the unconscious, 45,46 ; n cerebral excitation, 49.

Hearing-sensations of, 92.

Helmholtz-argument for unconscious, 52; on color sensations, 94; on nerve transmission, 110.

Herbart - on relation of psychology to metaphysics, 8 ; on faculties, 35; on the unconscious, 46 ; on the threshold of sensation, 107 theory of space perception, 133, 135; on retention, 155; on the categorical judgment, 296; on existential juklerment, $29 \mathrm{~S}$. 
Hering-theory of color, 95; on the impossibility of measuring sensasation, 108.

Herschel-illusions of, 259.

History - of psychology (references) 34.

Hobbes-on association by resemblance, 197 .

Horwicz-on emotion in association, 199.

Hume-on identical nature of presentation and representation, 147; on class images, 279 ; on nominalism, 280.

Huxley-on distinction between movement and consciousness, 2; on the double aspect theory, 5 .

Hypnotism - attention in the $\mathrm{h}$. state, 71 ; h. and discase, 73; motor phenomena of, 75; illusion in the h. state, 150 .

Hypothesis - h. as psychological method, 21, 31-33; scientïfic h., 236-237; in reasoning, 306-307.

Hypothetical-syllogism, 303; judgment, 295.

IDEA-insistent i., 1, 70; development of i. of identity, 281; of space, 133; of synthetic unity, 140 ; of self, 144, 179; of personal identity, 179; of time, 188; the suggesting $i$. in association, 192 ; association of, 192 ; continuance of the suggesting $i ., 211$; $i$. of the infinite, 242.

Identity - of presentation and representation: 1 . in illusion, 249; development of idea of, 281 ; law of, 254, 302; as ideal product of thought, 810; intuition of. 322.

Illusion (244-269) - as sbowing identity of presentation and representation, 150, 249; nature of. 24t-249; grounds of, 249-255;
Illusion-(Continued).

kind of, 255-259: detection of 266-269; relation of $i$. to mental pathology, 244-246; general character of, 246-249; relation to belief, 247; representative nature of, 243; due to interpretation, 249: absence of internal stimulus in, 249; organic stimulus in, 251; mental predisposition to. 252254 ; i. proper, 255-259; assimilation in, 256-257: physical aspect of, 257; elements of reality in, 258 ; $i$. of presentation and representation, $260-265$; i. of recognition, 261; of time, 261262 ; of memory, 262-263; of selfconsciousness, 264-265; of thought, 265; diminished intensity as test of i. 266; locality, as test of, 266-267; escort as test of, 26i-269; references on, 269.

Image-distinctness of, 151; subconscious 1., 155; power of imaging, 168; distinction between image and object in recognition, 172; generic i., 275; use of $i$. in conception. 278 .

Imagination (213-243)-passive $i$., 213-226; material of, 213; conditious of, 214-217; moles of passive i., 218-220; dissociation in, 218-220; composition by, 220; laws of passive 1., 220-224; of active $i ., 241$; 1 . by contiguity and resemblance, 220-223; law of preference in, 223; $i$. as funcy, 224-226; active or constructive $i$., 226-243; analysis of, 227-234; native appetence in, 22\%; preference in, 229-230; selective atten. tion in, 230-28:; feeling of fltness in, 232-234: kinds of, 234-240; scientific i., :335-238; relation of scientific i. to reality, 236; by- 
Imagination-(Continued). pothesis in, 236; æsthetic i., 238 240 ; relation of $i$. to thought, 240-242; ideal product of, 242243; physical basis of, 214-215; references on, 243.

Imitative-faculty, 74.

Incongruity - as test of illusion, 267.

Induction-as psychological method, 20-21; as a kind of reasoning, 307-311; i.vs. deduction, 308-309.

Infant - psychology, 16; i. consciousness, 62; references on i.psychology, 32 .

Infinite-idea of, 242-243; intuition of, 323.

Innervation-sensation of, 89.

Insistent-ideas, 70.

Instinct-in animals, 15.

Integration-in association, 191-2, 201.

Intellect-classification of the functions of, 36 ; relation of, to attention, 75-76; division of, 80 .

Intension-of concepts, 272-274.

Intensity-of mental states, 4 ; $i$ as a condition of memory, 163; $i$. of stimulus as an aid to reproduction, 167 ; $i$. as indicating position in time, 183-184; as a test of illusion, 266.

Intention -in imagination, 229-230.

Intuition-of sense, 138-141, 319; motor i., 140; ideal product of, 140 ; i. as a mental act, 314 ; as a mental product, 316 ; as immediate knowledge, 315 ; as a necessary postulate of knowledge, 316; as universal in its meaning, 317 ; as categorical, 318 ; sphere and kinds of, 318; universal i., 319 ; intuitive percepts, 319 ; concepts, 321 ; judgments, 322 ; $i$. of the world, self, God, 324-325; references on, 325 .
Involuntary-attention, 70.

JAMES—on the muscular sense, 89; on muscular perception of space, 122, 129; on units of time, 186.

Janet (Paul) -on space perception, 129.

- (Pierre)-on the unconscious, 58.

Jastron-on dreams of the blind, 66, 168.

Jevons-on method, 20; on law of identity in judgment and syllogism, 284, 302.

Jouffroy-on the faculties, 35 ; on consciousness, 43.

Journal of Speculative Philosophy article by James, 186.

Judgment (283-299)-nature of, 283-284; unity of, 285-286; possible relations asserted in, 288291; kinds of, 292-299; negative j., 293; à priori j., 304; intuitive j., 322 .

Justification-of classification of mental functions, 36 .

KANT-as illustrating errors of observation, 14; on the unconscious, 45; on sensation as opposed to perception, 84; on the impossibility of measuring sensasation, 108: on nativism of space, 134; on idea of synthetic unity, 141; on time form, 180, 187; on imagination, 220; $\mathrm{K}$.'s categories, 289 ; on à priori judgments, 304.

Kant-(Continued).

Kepler-K.'s laws, 102.

Kinds-of constructive imagination, 234; of judgment, 292; of reasoning, 299; of intuition, 318. Knovoledge-function of, 80 ; predicaments of, 291; intuition as 
Knovoledge-(Continued). postulate of, 316 ; reason as $k$., 314.

Kraffl-Ebing-on mental pathology, 244; on fixed ideas, 70 .

Krausse-elements of $K$. in the skin, 97.

Kries-on theories of color, 95 ; on distinction time, 111.

LACHELIER-on the classification of the senses, 84 .

Ladd-on physiological psychology, 27; on attention, 77 ; on the muscular sense, 89; on psycho physics, 107, 38-39; on psychometry, 112; on organic theory of memory, 165.

Lange (N.)-on attention in psychometry, 113.

Language-as mental growth, 18; function of naming in senseintuition, 140; 1 . and conception, 277 ; 1 . not a separate function, 37.

Laurie-on attention, 65, 117; on judgment as spiritual synthesis, 286.

Lavo-empirical 1. in psychology, 21 ; l. of nature, 21 ; psycho-physical 1., 32-33; 1. of association, 194; of imagination, 220, 242; of contradictory representation, 207; of identity in judgment, 284: of sufficient reason, 204.

Le Conte-on sight, $93,95$.

Lehmann-experiments on assocition, $177,197$.

Leabnita-on the unconsclous, 45, 46: on the theory of unity of mind, 100; on composition of colors, 105; on retention, 153 , 155.

Leves-on the double aspect theory, 5 ; on the unconscious, 55,56 ,
Lewes-(Continued).

$57-58$; on sentience, 58,82 ; on the muscular sense, 89 ; on the physiological effects of representation, 148; on the Nussbaumer case, 209; on association, 222; on emotion in illusions, 264 .

Limilations-on the experimental method, 29-31; of experiment in psychometry, 112.

Lipps-on temporal signs, 183.

Locul-memory, 189; signs, 123.

Localization-cerebral, 114 ; 1 . of sounds, 131 ; 1 . in time, 142 ; ideal product of temporal l., 188; references on, $115 ; 1$. in space, $120-133$; 1 . in time, 179-189; illusions of 1 . in time, 161, 162; 1. as test of illusions, 266; distinction between 1. and projection of an image, 267.

Locke-on consciousness, 43-44; on animal spirits, 163 ; on recognition, 172; on perception of time, 187.

Logic-relation to psychology, 2r1; 1. of conception, $274 ; 1$. of judg. ment, 284.

Logical-memory, 189.

Lotze-on distinction between the mental and the physical, 4, 6; on local signs, $53,123-124$; on the unconscious, 46, 60; on attention, 70 ; on the spiritual activity of relation, $65,27 \%$; on class images, 279; on the law of Identity in judgment, 284; on space perception, 122; on correlative nssociation, 202.

Maine dr Biran-on the unconsclous, 45; on the muscular sense, 91.

Malebrancho-on the physical ele. ment in memory, 155. 
Mansel-on the relative theory of consciousness, 62 ; on intelligible relations, 279 .

Mantagazza- on the transformation of mental force, 99 .

Martineau-on the relating function, 65.

Mass-massive sensations, 109; $\mathrm{m}$. of sensation, 106-109.

Material - of the imagination, 213.

Materialism-claims that psychol. ogy is a chapter of physiology, 2.

Maudsley-identification of physiology and psychology, 2 ; on the physiological method, 31 ; on effects of disease, 158; on confusion between presentation and representation. 149; on the physiology of speech, 278.

Maury-on attention during sleep, 185.

Maxuell (C.)-on chemical composition, 101.

Mayer-on illusions, 25.

$M c C o s h-o n$ distinction between the physical and the mental, 4; on the limitations of the experimental method, 29; on knowledge as positive, 63; on the relating power, 6i); on sensation vs. perception, 84; on recognition, 175; on time perception, 187; on correlative association, 202; on Cheselden case, 127; on Trinchinetti case, 130 ; on the infinite, 243; on the symbolic power, 278; on the predicaments, 289 ; on intuition, 321.

Measurement - application of, to mental states, $3 ; \mathrm{m}$. of duration and intensity of mental states, 4 .

Mechanical-nature of reflex attention, 71.
Mechanism-of muscular sense, 90 ; of hearing and sight, 92-93.

Meissner-M.'s elements, in the skin, 97; on local signs, 124.

Memory (145-190)-as psychological source, 11; as method, 23; $m$. as supporting the unconscious, 54 ; physical basis of, 161 ; development of the organic in m.,169-170; m. as mental growth, 170-171; kinds of, local, logical, $189 ; \mathrm{m}$. as condition of imagination, 214; nature, 145-146; definition of, 151-152; m. as retention, 15:-164; references on, 189-190.

Mental-m. facts measured, 4; subjective nature of $\mathrm{m}$. facts, $5 ; \mathrm{m}$. disease, 17 ; $\mathrm{m}$. continuity, 159$160 ; \mathrm{m}$. conditions of retention, 163 ; memory as m. growth, 170 $171 ; \mathrm{m}$. reconstruction of time, 181-188; of space, 121-122; intuition as a m. act, 314 .

Metaphysics-relation of, to psychology, 7; metaphysical predicaments, 291.

Method-psychological m., 20-34; principles of scientific m., 20-22; deduction and induction as $\mathrm{m}$., 20 ; joint or synthetic m., 20 ; stages of m., 21; observation as m., 21, 22-25; experiment as, 21, 25-31; hypothesis as, 21, 31-33.

$\operatorname{Mill}(\mathrm{J}$.$) -on æ$ sthetic imagination, 238 ; on association theory of belief, 254, 286.

Mill (J. S.)-on complexity of the mental life, 9 ; on state of psychological study, 30; on talent images, 166; on connotation of concepts, 273; on class images, 278-279; on association theory of belief, 286; on predicaments, 288-292; on theory of syllogism, 
Mill (J. S.)-(Continued).

304; on consciousness, 44; on the unconscious, 47; on time of cerebral series, 56; on habits of attention, 78 ; on composition of colors, 105; on theory of space perception. 135, 136: on hypothesis, 238; on induction, 308 .

Mind (periodical) - article on Beaunis, 89; art. by Hall, 90; art by Donaldson, $9 \tilde{\tau}$; art. by Ward, 109; art. on Cyon, 132.

Modes-of passive imagination, 218 . Morris-quotation from Kant, 141. Mocement $-m$. inapplicable to mental states, 2; relation to attentiou, 73-75; function of $\mathrm{m}$. in space perception, 123; $m$. in sense intuition, 139; motor intuition, $140 ; \mathrm{m}$. in development of consciousness, 66.

Müller (F. C.)-on Weber's law. 109; on the physical effects of representation, 148.

NAtivism-of space, 122, 134; of time. 186-187.

Nature-laws of, 21; uniformity of, 22,308 ; final appeal to, 22 .

Naville-on perception of space by the eye, 129 .

Negative-n. judgment, 293.

Neroton-imaging power of, 149 , 237; illusions of, 259.

Nicolai-illusions of, 259.

Nominalism-logical n., 280-281; references on, 311 .

Nunnely-case reported by, 127.

Nussbaumer-case, 208.

OBJECT-distinction between of and image in recognition, 172; o. predicaments, 290.

Objection-to the physiological theory of retention, 157-160.
Observation-external, 13-14, 2425; distinction between external and internal o., 13-14; 0 . as method, 21, 22-25; internal o., 2:2-24.

Open Court-article by Binet, 58. Organic-development of 0 . in memory, 169; o. sensations, 88.

Paccini-P.'s elements in the skin, 97.

Paffe-on sensibility, 39.

Passice-p. imagination, 214-226.

Pathology-mental p., 16, 18; proof from $p$. of dispositions in the brain, 160-161; relation of $p$. to illusions, 244.

Paulhan-on inherited motor tendencies, 159; on the organic in memory, 169.

Perception-of sense, 116-144; argument from $p$. for the unconscious, 52; definition of, 116: analysis of, 117; simple as op. posed to acquired p., 116-117; synthetic p., 11i; p. of space, 120-133; data for $p$. of space, 122; movements in p. of space, 123; local signs in p. of space, 123-124; $\mathrm{p}$. and the unconscious, 141; deceptious of, 143; p. of time by the ear, 188; references on, 144.

Perez-on the development of consciousuess, 66.

Personality -p. in attention, 70.

Philosophische Studien-article by Lange, 113 ; by Lehmann, 177.

Physiclogy-contrasted with psy. chology, 2; relation to psychol. ogy, 6-7; p. psychology (table). 83; p. aspect of illusion, 251.

Pisa-tower of, 48.

Plato- on retention, 152; P. as :t logical realist, 280. 
Pleasure and Pain-as sensations, 83, 85.

Popular Science Monthly-article by White, 244 .

Porter-on imagination, 237; on realism and nominalism, 280.

I'redicaments-288-292.

Predisposition-to illusion, 252254.

Preference-association by p., 202203 ; in passive and constructive imagination, 223, 228.

Presbyterian Review-article by Baldwin, 109.

Presentation (82, 145)-p. contrasted with affective states, 62 ; division of the function of, 80 . element of, in sensation, 84-97; p. of foreign body, 129; as opposed to representation, 147; antecedents of, 147; confusion of $p$. with representation, 149 ; illusions of p., 260.

Princeton Review - article by Baldwin, 28.

Problems-for futher study, 42, $68,79,115,144,190,212,243$, $269,311$.

Product-ideal p. of localization, 133; of recognition. 179; of temporal localization, 188; of imagination, 242; of conception, 276; of thought, 310 ; intuition as mental p., 316.

Proof (309-310)-references on, 311. Proposition (284)-parts of, 287.

Psychiatry-16, 245.

Psychology-definition of, 1-8; subject-matter of, 1 ; sources of, 1 , 11 ; relation to physiology, 6-7; to natural science, 7 ; to metaphysics, 7; difficulties and errors in, 8, 10; folk p., 15; animal p., 15; child p., 16; abnormal p., 16; method of, 120-134; experiment
Psychology-(Continued). in, 25-31; physiological p., 27, 31 ; relation of, to logic, 271 ; references on nature of, 33 ; on method of, 134.

Psychometry (109-117)-place in (table of) psychological system, 31; references on, 114.

Psychophysics (106-109)-place in (table of) psychological system, 31 ; references on, 115.

QUALITY - of sensation, 85; proof of specific q. of sensation, 98106.

Quantity-of sensation, 85, 106, 109.

RABIER-on nature and method of psychology, 1 ; on animal sensation, 3 ; on local signs, 125; on advantages of external observation, 17-18; on classification, 38; on the unconscious, 47 ; on space perception, 53, 35-36: on the uffective element in sensation, 85; on the muscular sense, 88 , 91 ; on unity of mind, 98 ; on identical nature of presentation and representation, 147; on recognition, 175; on dissociation, 219 ; on attention in imagination, 230; on primitive belief, 254.

Radestock-on consciousness in sleep, 61 ; on illusion due to dreams, 263.

Rational-r. psychology, 1; r. function distinguished, 80 .

Realism-logical, 280-281; references on, 311.

Reason (312-325)-law of suftcient r., 294, 310; definition of, 312; r. as constitutive of mind, $312-313 ; r$. as regulative of 
Reason-(Continued).

mind, 313-314; as knowledge or intuition, 314-325.

Reality-elements of $r$. in illusion, 258; relation of fancy to r., 225; of imagination to, 236; of conception to, $2 \tau 9$.

Reasoning (299-311)-nature and kinds, 299; deductive r., 300307; inductive r., 307-310; references on, 311.

Recognition (172-179)-nature of, 172-173; theories of, 173-178; $r$. due to return of image, 1i3; due to satisfaction of physical habit, 174; due to time perception. 175; due to reinstatement of apperceptive relations, 176177; subjective element of, 178; ideal product of, 1:9; illusions of, 261.

Reconstruction-meutal r. of space, 121-122; of time, 181-188.

References-on nature and method of psychology, 33-34; on relation of mind and body, 34; on child psychology, 34; on anjmal psychology, 34; on race psychology, 34; on history of psychology, 34; on classification and division, 42; on conscionsness and the unconscious, 67-68; on attention and apperception, 79; on perception, 144; on space perception, 144; on time percep. tion and lecalization, 190; on memory, 189-190; on association, 211, 212; on imagination, 243; on illusions, 269; on conception, judgment, pronf, rensoning, 811; on the reason, 325.

Reflection-ns psychological source, 9; disturbing effects of, 10; as method, 23, 24; as conscious.
Reflection-(Continued). ness, 63; as self-consciousness, 143; ideal product of, 144.

Reflex-r. attention, $i 0$.

Reid - on the faculties, 35 ; on consciousness, 43; on touch sensations, 96 ; on distinction between presentation and representation, 147, 149; on recognition, 175; on perception of time, 187 .

Relation-of psychology to physi. ology, 6; of mind and body, 28, (references) 34; r. theory of consciousness, 58-63; consciousness as $r$. between subject and object, 51 ; r. theory of knowledge, 63 : r. in apperception, 65 ; r. involved in association, 201-2; $r$. of fancy to reality, 225; r. of psychology to logic. 2i1-2i?: of scientific imagination to reality, 23r; conception as discovery of r.. 2i7; r. of scientific imagi. nation to thought, $240 ; r$. of language to conception and thought, 277; r. asserted in judgment, 288; r. of forces of judgment to one another, 296299.

Renouvier-on relative theory of consciousness, 62.

Repetition-ss condition of memory, 163; ns condition of associa. tion, 210.

Representation (tive), 145; r. states as referring to objects, 36; division of the r. functions, 80; na. ture of r., 146-14i; $r$. opposed to presentation, 147; antecedents and effects of, 147; confusion of $r$ with presentation, 149; continuity of, in association, 191: r. nature of illusional states, 246 . 248.

Reproduction - primary condition 
Reproduction-(Continued). of, 164; supplementary condition of, 165-166; physical basis of, 164-166; secondary aids to, $16 i-168$, r. as mental growth; 170-171; illusions of, 260 .

Resemblance-as secondary law of association, 195-198.

Resistance-sensations of, 89 .

Retention (152-164)-theories of, 152-160; metaphysical theory of, 153 ; r. as psychological habit, 153; subconscious theory of, $155-156$; physiological theory of, 157-163; mental conditions, 163 ; r. as mental growth, 170-171.

Revue Philosophique-article by Janet, 58; by Ribot, 70; by Mantagazza, 99; by Dumont, 170 .

Revue Scientifique-article by Maxwell, 101.

Ribot-on experiment in psychology, 7; on limitations of experiment, 29 ; on faculties, 35 ; on attention, 70,75; on local signs, 125 ; on memory, 157,160 ; on illusions of memory, 261.

Robertson (C.) - on perception of space, 121.

Rolando-fissure of, in the brain, 114.

SACHS-On the muscular sense, 310.

Savart-S.'s wheel, 47, 49, 50, 102, 104.

Schiff-on cerebral localization, 114.

Schopenhaver-on the unconscious, 45.

Science-of psychology, 1 ; scientific imagination, 235-238.

- - (periodical)-207.

Scottish Psychologists-on the un-
Scottish Psychologists-(Continued). conscious, 45 ; on the perception of time, 187 .

Self-s. consciousness as differentia of self, 63; recognition of s., 178-179; illusions of s.-consciousness, 264-265; intuition of s., 322.

Sensations (81-115)-relation of, to attention, 72-73; duration of, $73,109-114$; nature of, 82 ; contrasted with impression, 83; affective and presentative elements in, 84 ; meanings of the word s., 82-83; characters of, 85 ; complexity of, 86 ; organic s., 88 ; s. of smell, 86; of taste, 87; of muscular sense, 88-91; of hearing, 92; of sight, 93; of effort, resistance, innervation 89 ; of, color, 94-96; proof of specific s., 98-106; quantity of, 106-109; extensive or massive s., 109; tone of, 114; localization in the brain, 114; references on, 114115.

Senses-as means of knowing matter, 4.

Sensitive - s. function distinguished, 81.

Sensori-motor - connection, 161162.

Sentience-Lewes on, 58.

Sidgwick-on illusions of thought, 265, 310; on predicaments, 288.

Sight-sensations of, 93 ; visual perception of space, 127-129; of distance, $130-131$.

Signs-local s., 123; temporal s., 183.

Sigrart-on conception, 274; on categorical judgment, 298.

Sleep - consciousness during. 61; attention during, 185; s. as illustrating free association, 216. 
Simell (86-87).

Socrates-method of, 275.

Sound-sensations of, 92 ; localization of s. sensations, 131 .

Sources-of psychology, 1, 11; internal s., 11; external s., 12-18; unity of s. in consciousness, 18.

Space-argument for the unconscious from s. perception, 52 ; perception of, 120-133; data for, 122; movemeut and local sign in perception of, 123-124; nativism of, 132, 134; references on s. perception, 144.

Speech-located in Broca's convolution, 3, 114.

Spencer-on space perception, 123; on law of habit, 57 ; on relative theory of consciousuess, 59, 62; on perceived vs. real difference, 60 ; on sensation of resistance, 90,92 ; on reduction of mental force to unity, 100, 101, 102; on nervous shocks us mental units, 103; on evolution, 105; on the organic in memory, 169; on im. agination and thought, 240; on association theory of belief, 286 .

Stuges-of the thought process, 272.

Starr-on the physiology of speech, 278.

States-nature of revived s., 147; illusional s., 244-269.

St.Augualine-on retention, 152.

Stenort-on the fuculties, 35; on consciousness, 43; on time-per. ception, 18; ; on association by resemblance, 196.

Stimulu-accumulated s., 49-50, 53-54; new 8 . in reproduction, 165: absence of internul s. in illusion, 249, orgunic s. in il. lusion, 2.51; self 8. of sight, 251.

Stric-doctrine of imagination, 213,
Stoic-(Continued).

255; doctrine of conception, 283.

Subconscious-s. image in retention, 155; nature of, 57 .

Subject-relation of s. and object, 61.

Subjective-s. nature of mental states, 6 ; s. element of recognition, 178; s. aspect of imagination, $21 \%$.

Subordination-in association, 201; as a predicament, 288.

Substance-of the soul, 4.5.

Substitution-of sensations, 105.

Succession-as time, 180; association by, 201-206.

Suggestion-s. and association, 192. Sully-on inner observation, 23; on education of attention, 77 ; on psycho-physics, 108; on preperception, 113; on synthetic perception, 117; on local sigus, 124, 125; on perception of time, 187 ; on rhythm in sound, 188 ; on illusion of special seuses, 248 ; on sub-expectation, 252; on illusion of presentation, 260,261 ; of selfconsciousness, 265.

Syllogism-detinition of, 300 : conceptual interpretation of. 801; meaning and kinds of. 302: categurical s, 302; value of. 304; hypothetical, 803.

Synthesis-syuthetic judgment, 292 ; 8. perception, 117 ; as stage in conception, 275-276.

Systemic-sensatious, 88 .

TABน,E- of arrociation, 206; of psychology, according to meth. oil. 30.

Taine-on the unconscions, 46, 47. 49; on composition of mind, 101, 102; on memory 
Taine-(Continued).

157; on association by resemblance, 197; on perception as hallucination, 247.

Taste-sensations of, 87.

Telepathy-Guruey on, 269.

Temperature-t. sense. 97.

Test-of syllogism, 305,306 ; of illusion, 266-269.

Theory-of unity of composition of mind, 98-106; double aspect $t$., 5 ; $t$. of space perception, 133; of consciousness, 56 ; of time perception, 186-188.

Thought (270-311) - general nature of, 270-272; stages of, 272; ideal product of, 310 ; references on, 310-311; appereeptive nature of, 271 ; not a function of body, 3; division of the $t$. function, 81 ; illusions of, 265; laws of, 309.

Time-as measurement of mental states, 4 ; perception of, in recognition, 175; localization in, 179 , 189; mental reconstruction of, 181-188; data for time perception, 182-185; $t$. indicated by intensity, 183-184; t. indicnted by movements of attention, 184 185; theories of time perception, 186-188; perception of $t$. by the ear, 188; idea of t., 188; references on, 190; measurement of, psychometry, 109-117.

Tone-of seusation, 85. 114.

1ouch (96-99)-tactual space, 126.

Training-of attention, 77.

Trendelenberg - on the existential judgment, 298.

Trinchinetti-casereported by, 130 .

Tuke-case reported by, 256.

Type-concept as t., 280.

Unconscious-consciousness and the u., 48-58; the u. as sub-
Unconscious-(Continued). stance of the soul, 45; psychological meaning of the u., 46 ; perception and the $u ., 141$; references on the u., 68 .

Uniformity-of nature, 22, 308; of connection between mind and body, 28.

Units-of duration, 184-185; nervous shocks as mental u. 103 .

Unity - of psychological sources in consciousness, 18; of the three great classes of mental facts, in consciousuess, 40-41; u. arising from apperception, 66 ; $u$. in attention, 70; theory of $u$. of composition of mind, 9.9-106; u. of mental forces, 99; nervous shocks as mental units, 10:3; idea of synthetic u., 140, 281; idea of numerical u., 141; unity of mind, 159-160; unitary association, $206 ; \cdot u$. of the concept, 281 ; u. of the judgment, 285.

Utility - of the hypothesis of unconscious mind, 57; utility of an image in conception, 278.

Variation--in mental functions, 38, 39.

Visual-field of consciousness, 64.

Volkmann-on attention, 76; on representations as functions, 154 ; on recognition, 173; on pereention of time, 187; on constructive imagination, 230; on imagination and thought, 240; on Stoic doctrine of imagination, 255; on assimilation in illusion, 257; on illusions of self-consciousness, 265; on localization as opposed to projection, 267; on abstraction, 274.

Voluntary-attention, 71. 
WATTZ-on relation of psychology to metaphysics, 8; on movement in sense-intuition, 139; on reten tion, 153; on latent images, 156; on cerebral associations, 215; on the play of images in conception, 275.

Ward-on classification, 36; on consciousness, 44; on retention, 153; on mental recoustruction of time, 182; on duration and succession, 185; ou abstruction, 274.

Weber-W.'s law, 4, 106-109, (interpretation of) 108-109; on the muscular sense, 90 ; on sensation circles, 96, 125.

Will-class of, 36; characterized by effort, 37; first exercise of, 66.

While-on illusions, 244.

Wolfe-on association by resem. blance, 197.

World-intuition of, 324.

Wundt-on double aspect theory, 5 ; on unity of mind, 33; on the unconscious, 46, 142; on accumulated stimulus, 50; on feelings of innervation, 53; on physical dispositions, 56; on appercep.
Wundt-(Continued). tion, 66. 77 ; on motor aspects of attention, 77; on muscular sense, 90; on theories of color, 95; on chemical composition, 101; un unity of composition of mind, 106; on interpretation of Weber's law, 109; on distinction time, 111; on space perception. 122; on local sigus, 123, 125; on disease of eye-muscles, 128; on retention, 53; on mental habit, 154, 160; on physical basis of reproduction, 167; on associative counections in the brain, 193; on simultaneous association, 206; on active and passive imagination, 226, 241; on sense deceptions, 247; on apperceptive nature of thought, 271; doctrine that all kuowledge is judgment, 286.

Yocxe-theory of color, 94-95.

ZeLLER-On the Stoics, 283.

Zeno-conception, 283.

Zeitschrift für Vôlkerpsychologie, 15.

Zollner-argument for the unconscious, 52. 



\section{THE AMERICAN SCIENCE SERIES.}

THE principal objects of the series are to supp!y the lack-in some subjects very great-of authoritative books whose princle p.es are, so far as practicable, illustrated by familiar American facts, and also to supply the other lack that the advance of Science perennially creates, of text-books which at least do not contradict the latest generalizations. The scheme svstematically outlines the field of Science, as the term is usually employed with reference to generial education, and includes Advanced Courses for maturer college students, Briefer CuURSEs for beginners in school or college, and Elementary CoUrses for the youngest classes. The Briefer Courses are not merc abridgments of the larger works, but, with perhaps a single excep:ion, are much less technical in style and more el mentary in method. While somewhat narrower in rarge of topics, they give equal emphasis to controlling principles. The following books in this series are already published .

the human body. By H. Newell Martin. Professor in the lohns Hopkins University.

Advanced Course. 8vo. 655 pp.

Designed to impart the kind and amount of knowledge every educated person should possess of the structure and activities and the conditions of healthy working of the human body. While intelligible to the general reader, it is accurate and suffisiently minute in details to meet the requirements of students who are not making human anatomy and physiology subjects of special advanced study. The regular editions of the hook contain an appendix on Reproduction and Development. Copies withous this will be sent when specially ordered.

From the Cincaco Tribtinf: "The reader who follows him through to the end of the book will be betler informed on the subject of mnitern physiolngv in its general features than most of the medical practitioners who rest on the knowledge gained in comparatively an. tiquated text books, and will, if possessed of average good judgman. and powers of discrimination. not be in any way confused by staie. ments of dubious questions or conßlicting views." 


\section{THE HUMAN BODY.-Continued.}

\section{Briefer Course, I2mo. 364 pp.}

Aims to make the study of this branch of Natural Science a source of discipline to the observing and reasoning faculties, and not merely to present a set of facts, useful to know, which the pupil is to learn by heart, like the multiplication-table. With this in view, the author attempts to exhibit, so far as is prarticabie in an elementary treatise, the ascertained facts of Physiology as illustrations of, or deductions from, the two cardinal principles by which it, as a department of modern science, is controlled,-namely, the doctrine of the "Conservation of Energy" and that of the "Physiological Division of Labor." To the same end he also gives simple, practical directions to assist the teacher in demonstrating to the class the fundamental facts of the science. The book includes a chapter on the action upon ine body of stimulants and nuriotics.

From Henry Sewall, Professor of Physioingy, University of Michigan: "The number of poor books meant to serve the purpose of text-books of physiology for schools is so great that it is wel' to define clearly the needs of such a work: 1. That it shall contain accurate statements of fact. 2. That its facts shall not be too numerous, but chosen so that the important truths are recognized in their irue relations. 3. That the language shall be so lucid as to give no excuse for misunderstanding. 4. That the value of the study as a discipline to the reasoning faculties shall be continually kept in view. $I$ know no eleinentary text-book which is the superior, if the equal, of Prof. Martin's as judger by these conditions."

\section{Elementary Course. I2mo. $261 \mathrm{pr}$.}

A very earnest attempt to present the subject so that children may easily understand it, and, vehenever possible, to start with ?amiliar facts and gradually to lead up to less obvious ones. The action on the body of stimula-uts and narcotics is fully treated.

From W. S. Perry. Supuintendint of Schools. Ann Arbor. Mich.. "I find in it the same accuracy of statement and scholarly strength (hat characterize both the !arger editions. The iarge relative space given to hygiene is fully in accord with the latest educational opinion and practice; while the amount of anitomy and physiology comprised in the compact treatment of these divisions is quite enough for the most practical knowledge of the subject. The handing of alcohol and narcetics is. in my opinion, especially good. The most admira. bie feature of the book is its fine adaptation to the capacity of younger pupils. The diction is simple and pure, the style clear and direct, and the aianer of presentation bright and attractive." 
Astronomy. By Simon Newcomb, Professor in the lohns Hopkins Universitv. and EDwARD S. HOLDEN, Director of the Lick Observatory.

Advanced Course. 8ro. 512 pp.

To facilitate its use by students of different grades, the subject-matter is divided into two classes, distingurshed by the size of the type. The portions in large type form a complete course for the use of those who desire only such a general knowledge of the subject as can be acquired without the application of advanced mathematics. The portions in small type comprise additions for the use of those students who either desire a more detailed and precise knowledge of the subject, or who intend to make astronomy a special study.

From C. A. Young, Professor in Princeton College: "I conclude that it is decidedly superior to anything else in the rarket on the same subject and designed for the same purpose."

Briefer Course. $12 \mathrm{~m}$ (). $352 \mathrm{pp}$.

Aims to furnish a tolerably complete outline of the astronomy of to-day, in as elementary a shape as will yieid satisfactory returns for the lcarner's time and labor. it has been abridged from the larger work, not by compressing the same matter into less space, but by omitting the detalls of practical astronomy, thus giving to the descriptive portıons a greate? relative prominence.

From THR CRITIC: "The book is in refreshing contrast to the productions of the prufessionsl schoolbook-makers, who, having only a superficial knowledge of the matter in hand, gather their materia!, without sense or discrimination. from all sorts of authorities, and prisent as the result an irstigesia moles, a mass of crudities, not un. mixed with errors. The student of this book may feel secure as to the correciness of whatever he finds in it. Facts appear as facts, and theories and speculations stand for what they are, and are worth."

From IV. B. Graves. Master Scientific Department of Phillips Academy: "I have used the Briefer Course of Astronomy during the past year. It is up to the times, the points are put in a way to interest the student, and the size of the book makes it easy to go over the subject in the time allotted by our schedule."

From HeNkY Lefavour. late Teacher of Astrmomy. Wilisson Siminary: "The impression which 1 formed upon first examination, that it was in very many respects the best clementary texi-book on the subject, has been confirmed by my experience with it in the class. room." 
zoolocy hv A. S. PaCkard, Professor in Brown University.

Advanced Course. 8vo. $719 \mathrm{pp}$.

Designed to be used either in the recitation-room or in the laboratory. It will serve as a guide to the student who, with a desire to get at first-hand a general knowledge of the structure of leading types of life, examines living animals, watches their movements and habits, and finally dissects them. He is presented first with the facts, and led to a thorough knowledge of a few typical forms, then taught to compare these with others, and finally led to the principles or inductions growing out of the facts.

From A. E. Verrill, Professor of Zoology in Yale College: "The general treatmert of the subject is good, and the descriptions of structure and t':e definitions of groups are. for the most part, clear, concise, and not so much overburdened by technical terms as in sev. eral other n.anuals of structural zuology now in use."

\section{Eriefer Course. 12mo. $334 \mathrm{pp}$.}

The distinctive characteristic of this book is its use of the object method. The author would have the pupils first examine and roughly dissect a fish, in order to attain some notion of vertebrate structure as a basis of comparison. Beginning then with the loyvest forms, he leads the pupil through the whole animal kingdom until man is reached. As each of its great divisions comes under observation, he gives detailed instructions for dissecting some one animal as a type of the class, and bases the study of other forms on the knowledge thus obtained.

From Heriert Csionn, Professor of Zoology, Iorva Agricultural College: "I can gladly recommend it to any one desiring a work of such character. While I strongly insist that students should study animals from the animals themselves, $-a$ point strongly urged by Prof. Packard in his preface, - I also recognize the necessity of a reliable text-book as a guide. As such a guide, and covering the ground it does, I know of nothing better than Packard's."

First Lessons in Zoology. $12 \mathrm{mo} .290 \mathrm{pp}$.

In method this book differs considerably from those mentioned above. Since it is meant for young beginners, it describes but few types, mostly those of the higher orders, and discusses their relations to one another and to their surroundings. The aim, however, is the same with that of the others; namely, to make clear the general principles of the science, rather than to fill the pupil's mind with a mass of what may appear to him unrelated facts. 


\section{OOLOGY-Continued.}

From ScIExce: - The style is clear, and the subjecis made interest. ing. The student's mind is not confused by a mass of details, or by unsatisfactory descriptions of a large number of specimens which he can never expect to see. much less examine; but the brief sketches of a few of the most important torms will awaken in him a desire for wider knowledge. The figures are numerous, averaging almost one to each page; yet they are so well selected that, while one grudges so inuch space, he finds few which he would omit.

Botany. By Charles E. Bessey, Professor in the University of Nebraska.

Advanced Course. 8vo. 611 pp.

Aims to lead the student to obtain at first-hand his knowledge of the anatomy and physiology of plants. Accordingly. the presentation of matter is such as to fit the book for constant use in the laboratory, the text supplying the outline sletch which the student is to fill in by the aid of scalpel and microscope.

From J. C. Artule, Editor of The Bolanial Gazelie: "The first brtanical tcxt-book issued in America which treats the most important departments of the science with anything like due consideration. This is especially true in reference to the physiology and histology of plants, and also to special morphology. Structural Butany and classification have up to the present time monopolized the field, greatly retarding the diffusion of a more complete kinowiedge of the science."

Essentials of Botany. 12 mo. 292 pp.

A guide to beginners. Its principles are, that the true aim of botutical study is not so much to seek the family and proper mames of specimens as to ascertain the laws of plant structure and plant life: that this can be done only by examining and :lissecting the plants themselves: and that it is best to confine the attention to a few leading types, and to take up first the simpler and more casily understood forms. and afterwards those whose structure and functions are more complex. The latest cilitivis of the work contain a chapter on the Ciross Anatomy of Flowering Plants.

From J. T. Roturock, Professor in the L'nizersity of Pennsylin nia: "There is nothing superncial in it, nothing needless introduced. nothing essential left out. The language is lucid: and, as the crown. ing merit of the book. the author has infroduced throughout the vol. ume 'Practical Studies,' which direct the student in his effert to see fir himsclf wll that the text-bork teacties." 
Chemistry. By Ira Remsen, Professor in the Johns Hop. kins University.

Advanced Course. Sro. SaS pp.

The general plan of this work will be the same with that of the Briefer Course, already published. But the part in which the nembers of the different families are treated will be considerably enlarged. Some attention will be given to the lines of investigation regarding chemical affinity, dissociation, speed of chemical action, mass action, chemical equilibrium, thermochemistry, etc. The periodic law, and the numerous relations which have been traced between the chemical and physical properties of the elements and their positions in the periodic system will be specially emphasized. Reference will also be made to the subject of the chemical constitution of compounds, and the methods used in determining constitution.

Introduction to the Study of Chemistry. 12mo. $389 \mathrm{pp.}$

The one comprehensive truth which the author aims to make clear to the student is the essential nature of chemical action. With this in view, he devotes the first 208 pages of the book to a carefully selected and arranged series of simple experiments. in which are gradually developed the main principles of the subject. His method is purely inductive; and, wherever experience has shown it to be practicable, the truths are drawn out by pointed questions, rather than fully stated. Next, when the student is in a position to appreciate it, comes a simple account of the theory of the science. The last 150 pages of the book are given to a survey, fully illustrated by experiments, of the leading families of inorganic compounds.

From Arthuk W. Wright, Professor in Yale College:-The student is not merely made acquainted with the phenomena of chemistry, bu: is constantly led to reason upon them, to draw conclusions from them and to study their significance with reference to the processes of chemical action-a course which makes the book in a high degree dis. ciplinary as well as instructive.

From Thos. C. Van Nuys, Professor of Chemistry in the Indiana University:-It seems to me that Remsen's "Introduction to the Study of Chemistry" meets every requirement as a text or class book.

From C. Les MeEs, Professor of Chemistry in the Ohio University: -I unhesitatingly recommend it as the best work as yet published for the use of beginners in the study. Having used it, I feel justified in saving this much. 


\section{CHEMISTRY - Continued.}

\section{Elements of Chemistry, $12 \mathrm{mo} .272 \mathrm{pp}$.}

Utiiizes the facts of every-day experience to show what chem. istry is and how things are studied chemically. The language is untechnical, and the subject is fully illustrated by simple experiments, in which the pupil is led by questions to make his own inferences. The author has written under the belief that " a rational course in chemistry, whether for younger or older pupils, is something more than a lot of statements of facts of more or less importance; a lot of experiments of more or less beauty: or a lot of rules devised for the purpose of enabling the pupil to tell what things are made of. If the course does not to some extent help the pupil to think as well as to see it does not deserve to be called rational."

Cirase Palmer, Professor in the State Normal School, Salem. Mass.: - It is the best introduction to chemistry that I know, and I intend to put it into the hands of my pupils next Fall.

A. D. Gray. Instructor in Springfield (Mass.) High School :-Neat, attractive, clear, and accurate, it leaves little to be desired or sought for by one who would find the best book for an elementary course in our High Schools and Academies.

GENERAL B:OLOGY. By William T. Sedgwick, Professor in the Mass. Institute of Technolngy, and EDMUND B. WiLSoN. Professor in Bryn Mawr College. Part I. Svo. 193 pp.

This work is intended for college and university students as an introduction to the theoretical and practical study of biology. it is not zoology, botany, or physiology, and is intended not as a substitute, but as a foundation, for these more special studies. In accordance with the present obvious tendency of the best elementary biolngical teaching. it discusses broadiy some of the leading principles of the science on the substantial basis of a thorough examination of a limited number of typical forms, including both plants and animals. Part First, now published, is a general introduction to the subject illustrated by the sudv of a few types. Part Second will contain a detailed survey of various plants and animals.

W. G. Farlow, Professor in Harvard University, Cambridge, Mass.: - An introduction is always diffcult to write, and I know no work in which the general relations of plants and animals and the cell-struc. ture have been so well stated in a condensed form. 
political eCONOMY. By Francis A. Walker, President of the Massachusetts Institute of Technology.

Advanced Course. 8vo. 537 pp.

The peculiar merit of this book is its reality. The reader is brought to see the application of the laws of political economy to real facts. He learns the extent to which those laws hold good, and the manner in which they are applied. The subject is divided, as usual, into the three great branches of production, exchange, and distribution. An interesting and suggestive "book" on consumption is added, which serves to bring in conveniently the principles of population. The last part of the volume is given to the consideration of various practical applications of economic principles.

From Richmond Miyo Smith, Professor in Columbia College, $N$. Y.:-In my opinion it is the best text-book of political economy that we as yet possess.

From Woodrow Wilson, Professor in Princeton University, $N$. J.: -It serves better than any other book I know of as an introduction to the most modern point of view as to economical questions.

\section{Briefer Course. I2mo. $415 \mathrm{pp}$.}

The demand for a briefer manual by the same author for the use of schools in which only a short time can be given to the subject has led to the publication of the present volume. The work of abridgment has been effected mainly through excision, although some structural changes have been made, notably in the parts relating to distribution and consumption.

From Alexander Johnston, late Professor in Princeton University, $N$. J.:-Using the "Briefer Course" as a text-book, suited to any capacity, I am able at the same time to recommend the "Advanced Course" to those who are better able to use it as a book of reference, or more inclined to carry their work further.

Elementary Course. I2mo. $323 \mathrm{pp}$.

What has been attempted is a clear arrangement of topics; a simple, direct, and forcible presentation of the questions raised; the avoidance, as far as possible, of certain metaphysical distinctions which the author has found perplexing; a frequent repetition of cardinal doctrines, and especially a liberal use of concrete illustrations, drawn from facts of conmon experience or observation.

\section{HENRY HOLT \& CO., PUBlisheRS, N. Y.}




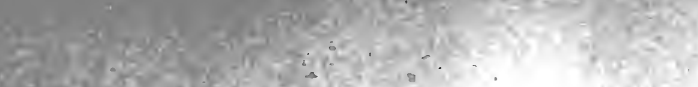

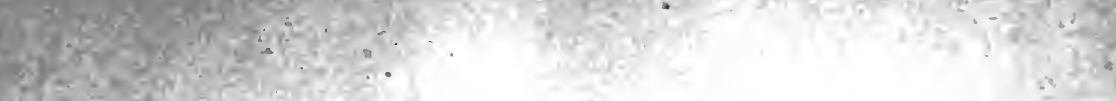

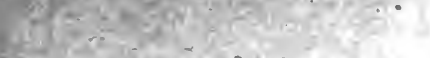

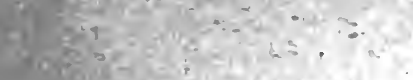

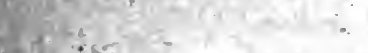

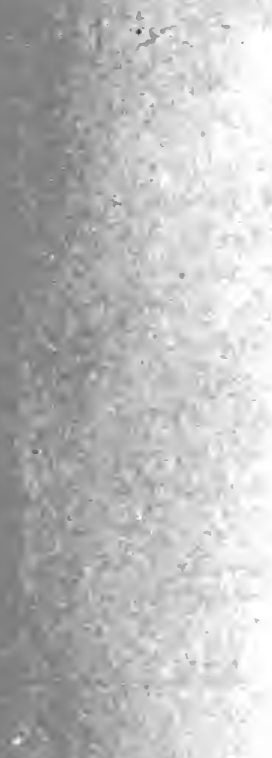

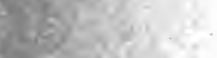

L. 15

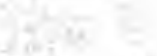

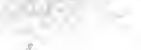

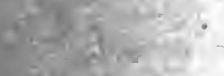

ing

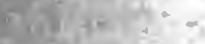

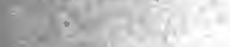

$\sin ^{2}+2$.

$2 x^{2}+3 y<5$

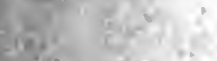

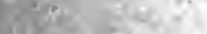

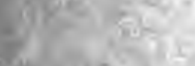

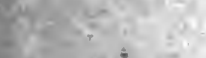

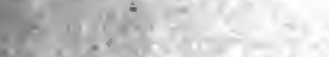

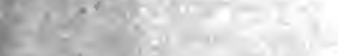

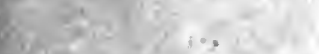

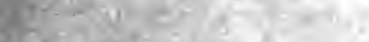

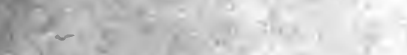

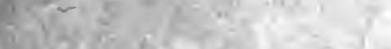

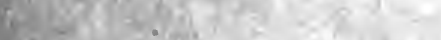

4.

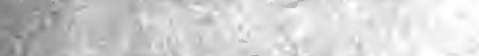

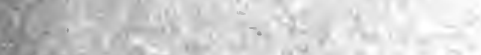

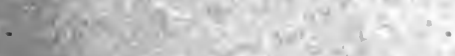

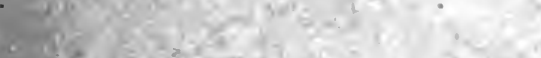

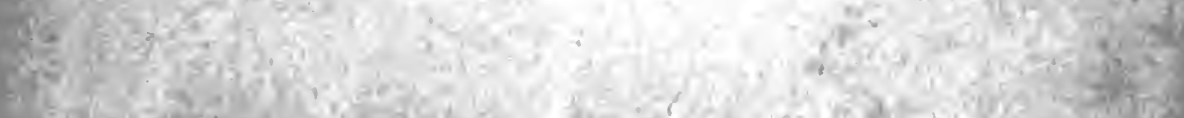

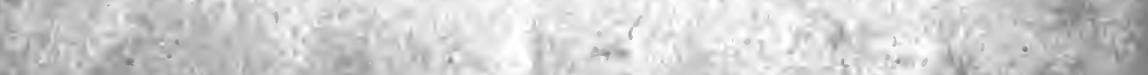

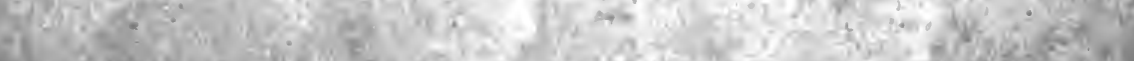

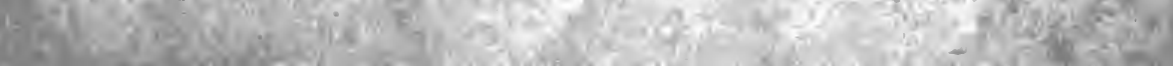




axtorses

ansto site

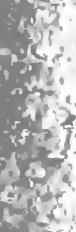

$\therefore$ fin.

a

$-\alpha$

:

.

70

an $y$ ?

$x^{2}+2$

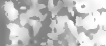

tin.

$x_{\rightarrow \rightarrow \infty} x^{2}$

$\rightarrow$ ess

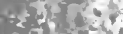

1.3

a)

and

5. 10

n) 20

$x^{2}+2 \sin$

$-4237$

तो 3 हो

(y)

a

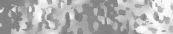

soy

(N)

$=4$ a difter

$\therefore x+6$

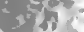

$\ldots+x^{2}$

is 4 .

is 4

(f)

Anest

at 3

50.1.

सexisa.

in

- 20

कर:"

>

is:

(z)

sin

inte

atic

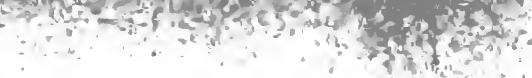

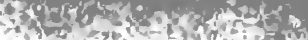

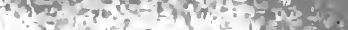





\section{University of Toronto Library}

\section{DO NOT}

REMOVE

THE

CARD

FROM

THIS

\section{POCKET}

Acme Library Card Pocket Under Pat "Ref. Indes Flle" Made by LIBRARY BUREAU 
